\title{
Trade and Uncertainty
}

\author{
Dissertation
}

zur Erlangung des wirtschaftswissenschaftlichen Doktorgrades der Wirtschaftswissenschaftlichen Fakultät der Universität Göttingen

vorgelegt von

Florian Johannsen

aus Kiel

Lübeck, 2014 
Erstgutachterin: Prof. Dr Inmaculada Martínez-Zarzoso Zweitgutachter: Prof. Stephan Klasen, PhD.

Tag der mündlichen Prüfung: 31. März 2014 


\section{Table of Contents}

Introduction

1 - Exchange Rate Volatility and the Euro Effect

I.I - Methodology

I.I.I - Estimation Issues

I.I.II - Data

I.II - Effect of Exchange Rate Volatility on Trade 12

$\begin{array}{ll}\text { I.II.I - Model Specification } & 12\end{array}$

$\begin{array}{ll}\text { I.II.II - Results } & 13\end{array}$

$\begin{array}{ll}\text { I.III - Conclusion and Policy Implications } & 17\end{array}$

II - The CFA Franc and the Euro $\quad 19$

$\begin{array}{ll}\text { II.I - Background } & 20\end{array}$

II.II - Literature $\quad 21$

$\begin{array}{ll}\text { II.III - Empirics } & 24\end{array}$

II.III.I - Results 26

$\begin{array}{ll}\text { II.IV - Conclusion } & 29\end{array}$

III - Exchange Rate Policy and Exports of Firms 31

III.I - Literature Review $\quad 33$

III.I.I - Theory 33

III.I.II - Empirical Studies

III.I.III - Hedging Behaviour of Firms

III.II - Empirical Analysis 39

III.II.I - Data 39

$\begin{array}{ll}\text { III.II.II - Volatility Measure } & 40\end{array}$

III.II.III - Model Specification 41

III.III - Results $\quad 42$

III.III.I - Imported Intermediates 48

III.III.II - Exchange Rate Uncertainty Exposure $\quad 49$

III.III.III - Political Instability $\quad 53$

III.III.IV - Regional Differences 54

III.IV - Conclusion $\quad 55$

IV - Direct and Indirect Exports and the Role of Uncertainty $\quad 57$

IV.I - Empirical Analysis $\quad 59$

IV.I.I - Model Specification $\quad 62$

IV.II - Main Findings $\quad 64$

IV.II.I - Goods versus Services $\quad 68$

IV.II.II - Robustness: Two-Stage Approach $\quad 71$

$\begin{array}{ll}\text { IV.III - Conclusion } & 73\end{array}$

$\underline{V}$ - Political Determinants of International Arms Transfers $\quad 74$

$\begin{array}{ll}\text { V.I - Literature } & 76\end{array}$

$\begin{array}{ll}\text { V.II - Data } & 78\end{array}$

$\begin{array}{ll}\text { V.II.I - Data on Arms Transfers } & 78\end{array}$

V.II.II - Political Dimensions 79 
V.II.III - Control Variables $\quad 82$

V.III - Analysis

V.III.I - Descriptive Analysis

V.III.II - Econometric Approach $\quad 86$

V.III.III - Volume of Transferred Arms $\quad 89$

V.III.IV - Two-Stage Approach $\quad 89$

V.III.V - Trade in Arms versus Trade of Goods $\quad 90$

$\begin{array}{ll}\text { V.IV - Findings } & 91\end{array}$

V.V - Conclusion $\quad 98$

\begin{tabular}{ll} 
Bibliography & 99 \\
\hline
\end{tabular}

\begin{tabular}{ll} 
Appendix & 107 \\
\hline
\end{tabular}

A Exchange Rate Volatility and the Euro Effect 108

B The CFA Franc Zone and the Euro $\quad 116$

C Exchange Rate Policy and Exports of Firms $\quad 118$

D Direct and Indirect Exports and the Role of Uncertainty 128

E Political Determinants of International Arms Transfers 130

\section{Index of Figures}

Figure 1: Exchange Rate Volatility and Trade 2

Figure V.II.1: Political Dimensions $\quad 80$

Figure V.Il.2: Political Orientation and Level of Democracy in Single Years $\quad 82$

Figure V.III.1: Similarity in Level of Democracy and Political Orientation 84

Figure V.III.2: Difference in Polity of Countries Transferring Arms $\quad 85$

Figure V.III.3: Difference in Voting Concordance with USA of Countries Transferring Arms $\quad 86$

Figure A.1: Share of Total Exports by BEC Category, 1996-2010 $\quad 108$

Figure A.2: Log of Total Trade Value $\quad 109$

\begin{tabular}{ll} 
Figure C.1: Range of the Share of Exports to EU-27 by Country & 121 \\
\hline
\end{tabular}

\begin{tabular}{ll} 
Figure C.2: Range of Volatility to the Euro & 123 \\
\hline
\end{tabular} 


\section{Index of Tables}

Table I.I.1: Share of Total Trade in the Sample $\quad 10$

Table I.II.1: Regression Results - Capital Goods 14

Table I.II.2: Regression Results - Intermediates 15

Table I.II.3: Regression Results - Final Goods $\quad 16$

Table II.III.1: Trade Volume Estimated with Country and Year Fixed-Effects and Country- and YearDummies

Table II.III.2: Trade Volume Estimated with Country-Year Fixed-Effects and Time-Varying Country-

Dummies $\quad 28$

Table II.III.3: FE Regressions with Time-Varying Country-Dummies by Sector $\quad 29$

Table III.I.1: Studies Investigating Trade Effects of Exchange Rate Volatility or Currency Unions at the \begin{tabular}{ll}
\hline Firm-level & 36 \\
\hline
\end{tabular}

Table III.III.1: Determinants of the Extensive Margin $\quad 44$

Table III.III.2: Determinants of the Intensive Margin $\quad 46$

Table III.III.3: Direction of Coefficients for Sectoral Regressions $\quad 47$

Table III.III.4: Determinants of Import Intensity $\quad 49$

Table III.III.5: Natural Hedging Regression Results 52

Table III.III.6: Political Instability $\quad 54$

\begin{tabular}{ll} 
Table IV.I.1: Variables & 60 \\
\hline
\end{tabular}

\begin{tabular}{ll} 
Table IV.I.2: Direct and Indirect Exporters & 61 \\
\hline
\end{tabular}

Table IV.I.3: Summary Statistics $\quad 62$

Table IV.II.1: Probit Regression Results - Probability to Export Indirectly 66

Table IV.II.2: OLS Regression Results - Share of Indirect Exports $\quad 67$

Table IV.II.3: Regression Results - Goods vs. Services $\quad 70$

\begin{tabular}{ll} 
Table IV.II.4: Beta Coefficients & 71 \\
\hline
\end{tabular}

Table IV.II.5: Heckman Two-StageRegression Results $\quad 72$

Table V.IV.1: Probability to Agree on a Transfer of Arms $\quad 93$

Table V.IV.2: Volume of Transferred Arms $\quad 95$

Table V.IV.3: Probability to Trade - Arms vs. Goods (1962-2007) 96

Table V.IV.4: Trade Volume - Arms vs. Goods (1962-2007)

\begin{tabular}{ll} 
Table A.1: Coverage & 110 \\
\hline
\end{tabular}

Table A.2: BEC Categories $\quad 110$

\begin{tabular}{ll} 
Table A.3: Variables & 111 \\
\hline
\end{tabular} 
\begin{tabular}{ll} 
Table A.5: Fixed Effects Regressions - Intermediates & 112 \\
\hline
\end{tabular}

Table A.6: Fixed Effects Regressions - Final Goods $\quad 113$

\begin{tabular}{ll} 
Table A.7: Beta Coefficients & 114 \\
\hline
\end{tabular}

\begin{tabular}{ll} 
Table A.8: Robustness Checks & 115 \\
\hline
\end{tabular}

Table B.1: Countries $\quad 116$

\begin{tabular}{ll} 
Table B.2: Variables & 117 \\
\hline
\end{tabular}

\begin{tabular}{lc} 
Table C.1: BEEPS Surveys & 118 \\
\hline
\end{tabular}

Table C.2: Number of Firms in Every Round of the Survey by Country $\quad 118$

\begin{tabular}{ll} 
Table C.3: Exporting Firms by Country & 119 \\
\hline
\end{tabular}

\begin{tabular}{ll} 
Table C.4: Exporting Firms by Industry & 120 \\
\hline
\end{tabular}

\begin{tabular}{ll} 
Table C.5: Firms per Industry and Country & 122 \\
\hline
\end{tabular}

\begin{tabular}{ll} 
Table C.6: Correlation Table & 124 \\
\hline
\end{tabular}

Table C.7: Probability to Export by Industry (Probit) $\quad 125$

Table C.8: Export Intensity Regression Results by Industry (OLS) 126

\begin{tabular}{ll} 
Table C.9: Robustness Check - Regional Differences & 127 \\
\hline
\end{tabular}

\begin{tabular}{ll} 
Table D.1: Covered Countries and Sectors & 128 \\
\hline
\end{tabular}

\begin{tabular}{ll} 
Table D.2: Correlation & 129 \\
\hline
\end{tabular}

\begin{tabular}{ll} 
Table E.1: List of Suppliers & 130 \\
\hline
\end{tabular}

\begin{tabular}{ll} 
Table E.2: List of Recipients & 131 \\
\hline
\end{tabular}

\begin{tabular}{ll} 
Table E.3: Transfers of Arms by Supplier & 132 \\
\hline
\end{tabular}

\begin{tabular}{ll} 
Table E.4: Variables & 133 \\
\hline
\end{tabular}

\begin{tabular}{ll} 
Table E.5: Summary Statistics & 134 \\
\hline
\end{tabular}

Table E.6: Probability to Agree on a Transfer of Arms $\quad 135$

\begin{tabular}{ll} 
Table E.7: Volume of Transferred Arms & 136 \\
\hline
\end{tabular}

Table E.8: Probability to Trade - Arms vs. Goods (1962-2007) 137

Table E.9: Volume of Trade - Arms vs. Goods (1962-2007) 138

Table E.10: Probability to Agree on a Transfer of Arms with Lagged Measures of Political

\begin{tabular}{ll} 
Orientation (1953-2007) & 139 \\
\hline
\end{tabular}

Table E.11: Probability to Agree on a Transfer of Arms (without USA) $\quad 140$

Table E.12: Volume of Transferred Arms (without USA) 141 


\title{
List of Abbreviations
}

\author{
BCEAO Banque Centrale des États de l'Afrique de l'Ouest \\ BEAC Banque Centrale des États d'Afrique Centrale \\ BEC Broad Economic Categories \\ BEEPS World Bank Enterprise Business Environment and Enterprise Performance Survey \\ CEFTA Central European Free Trade Agreement \\ CEMAC Central African Economic and Monetary Community \\ CEPII Centre d'Etudes Prospectives et d'Informations Internationales \\ CFA Communauté financière d'Afrique \\ Coopération financière en Afrique centrale \\ COW Correlates of War Project \\ CSCW Centre for the Study of Civil War \\ CU currency union \\ DID difference-in-difference \\ EBA Everything but Arms \\ ECB European Central Bank \\ EU European Union \\ EMU Economic and Monetary Union of the European Union \\ ERM II European Exchange Rate Mechanism II \\ EZ Eurozone \\ FE fixed-effects \\ (G)ARCH (generalized) autoregressive conditional heteroscedasticity \\ GDP gross domestic product \\ HS Harmonized Commodity Description and Coding Systems \\ ICRG International Country Risk Guide
}




$\begin{array}{ll}\text { IMF } & \text { International Monetary Fund } \\ \text { IMR } & \text { inverse Mill's ratio } \\ \text { IT } & \text { information technology } \\ \text { LMP } & \text { linear probability model } \\ \text { MCW } & \text { major conventional weapons } \\ \text { MTR } & \text { multilateral trade resistance } \\ \text { OCA } & \text { optimum currency area } \\ \text { OLS } & \text { ordinary least squares } \\ \text { RE } & \text { random-effects } \\ \text { RTA } & \text { regional trade agreement } \\ \text { SITC } & \text { Standard International Trade Classification } \\ \text { TIV } & \text { trend-indicator value } \\ \text { WGI } & \text { Uppsala Conflict Data Program } \\ \text { USA } & \text { United Nations } \\ \text { UN } & \text { Wnited Nations General Assembly } \\ \text { UNGA } & \text { World Development Indicators database } \\ \text { WAE } & \text { Unican }\end{array}$




\section{Introduction}

Among many economists and politicians the notion that bilateral trade increases welfare is widely accepted. In the past few decades, big steps towards a further liberalization of international trade were taken. Although successive rounds of multilateral trade negotiations have helped achieve deep reductions in import duties, other obstacles remain. These barriers to trade can have various forms and in most cases occur in the form of additional direct or indirect costs. The exact sum of these costs is usually uncertain. One aspect of this uncertainty is the unpredictability of future export revenues due to volatility in the exchange rate of the invoicing currency and the domestic currency. Lowering the level of uncertainty about exchange rates could therefore be promoting trade and thereby, as the ultimate goal, increase welfare in the world.

In Europe, major steps have been taken to eliminate this kind of uncertainty by introducing a common currency with the formation of the Eurozone. After the last round of accessions in January 2014, the Eurozone forms a currency union of 18 member countries with a total population of 333 millions and accounts for around 13 percent of the world's GDP. Before and in the early years after the introduction of the Euro, expectations of large economic gains from a currency union this large were widespread. On February $2^{\text {nd }} 2004$ in a keynote address at the conference "Euro Adoption in the Accession Countries - Opportunities and Challenges", Horst Köhler, at that time Managing Director of the International Monetary Fund (IMF), stated:

"Eventually joining the common currency area will provide a further significant boost to economic development through increased trade and financial flows by lowering transaction costs and eliminating market risks."

This implies that the introduction of the Euro has sizable and positive effect on the member country's pattern of international trade. The answer to the question whether or not this is true is of considerable interest as the Euro constitutes a unique natural experiment of several major economies introducing a common currency and therefore is carefully watched by countries considering to join the Eurozone or to form new currency unions in other parts of the world. The financial crisis of 2008 and the following debt crisis in Europe have clearly shown that potential gains from a common currency come at a certain cost: Giving up an independent monetary policy limits the options for countries to deal with such crisis. As positive effects in trade are used as one of the main arguments to justify the disadvantages of a common currency, it is necessary to 
investigate the relationship between exchange rate volatility and trade and assess the robustness of trade effects from currency unions. As argued by Rose (2000), the impact of a currency union goes beyond the effect of eliminating nominal exchange rate uncertainty as it is also limits the resources needed in handling currency exchange. In the literature this is often described as a nonlinear impact on trade (Figure 1) and referred to as the "Rose Effect" or "Euro Effect" (e.g. Baldwin (2006)).

Figure 1: Exchange Rate Volatility and Trade

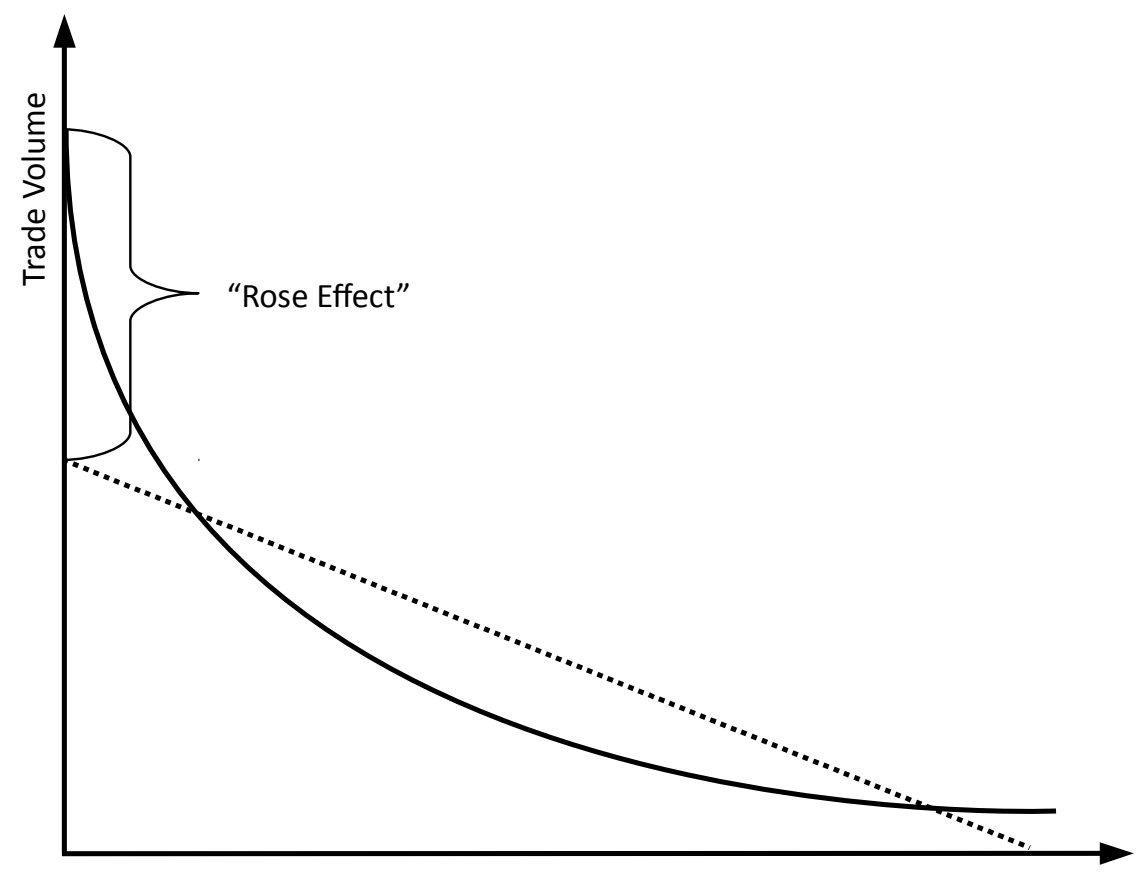

Exchange Rate Volatility

This thesis contributes to the existing literature by analyzing the impact of uncertainty in the form of exchange rate volatility on the intensive and extensive margin of trade using information at the firm- and country-level. I use advanced panel data estimation techniques and examine methodological problems in previous studies. Among the potential biases for empirical results that I try to account for are endogeneity issues, sample selection, multilateral resistance, firm heterogeneity and bilateral time-invariant heterogeneity. Furthermore, I distinguish between effects from exchange rate volatility and common currencies in order to properly assess the "Euro Effect".

The thesis is structured as follows: The first chapter presents country-level evidence for the impact of exchange rate volatility on bilateral trade for European countries and their biggest trading partners. In order to properly consider short-term effects and special sectoral characteristics, the data is disaggregated at the monthly and industry level. The second chapter turns to problems of 
endogeneity in the currency decision estimating trade flows between the CFA Franc Zone and the Eurozone before and after the introduction of the Euro. The underlying idea is to examine whether positive trade effects occur when the elimination of nominal exchange rate volatility is not explicitly wanted and is not associated with other trade facilitating attempts. The third chapter shifts the focus to the impact of exchange rate volatility and currency unions on export behavior at the firm-level using survey data of firms located in Eastern Europe and Central Asia. The main aim here is to validate and quantify the effect of exchange rate policy on a firms' probability to become an exporter, the firms' export intensity and the determinants of natural hedging, while accounting for differences between single industries and sectors. In chapter four the impact of uncertainty on the mode of export is investigated, using firm-level information from the same survey as in the previous chapter, in order to identify how uncertainty in various fields affects a firms' choice between direct exporting or exports via an intermediary. The fifth chapter looks at a very distinct aspect of uncertainty in the context of international trade. It focuses on the uncertainty that comes with trading major conventional weapons $(\mathrm{MCW})$ and tries to answer the questions whether being close in a political sense renders two countries more likely to engage in the exchange of deadly weapons. Having similar political views might help to reduce the uncertainty of potential consequences that is associated with the delivery of major arms by clearing doubts about their future use.

One of the main findings of this thesis is that uncertainty induced by volatility in the exchange rate has a significant negative impact on trade flows in Europe and that thus decreasing volatility increases trade. The introduction of a common currency is found to have an additional positive impact. Both results are based on data at the firm- and at the country-level. Nevertheless, the effect of the currency union is quantitively small, profoundly smaller than found in most previous studies. There is also evidence for strong sectoral differences, indicating that responsiveness to fluctuations in the exchange rate depends on industry-related features such as the investment horizon and access to financial markets. Furthermore, by using a natural experiment involving the CFA Franc Zone it was shown that misspecified models and endogeneity in the currency decision can be a serious problem in the empirical estimation and that, when being able to control for the bias, results may turn out to be insignificant. Exchange rate volatility and thus uncertainty about future revenues not only affects a firms' decision whether or not and how much to export, but 
among many other factors, also the choice for the mode of export. Firms in the service sector in Eastern Europe are more likely to involve an intermediary in their exporting activities and on a larger scale when volatility in the exchange rate of the domestic currency to the Euro increases.

The findings do not render currency unions a wrong endeavor. Nevertheless, they emphasize that the decision to join a currency union should not be based mainly on the expectation of large gains in terms of higher trade flows to other members of the currency union as the increase in bilateral trade flows so far has been rather small. A reduction in volatility in the exchange rate to the main invoicing currencies can also be achieved by using other tools of monetary policy. Although being designed only to facilitate the transition to the Euro, the European Exchange Rate Mechanism II (ERM II), that allows exchange rates to vary within a certain band to the Euro, could qualify as a better solution for some countries. In fact, trade effects for firms of the ERM II are found to be only slightly smaller than those of the Euro, but by design, the ERM II grants greater flexibility in times of crisis. If a reduction in uncertainty over future movements of the exchange rate is not possible, countries should ensure that firms have access to foreign markets via intermediaries. These implications are particularly important for countries in Eastern Europe, to whom the speech of Horst Köhler was mostly directed to. Several countries located in the region have already decided to join the Eurozone with Latvia in 2014 being the latest example and many more are expected to follow. As revoking participation in the Eurozone is extremely problematic, attempts to introduce the Euro need a solid ground of expertise with a thorough assessment of potential positive and negative effects and have to be based on realistic expectations.

With respect to the political determinants of arms transfers, I find that countries are more likely to trade when they have a similar political orientation. One possible explanation is that the level of uncertainty about the future use of the weapons is lower: countries have more trust that arms after their export are not used against the interests of the supplier when the recipient has similar political beliefs. I can also show that governments are more likely to transfer arms in order to help other countries when both share a certain political orientation. This has not changed fundamentally with the end of the Cold War. Also military pacts between countries and conflicts in the recipients remain to be relevant factors for the probability that two countries trade arms, as well as mandatory UN embargoes. It is important that any attempt to control the distribution of major arms, in a domestic approach or at the supranational level, acknowledges and reflects the political dimension as an important factor. 


\section{I - Exchange Rate Volatility and the Euro Effect}

based on joint work with Inmaculada Martínez-Zarzoso

The end of the Bretton Woods system in the early 1970's and the adoption of a floating exchange rate regime in 1973 raised the question of how the resulting increase in exchange rate volatility causes exchange rate risk and affects international trade and welfare. The EMU and the introduction of the Euro, associated with the abolition of several European currencies, has led to a huge debate among economists about the effects on trade. Very recently, the global financial crisis as a catalyst of the debt crises and the massive central bank interventions especially in Europe and the USA have increased exchange rate volatility and brought the topic back on the agenda.

In the light of the recent events, especially the case of Europe and the Euro is worth a second glance. The question whether joining a currency union and thereby eliminating exchange rate volatility with various other countries is boosting trade significantly is a very relevant question for many Central and Eastern European countries. The fact that countries like Poland postpone their accession to the Euro is a strong indicator for the uncertainty whether or not the negative consequences of a currency union outweigh positive effects, especially on trade.

Early theoretical studies including Clark (1973) and Hooper \& Kohlhagen (1978) find negative effects for exchange rate volatility on trade, but are based on strong assumptions. When these assumptions are relaxed, results depend on whether the firms are active in several countries (Makin 1978), adjustments of the inflation rate to exchange rate movements (Cushman 1983; Cushman 1986), flexibility of the firms in adjusting inputs (Canzoneri \& Clark 1984) or changing target markets (Broll \& Eckwert 1999), risk aversion of the firm (De Grauwe 1988; Viaene \& de Vries 1992) or the types of shocks firms are exposed to (Barkoulas et al. 2002). 
The empirical literature does not present unambiguous evidence on the relationship between exchange rate volatility and trade. Some studies find significant negative (e.g. Chit et al. 2010) or positive effects (e.g. Klein \& Shambaugh 2006), but in the majority of cases, no clear effect is obtained (e.g. Hondroyiannis et al. 2008; Boug \& Fagereng 2010; Eicher \& Henn 2011). ${ }^{1}$

Evidence on currency unions and unilateral dollarization is much clearer. While early studies find large effects and trade to triple (Rose 2000; Frankel \& Rose 2002), most recent studies report positive effects on trade of around 5 to 30 percent (e.g. Flam \& Nordström 2007; Baldwin \& Di Nino 2006; Eicher \& Henn 2011). Other authors do not describe significant effects (e.g. Berger \& Nitsch 2008; Santos Silva \& Tenreyro 2010). The usual argument why effects for currency unions are more significant is that a currency union goes beyond the mere elimination of exchange rate variability and lowers transaction costs to a much bigger extent. ${ }^{2}$ Although almost all empirical studies are based on the gravity equation on trade, they differ significantly in methodology, panel of countries, time frame, volatility measure and degree of disaggregation of the trade data.

The aim of this paper is to provide further empirical evidence on the relationship between exchange rate volatility, currency unions in case of the Eurozone and trade by presenting several novelties with respect to previous research. Higher frequency trade and exchange rate data is used to take into account the short term effects of volatility in the bilateral exchange rate. Disaggregated trade data is used to deal with differences among industries.

In contrast to many other studies, several econometric problems including the existence of zero trade values are taken into account. Investigating the impact of exchange rate volatility and the Euro at the same time allows us to disentangle the effect of a common currency beyond the elimination of any variation in the exchange rate with other members. Furthermore, due to a large dataset including very recent data, the developments of the past years with the financial crisis and the EU enlargement to the east are covered, yielding additional findings and policy implications.

Studies investigating the currency union effect by employing early Eurozone data can be assumed to be biased due to the boom in imports in the periphery countries from other Eurozone members that, as we know today, was a consumption and housing bubble and led to what is usually referred to as the European "debt crisis". Therefore, trade effects for the early years, especially for final goods, could have been overestimated.

1 See literature surveys of Côté (1994), McKenzie (1999), Ozturk (2006), Bahmani-Oskooee \& Hegerty (2007) and Auboin \& Ruta (2011).

2 Baldwin (2006) provides a good overview on the early literature. 
The rest of the paper is structured as follows: Section I.I describes the empirical strategy and issues in the estimation. Section I.II presents the results and finally, section I.III concludes with a summary of the main findings and policy implications.

\section{I.I - Methodology}

The empirical analysis is based on the standard gravity model of trade that was first developed by Tinbergen (1962). It is based on Newton's law of universal gravitation, according to which planets are mutually attracted in proportion to their physical mass and proximity. Transferred to the world of trade, physical mass is replaced with economic mass which is usually measured in GDP. Thus, trade between two countries is modeled as a function of their "economic mass" and the distance between them and has the following form:

$$
X_{i j}=G A_{i} B_{j} \phi_{i j}
$$

where $X_{i j}$ denotes the monetary value of exports from $i$ to $j, A_{i}$ comprises all exporter and $B_{j}$ all importer specific factors that make up the total production capacity and demand. $G$ is a variable that does not depend on $\mathrm{i}$ or $\mathrm{j}$ such as the level of trade liberalization. Finally, $\phi_{\mathrm{ij}}$ represents the ease of exporter $i$ to access market $j$ what is the inverse of bilateral trade costs.

\section{I.I.I - Estimation Issues}

The gravity equation of trade has seen numerous contributions and further developments in the past years. In particular the work of Anderson \& van Wincoop (2003) has been very influential. They show that for a well specified gravity equation trade costs must be seen in relative terms to the rest of the world in order to model a country's overall "resistance" to trade. This can be done by introducing "multilateral trade resistance" (MTR) in the gravity equation. The basic idea is that ceteris paribus two countries trade less with each other when they are surrounded by big economies than if they are surrounded by water, mountains or deserts and that the standard gravity equation does not account for that.

We are dealing with MTR by introducing country-year dummies that control for time-varying exporter and importer effects. Another serious issue, especially when dealing with sectoral trade flows or trade between small countries, is the existence of zero trade flows. While previous models were not capable of explaining the existence of zeros in trade flows and treated them as missing data, the monopolistic-competition model of heterogeneous firms developed by Melitz (2003) explains their existence with differences in productivity between firms. Helpman et al. 
(2008) specified a model that allows to control for zero trade flows using a two-stage procedure. In the first stage the extent of firms' entry into an export market (extensive margin), which is an unobserved variable in the standard gravity equation, is estimated using a probit model given by:

$$
\rho_{i j}=\operatorname{Pr}\left(T_{i j}=1\right)=\Theta\left(y_{0}+v_{i}+\sigma_{j}+\kappa V C_{i j}+\zeta F C_{i j}\right) \text {, }
$$

where the probability of exports from $\mathrm{i}$ to $\mathrm{j}$ depends on the importer and exporter dummies $v_{i}$ and $\sigma_{\mathrm{j}}$, bilateral variable exporting costs $\mathrm{VC}_{\mathrm{ij}}$ and fixed costs of entry $\mathrm{FC}_{\mathrm{ij}}$.

In the second stage the determinants of trade flows (in monetary value) are estimated with an augmented version of the gravity equation where the results of the first stage in form of the inverse Mill's ratio (IMR) are used to control for the sample selection bias due to omitted zero trade flows. Following this approach, the estimated equation is given by:

$$
X_{i j}=\beta_{0}+\mathrm{I}_{i}+\mathrm{I}_{j}+\kappa V C_{i j}+\ln \left(e^{\delta\left(z_{i j}+\eta_{i j}\right)}-1\right)+\beta_{\eta} \eta_{i j}+e_{i j},
$$

where trade flows between $i$ and $j$ is the dependent variable and $I_{i}$ and $I_{j}$ denote the exporter and importer individual effects. The term in brackets is the share of firms that export to $j, z$ is the fitted variable for the latent variable that was estimated in the first stage and $\eta_{i j}$ is the inverse Mill's ratio. A requirement of the approach is the use of a valid exclusion restriction: a variable that enters the first stage but not the second and that has no significant impact on the trade value, but on the probability to export is a good candidate. Most authors choose a dummy variables that identifies whether or not two countries share the same religion as the excluded variable. In the European context, we do not consider this a good choice, as all countries share a christian heritage and only some of their trading partners differ from that ${ }^{3}$. Also the main religion of a specific country does usually not vary over time. In this specific case of the EU members, we propose a different approach with the crossproduct of a time varying measure of corruption for exporter and importer. The channel through which it affects trade is by rising insecurity and associated extra fixed costs for the exporting firm stemming from a higher probability of authorities or criminals trying to extort bribes in their homeland or export destination (Crozet et al. 2009). For firms in countries with very low levels of corruption, this can be seen as a serious obstacle to start exporting as those countries are usually not used to this practices. But also positive effects for trade are conceivable: corrupt officials might allow firms to export or import even if their products do not meet technical, ethical, quality or safety standards. In over-regulated countries this could lower fixed trade costs

\footnotetext{
3 Namely China, India and Turkey.
} 
significantly (Rose-Ackerman 1999). Either way, by influencing fixed-costs rather than variable costs, corruption can be thought of as an additional barrier to trade, which should not have a significant impact on the value of trade once firms learn how to operate in a corrupt environment. The corruption data is taken from the International Country Risk Guide (ICRG) published by the PRS Group and is a component of the Political Risk Dataset. It has a scale from 0 (extremely high level of corruption) to 6 and assesses corruption within the political system ${ }^{4}$.

An additional possible source of estimation bias is the endogeneity of the decision to join a currency union. Frankel (2008) argues that endogeneity was not responsible for the extremely high estimates of early studies investigating currency union effects on trade. He presents estimates of similar magnitude to those found by a large number of early studies for the CFA Franc Zone, whose members have not decided to peg their currency to the Euro, but did so after France joined the Eurozone. The peg was not accompanied by other steps of integration that may have boosted trade and stands for an interesting natural experiment as the currency decision can be seen as exogenous ${ }^{5}$.

In our case we assume endogeneity of the currency decision not to be a serious issue as past integration steps for Eurozone members are controlled for with a dummy for membership in the European Union (EU). Besides the common currency, Eurozone members have the same degree of trade facilitating integration as members of the EU. We assume that the decision to join the Eurozone is a political decision that is mostly driven by other factors different from those influencing the value of trade.

\section{I.I.II - Data}

We have build a dataset with monthly bilateral trade for 35 countries over the period from January 1996 to December 2010. The countries included are either EU-27 countries or their major trading partners (Table A.1). ${ }^{6}$ We use nominal monthly bilateral trade data disaggregated according to the BEC classification ${ }^{7}$ from Eurostat. Unfortunately, Eurostat does not contain data on bilateral trade

4 In our dataset the crossproduct for both countries ranges from 2 to 36 .

5 The impact of the Euro on trade between the CFA Franc Zone and the Eurozone is further investigated in chapter II of this thesis.

6 Data for Bulgaria, Cyprus, Czech Republic, Estonia, Hungary, Latvia, Luxembourg, Malta, Poland, Romania, Slovakia and Slovenia is missing for the years from 1996 to 1998.

7 A thorough description of the BEC classification is available from the United Nations Department of Economic and Social Affairs (2007). 
between two non-EU members, therefore data on trade flows between countries that have never been members of the EU is missing. The share of total trade covered by our sample is for EU countries well above 80 percent (Table I.I.1).

Table I.I.1: Share of Total Trade in the Sample

\begin{tabular}{lclllc}
\hline \multicolumn{2}{c}{ Eurozone } & \multicolumn{2}{c}{ Other EU-Members } & \multicolumn{2}{c}{ Non-EU Members } \\
Country & Share in \% & Country & Share in \% & Country & Share in \% \\
\hline Austria & 87.07 & Bulgaria & 78.41 & Switzerland & 69.75 \\
Belgium & 91.62 & Czech Republic & 93.51 & China & 15.80 \\
Cyprus & 61.66 & Denmark & 83.75 & India & 19.60 \\
Germany & 80.58 & Estonia & 91.73 & Japan & 13.36 \\
Spain & 82.00 & United Kingdom & 82.91 & Norway & 72.39 \\
Finland & 85.16 & Hungary & 88.48 & Russia & 32.52 \\
France & 84.09 & Lithuania & 88.77 & Turkey & 49.57 \\
Greece & 71.01 & Latvia & 90.86 & USA & 19.04 \\
Ireland & 90.62 & Poland & 88.74 & & \\
Italy & 80.78 & Romania & 85.09 & & \\
Luxemburg & 96.18 & Sweden & 87.93 & & \\
Malta & 64.49 & & & & \\
Netherlands & 88.28 & & & & \\
Portugal & 86.63 & & & \\
Slovakia & 93.69 & & & \\
Slovenia & 72.39 & & & \\
\hline
\end{tabular}

Notes: Share is the average share of total trade value covered by our sample over all $16 \mathrm{BEC}$ categories and 15 years for a single country.

We assign the BEC sectors to three categories of goods, namely capital goods, intermediates and final goods, as recommended by the United Nations Department of Economic and Social Affairs (2007). The share for each BEC category in total trade for the whole sample is illustrated in Figure A.1 and the evolution over time of total trade for our three categories in Figure A.2. Nominal GDP data is taken from the World Development Indicators (WDI) database at an annual level. To construct the bilateral exchange rates $^{8}$ and the volatility measure, we use daily nominal middle exchange rates reported by Datastream from the WM Company/Reuters. ${ }^{9}$

Different measures of exchange rate volatility have been proposed in the related literature. Most approaches have in common to measure the variance, but differ in the implementation. Examples are the standard deviation of a rate of change or the moving standard deviation. Other measures, like $\mathrm{ARCH}$ and $\mathrm{GARCH}$ models, have gained popularity among researchers in recent years. The latter model the variance of the disturbance term for each period as a function of the errors in the

8 The bilateral exchange rate measure is the average exchange rate of the past six months.

9 This rate is the midpoint between the bid rate and the offered rate. 
previous periods. All measures have drawbacks, like for instance the high persistence of real exchange rate shocks when moving average representations are applied or low correlation in volatility when ARCH/GARCH models are the measure of choice (Baum et al. 2004). The introduction of new and more sophisticated measures has however not altered the results significantly in the empirical literature on the impact of exchange rate volatility on trade (Ćorić \& Pugh 2010).

Another important question is whether volatility of the nominal or the real exchange rate or both are included in the model. An advantage of the real exchange rate is that it reflects the true relative price of the good. However, it also captures variation in the price levels, what is not desirable. Several studies apply both exchange rates and compare the results. The differences they find are usually very small. ${ }^{10}$

Based on the recent literature, we have selected the standard deviation of the first difference of the logarithms of the nominal exchange rate, which has been used in various studies before (e.g. Clark et al. (2004)):

$$
\text { Volatility }_{i j t}=S t d . \operatorname{dev} \cdot\left[\ln \left(e_{i j t, d}\right)-\ln \left(e_{i j t-1}\right)\right] \quad d=1 \ldots 130,
$$

where e denotes the daily bilateral exchange rate between countries $\mathrm{i}$ and $\mathrm{j}$ at business day $\mathrm{d}$.

This measure has the advantage of being equal to zero when the exchange rate is on a consistent trend, which apparently could be forecasted and consequently would not be a source of uncertainty.

To avoid bias from changes in price levels via spurious correlation, we use nominal exchange rates. The measure is constructed as a short-term volatility measure with bilateral exchange rates from the past six months. Departing from most previous studies, we construct the exchange rate volatility measure with daily exchange rates which allow more precise measures than "end of the month" values as exchange rates sometimes tend to suffer more extreme movements at the end of each month. High persistence of exchange rate shocks is less of a problem as we only measure short-term volatility of the past six months with high frequency data. In contrast to studies investigating long- or mid-run volatility, we investigate the effect of short-term exchange rate volatility on trade by using a 6 month volatility measure. We assume that 6 months consist of 130 business days and thus construct the volatility measure accordingly.

10 A very profound comparison of the effects real and nominal exchange rate volatility on exports was conducted by Cotter \& Bredin (2011) finding that magnitude and direction are not changing, while timing effects can be different. 


\section{I.II - Effect of Exchange Rate Volatility on Trade}

Estimations are conducted for three different categories of products: capital goods, intermediates and consumption goods. The idea is that these three groups differ significantly in terms of contracting patterns and that our variables of interest might affect trade flows in a different direction or to a different extent.

\section{I.II.I - Model Specification}

First, we use fixed- (FE) and random-effects (RE) regressions with year-varying country fixed effects on the log of the value of bilateral exports. Therefore, we are estimating the following equation:

$$
\begin{gathered}
\ln X_{i j k t}=\beta_{0}+\beta_{1} \ln \left(Y_{i t} * Y_{j t}\right)+\beta_{2} \ln \text { Distance }_{i j}+\beta_{3} \text { EU }_{i j t}+\beta_{4} \text { Euro }_{i j t}+ \\
\beta_{5} \text { Border }_{i j}+\beta_{6} \text { Language }_{i j}+\beta_{7} \text { Landlocked }_{i j}+\beta_{8} \text { Island }_{i j}+\beta_{9} \text { Colony }_{i j}+ \\
\beta_{10} \text { Volatility }_{i j t}+\beta_{11} \ln \text { ExRate }_{i j t}+\beta_{12} \text { Corruption }_{i j t}+\kappa_{k}+\lambda_{m}+\alpha_{i y}+v_{j y}+\varepsilon_{i j k t}
\end{gathered}
$$

where the explained variable $X_{i j k t}$ denotes nominal exports in sector $k$ from the reporter country $i$ to the partner country $\mathrm{j}$ at time $\mathrm{t}$ (month $\mathrm{m}$ in year $\mathrm{y}$ ). The independent variable $\mathrm{k}_{\mathrm{k}}$ controls for industry differences with dummy variables for each BEC category and $\lambda_{m}$ controls for monthly seasonal effects with dummy variables for each month $m$ of the year $y$. The introduction of $\alpha_{\text {iy }}$ and $v_{\mathrm{jy}}$ proxies for multilateral resistance. The simultaneous inclusion of the measure of nominal exchange rate volatility and the dummy variable for mutual Euro membership allows us to capture convex effects as described by Baldwin (2006). Other variables are described in Table A.3 in the Appendix.

In order to control for zero trade flows, we follow the two stage approach from Helpman et al. (2008). The first step estimation is a probit regression on the probability to export:

$$
\begin{gathered}
\operatorname{Pr}\left(X_{i j k t}=1\right)=\Theta\left(\beta_{0}+\beta_{1} \ln Y_{i t} * Y_{j t}+\beta_{2} \ln \text { Distance }_{i j}+\beta_{3} \text { EU }_{i j t}+\beta_{4} \text { Euro }_{i j t}+\right. \\
\beta_{5} \text { Border }_{i j}+\beta_{6} \text { Language }_{i j}+\beta_{7} \text { Landlocked }_{i j}+\beta_{8} \text { Island }_{i j}+\beta_{9} \text { Colony }_{i j}+ \\
\left.\beta_{10} \text { Volatility }_{i j t}+\beta_{11} \ln \text { ExRate }_{i j t}+\beta_{12} \text { Corruption }_{i j t}+\kappa_{k}+\lambda_{m}+\alpha_{i}+v_{j}\right)
\end{gathered}
$$

The second step is then estimated as a FE and RE regression including the linear prediction of exports down-weighted by its standard error (ZHAT) and the inverse Mill's ratio (IMR). To fulfill the exclusion restriction, the variable Corruption $n_{i \mathrm{it}}$ is not included:

$$
\begin{aligned}
& \ln X_{i j k t}=\beta_{0}+\beta_{1} \ln \left(Y_{i t} * Y_{j t}\right)+\beta_{2} \ln \text { Distance }_{i j}+\beta_{3} E U_{i j t}+\beta_{4} \text { Euro }_{i j t}+ \\
& \beta_{5} \text { Border }_{i j}+\beta_{6} \text { Language }_{i j}+\beta_{7} \text { Landlocked }_{i j}+\beta_{8} \text { Island }_{i j}+\beta_{9} \text { Colony }_{i j}+ \\
& \beta_{10} \text { Volatility }_{i j t}+\beta_{11} \ln \text { ExRate }_{i j t}+\beta_{12} Z H A T+\beta_{13} I M R+\kappa_{k}+\lambda_{m}+\alpha_{i y}+v_{j y}+\varepsilon_{i j k t}
\end{aligned}
$$




\section{I.II.II - Results}

The extended gravity model is estimated for a sample of 35 countries over 15 years. Tables I.II.1 to I.II.3 present the estimates for capital goods, intermediates and final goods separately. The results show very robust negative effects for the volatility measure for the current period and for all lags. While for final goods (Table I.II.3) the effect is higher for the current value of the volatility variable than for the rest, for capital goods (Table I.II.1) lags of the volatility variable present higher coefficients than the current value. Finally, for intermediates (Table I.II.2) the current value and the first lag show higher elasticities than the second and third lags. Mutual EU membership has a significant positive effect on the probability to trade and the trade value. The coefficient of the EU dummy in the probit model is positive and statistically significant and ranges from 0.26 for capital goods over 0.34 for intermediates to 0.44 for final goods (column (3) in Tables I.II.1 to I.II.3). Thus, mutual EU membership increases the extensive margin of trade significantly, especially for industries producing final goods.

The estimated coefficient for EU membership in the FE model in column (4), which should give an idea of the effect of EU membership on the intensive margin, equals 0.09 for intermediate goods, about 0.11 for capital goods and 0.2 for final goods. Hence, the highest EU effect is found for final goods.

The results for the "Euro Effect" are more ambiguous than for the effect of the EU, but still significant at conventional levels. The probability to trade is negatively affected with estimated coefficients around -0.25 for final goods and intermediates and -0.33 for capital goods. Trade value is affected negatively for capital goods with estimates around -0.10 and positively with estimates around 0.08 and 0.07 for intermediates and final goods, respectively. In percentage points, the impact of the Euro on trade values lies according to our estimations at around 9 percent for intermediates and 7 percent for final goods. When not controlling for exchange rate volatility, the impact of the Euro on exports rises only slightly. For capital goods trade is around 11 percent lower and around 8 percent in the two stage approach. 
Table I.II.1: Regression Results - Capital Goods

\begin{tabular}{|c|c|c|c|c|c|}
\hline & & & $1^{\text {st }}$ Step & $2^{\text {nd }}$ Step & $2^{\text {nd }}$ Step \\
\hline & FE & RE & Probit & FE & RE \\
\hline \multirow{2}{*}{ In GDP $P_{i j t}$} & $0.447^{* * *}$ & $0.474^{* * *}$ & $0.462 * * *$ & $0.243^{* * *}$ & $0.467 * * *$ \\
\hline & (0.0395) & (0.0128) & $(0.00222)$ & (0.0402) & (0.0127) \\
\hline \multirow{2}{*}{ In Distance } & & $-1.206 * * *$ & $-0.861 * * *$ & & $-1.206 * * *$ \\
\hline & - & $(0.0543)$ & $(0.00653)$ & - & (0.0540) \\
\hline \multirow{2}{*}{$E U_{i j t}$} & $0.115^{* * *}$ & $0.112^{* * *}$ & $0.260 * * *$ & $0.122 * * *$ & $0.118 * * *$ \\
\hline & $(0.0161)$ & $(0.0161)$ & $(0.0103)$ & $(0.0161)$ & (0.0161) \\
\hline \multirow{2}{*}{ Euro $_{i \mathrm{jt}}$} & $-0.114 * * *$ & $-0.104 * * *$ & $-0.331 * * *$ & $-0.0708 * * *$ & $-0.0815^{* * *}$ \\
\hline & (0.0207) & $(0.0204)$ & $(0.0141)$ & $(0.0214)$ & (0.0210) \\
\hline \multirow{2}{*}{ Border $_{i j}$} & & $0.606 * * *$ & $1.041^{* * *}$ & & $0.659 * * *$ \\
\hline & - & $(0.0976)$ & $(0.0337)$ & - & (0.0984) \\
\hline \multirow{2}{*}{ Language $_{i j}$} & & $0.194^{*}$ & $0.0408^{*}$ & & $0.207^{*}$ \\
\hline & - & $(0.112)$ & $(0.0243)$ & - & $(0.112)$ \\
\hline \multirow{2}{*}{ Colony $_{\mathrm{ij}}$} & - & $0.539 * * *$ & $-0.138 * * *$ & & $0.578 * * *$ \\
\hline & - & $(0.118)$ & $(0.0281)$ & - & $(0.118)$ \\
\hline \multirow{2}{*}{ Island $_{i j}$} & - & $-0.698 * * *$ & $-0.247^{* * *}$ & & $-0.723 * * *$ \\
\hline & - & $(0.195)$ & $(0.00772)$ & - & (0.194) \\
\hline \multirow{2}{*}{ Landlocked } & & $-1.989 * * *$ & $-0.0988 * * *$ & & $-2.004 * * *$ \\
\hline & - & $(0.251)$ & $(0.00744)$ & - & $(0.250)$ \\
\hline \multirow{2}{*}{ Volatility $_{\text {ijt }}$} & $-2.805^{* * *}$ & $-2.758 * * *$ & $-1.688 * * *$ & $-1.518 * * *$ & $-2.231 * * *$ \\
\hline & $(0.514)$ & $(0.515)$ & $(0.368)$ & $(0.545)$ & $(0.542)$ \\
\hline \multirow{2}{*}{ L1.Volatility $_{\mathrm{ijt}}$} & $-3.482 * * *$ & $-3.432 * * *$ & $-1.475 * * *$ & $-2.200 * * *$ & $-2.885 * * *$ \\
\hline & $(0.612)$ & $(0.614)$ & $(0.363)$ & $(0.638)$ & $(0.636)$ \\
\hline \multirow{2}{*}{ L2.Volatility $_{\mathrm{ijt}}$} & $-3.527 * * *$ & $-3.425 * * *$ & $-1.430 * * *$ & $-2.244 * * *$ & $-2.901 * * *$ \\
\hline & $(0.509)$ & $(0.510)$ & $(0.358)$ & $(0.540)$ & $(0.537)$ \\
\hline \multirow{2}{*}{ L3.Volatility $_{\mathrm{ijt}}$} & $-1.451 * * *$ & $-1.402 * * *$ & $-1.555^{* * *}$ & -0.164 & -0.735 \\
\hline & $(0.531)$ & $(0.533)$ & $(0.364)$ & (0.559) & $(0.556)$ \\
\hline \multirow{2}{*}{ In ExRate ${ }_{\mathrm{ijt}}$} & $-0.301 * * *$ & $-0.296 * * *$ & -0.00373 & $-0.299 * * *$ & $-0.295 * * *$ \\
\hline & (0.0710) & $(0.0712)$ & (0.0501) & (0.0709) & $(0.0712)$ \\
\hline \multirow{2}{*}{ In L1.ExRate ${ }_{\mathrm{ijt}}$} & 0.0500 & 0.0578 & -0.0924 & 0.0500 & 0.0571 \\
\hline & $(0.0634)$ & $(0.0636)$ & (0.0840) & (0.0634) & $(0.0636)$ \\
\hline \multirow{2}{*}{ In L2.ExRate ${ }_{\mathrm{ijt}}$} & $0.271 * * *$ & $0.240 * * *$ & -0.0426 & $0.271 * * *$ & $0.241 * * *$ \\
\hline & $(0.0734)$ & $(0.0732)$ & $(0.0816)$ & (0.0734) & $(0.0732)$ \\
\hline \multirow{2}{*}{ In L3.ExRate ${ }_{\mathrm{ijt}}$} & 0.0826 & 0.0751 & 0.0656 & 0.0804 & 0.0733 \\
\hline & (0.0547) & (0.0549) & (0.0471) & (0.0547) & (0.0548) \\
\hline \multirow{2}{*}{ Corruption $_{\mathrm{ijt}}$} & $-0.0089 * * *$ & $-0.0088 * * *$ & $0.0156 * * *$ & & \\
\hline & $(0.00308)$ & $(0.00304)$ & $(0.000661)$ & - & - \\
\hline \multirow{3}{*}{ Zhat } & - & - & - & $0.0088 * * *$ & $0.0048 * * *$ \\
\hline & - & - & - & $(0.00118)$ & (0.00109) \\
\hline & & & & $2.047^{* * *}$ & $5.926 * * *$ \\
\hline IMR & - & - & - & $(0.631)$ & (0.509) \\
\hline Obs. & 283,895 & 283,895 & 345,268 & 283,895 & 283,895 \\
\hline $\mathbf{R}^{2}$ & 0.194 & 0.697 & - & 0.194 & 0.698 \\
\hline RMSE & 1.171 & 1.176 & - & 1.171 & 1.175 \\
\hline
\end{tabular}

Notes: Robust standard errors in parentheses; s ignificance levels: * $10 \% * * 5 \% * * * 1 \%$;

Reported R2 is within R2 for FE estimations and overall $R 2$ for RE estimations. 
Table I.II.2: Regression Results - Intermediates

\begin{tabular}{|c|c|c|c|c|c|}
\hline & & & $1^{\text {st }}$ Step & $2^{\text {nd }}$ Step & $2^{\text {nd }}$ Step \\
\hline & FE & RE & Probit & FE & RE \\
\hline \multirow{2}{*}{ In GDP $P_{\mathrm{ijt}}$} & $0.682^{* * *}$ & $0.510^{* * *}$ & $0.390 * * *$ & $0.660 * * *$ & $0.516 * * *$ \\
\hline & (0.0179) & (0.0105) & (0.000915) & $(0.0143)$ & (0.0105) \\
\hline \multirow{2}{*}{ In Distance } & & $-1.544 * * *$ & $-0.708 * * *$ & & $-1.562 * * *$ \\
\hline & - & (0.0489) & (0.00278) & - & $(0.0488)$ \\
\hline \multirow{2}{*}{$E U_{i j t}$} & $0.0896 * * *$ & $0.0873 * * *$ & $0.341 * * *$ & $0.0912 * * *$ & $0.0890 * * *$ \\
\hline & $(0.00902)$ & $(0.00901)$ & (0.00449) & $(0.00900)$ & (0.00900) \\
\hline \multirow{2}{*}{ Euro $_{i \mathrm{it}}$} & $0.0942 * * *$ & $0.0894 * * *$ & $-0.257 * * *$ & $0.0785 * * *$ & $0.0705^{* * *}$ \\
\hline & $(0.0116)$ & $(0.0115)$ & $(0.00613)$ & $(0.0120)$ & (0.0119) \\
\hline \multirow{2}{*}{ Border $_{i j}$} & & $1.147 * * *$ & $1.096 * * *$ & & $1.107 * * *$ \\
\hline & - & (0.0879) & $(0.0125)$ & - & $(0.0878)$ \\
\hline \multirow{2}{*}{ Language } & & 0.0904 & $0.117^{* * *}$ & & 0.0731 \\
\hline & - & $(0.102)$ & $(0.0102)$ & - & (0.101) \\
\hline \multirow{2}{*}{ Colony $_{\mathrm{ij}}$} & & $0.284 * * *$ & $-0.137 * * *$ & & $0.281 * * *$ \\
\hline & - & $(0.106)$ & $(0.0115)$ & - & $(0.106)$ \\
\hline \multirow{2}{*}{ Island $_{i j}$} & & $-0.570 * * *$ & $-0.193 * * *$ & & $-0.582 * * *$ \\
\hline & - & (0.170) & (0.00348) & - & $(0.170)$ \\
\hline \multirow{2}{*}{ Landlocked } & & $-2.071 * * *$ & $-0.243 * * *$ & & $-2.092 * * *$ \\
\hline & - & $(0.186)$ & $(0.00326)$ & & $(0.186)$ \\
\hline \multirow{2}{*}{ Volatility $_{\text {ijt }}$} & $-2.435^{* * *}$ & $-2.416 * * *$ & $-1.144 * * *$ & $-2.927 * * *$ & $-3.003 * * *$ \\
\hline & $(0.285)$ & $(0.285)$ & $(0.174)$ & (0.299) & $(0.298)$ \\
\hline \multirow{2}{*}{ L1.Volatility $_{\mathrm{ijt}}$} & $-2.560 * * *$ & $-2.522 * * *$ & $-0.868 * * *$ & $-3.033 * * *$ & $-3.090 * * *$ \\
\hline & (0.339) & (0.339) & $(0.171)$ & $(0.351)$ & $(0.350)$ \\
\hline \multirow{2}{*}{ L2.Volatility $y_{\mathrm{ijt}}$} & $-1.865^{* * *}$ & $-1.833 * * *$ & $-0.792 * * *$ & $-2.334 * * *$ & $-2.397 * * *$ \\
\hline & $(0.282)$ & $(0.282)$ & (0.169) & $(0.296)$ & $(0.296)$ \\
\hline \multirow{2}{*}{ L3.Volatility $_{i j t}$} & $-0.617^{* *}$ & $-0.594 * *$ & $-2.426 * * *$ & $-1.086 * * *$ & $-1.153 * * *$ \\
\hline & $(0.298)$ & $(0.298)$ & $(0.170)$ & $(0.312)$ & $(0.312)$ \\
\hline \multirow{2}{*}{ In ExRate } & $-0.0911 * *$ & $-0.0904 * *$ & $0.0503 * *$ & $-0.0911 * *$ & $-0.0904 * *$ \\
\hline & (0.0394) & $(0.0394)$ & $(0.0230)$ & $(0.0394)$ & $(0.0394)$ \\
\hline \multirow{2}{*}{ In L1.ExRate ${ }_{\mathrm{ijt}}$} & $0.0820 * *$ & $0.0820 * *$ & -0.0324 & $0.0824 * *$ & $0.0824 * *$ \\
\hline & (0.0349) & (0.0349) & $(0.0385)$ & $(0.0348)$ & $(0.0349)$ \\
\hline \multirow{2}{*}{ In L2.ExRate } & -0.0136 & -0.0145 & -0.0392 & -0.0134 & -0.0142 \\
\hline & (0.0409) & (0.0409) & $(0.0374)$ & (0.0409) & (0.0409) \\
\hline \multirow{2}{*}{ In L3.ExRate ${ }_{\mathrm{ijt}}$} & 0.0191 & 0.0195 & 0.00306 & 0.0186 & 0.0188 \\
\hline & (0.0301) & $(0.0301)$ & $(0.0216)$ & (0.0301) & $(0.0301)$ \\
\hline \multirow{2}{*}{ Corruption $_{\mathrm{ijt}}$} & 0.00117 & 0.00180 & $-0.0020 * * *$ & & \\
\hline & $(0.00169)$ & $(0.00168)$ & $(0.000282)$ & - & - \\
\hline \multirow{2}{*}{ Zhat } & - & _ & _ & $-0.0013 * * *$ & $-0.0016 * * *$ \\
\hline & - & - & - & $(0.000338)$ & (0.000329) \\
\hline & & & & $2.545 * * *$ & $2.833 * * *$ \\
\hline IMR & - & - & - & $(0.182)$ & $(0.178)$ \\
\hline Obs. & $1,045,992$ & $1,045,992$ & $1,381,072$ & $1,045,992$ & $1,045,992$ \\
\hline $\mathbf{R}^{2}$ & 0.113 & 0.623 & - & 0.113 & 0.623 \\
\hline RMSE & 1.243 & 1.244 & - & 1.243 & 1.244 \\
\hline
\end{tabular}

Notes: Robust standard errors in parentheses; sgnificance levels: * $10 \% * * 5 \% * * * 1 \%$; Reported R2 is within R2 for FE estimations and overall R2 for RE estimations. 
Table I.II.3: Regression Results - Final Goods

\begin{tabular}{|c|c|c|c|c|c|}
\hline & & & $1^{\text {st }}$ Step & $2^{\text {nd }}$ Step & $2^{\text {nd }}$ Step \\
\hline & FE & RE & Probit & FE & RE \\
\hline \multirow{2}{*}{ In GDP $P_{\mathrm{ijt}}$} & $0.416 * * *$ & $0.449 * * *$ & $0.451 * * *$ & $0.234 * * *$ & $0.450 * * *$ \\
\hline & $(0.0152)$ & $(0.00907)$ & $(0.00131)$ & $(0.0227)$ & $(0.00901)$ \\
\hline \multirow{2}{*}{ In Distance } & & $-1.267 * * *$ & $-0.734 * * *$ & & $-1.271 * * *$ \\
\hline & - & $(0.0420)$ & (0.00381) & - & (0.0417) \\
\hline \multirow{2}{*}{$E U_{i j t}$} & $0.202 * * *$ & $0.201 * * *$ & $0.439 * * *$ & $0.202 * * *$ & $0.200 * * *$ \\
\hline & $(0.00790)$ & $(0.00789)$ & (0.00609) & $(0.00787)$ & $(0.00787)$ \\
\hline \multirow{2}{*}{ Euro $_{\mathrm{ijt}}$} & $0.0648 * * *$ & $0.0681 * * *$ & $-0.241 * * *$ & $0.0741 * * *$ & $0.0718^{* * *}$ \\
\hline & (0.00999) & (0.00993) & $(0.00865)$ & (0.0104) & $(0.0103)$ \\
\hline \multirow{2}{*}{ Border $_{i j}$} & & $0.857 * * *$ & $1.060 * * *$ & & $0.865 * * *$ \\
\hline & - & $(0.0760)$ & (0.0189) & - & $(0.0758)$ \\
\hline \multirow{2}{*}{ Language $_{i j}$} & & $0.144^{*}$ & $-0.0883 * * *$ & & $0.157^{*}$ \\
\hline & - & (0.0871) & $(0.0135)$ & - & $(0.0866)$ \\
\hline \multirow{2}{*}{ Colony $_{i j}$} & & $0.338 * * *$ & $-0.129 * * *$ & & $0.349 * * *$ \\
\hline & - & $(0.0922)$ & $(0.0168)$ & - & $(0.0916)$ \\
\hline \multirow{2}{*}{ Island $_{\mathrm{ij}}$} & & $-0.244^{*}$ & $-0.0110 * *$ & & $-0.252^{*}$ \\
\hline & - & $(0.147)$ & $(0.00456)$ & - & $(0.146)$ \\
\hline \multirow{2}{*}{ Landlocked } & & $-0.665 * * *$ & $-0.233 * * *$ & & $-0.668 * * *$ \\
\hline & - & $(0.161)$ & $(0.00424)$ & - & $(0.160)$ \\
\hline \multirow{2}{*}{ Volatility $_{\mathrm{ijt}}$} & $-2.426 * * *$ & $-2.404 * * *$ & $-0.987 * * *$ & $-2.214 * * *$ & $-2.365 * * *$ \\
\hline & $(0.234)$ & $(0.234)$ & $(0.200)$ & $(0.248)$ & $(0.247)$ \\
\hline \multirow{2}{*}{ L1.Volatility $_{\mathrm{ijt}}$} & $-2.186 * * *$ & $-2.167 * * *$ & $-1.487 * * *$ & $-1.932 * * *$ & $-2.088 * * *$ \\
\hline & $(0.282)$ & $(0.282)$ & (0.199) & (0.295) & $(0.294)$ \\
\hline \multirow{2}{*}{ L2.Volatility $_{\mathrm{ijt}}$} & $-1.438 * * *$ & $-1.429 * * *$ & $-0.510 * * *$ & $-1.186 * * *$ & $-1.347 * * *$ \\
\hline & $(0.235)$ & $(0.235)$ & (0.197) & $(0.250)$ & $(0.249)$ \\
\hline \multirow{2}{*}{ L3.Volatility $_{\mathrm{ijt}}$} & $-0.968 * * *$ & $-0.957 * * *$ & $-2.208 * * *$ & $-0.724 * * *$ & $-0.879 * * *$ \\
\hline & $(0.247)$ & $(0.247)$ & (0.199) & $(0.261)$ & $(0.260)$ \\
\hline \multirow{2}{*}{ In ExRate ${ }_{\mathrm{ijt}}$} & $-0.276 * * *$ & $-0.276 * * *$ & $-0.268 * * *$ & $-0.274 * * *$ & $-0.275 * * *$ \\
\hline & $(0.0347)$ & $(0.0347)$ & $(0.0297)$ & $(0.0347)$ & $(0.0347)$ \\
\hline \multirow{2}{*}{ In L1.ExRate ${ }_{\mathrm{ijt}}$} & $-0.0592 *$ & $-0.0591^{*}$ & $-0.0931 *$ & $-0.0600 *$ & $-0.0599 *$ \\
\hline & $(0.0311)$ & $(0.0312)$ & (0.0499) & $(0.0311)$ & $(0.0312)$ \\
\hline \multirow{2}{*}{ In L2.ExRate ${ }_{\mathrm{ijt}}$} & $0.0667^{*}$ & $0.0655^{*}$ & $-0.116 * *$ & $0.0659 *$ & $0.0647^{*}$ \\
\hline & $(0.0360)$ & $(0.0360)$ & $(0.0484)$ & $(0.0360)$ & $(0.0360)$ \\
\hline \multirow{2}{*}{ In L3.ExRate ${ }_{\mathrm{ijt}}$} & $-0.0589 * *$ & $-0.0589 * *$ & $0.410 * * *$ & $-0.0602 * *$ & $-0.0593 * *$ \\
\hline & $(0.0268)$ & $(0.0268)$ & $(0.0278)$ & $(0.0268)$ & $(0.0268)$ \\
\hline \multirow{2}{*}{ Corruption $_{\mathrm{ijt}}$} & 0.0003 & 0.0006 & $0.0106 * * *$ & & \\
\hline & $(0.00149)$ & $(0.00148)$ & $(0.000390)$ & - & - \\
\hline \multirow{2}{*}{ Zhat } & & & & $0.0014 * * *$ & $0.00071^{* *}$ \\
\hline & - & - & - & $(0.000362)$ & (0.000353) \\
\hline \multirow[b]{2}{*}{ IMR } & & & & $5.923 * * *$ & $6.156 * * *$ \\
\hline & - & - & - & $(0.417)$ & $(0.382)$ \\
\hline Obs. & 879,509 & 879,509 & $1,035,804$ & 879,509 & 879,509 \\
\hline $\mathbf{R}^{2}$ & 0.167 & 0.683 & - & 0.167 & 0.683 \\
\hline RMSE & 1.006 & 1.007 & - & 1.006 & 1.007 \\
\hline
\end{tabular}

Notes: Robust standard errors in parentheses; significance levels: * $10 \% * * 5 \% * * * 1 \%$;

Reported $R 2$ is within R2 for FE estimations and overall R2 for RE estimations. 
When estimating the model excluding exchange rate movements, the estimated coefficients remain almost unchanged, whereas exchange rate volatility coefficients move slightly. Not controlling for exchange rate volatility leads to slightly higher estimates for the EU and Euro dummy (Tables A.4-A.6).

All coefficients of the other variables included in the gravity equation yield the expected signs. Estimates are always significant and positive for the GDP crossproduct and negative and significant for the distance between capitals. Controls for contiguity always yield significant positive estimates and the coefficient of the variable island is negative and significant. While the control variable for common official language shows mixed results, former colonial ties have a negative impact on the probability to export, but a positive on the value exported. The excluded variable in the second stage that, which is expected to have an impact only on the probability to trade, but not on the value, does a considerably good job. Our bilateral corruption measure has an insignificant impact on trade value and a significant impact on the probability. Only for capital goods, the impact on the value is significant, but very low.

When testing our results for robustness, we find that neither reducing the time period (Table A.8, columns (1) to (3)), nor excluding big non-European countries (Table A.8, columns (4) to (6)) from the sample significantly changes results for the EU or Euro dummies. Nevertheless, the volatility variables turn out to be less significant and their general impact less clear-cut. This is due to the fact that exchange rates in the full sample are more volatility before 1999 for countries that later joined the Euro and in general between EU-countries and countries with more or less free floating exchange rates like USA, Russia or India.

\section{I.III - Conclusion and Policy Implications}

In contrast to many previous studies, we do not find unambiguous results for exchange rate volatility. Instead, we find evidence for a significant negative impact, admittedly small in size. We find that sectors react differently with regard to the time frame and size of the impact. While mutual EU membership promotes trade via the extensive and intensive margin for most goods, Euro membership does so only via the intensive margin and not for capital goods. This could provide some evidence for a pronounced specialization process taking place in the Eurozone at the industry level after the introduction of the Euro, which results in countries exporting goods from less industries, but higher overall value. According to our results, the effect is slightly stronger for intermediates than for final goods. However, further research is needed to confirm this statement. 
The results for the extensive margin are very much in contrast to findings obtained by other authors (e.g. Bergin \& Lin 2010; Baldwin \& Di Nino 2006), who usually find positive Euro effects on the extensive margin. This is probably due to the lower level of disaggregation and higher frequency of our trade data. Negative effects on a monthly level do not necessarily mean that positive effects on a yearly and product level are not possible. It would mean that while the Euro forced a strong specialization process with pronounced seasonality on the industry level, the number of different products traded between members of the Eurozone on a yearly basis has increased. The introduction of controls for firm heterogeneity and sample selection bias does not change the results. Nonetheless, extensive and intensive margin are affected very differently by our variables of interest. When dropping most observations with higher volatility from the sample, the impact of exchange volatility on trade is less clear while the impact of mutual EU and Euro membership remains robust.

Policy implications stemming from our results are manifold. Policymakers should keep in mind, that currency unions come at great costs with regard to the flexibility of the domestic monetary policy and positive trade effects may be very limited and do not exist for all types of goods. The elimination of exchange rate volatility can also be achieved by a fixed peg. Although we find trade effects to be small, it still may be the best choice to avoid negative impacts as experienced currently in Eurozone and grants greater flexibility. The question whether stabilizing the exchange rate is a desirable objective for policymakers is unclear and it is also unclear to which extent the real exchange rate is a variable that policymakers should be able to influence or actually can influence, besides establishing a currency union, a fixed peg or Dollarization (Eichengreen 2007; Rodrik 2008).

In the light of the current economic and political crisis in Europe, our results provide evidence that a common currency may reduce investments and thus trade in capital goods within the currency union. Together with current account imbalances or real exchange rate misalignments, this may lead to a loss in competitiveness that can not be compensated by a devaluation of the domestic currency by a single member. 


\section{II - The CFA Franc and the Euro}

The controversial debate about the "Euro Effect" following the paper of Rose (2000) helped determine several methodological problems that occurred in investigations about trade effects stemming from currency unions based on the gravity equation of trade. More recent studies have found robust and much lower effects, but could not wash away concerns about one possible bias: Many authors argue that in case of the Euro and most other currency arrangements it is hard to isolate the effect of fixed exchange rates on trade due to the endogeneity of the currency decision (e.g. Baldwin, 2006; Frankel, 2008). This is due to the fact that countries are considered to be more likely to cooperate with countries that are close and they already have strong ties with. Furthermore, monetary cooperation is usually accompanied by other trade-promoting integration attempts.

In this context, the case of the CFA Franc Zone in Western Africa, as suggested by Frankel (2008), deserves a second look. As a byproduct of the introduction of the Euro in 1999, both CFA Franc were pegged to the Euro after only being pegged to the French Franc before. This provides an interesting natural experiment, as members of the CFA Franc Zone had no intention to peg their currency to currencies of the Eurozone (EZ) besides the French Franc and it did not happen within a process of deeper integration between both currency unions. The decision to form a fixed peg of the CFA Franc and the Euro can therefore be seen as exogenous. This allows to isolate the currency effect on trade from other trade promoting attempts and to quantify the effect without endogeneity bias in the currency decision.

In this paper, I use the gravity equation of trade to estimate the import and export effects of the introduction of the Euro on trade flows within the CFA Franc Zone and between Eurozone and the CFA Franc Zone with trade data for 128 countries and the years 1995-2009. Different to the approach by Frankel (2008), I use panel data estimation methods and, in order to account for 
multilateral resistance, include time varying country-dummies and cover also countries outside the Eurozone and the CFA Franc Zone. Furthermore, I try to ensure that the variables measure a strictly exogenous effect. The main aim of this study is to quantify the trade effect for flows between countries with a pegged exchange rate that is strictly exogenous and give an impression of the size of the endogeneity bias.

The results suggest that while there are positive effects for trade between the CFA Franc Zone and the Eurozone and within the CFA Franc Zone, these are limited to single sectors and the former are most likely the results of trade liberalization. The endogeneity bias appears to have a strong effect when estimating the model with OLS, as it was done in previous studies.

\section{II.I - Background}

The CFA Franc Zone was created in 1945 in the form of two currency unions with a pegged exchange rate to the French Franc. One is the West African Economic and Monetary Union $(\mathrm{WAEMU})^{11}$ and the other the Central African Economic and Monetary Community (CEMAC) ${ }^{12}$. As both currency unions have the same fixed exchange rate to the French Franc and later the Euro ${ }^{13}$, the exchange rate between both CFA Franc Zones is one.

All member states of the CFA Franc Zone are Sub-Saharan African countries and all but GuineaBissau and Equatorial Guinea were French colonies before gaining independence. A unique feature of the CFA Franc Zone is the involvement of France as the anchor currency country in the monetary policy of the central banks of the WAEMU and CEMAC. France guarantees the convertibility in their own currency and participates in the executive boards of the central banks with veto power and thus the ability to block any decisions. Today, the CFA Franc Zone goes beyond the features of a regular currency union. With the devaluation in 1994, rules of macroeconomic surveillance very similar to those established in the EMU were introduced and gradually implemented. The three main convergence criteria are an inflation rate below 3 percent, a debt-to-GDP ratio below 70 percent and a balanced budget (Hallet 2008).

The fixed peg of the CFA Franc to the French Franc/Euro serves as an an important anchor for monetary policy for the CFA members. As a disadvantage, it implies the lack of monetary and exchange rate policies as an option to support a smooth adjustment to regional or country-specific

11 In 2012 consisting of Benin, Burkina Faso, Ivory Coast, Guinea-Bissau, Mali, Niger, Senegal and Togo.

12 In 2012 consisting of Cameroon, Central African Republic, Chad, Republic of Congo, Equatorial Guinea and Gabon.

13 Since the last devaluation of the CFA Franc in 1994, the fixed exchange rates are FF $1=$ CFA 100 and Euro $1=$ CFA 655.957. 
shocks. According to Hallet (2008), it has contributed significantly to efforts in the region to achieve considerably higher macroeconomic stability than in most other parts of Sub-Saharan Africa. The convertibility to French Franc/Euro facilitates external transactions and provides the CFA Franc Zone with credibility and stability. This is broadly seen as enhancing the conditions for trade in general, not only for trade within the currency union.

At the same time, the CFA Franc Zone faces several severe problems: While monetary integration is well established, economic integration is still rather incomplete. Together with a weak economic environment and a heavy dependence on commodity exports with volatile prices it increases the likelihood of asymmetric shocks and of pro-cyclical fiscal behaviour. This is the main reason why overall compliance with the aforementioned convergence criteria has been insufficient in most of the member countries in the past.

\section{II.II - Literature}

Analysing trade effects within the framework of the CFA Franc Zone with two currency unions is rather complex. Both CFA Franc currency unions themselves have a fixed peg with the France and later the Eurozone as a whole. Therefore, the exchange rate between both CFA Francs is pegged indirectly. An extensive literature investigates the trade effects stemming from currency unions and fixed pegs. Both policies are very related as forming a currency union and a fixed peg of two currencies both imply the elimination of any volatility in the nominal bilateral exchange rate. The main difference is that a currency union is a more binding commitment and harder to withdraw from what makes currency handling easier as changes in the exchange rate policy are less likely. Therefore, the trade effect of a currency union is usually expected to go beyond the trade effect of a pegged currency. ${ }^{14}$

First, it is important to assess the relative importance and relevance of exchange rates as a barrier to trade in Sub-Saharan Africa. De Sousa \& Lochard (2005) investigate how exchange rates in comparison to other variables explain the "border effect puzzle". They use a gravity model approach and find between 17 and 28 percent of the total border effect for the CFA Franc Zone to be caused by currency related effects such as currency handling and exchange rate uncertainty and conclude that exchange rates indeed are a significant barrier to trade.

14 Given the one to one convertibility between both CFA Francs and the fact that France is the anchor currency with significant influence on the central bank policy for both currencies, one might also consider the two monetary unions of the CFA Franc Zone as one large currency union. In this study, I do not distinguish between both currency unions and treat the CFA Franc Zone as single currency union. 
The empirical literature investigating trade effects of exchange rate volatility in general does not have an unambiguous result. Most studies yield insignificant or weak but significant negative estimates. ${ }^{15}$ In contrast to that, studies investigating trade effects of currency unions usually find robust positive effects. While early studies have found extremely high results of up to 200 percent (Rose 2000), estimates have decreased to a positive effect between 5 and 30 percent in more recent studies, but remain robust. Most of the later studies have in common that they focus on trade effects of the Eurozone rather than currency unions in general. ${ }^{16}$

While numerous studies have examined trade effects of exchange rate volatility and currency unions for industrialized countries, studies for developing and especially Sub-Saharan African countries are scarce. In one of the very few exceptions, Fielding \& Shields (2005) investigate the impact of the CFA Franc on macroeconomic integration in form of trade intensity and business cycle synchronisation for the years from 1981-2000. They find evidence for positive effects for intra- and inter CFA Franc Zone trade that are declining over time. Results for the 1980s are of a similar magnitude as found by Rose (2000) for a global sample. The lower magnitude for more recent years, especially for the fixed exchange rate effect of inter-CFA Franc Zone trade, could be explained with a greater correlation between exchange rate stability and other forms of macroeconomic policy stability. Reforms in this field in countries with flexible exchange rates let potential gains of exchange rate stability diminish.

Masson (2008) tries to evaluate whether currency unions in Sub-Saharan Africa are justified by positive trade effects. He argues that due to asymmetries across countries and the low levels of trade among the members a selective expansion of existing fixed exchange rate agreements like the CFA Franc Zone or adoption of a foreign currency like the Euro in form of a dollarization would be preferable in terms of higher welfare than the formation of new currency unions in this area. He sees other trade facilitating attempts such as improving infrastructure, political stability and efficient merchandise handling as more promising in increasing trade than the formation of a currency union.

Tsangarides et al. (2006) investigate trade effects of currency unions employing an augmented version of the gravity model of trade for the case of Africa with data for 217 countries and the time of 1948-2002. They find bilateral trade to double when both country are members of the same

15 See survey papers on the relationship between exchange rate volatility and trade from Côté (1994), McKenzie (1999), Ozturk (2006), Bahmani-Oskooee \& Hegerty (2007) and Auboin \& Ruta (2011).

16 A good overview of the literature is delivered by Baldwin (2006). 
currency union and that the size of the effect is very similar for the African countries and the whole sample. They also find that the trade effect is not associated with trade diversion from noncurrency-union members and is stronger the longer the mutual currency union membership persists.

In the context of the "Euro Effect" literature, Frankel (2008) investigates the impact of the fixed exchange rate effect between Eurozone and the CFA Franc Zone with a gravity model of trade. His main goal is take advantage of the natural experiment given by the introduction of the Euro and to investigate the "Euro Effect" without endogeneity in the currency decision. He uses trade data for the years 1948-2006 and finds bilateral trade between members of the Eurozone and the CFA Franc Zone to be 76 percent higher after the introduction of the Euro. Mutual membership in the CFA Franc Zone he finds to decrease bilateral trade by 52 percent. Unfortunately, the observed positive effects for trade between the Eurozone and the CFA Franc Zone can not be seen as completely exogenous, as in this study France is treated as a normal Eurozone member. The currency decision of France certainly is a political decision and therefore endogenous.

Other authors investigate the question whether the CFA Franc Zone fulfils the criteria of an optimum currency area (OCA). Zhao \& Kim (2009) compare features of the CFA Franc Zone with the Eurozone using a structural vector autoregression method to model national outputs as determined by global, regional, and country-specific shocks. They find that domestic output of members of the CFA Franc Zone are heavily influenced by country-specific shocks, while regional shocks are more important in the Eurozone. They see this as evidence that the CFA Franc Zone countries are structurally different from each other and therefore are more likely to be affected by asymmetric shocks and thus that the CFA Franc Zone is in fact not fulfilling the criteria of an optimum currency area. Kurihara (2011) examines the suitability of the currency union among CFA Franc Zone members according to the OCA criteria focussing on business cycles and trade and endogeneity between variables. He finds that the currency union and elimination of nominal exchange rate variability results in large gains in active trade flows and convergence of business cycles.

In a descriptive study, Hallet (2008) describes a declining share of trade for the CFA Franc Zone with the Eurozone in the past decades. He attributes this to the longer-term adjustment from colonial economic ties and the increasing importance of emerging economies in Asia in more recent years. 
Thus, in addition to political instability, infrastructure and merchandise handling, currency related problems appear to be an important constraint to trade in Sub-Saharan Africa. While there are doubts that the CFA Franc Zone is an appropriate tool, empirical results show large positive effects on trade with the Eurozone and no signs of trade diversion, but evidence for the evolution of trade effects over time is mixed. This is despite the decreasing relative importance of the Eurozone in trade for the CFA Franc Zone found in the descriptive study by Hallet (2008). Results on trade effects within the CFA Franc Zone are in general mixed, indicating that the CFA Franc Zone is not contributing much to regional trade integration. All studies investigating trade effects have in common that they look at trade effects at the aggregate level and do not distinguish between different types of products.

\section{II.III - Empirics}

The dataset of this study covers 128 countries (Table B.1) for the years 1995-2009. Data on bilateral trade flows is from United Nations Comtrade. Data for variables capturing geographical and cultural closeness are from CEPII ${ }^{17}$ and bilateral data on regional trade agreements (RTA) and currency unions (CU) is from de Sousa (2012). Information on CFA Franc Zone membership was taken from the Banque Centrale des États d'Afrique Centrale (BEAC) and the Banque Centrale des États de l'Afrique de l'Ouest (BCEAO) and for Eurozone membership from Eurostat. All variables in the model are described in Table B.2.

In this study I estimate an augmented version of the gravity model of trade which represents trade between two economies as a function of their respective economic masses, the distance between them and a variety of other factors with ordinary least squares (OLS), fixed- (FE) and randomeffects (RE). The latter two take advantage of the panel structure and control for unobserved heterogeneity. One of the main aims of this study is to measure trade effects of currency unions or direct pegs where the currency decision is exogenous. Therefore, we first estimate all models also with dummy variables for trade between CFA Franc Zone and Eurozone that do not treat France as a member of the latter. The reason is that, unlike for all other Eurozone members, for France to assist in the peg of both CFA Francs to their currency and thus the Euro was a political decision and can not be seen as exogenous.

17 See Mayer \& Zignago (2011) for a more detailed description. 
In order to control for unobserved heterogeneity, we introduce several control variables including country-time fixed-effects. Allowing for a time variation in country fixed-effects is more consistent with the theoretical concept of "multilateral resistance" proposed by Anderson \& van Wincoop (2003), as multilateral resistance indices are likely to vary over time. As a robustness check the model is also estimated with no time variation in the country dummies.

The model is defined as follows:

$$
\begin{gathered}
\ln \text { Exports }_{i j t}=\beta_{0}+\beta_{1} \ln G D P_{i j t}+\beta_{2} \ln \text { Distance }_{i j}+\beta_{3} \text { CFAEZ }_{i j t}+ \\
\beta_{4} \text { EZCFA }_{i j t}+\beta_{5} \text { intraCFA }_{i j t}+\beta_{6} \text { Border }_{i j}+\beta_{7} \text { Language }_{i j}+\beta_{8} \text { Landlocked }_{i j}+ \\
+\beta_{9} \text { Colony }_{i j}+\beta_{10} \text { RTA }_{i j t}+\beta_{11} C U_{i j t}+\alpha_{i t}+v_{j t}+\varepsilon_{i j t}
\end{gathered}
$$

where Exports $s_{\mathrm{ijkt}}$ denotes the average of bilateral exports from country $\mathrm{i}$ to $\mathrm{j}$ at time $\mathrm{t}, \mathrm{GDP}_{\mathrm{ijt}}$ is the crossproduct of both countries average nominal GDP and Distance ${ }_{\mathrm{ij}}$ is the distance between both countries' capitals. We include dummy variables to identify trade flows from the CFA Franc Zone to the Eurozone $\left(C F A E Z_{i j t}\right)$, the Eurozone to CFA Franc Zone $\left(E_{Z C F A}{ }_{i j t}\right)$ and between CFA Franc Zone members $\left(\right.$ IntraCFA $\left._{i j t}\right)$. Border $i_{i j}$ is a dummy variable that equals one if both countries share a border, Language $\mathrm{i}_{\mathrm{ij}}$ equals one if a language is spoken by at least nine percent of the population in both countries, Landlocked ${ }_{i j}$ equals zero if none, one if one of the two, and two if both countries are landlocked. Colony $y_{i j}$ is a dummy variable that equals one if both countries have had any colonial ties, RTA ${ }_{\mathrm{ijt}}$ equals one if both countries have signed a regional trade agreement and $\mathrm{CU}_{\mathrm{ijt}}{ }^{18}$ equals one if both countries are members of the same currency union.

The model is estimated again for different sectors in order to identify which sectors drive the results. Therefore, trade data following the Standard International Trade Classification (SITC) Rev. 2 at the 2-digit level from United Nations Comtrade is assigned to three different groups of products: agricultural goods, mining and manufactures and estimated the aggregate level. The assignation to the three different good categories is done according to the conversion table by Rauch (1999).

18 The currency union dummy variable takes the value zero when both countries are a member of the CFA Franc Zone as this is already captured by the dummy variable for mutual CFA Franc Zone membership. 


\section{II.III.I - Results}

Results for the estimations with country and year fixed-effects including country and year dummies are shown in Table II.III.1. Estimation results with country dummies varying over time are presented in Table II.III.2. In all columns with odd numbers, dummy variables identifying trade flows between Eurozone and CFA Franc Zone treat France as a Eurozone member, in columns with even numbers France is not treated as Eurozone member.

Estimated effects for CFA/EZ trade links differ to a larger extent between the difference estimation techniques and the direction of the flow. When estimating effects for trade from CFA Franc Zone members to Eurozone members with OLS, we find negative effects of between 9 and 23 percent lower trade flows. These effects are less significant or insignificant when treating France not as a Eurozone member in order to minimize the endogeneity bias. Exports from Eurozone members to CFA Franc Zone members are between 8 and 17 percent higher. For FE and RE estimations the introduction of the Euro only yields insignificant results. Trade flows in the opposite direction show significant positive effects when allowing country-dummies to vary over time. Trade increases by 47 percent according to the FE estimations and 25 percent for RE estimations. The latter is weakly significant when treating France as Eurozone member and insignificant otherwise. Trade within the CFA Franc Zone yields mostly significant positive estimates. Only for the FE model and only with time-varying country-dummies results are insignificant. While estimates for the RTA dummy are positive and significant in all cases, results of currency unions are mostly negative or they are insignificant in the case of the FE estimations with time-varying country-dummies.

Variables measuring distance and dummies for common border, common language, landlockedness and colonial relations are dropped from all FE regressions due to perfect collinearity as these variables do not vary over time. In OLS and RE regressions, sharing a border, a common language or to have common colonial past all have a significant positive impact on trade flows. The GDP crossproduct has a significant positive impact on trade and distance between capitals a significant negative in all regressions.

The OLS estimates have the disadvantage of unobserved heterogeneity and the panel data structure of the data is not reflected in the estimation and therefore panel data estimation techniques are considered more appropriate. The preference for FE or RE estimations depends on the consistency of the RE estimates, which are more efficient. According to the Hausman test, all RE estimates are inconsistent. In this study, multilateral resistance is accounted for by including 
country-dummies in the model. As this resistance to trade can be expected to vary over time, it is important that this is reflected in the estimation. Therefore, the preferred model is a FE estimation with time-varying country-dummies shown in Table II.III.2 in columns (3) and (4).

Table II.III.1: Trade Volume Estimated with Country and Year Fixed-Effects and Country- and Year-Dummies

\begin{tabular}{|c|c|c|c|c|c|c|}
\hline & (1) & $(2)$ & (3) & (4) & (5) & (6) \\
\hline & OLS & OLS & FE & FE & RE & RE \\
\hline In GDP $P_{i j t}$ & $\begin{array}{c}0.807 * * * \\
(0.0247)\end{array}$ & $\begin{array}{c}0.805^{* * *} \\
(0.0247)\end{array}$ & $\begin{array}{c}0.928^{* * *} \\
(0.0279)\end{array}$ & $\begin{array}{c}0.928^{* * *} \\
(0.0279)\end{array}$ & $\begin{array}{c}0.914^{* * *} \\
(0.0277)\end{array}$ & $\begin{array}{c}0.914 * * * \\
(0.0277)\end{array}$ \\
\hline In Distance & $\begin{array}{l}-1.619 * * * \\
(0.00739)\end{array}$ & $\begin{array}{l}-1.619 * * * \\
(0.00739)\end{array}$ & $10-\frac{1}{1}$ & $1=0-1$ & $\begin{array}{c}-1.716 * * * \\
(0.0198)\end{array}$ & $\begin{array}{c}-1.716^{* * *} \\
(0.0198)\end{array}$ \\
\hline CFAEZ $_{\mathrm{ijt}}$ & $\begin{array}{l}-0.146 * * \\
(0.0717)\end{array}$ & $\begin{array}{c}-0.260 * * * \\
(0.0774)\end{array}$ & $\begin{array}{c}0.222 \\
(0.171)\end{array}$ & $\begin{array}{c}0.222 \\
(0.171)\end{array}$ & $\begin{array}{l}0.0992 \\
(0.146)\end{array}$ & $\begin{array}{l}0.0912 \\
(0.148)\end{array}$ \\
\hline EZCFA $_{\mathrm{ijt}}$ & $\begin{array}{c}0.183^{* * *} \\
(0.0347)\end{array}$ & $\begin{array}{c}0.129 * * * \\
(0.0366)\end{array}$ & $\begin{array}{c}0.0911 \\
(0.0664)\end{array}$ & $\begin{array}{c}0.0889 \\
(0.0662)\end{array}$ & $\begin{array}{c}0.0846 \\
(0.0606)\end{array}$ & $\begin{array}{c}0.0814 \\
(0.0614)\end{array}$ \\
\hline intraCFA $_{\mathrm{ijt}}$ & $\begin{array}{c}1.385 * * * \\
(0.0720)\end{array}$ & $\begin{array}{l}1.366^{* * *} \\
(0.0718)\end{array}$ & $\begin{array}{c}0.254^{* *} \\
(0.118)\end{array}$ & $\begin{array}{c}0.254^{* *} \\
(0.118)\end{array}$ & $\begin{array}{c}0.398^{* * *} \\
(0.111)\end{array}$ & $\begin{array}{c}0.398^{* * *} \\
(0.111)\end{array}$ \\
\hline Border $_{i j}$ & $\begin{array}{c}0.679 * * * \\
(0.0295)\end{array}$ & $\begin{array}{c}0.678^{* * *} \\
(0.0295)\end{array}$ & - & - & $\begin{array}{c}0.825^{* * *} \\
(0.106)\end{array}$ & $\begin{array}{c}0.825^{* * *} \\
(0.106)\end{array}$ \\
\hline Language $_{i j}$ & $\begin{array}{c}0.718^{* * *} \\
(0.0145)\end{array}$ & $\begin{array}{c}0.718 * * * \\
(0.0145)\end{array}$ & - & - & $\begin{array}{c}0.769 * * * \\
(0.0410)\end{array}$ & $\begin{array}{c}0.769 * * * \\
(0.0410)\end{array}$ \\
\hline Landlocked & $\begin{array}{c}0.603^{* * *} \\
(0.0898)\end{array}$ & $\begin{array}{l}0.601 * * * \\
(0.0898)\end{array}$ & - & - & $\begin{array}{c}1.032 * * * \\
(0.213)\end{array}$ & $\begin{array}{c}1.032 * * * \\
(0.213)\end{array}$ \\
\hline Colony $_{\mathrm{ij}}$ & $\begin{array}{l}1.016 * * * \\
(0.0269)\end{array}$ & $\begin{array}{l}1.017^{* * *} \\
(0.0268)\end{array}$ & - & - & $\begin{array}{c}0.993 * * * \\
(0.101)\end{array}$ & $\begin{array}{c}0.999 * * * \\
(0.101)\end{array}$ \\
\hline RTA $_{i j t}$ & $\begin{array}{c}0.588^{* * *} \\
(0.0154)\end{array}$ & $\begin{array}{c}0.586^{* * *} \\
(0.0154)\end{array}$ & $\begin{array}{c}0.129 * * * \\
(0.0210)\end{array}$ & $\begin{array}{c}0.129 * * * \\
(0.0210)\end{array}$ & $\begin{array}{l}0.203 * * * \\
(0.0202)\end{array}$ & $\begin{array}{c}0.203 * * * \\
(0.0202)\end{array}$ \\
\hline $\mathrm{Cu}_{\mathrm{ijt}}$ & $\begin{array}{c}-0.377 * * * \\
(0.0444)\end{array}$ & $\begin{array}{c}-0.382 * * * \\
(0.0444)\end{array}$ & $\begin{array}{c}-0.126 * * * \\
(0.0255)\end{array}$ & $\begin{array}{c}-0.126 * * * \\
(0.0255)\end{array}$ & $\begin{array}{c}-0.171 * * * \\
(0.0346)\end{array}$ & $\begin{array}{c}-0.171 * * * \\
(0.0346)\end{array}$ \\
\hline Constant & $\begin{array}{c}20.17^{* * *} \\
(0.345)\end{array}$ & $\begin{array}{c}20.17^{* * *} \\
(0.345)\end{array}$ & $\begin{array}{c}9.060 * * * \\
(0.160)\end{array}$ & $\begin{array}{c}9.060 * * * \\
(0.160)\end{array}$ & $\begin{array}{c}19.82 * * * \\
(0.542)\end{array}$ & $\begin{array}{c}19.82 * * * \\
(0.542)\end{array}$ \\
\hline Strict Exogeneity & No & Yes & No & Yes & No & Yes \\
\hline Obs. & 237,966 & 237,966 & 237,966 & 237,966 & 237,966 & 237,966 \\
\hline $\mathbf{R}^{2}$ overall & 0.737 & 0.737 & 0.138 & 0.138 & 0.733 & 0.733 \\
\hline $\mathbf{R}^{2}$ within & - & - & 0.138 & 0.138 & 0.138 & 0.138 \\
\hline
\end{tabular}

Notes: Robust standard errors in parentheses; significance levels: * $10 \%$ ** 5\% ***1\%; Strict exogeneity refers to exogeneity of the currency decision and indicates whether ("No") or not ("Yes") France is treated as a Eurozone member 
Table II.III.2: Trade Volume Estimated with Country-Year Fixed-Effects and Time-Varying Country-Dummies

\begin{tabular}{|c|c|c|c|c|c|c|}
\hline & (1) & $(2)$ & (3) & (4) & (5) & (6) \\
\hline & OLS & OLS & FE & FE & RE & RE \\
\hline In GDP & $\begin{array}{c}0.648^{* * *} \\
(0.0595)\end{array}$ & $\begin{array}{c}0.647^{* * *} \\
(0.0595)\end{array}$ & $\begin{array}{c}0.697^{* * *} \\
(0.0390)\end{array}$ & $\begin{array}{c}0.697^{* * *} \\
(0.0390)\end{array}$ & $\begin{array}{c}0.691^{* * *} \\
(0.0389)\end{array}$ & $\begin{array}{c}0.691^{* * *} \\
(0.0389)\end{array}$ \\
\hline In Distance $_{\mathrm{ij}}$ & $\begin{array}{l}-1.619 * * * \\
(0.00742)\end{array}$ & $\begin{array}{r}-1.619 * * * \\
(0.00742)\end{array}$ & - & - & $\begin{array}{c}-1.724 * * * \\
(0.0199)\end{array}$ & $\begin{array}{c}-1.724 * * * \\
(0.0199)\end{array}$ \\
\hline CFAEZ $_{i \mathrm{jt}}$ & $\begin{array}{c}-0.0928 \\
(0.0726)\end{array}$ & $\begin{array}{c}-0.211 * * * \\
(0.0787)\end{array}$ & $\begin{array}{c}0.384 * * \\
(0.164)\end{array}$ & $\begin{array}{c}0.384 * * \\
(0.164)\end{array}$ & $\begin{array}{l}0.226^{*} \\
(0.137)\end{array}$ & $\begin{array}{c}0.218 \\
(0.140)\end{array}$ \\
\hline EZCFA $_{\text {ijt }}$ & $\begin{array}{c}0.149 * * * \\
(0.0363)\end{array}$ & $\begin{array}{c}0.0873 * * \\
(0.0385)\end{array}$ & $\begin{array}{c}-0.0842 \\
(0.0773)\end{array}$ & $\begin{array}{c}-0.0843 \\
(0.0775)\end{array}$ & $\begin{array}{c}-0.0557 \\
(0.0690)\end{array}$ & $\begin{array}{l}-0.0643 \\
(0.0699)\end{array}$ \\
\hline intraCFA $_{\mathrm{ijt}}$ & $\begin{array}{c}1.426 * * * \\
(0.0753)\end{array}$ & $\begin{array}{c}1.399 * * * \\
(0.0751)\end{array}$ & $\begin{array}{l}0.0675 \\
(0.149)\end{array}$ & $\begin{array}{l}0.0675 \\
(0.149)\end{array}$ & $\begin{array}{c}0.278^{* *} \\
(0.132)\end{array}$ & $\begin{array}{c}0.275^{* *} \\
(0.132)\end{array}$ \\
\hline Border $_{i j}$ & $\begin{array}{c}0.678 * * * \\
(0.0295)\end{array}$ & $\begin{array}{c}0.678^{* * *} \\
(0.0295)\end{array}$ & - & - & $\begin{array}{c}0.828^{* * *} \\
(0.106)\end{array}$ & $\begin{array}{c}0.827^{* * *} \\
(0.107)\end{array}$ \\
\hline Language $_{\mathrm{ij}}$ & $\begin{array}{c}0.720 * * * \\
(0.0143)\end{array}$ & $\begin{array}{c}0.720 * * * \\
(0.0143)\end{array}$ & - & - & $\begin{array}{c}0.777^{* * *} \\
(0.0410)\end{array}$ & $\begin{array}{c}0.778 * * * \\
(0.0410)\end{array}$ \\
\hline Landlocked & $\begin{array}{c}-0.406 * * * \\
(0.150)\end{array}$ & $\begin{array}{c}-0.406 * * * \\
(0.150)\end{array}$ & - & - & $\begin{array}{l}-0.193 \\
(0.232)\end{array}$ & $\begin{array}{l}-0.193 \\
(0.232)\end{array}$ \\
\hline Colony $_{i j}$ & $\begin{array}{c}1.019 * * * \\
(0.0267)\end{array}$ & $\begin{array}{c}1.020 * * * \\
(0.0267)\end{array}$ & - & - & $\begin{array}{c}0.997^{* * *} \\
(0.101)\end{array}$ & $\begin{array}{c}1.002 * * * \\
(0.101)\end{array}$ \\
\hline RTA $_{i j t}$ & $\begin{array}{c}0.593 * * * \\
(0.0162)\end{array}$ & $\begin{array}{c}0.591^{* * *} \\
(0.0162)\end{array}$ & $\begin{array}{c}0.0994 * * * \\
(0.0229)\end{array}$ & $\begin{array}{c}0.0994 * * * \\
(0.0229)\end{array}$ & $\begin{array}{c}0.188^{* * *} \\
(0.0218)\end{array}$ & $\begin{array}{c}0.188 * * * \\
(0.0218)\end{array}$ \\
\hline $\mathrm{Cu}_{\mathrm{ijt}}$ & $\begin{array}{c}-0.373 * * * \\
(0.0460)\end{array}$ & $\begin{array}{c}-0.380 * * * \\
(0.0460)\end{array}$ & $\begin{array}{l}0.00956 \\
(0.0356)\end{array}$ & $\begin{array}{l}0.00957 \\
(0.0356)\end{array}$ & $\begin{array}{l}-0.0720 * \\
(0.0436)\end{array}$ & $\begin{array}{l}-0.0728 * \\
(0.0437)\end{array}$ \\
\hline Constant & $\begin{array}{c}23.66 * * * \\
(0.376)\end{array}$ & $\begin{array}{c}23.66^{* * *} \\
(0.376)\end{array}$ & $\begin{array}{c}10.54 \\
(194.8)\end{array}$ & $\begin{array}{c}10.55 \\
(68.97)\end{array}$ & $\begin{array}{c}23.63^{* * *} \\
(0.586)\end{array}$ & $\begin{array}{c}23.63^{* * *} \\
(0.586)\end{array}$ \\
\hline Strict Exogeneity & No & Yes & No & Yes & No & Yes \\
\hline Obs. & 237,966 & 237,966 & 237,966 & 237,966 & 237,966 & 237,966 \\
\hline $\mathbf{R}^{2}$ overall & 0.744 & 0.744 & 0.146 & 0.145 & 0.739 & 0.739 \\
\hline $\mathbf{R}^{2}$ within & - & - & 0.188 & 0.188 & 0.187 & 0.187 \\
\hline
\end{tabular}

Following the choice of the most appropriate estimation above, we reestimate column (4) in Table II.III.2 for three different sectors to assess which of them drives results at the aggregate level and show the estimates in Table II.III.3. Regression results at the sectoral level show that only trade of agricultural goods yields significant estimates, but not trade in goods from the mining or manufacturing sector. While exports of agricultural goods from the CFA Franc Zone to the Eurozone show a significant positive increase of 46 percent in trade value, exports in the opposite direction are affected negatively with a decrease of 25 percent. The former could be explained with the start of the Everything but Arms initiative (EBA) of the EU in 2001, under which all imports to the European Union from the least developed countries are duty-free and quota-free, with the 
exception of arms and ammunition ${ }^{19}$. In order to be applicable for a certain good, all phases of production have to occur within least developed countries. This is the case for only very few nonagricultural goods. Within the CFA Franc Zone, only manufactures show a weakly significant increase in the value traded of 24 percent.

Table II.III.3: FE Regressions with Time-Varying CountryDummies by Sector

\begin{tabular}{|c|c|c|c|}
\hline & (1) & $(2)$ & (3) \\
\hline & FE & FE & FE \\
\hline & Agricultural & Mining & Manufactures \\
\hline \multirow{2}{*}{ In GDP } & $0.588^{* * *}$ & $0.756 * * *$ & $0.670 * * *$ \\
\hline & $(0.0457)$ & $(0.0736)$ & $(0.0417)$ \\
\hline \multirow{2}{*}{ CFAEZ $_{\text {ijt }}$} & $0.377 * *$ & -0.233 & 0.287 \\
\hline & $(0.164)$ & $(0.262)$ & $(0.176)$ \\
\hline \multirow{2}{*}{ EZCFA $_{i \mathrm{jt}}$} & $-0.286 * *$ & 0.131 & -0.116 \\
\hline & $(0.122)$ & $(0.186)$ & $(0.0805)$ \\
\hline \multirow{2}{*}{ intraCFA $_{i j t}$} & 0.183 & -0.0466 & $0.214^{*}$ \\
\hline & $(0.201)$ & $(0.273)$ & $(0.130)$ \\
\hline \multirow{2}{*}{ RTA $_{i j t}$} & $0.116 * * *$ & $0.131 * * *$ & $0.0909 * * *$ \\
\hline & $(0.0270)$ & $(0.0418)$ & $(0.0240)$ \\
\hline \multirow{2}{*}{$\mathrm{Cu}_{\mathrm{ijt}}$} & $0.214^{* * *}$ & $0.428 * * *$ & -0.0410 \\
\hline & (0.0495) & (0.0887) & $(0.0382)$ \\
\hline \multirow{2}{*}{ Constant } & 10.08 & 9.165 & 10.18 \\
\hline & $(144.1)$ & $(270.3)$ & (556.6) \\
\hline Obs. & 186,469 & 122,824 & 216,534 \\
\hline $\mathbf{R}^{2}$ within & 0.144 & 0.149 & 0.188 \\
\hline
\end{tabular}

\section{II.IV - Conclusion}

The results of this study shed light on the robustness of trade effects from fixed exchange rates without endogeneity bias. In sharp contrast to the results of other authors, I find that the elimination of nominal exchange rate volatility between CFA Franc Zone and the Eurozone has boosted trade flows from the CFA Franc Zone to the Eurozone through an increase in exports of agricultural goods, but not the other way around. Results are most likely driven by the EBA initiative that due to its strict rules of origin is promoting almost exclusively the export of agricultural goods and that started about the same time as the Euro was introduced. Due to complex transitional agreements is hard to control for the initiative in an empirical setting.

19 The initiative includes transitional arrangements for sugar, rice and bananas until 2006. 
With regard to the endogeneity issues, results show that when estimating the model with OLS trade effects are much higher with France treated as an Eurozone member. In the strictly exogenous case, the significant effect on trade flows disappears. This leads to the conclusion that the high positive effects of the fixed peg between CFA Franc Zone and Eurozone found by Frankel (2008) are not robust to endogeneity in the currency decision and probably are to large. It also emphasizes that the bias caused by the endogeneity issues in studies investigating trade effects from exchange rate policy is significant and strong when using OLS.

It can also be seen as an indicator that unobserved factors like other trade-facilitating attempts beside RTAs, well established business links and trade networks play a much bigger role in this particular case of trade between Europe and Sub-Saharan Africa than exchange rate risks. France, due to its special role in the history of the region, may still have very special relationship with the members of the CFA Franc Zone that goes beyond a common colonial past or a common language. The veto power in the executive boards of both CFA Franc central banks is one example and presence of military troops in the region another. Investigating the economic and political role of France in Sub-Saharan Africa with regard to trade in goods goes beyond the scope of this paper but provides interesting research opportunities for future studies. 


\section{III - Exchange Rate Policy and Exports of Firms}

based on joint work with Inmaculada Martínez-Zarzoso

The impact of volatility and movements of exchange rates on trade remains to be a vivid topic of academic debate, which was dominated for a longer time by the introduction of the Euro. While for the Eurozone in particular and currency unions in general a consensus was reached for most economists that a robust positive effect exists, for volatility in the bilateral exchange rate the results remain mixed. In both fields, the most common approach to empirically evaluate the effect on trade has been to estimate a gravity model using aggregated or sectoral trade data at the country level.

A number of empirical studies however investigates the impact of exchange rate volatility on export behaviour using firm-level data yield mixed results. The estimated effects for the extensive margin are not significant for Spain (Campa 2004) and positive for France (Guillou 2008). Studies on the intensive margin find negative effects for France (Berthou \& Fontagne 2008) and China (Héricourt \& Poncet 2012) and no significant effects for Turkey (Solakoglu et al. 2008). The "Euro Effect" yields significant positive effects only for the extensive margin in the case of France (Berthou \& Fontagne 2008), only the intensive margin for Italy (Vicarelli \& Pappalardo 2012) or both margins for Germany (Etzel et al. 2013). All are single country studies with a focus on big economies with little volatility in the exchange rate or focus on large firms only.

In this paper we go a step further and extend the literature using firm-level data by examining a huge region of 26 countries instead of a single country and by focusing on Eastern Europe, a region where exchange rate fluctuations are considerable. The second novelty of this paper is the focus not only on the effect of exchange rate volatility on trade alone, but also on the currency regime effect. It is also worth mentioning that the region is dominated by countries that are not large in an economic sense and have no well-developed financial markets. Furthermore, we examine whether 
importing activities are affected in a similar fashion as exporting, the impact of different hedging tools on firms' engagement in international trade and provide results for several robustness checks.

The investigated region is particularly interesting as most countries located there have had a similar history in the last two decades, have undergone remarkable changes in exchange rate policy and continue to have different policy approaches today, which provides sufficient variation at the country level to implement this research. So far, only single country survey analyses have been conducted for Eastern Europe, in particular for Hungary and the Czech Republic, which investigate hedging practices of domestic firms (Bodnár 2009; Cadek et al. 2011).

Given the specific characteristics of the countries under examination, we first hypothesize that increasing volatility in the bilateral exchange rate to the Euro leads to a rise in uncertainty for firms about future revenues and thereby to less involvement in export activities. Secondly, we expect that the impact of the existing exchange rate agreements (e.g. Euro or ERM II) goes beyond the reduction or elimination of exchange rate volatility, as it reduces uncertainty about future changes in the exchange rate and makes policy changes more difficult due to the binding character of the agreements. The idea is that differences in the domestic exchange rate policy towards the Euro change the uncertainty horizon for the real value of firms' future revenues. While lower volatility in the exchange rate may encourage firms to engage in exporting activities in the short term, a certain degree of uncertainty remains as the exchange rate policy of their home country may change in the near future. More binding commitments in the form of the European Exchange Rate Mechanism II (ERM II) or Euro membership may lower the degree of uncertainty.

Our study is structured as follows: Section III.I provides a brief overview of the theoretical and empirical evidence with a focus on firm-level data studies. Section III.II contains information about our data and the empirical strategy, section III.III discusses the results and section III.IV concludes. 


\section{III.I - Literature Review}

In this section the main existing theories and empirical applications closely related to our work are outlined and discussed. The next subsection provides a summary of the theoretical aspects and the following a brief summary of empirical studies that evaluate the effect of exchange rate volatility on trade with a special focus on studies using firm-level data.

\section{III.I.I - Theory}

The theoretical analysis of exchange rate volatility and trade indicates that in most cases negative effects prevail due to uncertainty about future revenues as described by Clark (1973). But the varying effects described in numerous scenarios rely to a large extent on the assumptions made. In particular, results show that the firms' level of risk aversion, the flexibility of a firm to shift from one market to another and alter the composition and origin of inputs appears to play an important role.

Clark (1973) considers the case of a single firm with no market power producing a single good under perfectly competitive conditions without imported components that is entirely exported to a foreign market. The firm gets paid in the foreign currency and has to convert it at the current exchange rate. As movements of the exchange rate are unpredictable and access to currency hedging is assumed to be limited, the proceeds vary. High costs for adjustments to the scale of production keep the firm from altering output in advance of the realization of the exchange rate. Thus, uncertainty about future exchange rates directly translates into uncertainty about future receipts in the domestic currency.

Under the assumption that the firm is risk averse and maximizes profits, it has to determine a level of output that incorporates this uncertainty. In this situation, the variability of profits depends completely on changes in the exchange rate. Thus, an increase in volatility of the exchange rate while the average level remains unchanged - leads to a decrease in production, and hence in exports, due to the increased exchange rate risk. Inflexibility of firms to alter factor inputs can amplify the effect (Hooper \& Kohlhagen 1978).

Several studies have described certain scenarios in which increasing volatility may have a positive effect, e.g. due to the possibility of higher average revenues (Canzoneri \& Clark 1984) or via additional profit possibilities and the principle of sunk market-entry costs (Dixit 1989; Franke 
1991). Broll \& Eckwert (1999) describe the case of a firm that profits from variability in the exchange rate by seeing the home market as a safe harbour and foreign markets as a source for additional revenues when the domestic currency depreciates.

In the specific case of Eastern Europe, another source of positive effects may stem from firms' common practice in that region to take out loans in foreign currencies to profit from lower costs of credit $^{20}$. Intensifying export activities invoiced in the currency of the credit may then be seen as a way to lower credit risks in case of a depreciation of the firms' domestic currency. When assuming risk aversion, a firm may even accept lower revenues from exporting instead of selling to the domestic market in order to decrease total risk exposure. Higher exchange rate volatility can in this case lead to higher exports because of increasing exchange rate risks in order to lower credit risks. To our knowledge this effect has not yet been considered by the existing theories.

\section{III.I.II - Empirical Studies}

The empirical literature investigating trade effects of volatility in the bilateral exchange rate or currency unions is mostly based on country-level data. Some studies use disaggregated data to control for differences between industries or to emphasize the higher responsiveness of single sectors. There are no unambiguous results of empirical macro studies investigating the impact of exchange rate volatility, but most find weak and mostly significant negative effect. Studies differ in the sample of countries, the covered time period, the degree of disaggregation of the trade data and empirical methodology. ${ }^{21}$ In a very comprehensive meta-regression on empirical macro-studies of the topic, Ćorić \& Pugh (2010) find exchange rate volatility and trade to have a modestly negative relationship with pronounced heterogeneity and with little evidence of publication bias, but mainly positive evidence that this relationship is an authentic empirical effect. They find uncertainty arising from exchange rate volatility to be a serious concern for least developed countries, what points towards the importance of hedging instruments and thus the stage of development of financial markets in least developed countries.

The introduction of a common currency completely eliminates nominal exchange rate volatility between the members. Positive trade effects of currency unions can go beyond the elimination of volatility in the exchange rate as it also facilitates currency handling and lowers uncertainty in the

20 This Information has been obtained from surveys on exchange rate handling practice of firms for Hungary and the Czech Republic described in section III.I.III.

21 See survey papers on the relationship between exchange rate volatility and trade from Côté (1994), McKenzie (1999), Ozturk (2006), Bahmani-Oskooee \& Hegerty (2007) and Auboin \& Ruta (2011). 
long term due to the binding character of a currency union. Studies investigating trade effects of currency unions usually find robust positive effects. While early studies found extremely high results of an increase in trade up to 200 percent (Rose 2000), estimates have decreased to a positive effect between 5 and 30 percent, but remain robust. Most of the later studies focus on trade effects for the Eurozone. ${ }^{22}$

Only a few studies take advantage of data at the firm-level and usually focus on firms in a single country. Empirical studies on trade effects of currency unions and exchange rate volatility based on firm-level data are shown in Table III.I.1. Campa (2004) investigates the case of 2188 Spanish manufacturing firms for the years 1990-1997 and their responsiveness in export behaviour to exchange rate changes by estimating a dynamic discrete-choice model. He does not find a significant effect of exchange rate volatility on foreign market entry and exit, instead he finds evidence for sunk costs hysteresis to play an important role and that a depreciation of the domestic currency increases export volumes slightly via the extensive margin.

In a similar way, Guillou (2008) employs data on french manufacturing firms for the years 19942004 and distinguishes between effects on the probability to export and export intensity. On the one hand, she finds that for most industries a depreciation of the domestic currency affects the probability to export, while there is fairly no impact on the export intensity when introducing the lagged value of the dependent variable. Exchange rate volatility yields positive results on the probability to export for most industries.

Solakoglu et al. (2008) estimate the effect of exchange rate volatility on real exports for the years 2001-2003 using a sample of 143 large Turkish firms. According to their results, exchange rate volatility does not affect trade and firm size and the level of international activity do not influence a firms' responsiveness to volatility. They do find evidence for natural hedging via imported intermediaries.

In a more recent study, Héricourt \& Poncet (2012) investigate the effect of real effective exchange rate volatility on export performance and the role of financial constraints. They employ export data for more than 100,000 Chinese exporters over the period 2000-2006 and find a negative effect on extensive and intensive margins of trade.

22 A good overview of the literature is delivered by Baldwin (2006). 
Several studies analyse the effect of membership in a currency union (usually the Euro) on export behaviour of domestic firms. In general, studies using firm-level panel data find that Eurozone membership significantly lowers the exchange rate risk to which domestic firms are exposed to (e.g. Bartram \& Karolyi 2006). Vicarelli \& Pappalardo (2012) employ difference-in-difference estimation techniques for a panel of around 21,000 Italian firms for the years 1996-2004 and find that the euro has had a positive influence on Italian exports, mostly through the intensive margin. Etzel et al. (2013) try to explain Germany's export success story using data at the plant-level for the years 1996-2008. They find that higher plant-level competitiveness due to higher productivity or lower wages is positively correlated with export intensity at the intensive and extensive margins. This lets them conclude that the introduction of the Euro has led to higher export demand for the relatively cheaper German products as separate regressions for the pre- and post-Euro periods reveal that the export promoting effect of competitiveness is strongest shortly after the Euro was introduced.

In the only other empirical study that includes both variables, measures for exchange rate volatility and currency unions, Berthou \& Fontagne (2008) investigate export behaviour of French firms for the years 1998-2003. Estimating a model that consists of both variables allows to disentangle the trade effect of eliminated exchange rate volatility from the effect stemming from a common currency. They find trade deterring effects via the intensive and extensive margin of trade for exchange rate volatility and trade boosting effects for Euro membership only via the extensive margin.

Table III.I.1: Studies Investigating Trade Effects of Exchange Rate Volatility or Currency Unions at the Firm-level

\begin{tabular}{|c|c|c|c|c|c|c|c|}
\hline \multirow{2}{*}{\multicolumn{2}{|c|}{ Authors }} & \multicolumn{3}{|c|}{ Sample } & \multicolumn{2}{|c|}{ Effect on Margin } & Methodology \\
\hline & & \# of Firms & Time & Country & extensive & intensive & \\
\hline \multirow{5}{*}{ 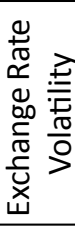 } & Campa (2004) & 2,188 & 1990-1997 & Spain & no effect & - & Dynamic discrete choice \\
\hline & Guillou (2008) & 47,716 & 1994-2004 & France & positive** & 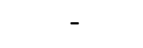 & RE Probit \\
\hline & Solakoglu et al. (2008) & 143 & 2001-2003 & Turkey & - & no effect & OLS, FE, RE \\
\hline & Berthou \& Fontagne (2008) & ? & $1998-2003$ & France & - & negative & $\mathrm{FE}, \mathrm{RE}$ \\
\hline & Héricourt \& Poncet (2012) & 113,368 & 2000-2006 & China & - & negative & $\mathrm{FE}$ \\
\hline \multirow{3}{*}{ 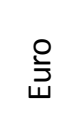 } & Berthou \& Fontagne (2008) & $?$ & $1998-2003$ & France & positive & no effect & $\mathrm{FE}, \mathrm{RE}$ \\
\hline & Vicarelli \& Pappalardo (2012) & 21,000 & 1996-2004 & Italy & no effect & positive & Difference in Difference \\
\hline & Etzel et al. (2013) & $16,000^{*}$ & 1996-2008 & Germany & positive & positive & FRACP, FRACPL, Tobit, Probit \\
\hline
\end{tabular}
Notes: *observations at the plant level; **probability to export. 
Other studies focus on the impact of exchange rate volatility on general economic performance of firms (Carranza et al. 2003), firm value (Hutson \& O'Driscoll 2010), plant-level investment (Kandilov \& Leblebicioglu 2011) or are only descriptive (Sanderson 2009).

Recent findings suggest that the impact of exchange rates on trade flows in general may be lower than expected due to the type of firms that export. Berman et al. (2012) find that exporting firms are generally bigger and more productive than non-exporters and in a situation of depreciation of the domestic currency tend to increase their margins rather than the volume of sales. For less productive firms, the reverse is true: they increase the volume of exports rather than prices. Although there is a positive impact of an exchange rate depreciation on the number of exporting firms or extensive margin, the effect is less evident on a macro level due to the smaller size of the firms starting to export.

\section{III.I.III - Hedging Behaviour of Firms}

There are several ways in which firms can reduce the exposure to exchange rate uncertainty. For instance, they can use internal hedging tools by importing intermediates in the currency of the export destination. This only works when imports and exports are denoted in the same currency ${ }^{23}$ and prices are passed through to the domestic market ${ }^{24}$. This firm behaviour is is usually referred to as "natural hedging". Alternative forms of internal hedging include pricing in the currency in which the majority of the costs are incurred or in the currency of major competitors, ensuring that comparative prices are less affected and inserting an exchange rate variation clause in trade contracts to protect margins. In addition, firms can to a certain degree expedite or defer payments and thereby lower the exposure to exchange rate peaks.

The main alternative is hedging with the help of a financial institution. For this external hedging to be effective, access to a well-developed and functioning financial market is crucial. When available, a wide range of financial instruments is offered that allow to lower or eliminate the risk exposure. Among these are forward contracts, call and put options and swaps. Furthermore, firms can lend and borrow in foreign currencies, preferably in the currency of their export markets. Firms that are

23 Exports and imports do not have to be necessarily denoted in the same currency to offset uncertainty effects. When volatility in the exchange rate is mostly driven by the domestic currency and exports and imports are denoted in different but less volatile currencies, exposure to uncertainty will already be lower and could by described as indirect hedging.

24 Fauceglia et al. (2012) provide evidence for a high exchange rate pass-through for intermediates in Switzerland. 
part of large multinationals are even more flexible in this regard and have direct access to the financial sector in several countries and commonly hold assets and liabilities in more than one currency.

Nevertheless, all forms of hedging are either imperfect, associated with additional costs and risks or availability is limited to large firms ${ }^{25}$. Natural hedging is also not available when importing intermediates is not an option or suppliers of intermediates can not be changed. In a study covering several countries in Eastern Europe and Central Asia, Raddatz (2011) finds that countries with more volatile exchange rates tend to export goods from sectors where natural hedging is possible and that this can help reduce the exposure to exchange rate risk. He finds only weak evidence showing that the availability of financial derivatives used for external hedging lowers the importance of natural hedging in a given sector.

Little evidence exists so far on how common the use of hedging instruments in the region covered by our study is. Two descriptive studies on hedging practice in Eastern Europe yield interesting findings. Cadek et al. (2011) investigate hedging behaviour of 2330 Czech firms using a survey. They find that around 60 percent of the firms are indeed hedging exports and that smaller firms are less likely to hedge. In addition, their findings indicate that the firms have not altered their hedging behaviour after the financial crisis. Bodnár (2009) analysing survey data for 672 firms for the year 2006 in a similar attempt for Hungary finds that firms take out a considerably large share of loans in Euros and Swiss Franc, but only an extremely small amount in US Dollars. Around 30 percent of Hungarian firms raise debt in foreign currencies and 25 percent of them claim to do so because of net income in foreign currencies. Hedging via the financial sector appears to be only a minor reason for taking loans in foreign currencies and only a small fraction of firms in the sample, around 7 percent, use foreign currencies mainly to hedge export revenues. According to the survey, firms report to have debt in foreign currencies due to lower costs of credits as the most important reason. Nevertheless, exchange rate volatility is expected by the firms to have a negative impact on the revenues, especially by those with loans in foreign currencies.

25 Large corporations in the Eurozone have indeed access to hedging instruments to reduce exchange rate risk and they make use of it intensively (Döhring 2008). For small firms, this does not have to be the case. 
Summarizing, there is evidence that internal and external hedging are used by a notable number of firms in the region of interest depending on their size and sector. It is worth to note that in the case of external hedging it remains unclear whether hedging is the main purpose or just a side effect in the firms' efforts to lower the costs of credits. Some evidence points in the direction of the latter.

\section{III.II - Empirical Analysis}

Our empirical analysis is separated in two parts. First, we quantify the impact of volatility of the bilateral exchange rate of the domestic currency with the Euro and membership of currency agreements on a firms' probability to export and second, on the export intensity. The first question we try to answer with a probit regression on the probability of a single firm to export and the second with a regression on the share of produced goods and services that is exported.

\section{III.II.I - Data}

Firm-level data is from the Eastern Europe \& Central Asia Panel Dataset of the World Bank Enterprise Surveys BEEPS and covers the years 2002, 2005, 2007 and 2009. The dataset combines information gathered in different surveys and are matched by the World Bank. The panel structure of the data is displayed in Tables C.1 and C.2 and countries and industries covered in this study are shown in Tables C.3, C.4 and C.5.

Information for the exchange rate policy dummies comes from IMF, ECB, Eurostat and national central banks. We distinguish between separate dummies for pegged exchange rates and membership in the European Exchange Rate Mechanism II (ERM II) or the Euro ${ }^{26}$ and define exports as the sum of direct and indirect exports as reported by the firms. The number of regional trade agreements (RTA) signed by each country in the panel as a measure of trade liberalization is taken from De Sousa et al. (2012).

Unfortunately, the BEEPS dataset contains only limited information about the number of employees for each firm. Only for some cohorts questions about the precise number of employees are included in the questionnaire and due to the matching process, the BEEPS dataset only includes information on the number of employees in categorical variables. This makes it impossible to calculate a good measure of productivity without losing most of the observations and thus, we do not include a measure of productivity in our empirical approach.

26 We treat the unilateral adoption of the Euro in the case of Montenegro like a Euro membership. 


\section{III.II.II - Volatility Measure}

The measure volatility we use is the standard deviation of the first difference of the logarithms of the monthly domestic exchange rate to the Euro for the twelve months of the past year:

$$
\text { Volatility }_{j t}=\operatorname{Std} . \text { dev. }\left[\ln \left(e_{j, m}\right)-\ln \left(e_{j, m-1}\right)\right], m=1 \ldots 12 \text {, }
$$

where e is the exchange rate of country $\mathrm{j}$ in month $\mathrm{m}$.

Exchange rate movements are measured as the natural logarithm of the difference between the average exchange rate of the past year and the year before. Data for the volatility measure and exchange rate movements are nominal monthly exchange rates from OANDA.com. Since we do not have information about the destination of exports, we assume that the volatility of the local currency with respect to the Euro is a good proxy for exchange rate volatility in general. This assumption is reasonable, because the main export destination for Eastern European countries is the $\mathrm{EU}$, as shown in Figure $\mathrm{C} \cdot 1^{27}$. The $\mathrm{EU}$ is also the main competitor and the Euro is increasingly been used as an invoicing currency, especially in countries with the prospect to adopt the Euro in the future ${ }^{28}$. Evidence from some firm surveys supports this assumption. For instance in the Czech Republic, Cadek et al. (2011) find that more than 90 percent of firm exports go to other European countries and 75 percent of all export revenues are in Euro.

Thus, the importance of the Euro is obvious for countries already aligning their monetary or foreign policy towards the EU and the Euro, but less convincing for others. We assume that for the countries in our sample that have a more or less free-floating exchange rate, volatility of the exchange rate with the Euro is dominated by the volatility of the domestic currency and not volatility of the Euro. As a robustness check, we have estimated the same regressions with a volatility measure constructed with exchange rates with respect to the US Dollar. Estimated coefficients are lower and slightly less significant, but the general picture remains the same ${ }^{29}$.

The use of nominal exchange rates instead of real exchange rates is justified by the fact that reliability and availability of real exchange rates is not given for many countries in the sample. Furthermore, empirical evidence suggests that the choice between real and nominal exchange rates does not change the magnitude and direction of the estimated coefficients and only timing

27 For most countries in the sample, more than half of total exports is exported to the EU-27 (Figure C.1). Most currencies of countries that are members of the EU but not the Eurozone have a rather stable exchange rate to the Euro.

28 The increasing relevance of the Euro as invoicing currency was found and well described by Kamps (2006).

29 Estimated coefficients for regressions with volatility to the US Dollar as an explanatory variable instead of volatility to the Euro are available upon request. 
effects can be different (Cotter \& Bredin 2011). In macro studies, a broad variety of exchange rate volatility measures has been used in the past. Nevertheless, a recent study shows that using more sophisticated measures does not change the results significantly (Ćorić \& Pugh 2010). The range of the volatility measure for each country for the years covered in our sample is displayed in Figure C.2.

\section{III.II.III - Model Specification}

Based on the theoretical literature of heterogenous firms and international trade, we distinguish between the extensive and intensive margin of exports and estimate its determinants using two separate model specifications. In order to estimate the determinants of the probability to export, that we define as the extensive margin of trade, we estimate a probit model that includes a number of firm- and country-specific variables and also industry $(k)$, country $(j)$ and time $(t)$ fixedeffects and is given by:

$$
\begin{aligned}
& \operatorname{Pr}\left(\text { Exporter }_{i j k t}=1\right)=\Phi\left(\beta_{0}+\beta_{1} \ln \text { Sales }_{i j k t}+\beta_{2} \text { FirmSize }_{i j k t}+\beta_{3} \text { Quality }_{i j k t}+\beta_{4} \text { Euro }_{j t}+\right. \\
& \left.\beta_{5} \text { ERM }_{j t}+\beta_{6} \text { Peg }_{j t}+\beta_{7} \ln \text { ExchangeRate }_{j t}+\beta_{8} \text { Volatility }_{j t}+\beta_{9} \text { RTA }_{j t}+\kappa_{j}+\lambda_{k}+\alpha_{t}+\varepsilon_{i j k t}\right) \text {, }
\end{aligned}
$$

where Exporter $_{\mathrm{ijkt}}$ is a dummy variable that takes the value one if firm $\mathrm{i}$ is an Exporter at time $\mathrm{t}$ and zero otherwise, In Sales $\mathrm{ijkt}_{\text {d }}$ denotes the natural log of total sales, FirmSize $\mathrm{ijkt}_{\mathrm{jkt}}$ is a measure of firm size in terms of employees ${ }^{30}$, Quality ${ }_{\mathrm{ijkt}}$ is a dummy variable that takes the value of one if the firm has an internationally-recognized quality certification and zero otherwise.

We have introduced three dummy variables to control for the exchange rate policy in country $\mathrm{j}$ : First, Euro ${ }_{j t}$ takes the value one if the Euro is the domestic currency at time $t$ in country $j$ and zero otherwise. Second, $E M_{\mathrm{jt}}$ takes the value one if country $\mathrm{j}$ takes part in the European Exchange Rate Mechanism II and finally, Peg $\mathrm{j}_{\mathrm{t}}$ takes the value one if the domestic currency is pegged to the Euro or to a basket of currencies that includes the Euro. Volatility $y_{j t}$ is our measure of choice for volatility of the exchange rate of the domestic currency with the Euro for the twelve months of the past year specified in equation (III.1) and In ExchangeRate ${ }_{j t}$ is the natural log of the first difference of the average exchange rate of country $\mathrm{j}$ with respect to the Euro in year $\mathrm{t}-1$. As a control for the degree of trade liberalization in a given country, the model includes the variable RTA $_{\mathrm{jt}}$, which is the total

30 Firm size is a binary variable that takes the value one if the firm has less than 20 employees, two if the firm has between 20 and 99 and three if the firm has 100 or more employees. 
number of RTAs in which country $\mathrm{j}$ participates in year $\mathrm{t}$. In addition to a standard probit regression, we estimate the model with random-effects and with and without industry, country and year dummies.

Furthermore, we estimate the determinants of the intensive margin of exports, defined as share of sales to foreign markets. The model is given by:

$$
\begin{gathered}
\text { ExportIntensity }_{i j k t}=\beta_{0}+\beta_{1} \ln \text { Sales }_{i j k t}+\beta_{2} \text { FirmSize }_{i j k t}+\beta_{3} \text { Quality }_{i j k t}+\beta_{4} \text { Euro }_{j t}+ \\
\beta_{5} \text { ERM }_{j t}+\beta_{6} \text { Peg }_{j t}+\beta_{7} \ln \text { ExchangeRate }_{j t}+\beta_{8} \text { Volatility }_{j t}+\beta_{9} \text { RTA }_{j t}+\kappa_{j}+\lambda_{k}+\alpha_{t}+\varepsilon_{i j k t}
\end{gathered},
$$

where ExportIntensity ${ }_{\mathrm{ijkt}}$ is the share of total production that is exported of firm $\mathrm{i}$ at time $\mathrm{t}$ and varies between 0 and 100. All other variables are the same as described for equation (III.2).

The models specified in equations (III.2) and (III.3) are estimated with and without industry, country and year dummies. In addition, each sector is estimated separately in order to analyse sectoral differences in the responsiveness to exchange rate policy.

\section{III.III - Results}

In this section we present the estimation results of the determinants of the extensive and intensive margin of exports. Table III.III.1 shows the results of model (III.2), which estimates the determinants of the extensive margin. In the first three columns a pooled probit model is estimated, that is augmented with year and industry fixed-effects in column two and country fixedeffects are added in column three. Our measure for exchange rate volatility yields negative and mostly significant estimates. This indicates that lower volatility in the exchange rate with respect to the Euro increases a firms' probability to export.

The estimates for variables capturing firm specific characteristics yield the expected signs and are statistically significant. The natural log of sales, the number of employees and the existence of internationally recognized quality certificates in the firm all have a positive impact on the probability and the intensity of exports. Higher sales and holding international and quality certificates increases the probability to export. For country specific variables, estimates are rather mixed, especially for the exchange rate agreement dummies. Imperfections in the financial sector, which are likely to be present in many countries of our sample, can disturb the link between exchange rate movements and exports (Berman \& Berthou 2009). Nevertheless, our variable capturing movements of the exchange rate has the expected sign and is mostly significant. Euro 
and ERM II membership increase the probability to export. Our measure for trade liberalization yields significant positive estimates for all regressions, indicating that a higher number of signed regional trade agreements in a country increases the probability of a domestic firm to export.

Reliability of our probit estimates may for some variables suffer from unobserved heterogeneity and in this case it is not possible to interpret them as a causal relationship, but only as correlations between dependent and independent variables. Therefore, we estimate a linear probability and a probit model in a differences-in-differences (DID) design, which are reported in column four to six. While the interaction term for the year 2009 and ERM II dummy yields always insignificant estimates, it is always positive and significant for the Euro in the probit model. Interactions for different years and our dummy for fixed pegs yields mixed results. Thus, once we estimate our model in setting insusceptible for unobserved heterogeneity, the Euro is the only dummy variable measuring exchange rate policy that has significant positive impact on the probability to become an exporter. Movements and volatility of the exchange rate we assume to be exogenous as they depend on the interaction of domestic and foreign factors via financial markets. 
Table III.III.1: Determinants of the Extensive Margin

\begin{tabular}{|c|c|c|c|c|c|c|}
\hline & \multirow[b]{2}{*}{ (1) } & \multirow[b]{2}{*}{$(2)$} & \multirow[b]{2}{*}{ (3) } & \multicolumn{3}{|c|}{ Differences in Differences } \\
\hline & & & & (4) & (5) & (6) \\
\hline & Probit & Probit & Probit & LPM & Probit & Probit \\
\hline \multirow[t]{2}{*}{ In Sales } & $0.0625 * * *$ & $0.130 * * *$ & $0.167 * * *$ & $0.0302 * * *$ & $0.121 * * *$ & $0.129 * * *$ \\
\hline & $(0.00529)$ & $(0.00655)$ & (0.00988) & $(0.00173)$ & $(0.00691)$ & $(0.00722)$ \\
\hline \multirow[t]{2}{*}{ Quality } & $0.470 * * *$ & $0.424 * * *$ & $0.356 * * *$ & $0.123 * * *$ & $0.381 * * *$ & $0.373^{* * *}$ \\
\hline & $(0.0261)$ & $(0.0286)$ & $(0.0299)$ & $(0.00889)$ & $(0.0286)$ & $(0.0288)$ \\
\hline \multirow[t]{2}{*}{ Size } & $0.293 * * *$ & $0.183 * * *$ & $0.163 * * *$ & $0.0585 * * *$ & $0.199 * * *$ & $0.183 * * *$ \\
\hline & $(0.0169)$ & $(0.0188)$ & $(0.0230)$ & $(0.00533)$ & $(0.0195)$ & (0.0199) \\
\hline \multirow[t]{2}{*}{ Euro } & $0.170 * * *$ & $0.394 * * *$ & & 0.0329 & $-2.799 * * *$ & $-2.994 * * *$ \\
\hline & $(0.0620)$ & $(0.0710)$ & - & $(0.0376)$ & $(0.204)$ & $(0.206)$ \\
\hline \multirow[t]{2}{*}{ Euro\#2009 } & & & & 0.0622 & $3.249 * * *$ & $3.336^{* * *}$ \\
\hline & - & - & - & $(0.0428)$ & $(0.218)$ & $(0.217)$ \\
\hline \multirow[t]{2}{*}{ ERM } & 0.0677 & $0.232 * * *$ & & $0.0652 * * *$ & $0.183 * * *$ & $0.250 * * *$ \\
\hline & $(0.0423)$ & $(0.0472)$ & - & $(0.0178)$ & $(0.0613)$ & $(0.0639)$ \\
\hline \multirow[t]{2}{*}{ ERM\#2009 } & & & & -0.0370 & 0.0633 & -0.101 \\
\hline & - & - & - & $(0.0250)$ & $(0.0832)$ & $(0.0910)$ \\
\hline \multirow[t]{2}{*}{ Peg } & -0.0282 & $-0.0809 *$ & & -0.0224 & $-0.184^{*}$ & -0.108 \\
\hline & $(0.0356)$ & $(0.0419)$ & - & $(0.0298)$ & $(0.106)$ & $(0.108)$ \\
\hline \multirow[t]{2}{*}{ Peg\#2005 } & & & & 0.0280 & 0.180 & 0.121 \\
\hline & - & & - & $(0.0385)$ & (0.149) & $(0.150)$ \\
\hline \multirow[t]{2}{*}{ Peg\#2007 } & & & & $-0.433 * * *$ & 0.0227 & $-1.514 * * *$ \\
\hline & - & - & - & $(0.0838)$ & $(0.126)$ & (0.339) \\
\hline \multirow[t]{2}{*}{ Peg\#2009 } & & & & 0.0313 & $0.288^{* *}$ & 0.201 \\
\hline & - & - & - & $(0.0336)$ & $(0.122)$ & $(0.124)$ \\
\hline \multirow[t]{2}{*}{ In ExchangeRate } & $-0.0324 * * *$ & $-0.0340 * * *$ & $-0.380 * *$ & $-0.0106 * * *$ & $-0.0107 * * *$ & -0.0529 \\
\hline & $(0.00435)$ & (0.00469) & $(0.158)$ & $(0.00143)$ & $(0.00142)$ & $(0.0423)$ \\
\hline \multirow[t]{2}{*}{ Volatility } & $-0.716^{*}$ & -0.590 & $-0.875^{* *}$ & $-0.235^{*}$ & -0.150 & $-0.266^{* *}$ \\
\hline & $(0.432)$ & $(0.392)$ & $(0.370)$ & $(0.142)$ & $(0.117)$ & (0.109) \\
\hline \multirow[t]{2}{*}{ RTA } & $0.00559 * * *$ & $0.00960 * * *$ & $0.00556 * *$ & $0.00184^{* * *}$ & $0.00295 * * *$ & $0.00225^{* * *}$ \\
\hline & $(0.000756)$ & $(0.000983)$ & $(0.00251)$ & $(0.000248)$ & $(0.000298)$ & (0.000629) \\
\hline \multirow[t]{2}{*}{ RTA\#2005 } & - & & & & & $0.0140 * *$ \\
\hline & - & - & - & - & - & $(0.00561)$ \\
\hline \multirow[t]{2}{*}{ RTA\#2007 } & & & & & & $0.170 * * *$ \\
\hline & - & - & - & - & - & $(0.0331)$ \\
\hline \multirow[t]{2}{*}{ RTA\#2009 } & & & & & & $0.0228 * * *$ \\
\hline & - & - & - & - & - & $(0.00545)$ \\
\hline Year Dummies & No & Yes & Yes & Yes & Yes & Yes \\
\hline Industry Dummies & No & Yes & Yes & Yes & Yes & Yes \\
\hline Country Dummies & No & No & Yes & No & No & No \\
\hline Observations & 17,354 & 17,354 & 17,354 & 17,354 & 17,354 & 17,354 \\
\hline (Pseudo) $\mathrm{R}^{\wedge} 2$ & 0.104 & 0.216 & 0.260 & 0.214 & - & - \\
\hline
\end{tabular}

Notes: Robust standard errors in parentheses; ${ }^{* *} p<0.01,{ }^{* *} p<0.05,{ }^{*} p<0.1$

Results of model (III.3), that estimates the effect of exchange rate policy on export intensity or the intensive margin, are presented in Table III.III.2 columns (1) to (3). The estimates of the effect of our measure of exchange rate volatility on export intensity are always negative and significant. When estimating with year and industry dummies, Euro membership increases the export intensity 
by slightly over five percentage points. The impact of ERM II membership is slightly lower with slightly less than five percentage points. Much lower is the effect of exchange rate pegs with around two percentage points.

When considering the unobserved heterogeneity and estimating the model with a DID design similar to estimations on the extensive margin, estimates for the interactions measuring the effect of exchange rate policy, as shown in columns four and five, are no longer significant. Also pegged exchange rates do no longer have a significant impact on export intensity. While exchange rate volatility still has significant negative impact, it turns insignificant for exchange rate movements. 
Table III.III.2: Determinants of the Intensive Margin

\begin{tabular}{|c|c|c|c|c|c|}
\hline & & & & DI & ID \\
\hline & $(1)$ & $(2)$ & (3) & (4) & $(5)$ \\
\hline & OLS & OLS & OLS & OLS & OLS \\
\hline In Sales & $\begin{array}{c}0.126 \\
(0.0964)\end{array}$ & $\begin{array}{c}0.772 * * * \\
(0.0990)\end{array}$ & $\begin{array}{c}1.170 * * * \\
(0.145)\end{array}$ & $\begin{array}{c}0.688^{* * *} \\
(0.104)\end{array}$ & $\begin{array}{c}0.747^{* * *} \\
(0.106)\end{array}$ \\
\hline Quality & $\begin{array}{c}5.900 * * * \\
(0.590)\end{array}$ & $\begin{array}{c}4.762 * * * \\
(0.557)\end{array}$ & $\begin{array}{c}3.751^{* * *} \\
(0.558)\end{array}$ & $\begin{array}{c}4.783 * * * \\
(0.557)\end{array}$ & $\begin{array}{c}4.604 * * * \\
(0.557)\end{array}$ \\
\hline Size & $\begin{array}{c}7.030 * * * \\
(0.348)\end{array}$ & $\begin{array}{c}4.899 * * * \\
(0.324)\end{array}$ & $\begin{array}{c}4.556^{* * *} \\
(0.378)\end{array}$ & $\begin{array}{c}5.052 * * * \\
(0.332)\end{array}$ & $\begin{array}{c}4.936 * * * \\
(0.338)\end{array}$ \\
\hline Euro & $\begin{array}{l}2.505^{*} \\
(1.330)\end{array}$ & $\begin{array}{c}5.068 * * * \\
(1.245)\end{array}$ & - & $\begin{array}{c}6.481^{* *} \\
(2.958)\end{array}$ & $\begin{array}{c}4.419 \\
(2.956)\end{array}$ \\
\hline Euro\#2009 & - & - & - & $\begin{array}{c}-1.129 \\
(3.240)\end{array}$ & $\begin{array}{l}-0.963 \\
(3.210)\end{array}$ \\
\hline ERM & $\begin{array}{c}1.561^{*} \\
(0.880)\end{array}$ & $\begin{array}{c}4.695^{* * *} \\
(0.816)\end{array}$ & - & $\begin{array}{c}4.484^{* * *} \\
(1.019)\end{array}$ & $\begin{array}{c}5.671 * * * \\
(1.056)\end{array}$ \\
\hline ERM\#2009 & - & - & - & $\begin{array}{c}0.778 \\
(1.455)\end{array}$ & $\begin{array}{l}-2.344 \\
(1.601)\end{array}$ \\
\hline Peg & $\begin{array}{c}3.714^{* * *} \\
(0.756)\end{array}$ & $\begin{array}{c}2.062 * * * \\
(0.717)\end{array}$ & - & $\begin{array}{l}3.459 * \\
(2.099)\end{array}$ & $\begin{array}{c}5.168 * * \\
(2.106)\end{array}$ \\
\hline Peg\#2005 & - & - & - & $\begin{array}{c}1.210 \\
(2.757)\end{array}$ & $\begin{array}{c}-0.178 \\
(2.766)\end{array}$ \\
\hline Peg\#2007 & - & - & - & $\begin{array}{c}-4.380 * \\
(2.554)\end{array}$ & $\begin{array}{c}-9.434 \\
(6.177)\end{array}$ \\
\hline Peg\#2009 & - & - & - & $\begin{array}{c}-0.532 \\
(2.321)\end{array}$ & $\begin{array}{l}-2.479 \\
(2.335)\end{array}$ \\
\hline In ExchangeRate & $\begin{array}{l}-0.154^{*} \\
(0.0808)\end{array}$ & $\begin{array}{c}-0.139 * \\
(0.0761)\end{array}$ & $\begin{array}{c}-10.84 * * * \\
(2.418)\end{array}$ & $\begin{array}{c}-0.117 \\
(0.0765)\end{array}$ & $\begin{array}{c}-0.116 \\
(0.0774)\end{array}$ \\
\hline Volatility & $\begin{array}{c}-17.71 * * * \\
(5.131)\end{array}$ & $\begin{array}{c}-20.81^{* * *} \\
(4.900)\end{array}$ & $\begin{array}{c}-11.53^{* *} \\
(5.139)\end{array}$ & $\begin{array}{c}-19.21 * * * \\
(4.883)\end{array}$ & $\begin{array}{c}-22.49 * * * \\
(4.971)\end{array}$ \\
\hline RTA & $\begin{array}{c}0.133^{* * *} \\
(0.0137)\end{array}$ & $\begin{array}{c}0.125^{* * *} \\
(0.0141)\end{array}$ & $\begin{array}{l}-0.0135 \\
(0.0347)\end{array}$ & $\begin{array}{c}0.128 * * * \\
(0.0142)\end{array}$ & $\begin{array}{c}-0.347^{* * *} \\
(0.0951)\end{array}$ \\
\hline RTA\#2005 & - & - & - & - & $\begin{array}{c}0.399 * * * \\
(0.0975)\end{array}$ \\
\hline RTA\#2007 & - & - & - & - & $\begin{array}{c}0.822 \\
(0.567)\end{array}$ \\
\hline RTA\#2009 & - & - & - & - & $\begin{array}{c}0.543^{* * *} \\
(0.0959)\end{array}$ \\
\hline Constant & $\begin{array}{c}-6.626^{* * *} \\
(1.005)\end{array}$ & $\begin{array}{c}4.174 * * * \\
(1.336)\end{array}$ & $\begin{array}{c}56.35^{* * *} \\
(11.49)\end{array}$ & $\begin{array}{c}4.726^{* * *} \\
(1.375)\end{array}$ & $\begin{array}{c}8.164 * * * \\
(1.683)\end{array}$ \\
\hline Year Dummies & No & Yes & Yes & Yes & Yes \\
\hline Industry Dummies & No & Yes & Yes & Yes & Yes \\
\hline Country Dummies & No & No & Yes & No & No \\
\hline Observations & 17.354 & 17.354 & 17.354 & 17,354 & 17,354 \\
\hline$R^{\wedge} 2$ & 0.087 & 0.191 & 0.217 & 0.192 & 0.194 \\
\hline
\end{tabular}

In order to investigate sectoral differences, the regressions in column (2) in Tables III.III.1 and III.III.2 are run for each industry in the sample. The sign of the estimates are presented in Table III.III.3 and Tables C.7 and C.8 in the Appendix show the complete regression results. We find negative effects for exchange rate volatility on the probability to export for 13 of 18 industries, 
which are significant only for the following six sectors: other manufacturing, fabricated metal products, retail, hotels and restaurants and IT. Export intensity is affected negatively in 12 of 18 sectors and the effect is significant for five sectors. An appreciation of the domestic currency leads to a lower probability to export in 15 of 18 sectors with effects being significant for eight sectors, and to a lower export intensity in 14 of 18 sectors, only in five cases. Surprisingly, an appreciation increases export intensity of garments and IT sector ${ }^{31}$.

Euro and ERM II membership increase the probability to export in 12 of 18 sectors and the export intensity in 14 of 18 sectors. Direct pegs yield very mixed estimates with 12 of 18 sectors facing negative effects on the probability to export and 8 on the export intensity. Trade liberalization measured as the number of signed RTAs a has positive and significant impact on the probability to export and export intensity for all non-service industries besides food.

Table III.III.3: Direction of Coefficients for Sectoral Regressions Probability to Export Export Intensity

\begin{tabular}{clcccccccccc}
\hline \multicolumn{1}{c}{ Industry } & Euro & ERM & Peg & ExRate & Volatility & Euro & ERM & Peg & ExRate Volatility \\
\hline 2 & Other manufacturing & + & - & - & - & - & + & + & - & + & - \\
15 & Food & + & + & - & - & + & - & + & - & - & - \\
17 & Textiles & - & + & - & - & - & - & + & - & - & - \\
18 & Garments & - & + & + & - & - & - & + & + & + & - \\
$23-24$ & Chemicals & - & - & + & - & + & + & + & + & - & + \\
25 & Plastics \& rubber & + & + & + & - & - & + & + & + & - & + \\
26 & Non-met. mineral products & + & - & - & + & - & + & + & + & + & + \\
27 & Basic metals & + & - & - & - & - & + & - & - & - & - \\
28 & Fabricated metal products & - & + & - & - & - & + & + & - & - & - \\
29 & Machinery and equipment & + & + & + & - & + & + & + & + & - & + \\
$31-32$ & Electronics & - & + & - & - & - & + & + & - & - & - \\
45 & Construction & + & + & + & - & - & + & + & + & - & - \\
50 & Other services & + & + & + & - & + & + & + & + & - & + \\
51 & Wholesale & + & + & - & - & + & + & + & + & - & + \\
52 & Retail & + & + & - & - & - & + & - & - & - \\
55 & Hotels and restaurants & - & - & - & + & - & + & - & - & - \\
$60-64$ & Transport & + & + & - & - & - & + & + & + & - & - \\
72 & IT & + & - & - & + & - & - & - & + & + \\
\hline Notes: Shaded fields indicate significance at 10\% level & & & & & &
\end{tabular}

Notes: Shaded fields indicate significance at $10 \%$ level.

31 Results for the IT sector should be interpreted with caution, as more then half of the firms in this sector are from Bulgaria. 


\section{III.III.I - Imported Intermediates}

Firms are not only facing uncertainty about their revenues from exporting final goods and services due to exchange rate volatility, but also about their variable costs when importing inputs. To further investigate the impact of exchange rate policy on the use of imported intermediates, we use the share of directly and indirectly imported intermediates as the dependent variable in the following equation:

$$
\begin{gathered}
\text { ImpIntermediates }_{i j k t}=\beta_{0}+\beta_{1} \ln \text { Sales }_{i j k t}+\beta_{2} \text { FirmSize }_{i j k t}+\beta_{3} \text { Quality }_{i j k t}+\beta_{4} \text { Euro }_{j t}+ \\
\beta_{5} \text { ERM }_{j t}+\beta_{6} \text { Peg }_{j t}+\beta_{7} \ln \text { ExchangeRate }_{j t}+\beta_{8} \text { Volatility }_{j t}+\beta_{9} \text { RTA }_{j t}+\kappa_{j}+\lambda_{k}+\alpha_{t}+\varepsilon_{i j k t}
\end{gathered}
$$

with all independent variables being identical to the ones described for model (III.2).

Regression results presented in Table III.III.4 appear to be similar for some variables to the previous regressions on the intensive margin of exports. Sales and quality certificates have a significant positive impact as do the more binding exchange rate agreements Euro and ERM II. The peg dummy is also positive and significant, but only as long as no year or industry dummies are added to the model.

Different to the regression on export intensity in section III.II.III, a higher number of employees has a negative impact on import intensity, which is significant in half of the regressions. Coefficients of our volatility measure are all insignificant and turn positive when country dummies are included in the regression. Surprisingly, a depreciation of the domestic exchange rate leads to higher import shares for intermediates, although one should expect real prices for intermediates to increase ${ }^{32}$. This may be due to increased competitiveness and therefore increasing production due to higher foreign demand and no or little ability to substitute foreign intermediates with others from domestic production and the demand effect being stronger than the increase in production costs. Controlling for unobserved heterogeneity in columns (4) and (5) does not alter the results or interpretation to a larger extent. Also the positive and significant effect of Eurozone membership remains.

32 Assuming a high pass-through for prices of intermediates. 
Table III.III.4: Determinants of Import Intensity

\begin{tabular}{|c|c|c|c|c|c|}
\hline & \multirow{2}{*}{ (1) } & \multirow{2}{*}{$(2)$} & \multirow{2}{*}{ (3) } & \multicolumn{2}{|c|}{ DID } \\
\hline & & & & (4) & (5) \\
\hline & OLS & OLS & OLS & OLS & OLS \\
\hline \multirow[t]{2}{*}{ In Sales } & $1.686 * * *$ & $1.534^{* * *}$ & $2.685 * * *$ & $1.379 * * *$ & $1.245^{* * *}$ \\
\hline & $(0.222)$ & $(0.223)$ & $(0.285)$ & $(0.233)$ & $(0.235)$ \\
\hline \multirow[t]{2}{*}{ Quality } & $3.824 * * *$ & $4.407 * * *$ & $2.734 * * *$ & $4.387 * * *$ & $4.160 * * *$ \\
\hline & $(0.921)$ & $(0.901)$ & $(0.881)$ & $(0.898)$ & $(0.897)$ \\
\hline \multirow[t]{2}{*}{ Size } & $-1.084^{*}$ & -0.552 & $-2.287 * * *$ & -0.269 & 0.0739 \\
\hline & $(0.636)$ & $(0.611)$ & (0.689) & $(0.624)$ & $(0.627)$ \\
\hline \multirow[t]{2}{*}{ Euro } & 4.318 & $8.505^{* * *}$ & & -9.181 & -9.485 \\
\hline & $(2.626)$ & $(2.647)$ & - & (6.605) & $(7.136)$ \\
\hline Euro\#2009 & - & - & - & $\begin{array}{c}20.40 * * * \\
(7.208)\end{array}$ & $\begin{array}{c}16.38^{* *} \\
(7.689)\end{array}$ \\
\hline ERM & $\begin{array}{c}5.972 * * * \\
(1.472)\end{array}$ & $\begin{array}{c}11.17^{* * *} \\
(1.440)\end{array}$ & - & $\begin{array}{c}7.848^{* * *} \\
(1.571)\end{array}$ & $\begin{array}{c}8.511 * * * \\
(1.601)\end{array}$ \\
\hline ERM\#2009 & - & - & - & $\begin{array}{c}14.73 * * * \\
(3.072)\end{array}$ & $\begin{array}{c}9.182 * * * \\
(3.352)\end{array}$ \\
\hline Peg & $\begin{array}{c}5.778 * * * \\
(1.300)\end{array}$ & $\begin{array}{c}-0.443 \\
(1.318)\end{array}$ & - & $\begin{array}{c}-6.869 * * * \\
(2.595)\end{array}$ & $\begin{array}{l}-3.470 \\
(2.642)\end{array}$ \\
\hline Peg\#2005 & - & - & - & $\begin{array}{c}7.171^{* *} \\
(3.459)\end{array}$ & $\begin{array}{c}3.935 \\
(3.492)\end{array}$ \\
\hline Peg\#2007 & - & - & - & $\begin{array}{c}3.252 \\
(3.595)\end{array}$ & $\begin{array}{c}67.50 * * * \\
(11.59)\end{array}$ \\
\hline Peg\#2009 & - & - & - & $\begin{array}{c}14.60 * * * \\
(3.713)\end{array}$ & $\begin{array}{c}11.08 * * * \\
(3.740)\end{array}$ \\
\hline In ExchangeRate & $\begin{array}{c}-0.581 * * * \\
(0.138)\end{array}$ & $\begin{array}{c}-0.425^{* * *} \\
(0.134)\end{array}$ & $\begin{array}{c}-16.56 * * * \\
(4.220)\end{array}$ & $\begin{array}{c}-0.401 * * * \\
(0.136)\end{array}$ & $\begin{array}{c}-0.394 * * * \\
(0.137)\end{array}$ \\
\hline Volatility & $\begin{array}{c}-3.530 \\
(10.59)\end{array}$ & $\begin{array}{l}-3.982 \\
(10.28)\end{array}$ & $\begin{array}{c}2.811 \\
(10.97)\end{array}$ & $\begin{array}{c}0.0992 \\
(10.15)\end{array}$ & $\begin{array}{l}-10.07 \\
(10.09)\end{array}$ \\
\hline RTA & $\begin{array}{l}-0.0452^{*} \\
(0.0243)\end{array}$ & $\begin{array}{c}-0.130 * * * \\
(0.0283)\end{array}$ & $\begin{array}{c}0.0160 \\
(0.0548)\end{array}$ & $\begin{array}{c}-0.139 * * * \\
(0.0288)\end{array}$ & $\begin{array}{c}-1.117^{* * *} \\
(0.159)\end{array}$ \\
\hline RTA\#2005 & - & - & - & - & $\begin{array}{c}0.950 * * * \\
(0.164)\end{array}$ \\
\hline RTA\#2007 & - & - & - & - & $\begin{array}{c}-6.064^{* * *} \\
(1.155)\end{array}$ \\
\hline RTA\#2009 & - & - & - & - & $\begin{array}{c}1.144 * * * \\
(0.164)\end{array}$ \\
\hline Constant & $\begin{array}{c}12.51 * * * \\
(2.369)\end{array}$ & $\begin{array}{c}27.35 * * * \\
(2.794)\end{array}$ & $\begin{array}{c}115.0 * * * \\
(20.07)\end{array}$ & $\begin{array}{c}28.09 * * * \\
(2.861)\end{array}$ & $\begin{array}{c}37.32 * * * \\
(3.265)\end{array}$ \\
\hline Year Dummies & No & Yes & Yes & Yes & Yes \\
\hline Industry Dummies & No & Yes & Yes & Yes & Yes \\
\hline Country Dummies & No & No & Yes & No & No \\
\hline Observations & 11,625 & 11,625 & 11,625 & 11,625 & 11,625 \\
\hline $\mathrm{R}^{\wedge} 2$ & 0.018 & 0.104 & 0.159 & 0.108 & 0.115 \\
\hline
\end{tabular}

\section{III.III.II - Exchange Rate Uncertainty Exposure}

In this section, we look at the impact of the availability of hedging instruments on a firms' reluctance to be exposed to exchange rate uncertainty from trade activities. We propose a measure of exchange rate volatility exposure that accounts for natural hedging in the form of 
imported intermediates by taking the absolute difference between the share of directly or indirectly exported goods and services and directly and indirectly imported intermediate inputs. The measure takes the value 0 if the firm is neither importing nor exporting or shares of imports and exports are identical and 100 if the firm exports all products and does not import any inputs or imports all intermediates without exporting any final goods or services.

We control for access to the financial market by introducing as an additional variable the involvement of private and public banks in investments in fixed assets. As firms partly or completely owned by foreign firms or individuals may have better access to internal hedging and foreign financial markets, we try to reflect that in our regression by including the share of foreign and state ownership of the individual firm as additional variables.

We introduce the new dependent and independent variables in equation (III.3) and estimate the following model:

$$
\begin{gathered}
\text { Uncertainty }_{i j k t}=\beta_{0}+\beta_{1} \ln \text { Sales }_{i j k t}+\beta_{2} \text { FirmSize }_{i j k t}+\beta_{3} \text { Puality }_{i j k t}+\beta_{4} \text { Euro }_{j t}+\beta_{5} \text { ERM }_{j t}+ \\
\beta_{6} \text { Peg }_{j t}+\beta_{7} \ln \text { ExchangeRate }_{j t}+\beta_{8} \text { Volatility }_{j t}+\beta_{9} \text { RTA }_{j t}+\beta_{10} \text { ForeignOwner }_{i j k t}+ \\
\beta_{11} \text { StateOwned }_{i j k t}+\beta_{12} \text { PrivateLoans }_{i j k t}+\beta_{13} \text { PublicLoans }_{i j k t}+\kappa_{j}+\lambda_{k}+\alpha_{t}+\varepsilon_{i j k t}
\end{gathered}
$$

where Uncertainty $\mathrm{ijkt}_{\mathrm{j} t}$ is our measure of exposure to exchange rate uncertainty. ForeignOwner $\mathrm{r}_{\mathrm{ijkt}}$ denotes the percentage of this firm that is owned by private foreign individuals, companies or organizations and StateOwned $\mathrm{i}_{\mathrm{ijkt}}$ the percentage of this firm that is owned by the state or government. The proportion of a firms' total purchases of fixed assets in the past year that was financed is represented by PrivateLoans $\mathrm{ijkt}_{\mathrm{j}}$ for funds from private banks, while PublicLoans $\mathrm{ijkt}_{\mathrm{jkt}}$ represents the proportion financed via state-owned banks. All other variables are the same as described in section III.II.

Regression results are presented in Table III.III.5. Unfortunately, the number of observations in this regression is considerably lower due to a high number of missing observations for the additional variables and the uncertainty measure. Again, sales and quality certificates show a significant positive impact. Coefficients for all exchange rate policy dummies are positive with only ERM II and Euro being significant. Firm size in terms of number of employees has a negative impact on the exchange rate risk levels firms are willing to accept. Exchange rate movements show a significant negative impact in most regressions, while our volatility measure is always positive and mostly significant. 
The results indicate that membership in a more binding currency agreement allows firms to engage in international trade with a lower degree of internal hedging. Thus, a greater discrepancy between exports and imports is acceptable for firms and allows for more flexibility with regard to import and export activities.

Access to and willingness to utilize hedging tools offered by the private financial sectors appears to be important, as well. For the public financial sector, we do not find a similar effect. Government or state owned firms choose to be less engaged in cross-border trade and thus less exposed to the uncertainty associated. The reason for the latter outcome could also be of political nature, e.g. using local inputs to support the domestic industry or the production of government subsidized goods for domestic consumption only. A depreciation of the domestic currency we find to increase exposure to exchange rate risk, probably driven by increasing exports due to improved competitiveness. Controls for unobserved heterogeneity with a DID approach shown in columns (4) and (5) do not alter results considerably. 
Table III.III.5: Natural Hedging Regression Results

\begin{tabular}{|c|c|c|c|c|c|}
\hline & \multirow{2}{*}{ (1) } & \multirow{2}{*}{ (2) } & \multirow{2}{*}{ (3) } & \\
\hline & & & & $(4)$ & (5) \\
\hline & OLS & OLS & OLS & OLS & OLS \\
\hline \multirow[t]{2}{*}{ In Sales } & $1.930 * * *$ & $1.602 * * *$ & $2.610 * * *$ & $1.573 * * *$ & $1.451 * * *$ \\
\hline & $(0.278)$ & $(0.285)$ & $(0.347)$ & $(0.290)$ & $(0.294)$ \\
\hline \multirow[t]{2}{*}{ Quality } & $2.514^{* *}$ & $2.883 * * *$ & $2.050 * *$ & $2.857 * * *$ & $2.913^{* * *}$ \\
\hline & $(0.988)$ & (0.997) & $(1.000)$ & (0.997) & $(1.000)$ \\
\hline \multirow[t]{2}{*}{ Size } & $-6.283 * * *$ & $-5.604 * * *$ & $-7.035^{* * *}$ & $-5.517 * * *$ & $-5.256 * * *$ \\
\hline & $(0.739)$ & $(0.740)$ & $(0.827)$ & $(0.748)$ & $(0.756)$ \\
\hline \multirow[t]{2}{*}{ Euro } & $11.05^{* * *}$ & $11.30 * * *$ & & $-26.39 * * *$ & $-24.68 * * *$ \\
\hline & $(2.505)$ & (2.589) & - & (1.706) & (1.847) \\
\hline \multirow{2}{*}{ Euro\#2009 } & & & & $39.55 * * *$ & $38.23 * * *$ \\
\hline & - & - & - & (3.349) & (3.358) \\
\hline \multirow[t]{2}{*}{ ERM } & $7.392 * * *$ & $8.118 * * *$ & & $6.022 * * *$ & $5.319 * * *$ \\
\hline & $(1.516)$ & $(1.521)$ & - & $(1.693)$ & $(1.724)$ \\
\hline \multirow[t]{2}{*}{ ERM\#2009 } & & & & $9.444 * * *$ & $10.66 * * *$ \\
\hline & - & - & - & (3.177) & $(3.421)$ \\
\hline \multirow[t]{2}{*}{ Peg } & 2.034 & 1.407 & & -4.108 & -1.008 \\
\hline & (1.699) & (1.659) & - & $(2.761)$ & $(2.823)$ \\
\hline \multirow[t]{2}{*}{ Peg\#2005 } & & & & $7.480 * *$ & 4.440 \\
\hline & - & - & - & $(3.800)$ & (3.844) \\
\hline \multirow[t]{2}{*}{ Peg\#2009 } & & & & $9.463^{* *}$ & 6.455 \\
\hline & - & - & - & (3.992) & $(4.034)$ \\
\hline \multirow[t]{2}{*}{ In ExchangeRate } & $-0.309 * *$ & $-0.304 * *$ & -4.905 & $-0.292 * *$ & -0.176 \\
\hline & $(0.148)$ & $(0.146)$ & $(5.020)$ & $(0.147)$ & (0.149) \\
\hline \multirow[t]{2}{*}{ Volatility } & 15.14 & 15.01 & 12.46 & $15.86^{*}$ & 5.552 \\
\hline & (9.432) & (9.175) & (11.21) & (9.173) & (9.456) \\
\hline \multirow[t]{2}{*}{ RTA } & $-0.241 * * *$ & $-0.278 * * *$ & -0.0786 & $-0.289 * * *$ & $-1.025 * * *$ \\
\hline & $(0.0263)$ & $(0.0312)$ & $(0.0695)$ & $(0.0315)$ & (0.171) \\
\hline \multirow[t]{2}{*}{ RTA\#2005 } & & & & & $0.791^{* * *}$ \\
\hline & - & - & - & - & $(0.176)$ \\
\hline \multirow[t]{2}{*}{ RTA\#2009 } & & & & & $0.713^{* * *}$ \\
\hline & - & - & - & - & (0.177) \\
\hline \multirow[t]{2}{*}{ Foreign Owner } & $0.109 * * *$ & $0.102 * * *$ & $0.0919 * * *$ & $0.101 * * *$ & $0.102 * * *$ \\
\hline & $(0.0146)$ & $(0.0145)$ & $(0.0145)$ & $(0.0145)$ & $(0.0145)$ \\
\hline \multirow[t]{2}{*}{ State Owned } & $-0.0760 * * *$ & $-0.0555 * * *$ & $-0.0561 * * *$ & $-0.0553 * * *$ & $-0.0523 * * *$ \\
\hline & $(0.0145)$ & $(0.0151)$ & $(0.0152)$ & $(0.0151)$ & $(0.0151)$ \\
\hline \multirow[t]{2}{*}{ Private Loans } & $0.0587 * * *$ & $0.0590 * * *$ & $0.0434 * * *$ & $0.0567 * * *$ & $0.0587 * * *$ \\
\hline & $(0.0150)$ & $(0.0147)$ & $(0.0147)$ & (0.0147) & $(0.0148)$ \\
\hline Public Loans & -0.0122 & -0.0142 & 0.00864 & -0.0125 & -0.00597 \\
\hline & (0.0239) & $(0.0237)$ & $(0.0243)$ & $(0.0238)$ & $(0.0238)$ \\
\hline Constant & $18.01^{* * *}$ & $30.24 * * *$ & $55.63 * *$ & $30.37 * * *$ & $36.93 * * *$ \\
\hline & (2.994) & (3.436) & $(24.17)$ & (3.509) & (3.854) \\
\hline Year Dummies & No & Yes & Yes & Yes & Yes \\
\hline Industry Dummie & No & Yes & Yes & Yes & Yes \\
\hline Country Dummie & No & No & Yes & No & No \\
\hline Observations & 7,344 & 7,344 & 7,344 & 7,344 & 7,344 \\
\hline $\mathrm{R}^{\wedge} 2$ & 0.04 & 0.074 & 0.105 & 0.077 & 0.080 \\
\hline
\end{tabular}




\section{III.III.III - Political Instability}

Times of political instability can undermine trust in the independence of the central bank and future monetary and exchange rate policy and thereby lead to an increase in volatility of the exchange rate. In such a case, trade deterring effects may actually stem from political uncertainty rather than from exchange rate uncertainty. To ensure that political uncertainty is not the driver of the negative trade effects we have found, we reestimate column (2) of Tables III.III.1 and III.III.2 and include a measure for political instability and present the estimates in Table III.III.6. We use the "political stability and absence of violence" variable from the Worldwide Governance Indicators (WGI) project of the World Bank which is supposed to capture "perceptions of the likelihood that the government will be destabilized or overthrown by unconstitutional or violent means, including politically-motivated violence and terrorism ${ }^{\prime 33}$. It is in standard normal units and ranges from -2.5 (high instability) to 2.5 (low instability). Although the measure for political instability is significant and has the expected positive sign, coefficients of our exchange rate volatility measure change only slightly and remain highly significant for the intensive margin.

33 For a thorough description of the dataset see Kaufmann et al. (2010). 
Table III.III.6: Political Instability

\begin{tabular}{|c|c|c|c|c|}
\hline & \multicolumn{2}{|c|}{ Probability to Export } & \multicolumn{2}{|c|}{ Export Intensity } \\
\hline & $(1)$ & $(2)$ & (3) & $(4)$ \\
\hline & Probit & Probit & OLS & OLS \\
\hline \multirow[t]{2}{*}{ In Sales } & $0.0385 * * *$ & $0.0371 * * *$ & $0.772 * * *$ & $0.734 * * *$ \\
\hline & $(0.00196)$ & $(0.00196)$ & $(0.0990)$ & $(0.0982)$ \\
\hline \multirow[t]{2}{*}{ Quality } & $0.140 * * *$ & $0.139 * * *$ & $4.762 * * *$ & $4.734 * * *$ \\
\hline & $(0.0100)$ & $(0.0100)$ & $(0.557)$ & $(0.557)$ \\
\hline \multirow[t]{2}{*}{ Size } & $0.0580 * * *$ & $0.0612 * * *$ & $4.899 * * *$ & $4.987 * * *$ \\
\hline & $(0.00568)$ & $(0.00570)$ & $(0.324)$ & $(0.324)$ \\
\hline \multirow[t]{2}{*}{ Euro } & $0.140 * * *$ & $0.126 * * *$ & $5.068 * * *$ & $4.592 * * *$ \\
\hline & $(0.0264)$ & $(0.0263)$ & $(1.245)$ & $(1.259)$ \\
\hline \multirow[t]{2}{*}{ ERM } & $0.0886 * * *$ & $0.0845^{* * *}$ & $4.695 * * *$ & $4.529 * * *$ \\
\hline & $(0.0165)$ & $(0.0164)$ & $(0.816)$ & $(0.818)$ \\
\hline \multirow[t]{2}{*}{ Peg } & -0.0116 & -0.0111 & $2.062 * * *$ & $2.078 * * *$ \\
\hline & (0.0119) & (0.0119) & $(0.717)$ & $(0.718)$ \\
\hline \multirow[t]{2}{*}{ In ExchangeRate } & $-0.0107 * * *$ & $-0.0110 * * *$ & $-0.139 *$ & $-0.155^{* *}$ \\
\hline & $(0.00142)$ & $(0.00142)$ & $(0.0761)$ & $(0.0765)$ \\
\hline \multirow{2}{*}{ Volatility } & -0.150 & -0.0945 & $-20.81 * * *$ & $-18.88 * * *$ \\
\hline & $(0.117)$ & $(0.118)$ & $(4.900)$ & $(4.926)$ \\
\hline \multirow[t]{2}{*}{ RTA } & $0.0030 * * *$ & $0.0021 * * *$ & $0.125^{* * *}$ & $0.0911 * * *$ \\
\hline & (0.000298) & $(0.000348)$ & $(0.0141)$ & $(0.0167)$ \\
\hline \multirow[t]{2}{*}{ Political Stability } & & $0.0360 * * *$ & & $1.370 * * *$ \\
\hline & - & $(0.00752)$ & - & $(0.347)$ \\
\hline \multirow[t]{2}{*}{ Constant } & & & $4.174 * * *$ & $4.277^{* * *}$ \\
\hline & - & - & $(1.336)$ & $(1.336)$ \\
\hline Year Dummies & Yes & Yes & Yes & Yes \\
\hline Industry Dummies & Yes & Yes & Yes & Yes \\
\hline Country Dummies & No & No & No & No \\
\hline Observations & 17,354 & 17,352 & 17,354 & 17,352 \\
\hline$R^{\wedge} 2$ & - & - & 0.191 & 0.192 \\
\hline
\end{tabular}

\section{III.III.IV - Regional Differences}

Despite many similarities with regard to their common history as Post-Soviet states, economic and political background and orientation differ within our sample of countries especially between countries in Europe and Asia. We want to identify whether a firms' export behaviour is affected differently by our variables of interest depending on the location.

Therefore, in an additional robustness check we split the sample in two parts. The first part consists of countries that are located on the European continent, the second of countries located in Asia. We reestimate model (III.3) on export intensity for both groups of countries. Estimation results are presented in Table C.9. Coefficients for firm characteristics, namely the natural logarithm of sales, the dummy variable controlling for quality certificates and the number of 
employees in a firm, are positive and significant. The effect of quality certificates on export intensity is higher for Central Asian firms and the number of employees has a stronger impact of European firms. The exchange rate variables show very particular effects for both regions. While an exchange rate appreciation yields positive but insignificant estimates for Asian firms, coefficients are positive for European countries and significant when country dummies are included. Exchange rate volatility yields always negative but significant estimates for European firms and positive and mostly significant estimates for their Asian counterparts. Estimates for the number of signed RTAs is mostly positive, but insignificant. Exchange rate agreements were only signed by European countries, thus there are no estimates for these variables for Asian firms.

The results indicate that the significant negative estimates for the volatility measure in the other models were driven by European firms in the sample. The same applies for movements in the exchange rate. Thus, the exchange rate appears to have very little impact on export activities for Asian firms. Possible reasons are manifold, ranging from a higher importance of other trade barriers such as tariffs, non-tariff barriers and transport costs to sufficient access to internal and external hedging instruments or a higher importance of regional trade that is less affected by exchange rate variations of the domestic currency to the Euro.

\section{III.IV - Conclusion}

We find strong evidence for both the hypotheses tested in this paper: First, we find a clear negative effect of exchange rate volatility on a firms' probability to export and on their export intensity. Second, we find a significant positive impact of more binding currency agreements in the form of Euro or ERM II membership. The latter we find to be robust for the extensive margin only.

Our results concerning exchange rate volatility are in contrast to some of the previous empirical firm-level studies, but are more in line with country-level studies. Differences in the outcome in comparison to earlier micro studies are probably due to differences between observed countries, smaller average firm size in our sample compared to previous studies and slight differences in methodology and variables in the estimated models. Robustness checks show that the significant negative results for exchange rate volatility are driven by firms located in Eastern Europe, while for firms in Central Asia other aspects rather than movements of or volatility in the exchange rate to the Euro seem to determine export activities. Furthermore, the effect of exchange rate volatility can not be attributed to political instability that could be increasing volatility of the domestic 
exchange rate to the Euro and thereby has an impact on a firms' export behaviour. The effects of Euro and ERM II on export intensity are smaller than the usual effect for Euro membership on export volume found in most recent macro studies.

It is very striking that positive effects of Euro and ERM II membership are larger and significant for sectors where long term investments play a huge role, such as machinery and equipment and manufacturing. A possible explanation is that more binding currency agreements encourage investments in these sectors. While the impact of exchange rate volatility on export behaviour is more significant for sectors providing services, currency agreements have a more pronounced and significant impact on industries producing goods. This could be attributed to the nature of contracts that are more short-term based for services and therefore are less affected by long term exchange rate agreements. For manufacturing exchange rate agreements are more important.

We also find evidence that firms do not lower the overall exposure to exchange rate risks from trade activities when exchange rate volatility is rising, but binding exchange rate arrangements, access to private credits and a higher share of foreign ownership lets them increase their exposure. As argued in section III.I.III, this could be due to firms taking out loans in foreign currencies due to lower costs of credits and intensifying export activities to hedge for the exchange rate risks of the loans. The significant impact of private credits on exchange rate exposure due to importing and exporting activities could indicate this. 


\section{IV - Direct and Indirect Exports and the Role of Uncertainty}

based on joint work with Inmaculada Martínez-Zarzoso

In the past two decades, there has been a growing interest in the study of the internationalization strategies of firms (Bernard et al. 2003; Bernard \& Jensen 2004). Three main modes of sales have been considered in the related literature, namely domestic sales, direct exports and exports using an intermediary (indirect exports). A first strand of papers focused on studying the determinants of the choice between exporting or not, without paying attention to the choice between direct and indirect exporting. In this line, according to the seminal paper by Melitz (2003) firms have to pay a fixed entry cost to access foreign markets accompanied by variable trade costs when a product is exported directly. If the fixed cost is high and expected sales are low, a firm is likely to serve only the domestic market. The decision mainly depends on the productivity level of a firm in comparison to other firms in the country. Only the most productive firms will select into exporting, whereas the less productive firms will sell domestically. Trade liberalization will lead to reallocation of firms within industries and to an increase in the average productivity.

As for the choice whether to export directly or indirectly, several factors have been identified in the related literature influencing the decision. Specifically, intermediaries reduce search costs for the producing firms (Spulber 1999), facilitate matching of sellers and buyers (Rubinstein \& Wolinsky 1987) and can act as guarantor of quality (Biglaiser 1993). Studies that extend the model of Melitz (2003) with intermediaries indicate that for less productive firms exporting could be an option using a middleman. Indirect exporting is assumed to have higher marginal costs, but lower or even no fixed costs (Akerman 2014; Ahn et al. 2011; Felbermayr \& Jung 2011; Crozet et al. 2013). Firms tend to rely more on intermediaries when fixed costs are high or when destination markets are small and higher-than-average productivity levels are needed to overcome lower profits. 
A recent study by McCann (2013) investigating the determinants of export behaviour with firmlevel data finds that productivity of indirect exporters lies between productivity levels of direct and non-exporters. He also finds strong evidence supporting the importance of productivity as well as of other features and characteristics of wholesalers as determinants of the export decision. According to Bernard et al. (2011), wholesalers in Italy are smaller than direct exporting manufacturers and export a larger variety of products to less countries. They emphasize the importance of intermediaries when firms are exporting to destinations with weak contracting environments and when exporting homogeneous products. Crozet et al. (2013) find that French wholesalers mainly serve countries with smaller market size and higher trade costs than the average destination.

Abel-Koch (2011), using survey data for Turkey, shows that indirect exporters are mostly small firms, producing low-quality goods, or introducing an entirely new product to foreign markets, but other factors such as foreign ownership or the existence of credit constraints do not influence the decision of exporting indirectly. Also using a World Bank survey data, but for firms in Sub-Saharan Africa, Zerihun (2012) provides evidence showing that the decision to export indirectly is positively influenced by firm size, being a subsidiary of a multi-plan firm and having access to information technology and negatively affected by the firms' perceptions of obstacles in the form of corruption or access to finance.

In the above-mentioned studies, little emphasis has been put on the role of perceived uncertainty on the decision of exporting indirectly. To export directly a firm has to deal with several potential obstacles that can induce additional costs of unforeseeable size. These include, among others, foreign and domestic bureaucracy and corruption, customs proceedings, transportation and crossborder financial transactions. Due to the uncertainty of these costs, risk averse firms may choose to use a middleman in some markets in order to lower the overall exposure to uncertainty. Especially in unstable foreign markets, firms will be willing to accept higher variable costs even if the productivity level is above average. Risk averse firms may also want to test demand in a foreign market using an intermediary first paying the fixed costs of entry for direct exporting, even more so when fixed costs are high or market potential is low.

We investigate the determinants of the decision to export directly or via intermediaries with a special focus on the firms' perception of uncertainty that affects transaction costs. In particular, factors such transportation impediments, crime, weak legal systems and volatility in the exchange 
rate are considered. To our knowledge, this is the first paper to investigate this issue with a larger variety of measures used as proxies for perceived obstacles to trade. In addition, we distinguish between trade in goods and trade in services, as the characteristics of both activities are different and could be affected by uncertainty in different ways. We focus on the Eastern Europe and Central Asia for three reasons. First, the region is particularly interesting as it consists of many highly integrated countries for historic reasons that share a similar cultural background with most of their direct neighbours and have lower language barriers. Second, in these countries political instability, corruption and criminality are well-known factors deterring a well-functioning market economy. Finally, this is the first paper to focus in the effect of uncertainty on the internationalization strategies of firms in Eastern Europe and Central Asia ${ }^{34}$.

We assume that the uncertainty is a greater threat to direct exporters and can be avoided by using an intermediary. The modelling strategy consists of an estimation of a probit model to investigate the determinants of the decision to export indirectly and a fixed effects model to estimate the effects on the intensity of the indirect exporting. As a robustness check we also estimate a twostage approach that consists of estimating the probability to export in the first step as a selection equation and the share of indirect exports with respect to total exports in the second step including elements of the first step to control for sample selection bias.

The main results suggest that firms that are larger and more productive export a smaller share of their exports indirectly. While perception of transportation and the legal system as an obstacle and higher volatility in the exchange rate increases the share of indirect exports especially for services, crime has a similar effect on exports of goods.

The paper is structured as follows: section IV.I analyses the data and explains the empirical approach, section IV.II presents the findings and section IV.III concludes.

\section{IV.I - Empirical Analysis}

In this study we focus on the perception of obstacles to trade and their influence on the decision to export directly or via an intermediary. In order to obtain the variables that are used as determinants of this decision we combine information from the World Bank Enterprise Business Environment and Enterprise Performance Survey (BEEPS) with country specific information on

34 McCann (2013) also focuses on Eastern Europe and Central Asia. However, his main aim is different to ours, as he gives descriptive evidence of the characteristics of indirect exporters, compares the likelihood to export indirectly of single-product and multi-product firms and focuses exclusively on manufacturing firms, excluding the service sector from the analysis. 
regional integration and volatility in the exchange rate of the different currencies with respect to the Euro. Data on exchange rates comes from OANDA Corporation. A description of the variables is shown in Table IV.I.1.

Table IV.I.1: Variables

\begin{tabular}{|c|c|c|}
\hline Variable & Description & Range \\
\hline \multicolumn{3}{|c|}{ Dependent variable } \\
\hline \multicolumn{2}{|c|}{ Indirectexports $_{\mathrm{ijkt}}$ share of indirect exports of total exports } & $0-100$ \\
\hline \multicolumn{3}{|c|}{ Firm characteristics } \\
\hline In Employees $\mathrm{ijkt}_{\mathrm{j}}$ & natural logarithm of the number of permanent full-time workers & $0-9.21$ \\
\hline In LaborProd ${ }_{\mathrm{ijkt}}$ & natural logarithm of sales divided by the number of workers & $1.72-26.84$ \\
\hline Exportintensity $_{\mathrm{ijkt}}$ & share of exported sales & $1-100$ \\
\hline Foreign $_{\mathrm{ijkt}}$ & $=1$ if a part of the firm is owned by foreign private individuals & 0 or 1 \\
\hline Transportation $_{\mathrm{ijkt}}$ & perception of transportation as an obstacle & $0=$ no obstacle $-4=$ very severe \\
\hline Customs $_{\mathrm{ijkt}}$ & perception of customs and trade regulation as an obstacle & $0=$ no obstacle $-4=$ very severe \\
\hline Crime $_{\mathrm{ijkt}}$ & perception of crime, theft and disorder as an obstacle & $0=$ no obstacle $-4=$ very severe \\
\hline Legalsystem $_{\mathrm{ijkt}}$ & perception of the court system as fair, impartial and uncorrupted & 1=agree $-4=$ disagree \\
\hline Customstime $_{\mathrm{ijkt}}$ & number of av. days it tool for exported goods to clear customs & $1=1$ or less $-5=$ more than 20 \\
\hline \multicolumn{3}{|l|}{ Country variables } \\
\hline $\mathrm{EU}_{\mathrm{jt}}$ & $=1$ if country $\mathrm{j}$ was a member of the $\mathrm{EU}$ in year $\mathrm{t}$ & 0 or 1 \\
\hline CEFTA $_{j \mathrm{j}}$ & $=1$ if country $j$ was a member of the CEFTA in year $t$ & 0 or 1 \\
\hline Volatility $_{\mathrm{jt}-1}$ & measure for volatility in the exchange rate of $\mathrm{j}$ and the Euro in $\mathrm{t}-1$ & $0-0.47$ \\
\hline
\end{tabular}

The dataset includes information taken from BEEPS for 26 countries over 4 years $(2002,2005,2007$ and 2009) and 18 sectors. A number of variables related to transaction costs and uncertainty are selected from the surveys. In particular, foreign ownership, perception of transportation, customs, crime and legal system as being an obstacle for the firm's activity, time needed to clear customs. The surveys used stratified random sampling techniques to select a representative sample for each country using industry, establishment size and region as levels of stratification.

We use a broad definition of indirect exports, which includes all firms that export through an intermediary. This also includes those using a mixed strategy with part of their foreign sales exported directly ${ }^{35}$. Table IV.I.2 presents a list of covered sectors and the share of firms that use intermediaries for at least a part of their exports. Out of all exporters, most firms in our sample

35 We follow McCann (2013) in using the same definition of indirect exports. Although he first uses a narrow definition, he justifies the use of the broad definition in the core of his paper. 
only export directly and around 24 percent use also or exclusively an intermediary. The share varies across sectors going from 11 percent for the IT-sector to 34 percent for hotels and restaurants.

Table IV.I.2: Direct and Indirect Exporters

\begin{tabular}{lccccc}
\hline \multirow{2}{*}{ Sector } & \multirow{2}{*}{ Code } & \multicolumn{3}{c}{ Any indirect exports } & \multirow{2}{*}{ Total } \\
& & No & Yes & \% & \\
\hline Other manufacturing & 2 & 338 & 139 & 29.14 & 477 \\
Food & 15 & 705 & 226 & 24.27 & 931 \\
Textiles & 17 & 110 & 37 & 25.17 & 147 \\
Garments & 18 & 244 & 103 & 29.68 & 347 \\
Chemicals & 24 & 98 & 35 & 26.32 & 133 \\
Plastics \& rubber & 25 & 68 & 26 & 27.66 & 94 \\
Non metallic mineral products & 26 & 71 & 17 & 19.32 & 88 \\
Basic metals & 27 & 31 & 10 & 24.39 & 41 \\
Fabricated metal products & 28 & 286 & 92 & 24.34 & 378 \\
Machinery and equipment & 29 & 270 & 80 & 22.86 & 350 \\
Electronics & 31 & 66 & 19 & 22.35 & 85 \\
Construction & 45 & 161 & 32 & 16.58 & 193 \\
Other services & 50 & 230 & 39 & 14.50 & 269 \\
Wholesale & 51 & 401 & 120 & 23.03 & 521 \\
Retail & 52 & 180 & 56 & 23.73 & 236 \\
Hotel and restaurants & 55 & 69 & 35 & 33.65 & 104 \\
Transport & 60 & 322 & 117 & 26.65 & 439 \\
IT & 72 & 76 & 9 & 10.59 & 85 \\
Total & - & $\mathbf{3 7 2 6}$ & $\mathbf{1 1 9 2}$ & $\mathbf{2 4 . 2 4}$ & $\mathbf{4 9 1 8}$ \\
\hline
\end{tabular}

Table D.1 in the Appendix shows the distribution of exporting firms for all sectors over all countries. The largest sectors in the sample in terms of number of firms are food, wholesale and other manufacturing. Concerning the countries in the sample, Bulgaria, Croatia and Slovenia are the ones with the largest share of firms in the dataset. Summary statistics of firm and country specific variables are displayed in Table IV.I.3. The average share of exports over total sales is 42 percent, of which 17 percent on average are exported indirectly. About 26.5 percent of the firms are at least partly foreign owned and while 36 percent are located in a member country of the European Union (EU), 31 percent are located in a member of the Central European Free Trade Agreement (CEFTA). 
Table IV.I.3: Summary Statistics

\begin{tabular}{lccccc}
\hline Variable & Obs. & Mean & Std. Dev & Min & Max \\
\hline Indirectexports $_{\mathrm{ijkt}}$ dependent variable & 4,918 & 17.173 & 34.578 & 0 & 100 \\
\multicolumn{5}{c}{ firm characteristics } \\
In Employees $_{\mathrm{ijkt}}$ & 4,918 & 4.144 & 1.573 & 0 & 9.206 \\
In LaborProd $_{\mathrm{ijkt}}$ & 4,918 & 10.623 & 1.768 & 1.725 & 26.843 \\
Exportintensity $_{\mathrm{ijkt}}$ & 4,918 & 41.924 & 34.662 & 1 & 100 \\
Foreign $_{\mathrm{ijkt}}$ & 4,918 & 0.265 & 0.441 & 0 & 1 \\
Transportation $_{\mathrm{ijkt}}$ & 4,918 & 0.818 & 1.146 & 0 & 4 \\
Customs $_{\mathrm{ijkt}}$ & 4,918 & 1.211 & 1.162 & 0 & 4 \\
Crime $_{\mathrm{ijkt}}$ & 4,918 & 0.948 & 1.138 & 0 & 4 \\
Legalsystem $_{\mathrm{ijkt}}$ & 4,918 & 2.501 & 0.979 & 1 & 4 \\
Customstime $_{\mathrm{ijkt}}$ & 3,538 & 1.711 & 0.924 & 1 & 5 \\
& \multicolumn{7}{c}{ country variables } & & \\
EU $_{\mathrm{jt}}$ & 4,918 & 0.362 & 0.481 & 0 & 1 \\
CEFTA $_{\mathrm{jt}}$ & 4,918 & 0.313 & 0.464 & 0 & 1 \\
Volatility $_{\mathrm{jt}-1}$ & 4,300 & 0.020 & 0.043 & 0 & 0.470 \\
\hline
\end{tabular}

\section{IV.I.I - Model Specification}

The first part of our econometric approach consists of estimating a probit model with country and industry fixed-effects to explain the probability of exporting indirectly. In a second step we estimate a OLS regression with fixed-effects using the share of indirect exports over total exports as dependent variable. As a robustness check, we use a two-stage approach to correct for potential sample selection bias, which could be present due to the fact that we restrict our sample to exporting firms only.

The specification of the probit model used to predict indirect exports is given by:

$$
\begin{gathered}
\operatorname{Pr}\left(\text { IndirectExporter }_{i j k t}=1\right)=\Phi\left(\beta_{0}+\beta_{1} \ln \text { Employees }_{i j k t}+\beta_{2} \text { LaborProd }_{i j k t}+\right. \\
\beta_{3} \text { Exportintensity }_{i j k t}+\beta_{4} \text { Foreign }_{i j k t}+\beta_{5} \text { Transportation }_{i j k t}+\beta_{6} \text { Customs }_{i j k t}+\beta_{7} \text { Crime }_{i j k t}+ \\
\left.\beta_{8} \text { Legalsystem }_{i j k t} \beta_{9}+\text { Customstime }_{i j k t}+\beta_{10} \text { EU }_{j t}+\beta_{11} \text { CEFTA }_{j t}+\beta_{12} \text { Volatility }_{j t-1}+\kappa_{j}+\lambda_{k t}+\varepsilon_{i j k t}\right)
\end{gathered}
$$

where IndirectExporter ${ }_{\mathrm{ijkt}}$ is a dummy variable that takes the value one if firm $\mathrm{i}$ in country $\mathrm{j}$ and sector $\mathrm{k}$ exports a part of its foreign sales using an intermediary and zero if all exports are direct exports. Firm specific variables include In Employees ${ }_{\mathrm{ijkt}}$, which is the natural log of the total number of permanent full-time workers, In LaborProd ${ }_{\mathrm{ijkt}}$ for the natural log of total annual sales divided by the number of workers, Exportintensity ${ }_{\mathrm{ijkt}}$, that denotes the share of exported sales and Foreign $\mathrm{ijkt}_{\text {, }}$ 
which is dummy variable that takes the value of one when a part of the firm is owned by a foreign individual or firm and zero otherwise ${ }^{36}$. A firms' perception of obstacles is captured by three different variables on a scale from zero to four. First, for transportation (Transportation ${ }_{\mathrm{ijkt}}$ ), second for customs and trade regulation (Customs $\mathrm{ijkt}_{\mathrm{j}}$ ) and third for crime, theft and disorder (Crime $\mathrm{ijkt}_{\mathrm{i} t}$. The perception of fairness of the legal system is also measured on a scale from one to four (Legalsystem $\mathrm{ijkt}_{\mathrm{jkt}}$ ), while for time efficiency of customs authorities we use a scale from one to five (Customstime ${ }_{i \mathrm{jkt}}$ ). We introduce country specific dummy variables that take the value one if country $\mathrm{j}$ is member of the European Union $\left(\mathrm{EU}_{\mathrm{jt}}\right)$ or the Central European Free Trade Agreement $\left(\mathrm{CEFTA}_{\mathrm{jt}}\right)$ in year $\mathrm{t}$ and a measure of volatility for the nominal exchange rate of the domestic currency with the Euro (Volatility $\mathrm{j}_{\mathrm{jt}-1}$ ). The latter is defined as the standard deviation of the first difference of the logarithms of the monthly domestic nominal exchange rate to the Euro for the twelve month of the past year:

$$
\text { Volatility }_{j t-1}=\text { Std. dev. }\left[\ln \left(e_{j, m}\right)-\ln \left(e_{j, m-1}\right)\right], m=1 \ldots 12
$$

In a next step, we estimate the determinants of a firms' intensity of indirect exports with pooled OLS and fixed-effects:

$$
\begin{aligned}
& \text { Indirectexports }_{i j k t}=\beta_{0}+\beta_{1} \ln \text { Employees }_{i j k t}+\beta_{2} \text { LaborProd }_{i j k t}+\beta_{3} \text { Exportintensity }_{i j k t}+ \\
& \beta_{4} \text { Foreign }_{i j k t}+\beta_{5} \text { Transportation }_{i j k t}+\beta_{6} \text { Customs }_{i j k t}+\beta_{7} \text { Crime }_{i j k t}+\beta_{8} \text { Legalsystem }_{i j k t}+\text {, (IV.3) } \\
& \beta_{9} \text { Customstime }_{i j k t}+\beta_{10} \text { EU }_{j t}+\beta_{11} \text { CEFTA }_{j t}+\beta_{12} \text { Volatility }_{j t-1}+\kappa_{j}+\lambda_{k t}+\varepsilon_{i j k t}
\end{aligned}
$$

where the dependent variable is the share of indirect exports of total exports for firm $\mathrm{i}$ in year $\mathrm{t}$. All other variables are identical to the model in (IV.1).

The previous two models assume that firms first decide whether or not to export and second about the modality and that both decisions are independent from each other. Following the approach of Heckman (1978), we estimate a two-stage model that allows us to control for the sample selection bias caused by ignoring non-exporters and by assuming that the error terms in equation (IV.1) and (IV.3) are independent.

In the first stage, we estimate a probit model on the probability to export:

$$
\begin{aligned}
& \operatorname{Pr}\left(\text { Exporter }_{i j k t}=1\right)=\Phi\left(\beta_{0}+\beta_{1} \ln \text { Employees }_{i j k t}+\beta_{2} \text { LaborProd }_{i j k t}+\beta_{3} \text { Foreign }_{i j k t}+\right. \\
& \beta_{4} \text { Transportation }_{i j k t}+\beta_{5} \text { Customs }_{i j k t}+\beta_{6} \text { Crime }_{i j k t}+\beta_{7} \text { Legalsystem }_{i j k t}+ \\
& \left.\beta_{8} E U_{j t}+\beta_{9} \text { CEFTA }_{j t}+\beta_{10} \text { Volatility }_{j t-1}+\kappa_{j}+\lambda_{k t}+\varepsilon_{i j k t}\right)
\end{aligned}
$$

36 We are unable to include a measure of productivity in the model, as the World Bank firm-level data for the selected region does not provide the number of employees for each firm, but only a discrete variable with 4 group-size categories. 
The second stage is estimated using an OLS model with fixed-effects and is given by:

$$
\begin{gathered}
\text { Indirectexports }_{i j k t}=\beta_{0}+\beta_{1} \ln \text { Employees }_{i j k t}+\beta_{2} \text { LaborProd }_{i j k t}+ \\
\beta_{3} \text { Foreign }_{i j k t}+\beta_{4} \text { Transportation }_{i j k t}+\beta_{5} \text { Crime }_{i j k t}+\beta_{6} \text { Legalsystem }_{i j k t}+\ldots \text { (IV.5) } \\
\beta_{7} E U_{j t}+\beta_{8} \text { CEFTA }_{j t}+\beta_{9} \text { Volatility }_{j t-1}+\text { IMR }^{2}+\kappa_{j}+\lambda_{k t}+\varepsilon_{i j k t}
\end{gathered}
$$

In order to fulfil the exclusion restriction, we use a variable that only affects the probability to export, but not the intensity of indirect exporting. Therefore, we estimate the second stage without the variable measuring the perception of customs proceedings as an obstacle, which yields no significant estimates when controlling for differences between countries in the sample. In the second step regression, we include the inverse Mill's ratio (IMR) in the model. It is a correction for sample selection which addresses the biases generated by unobserved shocks.

\section{IV.II - Main Findings}

Results from the probit estimation are shown in Table IV.II.1 in the form of marginal effects at mean of the independent variables. A number of versions are estimated including different sets of fixed effects and control variables. Column (1) shows the results from estimating the model with country, year and industry fixed effects, while column (2) includes country and industry-year fixed effects as specified in model (IV.1). The inclusion of the exchange rate volatility variable reduces the sample size considerably. Hence, for comparison purposes the model is estimated in columns (3) and (4) with and without this variable for the same sample. Finally in column (5), the variable measuring time intensity of customs proceedings, for which there are many missing observations, is added.

According to our estimates, larger firms in terms of more employees tend to have a lower probability to export indirectly, whereas firms with a larger share of total sales going to nondomestic markets are more likely to export using an intermediary. A possible explanation for the latter could be the greater exposure to uncertainty concerning expected profits when exporting directly, which increases when exporting a lot. The use of an intermediary lowers uncertainty as it only involves higher variable costs. In particular, a 10 percentage points increase in overall export intensity of a firm increases the probability to use an intermediary by 0.5 percent according to column (2). A 1 percent increase in the number of employees decreases the probability to use an intermediary by around 1 percent. The estimates turn out to be positive and insignificant when a 
variable controlling for the time to clear customs is included in the model. This is probably due to the fact that the inclusion of this variable considerably reduces the number of observations by more than one fifth.

Foreign ownership decreases the probability of export indirectly by around 7 percentage points. This fact could be explained by the lower fixed costs of exporting or accessing to the owners international networks. While potential obstacles like transportation, crime and the legal system lower the probability to export directly significantly, customs impediments do not show a statistically significant effect. A 1 point increase in the perception of the severity increases the probability of indirect exporting by around 2 percentage points for transportation, 1.4 percentage points for crime and 1.5 percentage points for the legal system. Longer time to clear customs and volatility in the exchange rate also increase the probability of exporting indirectly. Although the decision for the mode of export appears to be affected significantly by the perception of uncertainty in various fields, we do not find any significant effects of membership in EU or CEFTA on the probability to use an intermediary. 
Table IV.II.1: Probit Regression Results - Probability to Export Indirectly

\begin{tabular}{|c|c|c|c|c|c|}
\hline & (1) & (2) & (3) & (4) & (5) \\
\hline In Employees ijkt $_{\text {ikt }}$ & $\begin{array}{l}-0.0103 * * \\
(0.00429)\end{array}$ & $\begin{array}{c}-0.0109 * * \\
(0.00435)\end{array}$ & $\begin{array}{c}-0.0133^{* * * *} \\
(0.00473)\end{array}$ & $\begin{array}{c}-0.0136 * * * \\
(0.00474)\end{array}$ & $\begin{array}{l}0.000476 \\
(0.00402)\end{array}$ \\
\hline In LaborProd ${ }_{\mathrm{ijkt}}$ & $\begin{array}{l}-0.00580 \\
(0.00512)\end{array}$ & $\begin{array}{l}-0.00448 \\
(0.00524)\end{array}$ & $\begin{array}{c}-0.0235^{* * *} \\
(0.00683)\end{array}$ & $\begin{array}{c}-0.0243^{* * *} \\
(0.00685)\end{array}$ & $\begin{array}{l}0.000497 \\
(0.00525)\end{array}$ \\
\hline Exportintensity $_{\mathrm{ijkt}}$ & $\begin{array}{c}0.00052 * * * \\
(0.000192)\end{array}$ & $\begin{array}{r}0.00052^{* * *} \\
(0.000193)\end{array}$ & $\begin{array}{c}0.00071 * * * \\
(0.000211)\end{array}$ & $\begin{array}{c}0.00071 * * * \\
(0.000211)\end{array}$ & $\begin{array}{c}0.00099 * * * \\
(0.000178)\end{array}$ \\
\hline Foreign $_{\mathrm{ijkt}}$ & $\begin{array}{c}-0.0697^{* * *} \\
(0.0137)\end{array}$ & $\begin{array}{c}-0.0733^{* * *} \\
(0.0137)\end{array}$ & $\begin{array}{c}-0.0681^{* * *} \\
(0.0152)\end{array}$ & $\begin{array}{c}-0.0663^{* * *} \\
(0.0152)\end{array}$ & $\begin{array}{c}-0.0372 * * * \\
(0.0127)\end{array}$ \\
\hline Transportation $_{\mathrm{ijkt}}$ & $\begin{array}{c}0.0191 * * * \\
(0.00590)\end{array}$ & $\begin{array}{r}0.0186 * * * \\
(0.00592)\end{array}$ & $\begin{array}{c}0.0178 * * * \\
(0.00636)\end{array}$ & $\begin{array}{c}0.0177^{* * *} \\
(0.00635)\end{array}$ & $\begin{array}{c}0.0191^{* * *} \\
(0.00544)\end{array}$ \\
\hline Customs $_{i \mathrm{ijkt}}$ & $\begin{array}{c}0.00430 \\
(0.00601)\end{array}$ & $\begin{array}{c}0.00377 \\
(0.00603)\end{array}$ & $\begin{array}{c}0.00508 \\
(0.00650)\end{array}$ & $\begin{array}{c}0.00520 \\
(0.00651)\end{array}$ & $\begin{array}{c}0.00185 \\
(0.00573)\end{array}$ \\
\hline Crime $_{\mathrm{ijkt}}$ & $\begin{array}{l}0.0149 * * \\
(0.00578)\end{array}$ & $\begin{array}{l}0.0149 * * \\
(0.00581)\end{array}$ & $\begin{array}{l}0.0144 * * \\
(0.00630)\end{array}$ & $\begin{array}{l}0.0140 * * \\
(0.00630)\end{array}$ & $\begin{array}{c}0.0103^{*} \\
(0.00542)\end{array}$ \\
\hline Legalsystem $_{\mathrm{ijkt}}$ & $\begin{array}{l}0.0139 * * \\
(0.00701)\end{array}$ & $\begin{array}{l}0.0148 * * \\
(0.00705)\end{array}$ & $\begin{array}{l}0.0167^{* *} \\
(0.00779)\end{array}$ & $\begin{array}{l}0.0165^{* *} \\
(0.00779)\end{array}$ & $\begin{array}{c}0.00968 \\
(0.00672)\end{array}$ \\
\hline $\mathrm{EU}_{\mathrm{jt}}$ & $\begin{array}{c}-0.0521 \\
(0.0510)\end{array}$ & $\begin{array}{l}-0.0599 \\
(0.0516)\end{array}$ & $\begin{array}{c}-0.0413 \\
(0.0700)\end{array}$ & $\begin{array}{r}-0.00222 \\
(0.0764)\end{array}$ & $\begin{array}{l}0.00370 \\
(0.0528)\end{array}$ \\
\hline CEFTA $_{j t}$ & $\begin{array}{l}-0.0128 \\
(0.0353)\end{array}$ & $\begin{array}{l}-0.0172 \\
(0.0359)\end{array}$ & $\begin{array}{c}0.0158 \\
(0.0522)\end{array}$ & $\begin{array}{c}0.0613 \\
(0.0604)\end{array}$ & $\begin{array}{l}0.00724 \\
(0.0351)\end{array}$ \\
\hline Customstime $_{\mathrm{ijkt}}$ & - & - & - & - & $\begin{array}{c}0.0172 * * * \\
(0.00635)\end{array}$ \\
\hline Volatility $_{\mathrm{jt}-1}$ & - & - & - & $\begin{array}{c}0.455^{* *} \\
(0.206)\end{array}$ & - \\
\hline Year Dummies & Yes & No & No & No & No \\
\hline Industry Dummies & Yes & No & No & No & No \\
\hline Country Dummies & Yes & Yes & Yes & Yes & Yes \\
\hline Year-Industry Dum. & No & Yes & Yes & Yes & Yes \\
\hline Observations & 4,918 & 4,916 & 4,287 & 4,287 & 3,415 \\
\hline$R^{\wedge} 2$ & 0.0446 & 0.0529 & 0.0560 & 0.0571 & 0.0728 \\
\hline
\end{tabular}

Notes: Reported values are marginal effects at the mean of the independent variables; Robust standard errors in parentheses; *** $p<0.01, * * p<0.05, *$ $p<0.1$; Sample in (3) is reduced to the same observations as used in (4).

Regression estimates of the OLS model with fixed-effects specified in model (IV.3), with the share of indirect exports as the dependent variable, are provided in Table IV.II.2. The main results are in general similar to the ones of the previous model in terms of significance levels. The main difference is that estimates for country specific dummy variables for EU and CEFTA membership yield significant results indicating that membership in either of the two agreements decreases the share of indirect exports. This can be attributed to economic integration facilitating export procedures and thereby lowering fixed costs of exporting, which in turn affects mainly direct exporting. The effect is larger for the EU with a decrease in the share of indirect exports of around 11 percentage points than for CEFTA with a decrease of around 5 percentage points (column (2)). 
Both variables turn insignificant when controls for exchange rate volatility and time to clear customs are added to the model. However, we are able to show in column (3), which shows insignificant estimates for both agreements, that this is due to the reduction in observations and not due to the inclusion of the additional variables. Column (3) includes the same variables used in column (2), but with the same observations as in column (4). Another difference in the estimates is found for export intensity. While the effect is positive and highly significant for the probability to export indirectly, it is only weakly significant and mostly negative for the share of indirect exports. Only in column (5) with a reduced sample and estimated with the time to clear customs as an additional variable, the effect is significant and positive.

Table IV.II.2: OLS Regression Results - Share of Indirect Exports

\begin{tabular}{|c|c|c|c|c|c|}
\hline & (1) & (2) & (3) & (4) & (5) \\
\hline In Employees Emkt $_{\mathrm{ijk}}$ & $\begin{array}{c}-1.427^{* * *} \\
(0.350)\end{array}$ & $\begin{array}{c}-1.429 * * * \\
(0.354)\end{array}$ & $\begin{array}{c}-1.523^{* * *} \\
(0.381)\end{array}$ & $\begin{array}{c}-1.551^{* * *} \\
(0.381)\end{array}$ & $\begin{array}{l}-0.0361 \\
(0.204)\end{array}$ \\
\hline In LaborProd ${ }_{\mathrm{ijkt}}$ & $\begin{array}{c}-0.940 * * \\
(0.455)\end{array}$ & $\begin{array}{c}-0.823^{*} \\
(0.464)\end{array}$ & $\begin{array}{c}-2.516^{* * *} \\
(0.585)\end{array}$ & $\begin{array}{c}-2.585^{* * *} \\
(0.586)\end{array}$ & $\begin{array}{c}0.00845 \\
(0.330)\end{array}$ \\
\hline Exportintensity $_{\mathrm{ijkt}}$ & $\begin{array}{l}-0.0269 * \\
(0.0152)\end{array}$ & $\begin{array}{l}-0.0266^{*} \\
(0.0153)\end{array}$ & $\begin{array}{c}-0.0191 \\
(0.0167)\end{array}$ & $\begin{array}{c}-0.0199 \\
(0.0167)\end{array}$ & $\begin{array}{c}0.0326 * * * \\
(0.00940)\end{array}$ \\
\hline Foreign $_{\mathrm{ijkt}}$ & $\begin{array}{c}-4.778 * * * \\
(1.089)\end{array}$ & $\begin{array}{c}-5.066 * * * \\
(1.093)\end{array}$ & $\begin{array}{c}-4.163 * * * \\
(1.186)\end{array}$ & $\begin{array}{c}-3.972^{* * *} \\
(1.188)\end{array}$ & $\begin{array}{c}-1.971 * * * \\
(0.635)\end{array}$ \\
\hline Transportation $_{\mathrm{ijkt}}$ & $\begin{array}{c}1.295^{* *} \\
(0.515)\end{array}$ & $\begin{array}{c}1.217^{* *} \\
(0.514)\end{array}$ & $\begin{array}{c}1.173 * * \\
(0.543)\end{array}$ & $\begin{array}{c}1.169 * * \\
(0.541)\end{array}$ & $\begin{array}{c}0.793^{* *} \\
(0.321)\end{array}$ \\
\hline Customs $_{\mathrm{ijkt}}$ & $\begin{array}{c}-0.231 \\
(0.487)\end{array}$ & $\begin{array}{c}-0.245 \\
(0.489)\end{array}$ & $\begin{array}{l}-0.285 \\
(0.524)\end{array}$ & $\begin{array}{c}-0.271 \\
(0.524)\end{array}$ & $\begin{array}{l}0.0969 \\
(0.313)\end{array}$ \\
\hline Crime $_{\mathrm{ijkt}}$ & $\begin{array}{c}1.237^{* *} \\
(0.493)\end{array}$ & $\begin{array}{c}1.243^{* *} \\
(0.493)\end{array}$ & $\begin{array}{l}1.178^{* *} \\
(0.529)\end{array}$ & $\begin{array}{c}1.138^{* *} \\
(0.529)\end{array}$ & $\begin{array}{c}0.380 \\
(0.303)\end{array}$ \\
\hline Legalsystem $_{\mathrm{ijkt}}$ & $\begin{array}{l}1.056 * \\
(0.560)\end{array}$ & $\begin{array}{c}1.053^{*} \\
(0.565)\end{array}$ & $\begin{array}{c}1.037 * \\
(0.624)\end{array}$ & $\begin{array}{c}1.017 \\
(0.624)\end{array}$ & $\begin{array}{c}0.549 \\
(0.335)\end{array}$ \\
\hline $\mathrm{EU}_{\mathrm{jt}}$ & $\begin{array}{c}-10.39 * * * \\
(3.974)\end{array}$ & $\begin{array}{c}-11.09 * * * \\
(4.058)\end{array}$ & $\begin{array}{l}-8.263 \\
(5.074)\end{array}$ & $\begin{array}{l}-5.559 \\
(5.110)\end{array}$ & $\begin{array}{l}-2.455 \\
(2.482)\end{array}$ \\
\hline CEFTA $_{j \mathrm{t}}$ & $\begin{array}{c}-4.682^{*} \\
(2.620)\end{array}$ & $\begin{array}{c}-4.837^{*} \\
(2.684)\end{array}$ & $\begin{array}{l}-1.480 \\
(3.491)\end{array}$ & $\begin{array}{c}1.756 \\
(3.575)\end{array}$ & $\begin{array}{l}-1.564 \\
(1.525)\end{array}$ \\
\hline Customstime $_{\mathrm{ijkt}}$ & - & - & - & - & $\begin{array}{l}0.693^{*} \\
(0.358)\end{array}$ \\
\hline Volatility $_{\mathrm{jt-1}}$ & - & - & - & $\begin{array}{c}42.01^{* * *} \\
(16.14)\end{array}$ & - \\
\hline Constant & $\begin{array}{c}24.70 * * * \\
(5.948)\end{array}$ & $\begin{array}{c}37.40 * * * \\
(12.67)\end{array}$ & $\begin{array}{c}55.82^{* * *} \\
(17.76)\end{array}$ & $\begin{array}{c}55.83 * * * \\
(17.74)\end{array}$ & $\begin{array}{l}-6.365 \\
(4.026)\end{array}$ \\
\hline Year Dummies & Yes & No & No & No & No \\
\hline Industry Dummies & Yes & No & No & No & No \\
\hline Country Dummies & Yes & Yes & Yes & Yes & Yes \\
\hline Year-Industry Dur & No & Yes & Yes & Yes & Yes \\
\hline Observations & 4,918 & 4,918 & 4,300 & 4,300 & 3,538 \\
\hline $\mathrm{R}^{\wedge} 2$ & 0.050 & 0.060 & 0.065 & 0.067 & 0.047 \\
\hline
\end{tabular}




\section{IV.II.I - Goods versus Services}

The dataset used in this study covers firms producing goods and services and both are very different in terms of export procedures. For this reason we present in this section separate estimates for each type of firms. Thereby we will be able to analyse the differences in the impact of perception of uncertainty on the decision to export indirectly between both sets of exporters. We estimate the models (IV.1) and (IV.3) separately for goods and services with the same specification as in column (2) and (4) in Table IV.II.1 and Table IV.II.2 to be able to compare the estimates. Table IV.II.3 shows the estimation results for goods in columns with uneven numbers and for services in columns with even numbers. The table is divided into two parts. The first part with columns (1) to (4) shows the results of estimating model (IV.3) and the second with columns (5) to (8) shows estimates of model (IV.1).

According to the results shown in Table IV.II.3 for goods and services separately and the whole sample, a higher export intensity has a significant positive impact on the probability to use an intermediary for firms producing goods, but a negative impact on the share of exports via a middleman for firms in the service sector. Foreign ownership promotes direct exports only of goods, but not for services. With regard to regional integration, EU membership decreases indirect export intensity to a very similar extent for goods and services, while CEFTA membership does so only for services. The effect of volatility in the exchange rate to the Euro increases the probability of indirect exports for services only, but no effect is found for goods. A similar outcome is obtained for perception of legal system, which only shows a positive and significant estimate for indirect exports of services. While perception of crime as an obstacle has a significant impact on the probability to export directly and their volume of goods, Transportation has a higher and more significant impact on the choice of the export channel for services than for goods.

Summarizing, determinants of the probability to export indirectly and the intensity of indirect exports differ to some extent for goods and services. While the perception of crime as an obstacle appears to be more important for trade in goods, exports of services are more affected by uncertainty related to future revenues due to volatility in the domestic exchange rate and to a well-functioning legal system. The first outcome seems intuitive when considering crime in the form of physical theft of goods. The latter could be due to peculiarities of the service sectors in general that make it more vulnerable to fluctuations in the exchange rate. For instance, infrequent use of indirect hedging as less inputs are needed in the production process of services or more 
difficult access to financial hedging due to a lack of assets could be reasons for these findings. Furthermore, transportation is a greater concern for firms in the service sector than for firms in goods sectors. A likely explanation is that services are frequently non-traded goods and often provided in locations close to the customer and hence make it necessary for firm providing the service to transport employees and tools. In such a case, transportation obstacles could be a serious concern. In contrast to that, cross-border transport of goods are usually taken care of by a logistics company, which is then affected by obstacles with regard to the transportation of goods. From the perspective of the firm, these obstacles do increase the costs of exporting and thereby affect the decision to export ${ }^{37}$. But as transporting the goods is not an issue the firms have to deal with directly, perception of transportation as an obstacle might be seen only with reference to transportation conducted by the firm itself. Results may look different for questions regarding the perception of other trade costs as an obstacle, different form transportation. Unfortunately, questions going in this direction are not included in the survey of the World Bank.

37 See section IV.II.II for the impact of the perception of transportation as an obstacle on the decision to export at all. 
Table IV.II.3: Regression Results - Goods vs. Services

\begin{tabular}{|c|c|c|c|c|c|c|c|c|}
\hline & (1) & (2) & (3) & (4) & (5) & (6) & (7) & (8) \\
\hline & OLS & OLS & OLS & OLS & Probit & Probit & Probit & Probit \\
\hline & Goods & Services & Goods & Services & Goods & Services & Goods & Services \\
\hline \multirow{2}{*}{ In Employees $\mathrm{ijkt}_{\mathrm{jkt}}$} & $-1.822 * * *$ & $-1.162^{* *}$ & $-1.923 * * *$ & $-1.254^{* *}$ & $-0.0136^{* *}$ & -0.00829 & $-0.0164^{* *}$ & -0.0106 \\
\hline & $(0.485)$ & $(0.525)$ & (0.510) & $(0.572)$ & (0.00597) & $(0.00635)$ & (0.00642) & $(0.00705)$ \\
\hline \multirow{2}{*}{ In LaborProd ${ }_{\mathrm{ijkt}}$} & -0.659 & $-1.359^{*}$ & $-2.602 * * *$ & $-2.545 * * *$ & -0.00621 & -0.00441 & $-0.0260 * * *$ & $-0.0215^{* *}$ \\
\hline & (0.598) & $(0.763)$ & $(0.752)$ & $(0.964)$ & (0.00694) & $(0.00822)$ & $(0.00930)$ & (0.0104) \\
\hline \multirow{2}{*}{ Exportintensity $_{\mathrm{ijk}}$} & 0.000160 & $-0.0667 * * *$ & 0.00903 & $-0.0708 * *$ & $0.00064 * * *$ & 0.000331 & $0.00084 * * *$ & 0.000431 \\
\hline & $(0.0192)$ & $(0.0255)$ & $(0.0206)$ & $(0.0285)$ & $(0.000246)$ & $(0.00032)$ & $(0.00027)$ & $(0.00036)$ \\
\hline \multirow{2}{*}{ Foreign $_{\mathrm{ijkt}}$} & $-7.277 * * *$ & -2.318 & $-6.391 * * *$ & -0.468 & $-0.103 * * *$ & -0.0364 & $-0.0985 * * *$ & -0.0204 \\
\hline & (1.365) & (1.876) & (1.453) & (2.073) & $(0.0173)$ & $(0.0223)$ & (0.0189) & (0.0257) \\
\hline \multirow{2}{*}{ Transportation $_{\mathrm{ijkt}}$} & 0.800 & $1.816^{* *}$ & 0.865 & $1.607^{*}$ & $0.0132 *$ & $0.0267 * * *$ & $0.0143^{*}$ & $0.0225^{* *}$ \\
\hline & $(0.622)$ & $(0.900)$ & $(0.654)$ & (0.949) & $(0.00755)$ & $(0.00956)$ & (0.00808) & $(0.0103)$ \\
\hline \multirow{2}{*}{ Customs $_{i \mathrm{jkt}}$} & -0.747 & 0.607 & -0.620 & 0.375 & -0.000117 & 0.00829 & 0.00216 & 0.00777 \\
\hline & $(0.632)$ & (0.779) & (0.669) & $(0.850)$ & $(0.00783)$ & $(0.00941)$ & (0.00839) & (0.0104) \\
\hline \multirow{2}{*}{ Crime $_{\mathrm{ijkt}}$} & $1.893^{* * *}$ & -0.0340 & $1.755^{* * *}$ & -0.0774 & $0.0214 * * *$ & 0.00350 & $0.0197^{* *}$ & 0.00534 \\
\hline & $(0.625)$ & (0.809) & $(0.667)$ & (0.867) & $(0.00748)$ & $(0.00925)$ & (0.00804) & $(0.0102)$ \\
\hline \multirow{2}{*}{ Legalsystem $_{\mathrm{ijkt}}$} & 0.515 & $1.740^{*}$ & 0.650 & $1.679 *$ & 0.0118 & 0.0174 & $0.0168 *$ & 0.0157 \\
\hline & $(0.732)$ & (0.894) & (0.799) & (1.002) & $(0.00922)$ & (0.0109) & $(0.0102)$ & (0.0122) \\
\hline \multirow{2}{*}{$\mathrm{EU}_{\mathrm{jt}}$} & $-10.39 *$ & $-11.06^{*}$ & -8.968 & -1.694 & -0.0550 & -0.0362 & -0.0613 & 0.0935 \\
\hline & (5.407) & (6.349) & (6.876) & (8.063) & (0.0716) & (0.0774) & (0.0988) & $(0.128)$ \\
\hline \multirow{2}{*}{ CEFTA $_{\mathrm{jt}}$} & -2.078 & $-7.738^{*}$ & 0.477 & 3.797 & 0.0167 & -0.0454 & 0.0293 & 0.112 \\
\hline & (3.661) & (4.074) & (5.219) & (5.204) & (0.0515) & (0.0514) & (0.0800) & (0.0961) \\
\hline Volatility $_{\mathrm{jt}-1}$ & - & - & $\begin{array}{c}6.547 \\
(20.79)\end{array}$ & $\begin{array}{c}84.12^{* * *} \\
(24.03)\end{array}$ & - & - & $\begin{array}{c}-0.0722 \\
(0.321)\end{array}$ & $\begin{array}{c}0.968^{* * *} \\
(0.295)\end{array}$ \\
\hline Constant & $\begin{array}{c}38.42 * * * \\
(13.35)\end{array}$ & $\begin{array}{c}22.79 * * \\
(10.28)\end{array}$ & $\begin{array}{c}58.01 * * * \\
(18.71)\end{array}$ & $\begin{array}{c}30.68 * * \\
(12.40)\end{array}$ & - & - & & - \\
\hline Observations & 3,071 & 1,847 & 2,685 & 1,615 & 3,071 & 1,839 & 2,685 & 1,596 \\
\hline $\mathrm{R}^{\wedge} 2$ & 0.063 & 0.075 & 0.072 & 0.083 & 0.0525 & 0.0712 & 0.0588 & 0.0751 \\
\hline
\end{tabular}

Notes: Reported values for probit regressions are marginal effects at the mean of the independent variables; Robust standard errors in parentheses; *** $p<0.01,{ }^{* *} p<0.05,{ }^{*} p<0.1$.

In order to assess the relative importance of each of the variables in model (IV.3) in comparison to our measure of exchange rate volatility, we present beta coefficients in Table IV.II.4. Beta coefficients are measured in standard deviations and therefore the magnitude of the coefficients can be compared also for variables measured in different units. As shown in column (1), which contains the beta coefficients for the model in Table IV.II.2 column (2), a one standard deviation increase in export intensity decreases the share of indirect exports on total exports by 0.0199 standard deviations. Beta coefficients based on models estimated in Table IV.II.3 columns (3) and (4) indicate the relative importance of labor productivity for goods and services and of foreign ownership for goods in explaining the share of intermediated exports. In comparison with the other variables in our models, we find volatility in the domestic exchange rate with the Euro to 
have a relatively large impact on the share of intermediated exports of services (column (3)). The impact on the share of intermediated exports of goods we find, besides that the estimates are insignificant, to be rather small.

Table IV.II.4: Beta Coefficients

\begin{tabular}{|c|c|c|c|}
\hline & $(1)$ & $(2)$ & (3) \\
\hline & OLS & OLS & OLS \\
\hline & All & Goods & Services \\
\hline In Employees ${ }_{\mathrm{ijkt}}$ & -0.0702 & -0.0809 & -0.0586 \\
\hline In LaborProd ${ }_{\mathrm{ijkt}}$ & -0.129 & -0.129 & -0.126 \\
\hline Exportintensity $_{\mathrm{ijkt}}$ & -0.0199 & 0.00917 & -0.0664 \\
\hline Foreign $_{\mathrm{ijkt}}$ & -0.0500 & -0.0810 & -0.00581 \\
\hline Transportation $_{\mathrm{ijkt}}$ & 0.0393 & 0.0293 & 0.0534 \\
\hline Customs $_{\mathrm{ijkt}}$ & -0.00911 & -0.0210 & 0.0124 \\
\hline Crime $_{\mathrm{ijkt}}$ & 0.0377 & 0.0584 & -0.00253 \\
\hline Legalsystem $_{\mathrm{ijkt}}$ & 0.0287 & 0.0182 & 0.0479 \\
\hline $\mathrm{EU}_{j \mathrm{jt}}$ & -0.0790 & -0.128 & -0.0238 \\
\hline CEFTA $_{j \mathrm{t}}$ & 0.0243 & 0.00646 & 0.0537 \\
\hline Volatility $_{\mathrm{jt}-1}$ & 0.0523 & 0.00762 & 0.115 \\
\hline Country Dummies & Yes & Yes & Yes \\
\hline Year-Industry Dum. & Yes & Yes & Yes \\
\hline Observations & 4,300 & 2,685 & 1,615 \\
\hline $\mathrm{R}^{\wedge} 2$ & 0.067 & 0.072 & 0.083 \\
\hline
\end{tabular}

Notes: Reported values are beta coefficients.

\section{IV.II.II - Robustness: Two-Stage Approach}

Estimates for the two-stage approach are presented in Table IV.II.5. The first stage specified in model (IV.4) uses as dependent variable the probability to export and the second stage denoted in model (IV.5) the share of indirect exports. While a higher number of employees, labor productivity and foreign ownership increase a firms' probability to export and decreases the share of indirect exports, stronger perception of crime and transportation as an obstacle decreases the probability to export and increases the share of intermediated exports. The quality of the legal system only seems to affect the choice of the export mode by promoting direct exports, but it does not seem to affect the decision to export. Surprisingly, the variable customs proceedings shows a significant and positive effect on the probability to export, indicating that when customs proceedings are seeing as major obstacle, firms are more likely to export. Apparently, firms that do export and have 
experience with problems associated with exporting see customs proceedings as a bigger problem. As explained in Section IV.I, we exclude the latter variable from the second stage to fulfil the exclusion restriction.

Euro and CEFTA dummies as controls for economic and trade integration have a significant positive impact on the probability to the export of 12 and 6 percentage points and decrease the share of intermediated exports by 12 and 5 percent. Both variables turn insignificant when the measure of exchange rate volatility to the Euro is introduced as they did in the estimates without controls for sample selection bias in Table IV.II.2. While volatility in the domestic exchange rate has no significant impact on the probability to export, it increases the share of indirect exports. The fact that the inverse Mill's ratio is significant in the second stage indicates that there is evidence that a selection bias is present in model (IV.3), but the effect on coefficients appears to be rather small.

Table IV.II.5: Heckman Two-StageRegression Results

\begin{tabular}{|c|c|c|c|c|}
\hline & (1) & (2) & (3) & (4) \\
\hline & $1^{\text {st }}$ Stage & $2^{\text {nd }}$ Stage & $1^{\text {st }}$ Stage & $2^{\text {nd }}$ Stage \\
\hline & Probit & OLS & Probit & OLS \\
\hline \multirow{2}{*}{ In Employees ${ }_{\mathrm{ijkt}}$} & $0.0791^{* * *}$ & $-1.637 * * *$ & $0.0777 * * *$ & $-1.512 * * *$ \\
\hline & $(0.00292)$ & $(0.380)$ & $(0.00259)$ & $(0.354)$ \\
\hline \multirow{2}{*}{ In LaborProd ${ }_{\mathrm{ijkt}}$} & $0.0352 * * *$ & $-2.601 * * *$ & $0.0226 * * *$ & $-0.824 *$ \\
\hline & $(0.00404)$ & $(0.585)$ & (0.00295) & $(0.464)$ \\
\hline \multirow{2}{*}{ Foreign $_{\mathrm{ijkt}}$} & $0.167^{* * *}$ & $-4.287 * * *$ & $0.184^{* * *}$ & $-5.453 * * *$ \\
\hline & (0.0141) & (1.176) & $(0.0126)$ & $(1.082)$ \\
\hline \multirow{2}{*}{ Transportation $_{\mathrm{ijkt}}$} & $-0.0101 * *$ & $1.088 * *$ & $-0.00834^{* *}$ & $1.130 * *$ \\
\hline & $(0.00418)$ & (0.509) & $(0.00375)$ & $(0.484)$ \\
\hline \multirow{2}{*}{ Customs $_{\mathrm{ijkt}}$} & $0.0692 * * *$ & & $0.0650 * * *$ & \\
\hline & $(0.00404)$ & - & $(0.00356)$ & 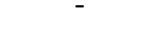 \\
\hline \multirow{2}{*}{ Crime $_{\mathrm{ijkt}}$} & $-0.0288 * * *$ & $1.127 * *$ & $-0.0288 * * *$ & $1.233^{* *}$ \\
\hline & $(0.00388)$ & $(0.522)$ & (0.00349) & $(0.488)$ \\
\hline \multirow{2}{*}{ Legalsystem $_{\mathrm{ijkt}}$} & 0.00412 & $1.024^{*}$ & -0.000372 & $1.090^{*}$ \\
\hline & $(0.00483)$ & $(0.622)$ & (0.00425) & $(0.564)$ \\
\hline \multirow{2}{*}{$\mathrm{EU}_{\mathrm{jt}}$} & -0.00476 & -5.524 & $0.0728 * *$ & $-11.21 * * *$ \\
\hline & $(0.0430)$ & (5.103) & (0.0329) & $(4.056)$ \\
\hline \multirow{2}{*}{ CEFTA $_{j t}$} & -0.0246 & 1.624 & $0.0442 * *$ & $-5.062^{*}$ \\
\hline & (0.0314) & (3.572) & $(0.0221)$ & $(2.683)$ \\
\hline \multirow{2}{*}{ Volatility $_{\mathrm{jt}-1}$} & -0.133 & $41.73 * * *$ & \multirow[b]{2}{*}{ - } & \multirow{2}{*}{ (2.000 } \\
\hline & $(0.136)$ & $(16.18)$ & & \\
\hline Inverse Mills Ratio & - & $\begin{array}{c}-836.4 * * * \\
(214.4)\end{array}$ & - & $\begin{array}{c}-184.7^{* *} \\
(82.41)\end{array}$ \\
\hline Constant & - & $\begin{array}{c}55.21 * * * \\
(17.79)\end{array}$ & - & $\begin{array}{c}36.22 * * * \\
(12.71)\end{array}$ \\
\hline Country Dummies & Yes & Yes & Yes & Yes \\
\hline Year-Industry Dum. & Yes & Yes & Yes & Yes \\
\hline Observations & 13,626 & 4,300 & 16,304 & 4,918 \\
\hline$R^{\wedge} 2$ & 0.280 & 0.067 & 0.273 & 0.059 \\
\hline
\end{tabular}

Notes: Reported values for probit regressions are marginal effects at the mean of the independent variables; Robust standard errors in parentheses; *** $p<0.01, * * p<0.05, * p<0.1$. 


\section{IV.III - Conclusion}

Although being vague in its nature, uncertainty, measured as the perceived severity of obstacles, appears to play an important role in explaining a firms' choice between direct and indirect exporting and seems to have a slightly different impact on goods than services.

Firms that are large, more productive, foreign owned and export a higher share of their production prefer direct exporting, while uncertainty in different fields makes firm prefer increasingly the use of intermediaries. In particular, the perception of potential threats like criminality, problems with the transport infrastructure or the legal system have a significant impact on the mode of export. Furthermore, we show that uncertainty about future revenues due to volatility in the domestic exchange rate with the Euro increases the share of indirect exports on total exports for services, but has no significant impact on exports of goods. We could also show that our results are not driven by sample selection bias and the inclusion of various controls confirms its robustness.

Finally, our findings highlight the importance of intermediaries in countries where firms perceive challenges in the business environment that increase the level of uncertainty and thus the fixed costs of exporting. Lowering perceived uncertainty as well as improving conditions for intermediaries would help domestic firms with their exporting activities. 


\section{V - Political Determinants of International Arms Transfers}

based on joint work with Inmaculada Martínez-Zarzoso

In the past few years, a number of investigations have stressed the importance of analysing the determinants of international trade at the industry/product level, in particular to be able to account for specific economic and political factors that are industry-specific. The armament industry is usually referred to as being particularly different from other industries with regard to the role played by the political environment on the decision to export. Many fast growing developing countries have been increasing their capacity to produce arms and are trying to establish a domestic military industry to be less dependent on imported arms (Brauer 2000). However, these countries have not yet been successful in becoming exporters of arms on a larger scale (Brauer 2007). For this reason, supply of military goods is very concentrated globally ${ }^{38}$ and international trade of arms remains an important issue.

Understanding how the political environment affects the decision to export arms is crucial to provide a scientific basis to the public debate about the regulation of trade in major weapon systems. Furthermore, it is also relevant to investigate the relative importance of the main drivers of demand constraints in arms' trade, in particular conflicts, the degree of militarization of the society, the existence of military agreements and the effectiveness of embargoes. Despite the undisputed importance of the political environment in the transfer decision, little has been done so far to investigate the political factors determining transfers of arms between countries. To the best of our knowledge, there are only two studies (Akerman \& Seim 2012; Comola 2012) that have made some progress in this direction.

38 This is commonly attributed to "military malthusianism", which describes that unit costs of major weapon systems rise faster than government budget revenues and make it impossible for countries to achieve economies of scale and entirely cope with costs of development and production of arms for a country on its own (Brauer \& Dunne 2011). 
The principal aim of this paper is to investigate a number of political factors that affect the decision to exports arms and the value of the transfer. As main political factors, we consider the level of democracy in the trading partners as well as the political orientation of the ruling governments. Moreover, we also account for the political differences between trading partners and the political environment in their respective regions and for military and strategic pacts. To our knowledge, this is the first study that consistently investigates the political determinants of the extensive and intensive margins of international trade in arms using up-to-date panel data econometric models and a comprehensive sample of countries and years.

The main novelties with respect to previous studies are threefold. First, we focus not only on the level of democracy as Akerman \& Seim (2012) do, but also on the political orientation of the ruling governments and on the political similarities between trading partners and the political environment of regions where they are located. Second, whereas Comola (2012) used a categorical variable with only three dimensions, limited time coverage and country-time variation to measure political orientation, we use a measure based on the countries' voting behaviour in the United Nations General Assembly, which has more variability and an extended time coverage. Third, in our research, we control for a number of factors that were not included in previous studies and we also distinguish between the determinants of the decision to export (extensive margin of exports) and the determinants of the average amount exported (intensive margin of exports). Since both decisions are related, we use a Helpman et al. (2008) two-stage estimation procedure to control for selection bias and firm heterogeneity. We also control for time-invariant unobservable heterogeneity by experimenting with different sets of fixed effects. Our estimation framework is based on a theoretically justified gravity model of trade, which is applied to data for more than 100 countries over the period of 1950 to 2007. In order to test for the robustness of the results, we estimate the model using several variations of our dataset and estimation techniques. Furthermore, we compare the transfer of arms with trade in other goods and evaluate differences in the impact of the two political dimensions.

The main results show that the political factors considered are relevant in explaining the two trade margins of arms transfers. The end of the Cold War appears to have changed the impact and direction for several political factors, especially for those measuring the political environment in the region. Differences in political orientation continue to have a significant negative impact on two countries' probability to transfer arms. 
This paper is structured as follows: section V.I describes the existing empirical literature in this field and section V.II gives an overview of the data used. Section V.III presents the empirical analysis, section V.IV discusses the main findings and section V.V concludes.

\section{V.I - Literature}

In order to approve a transfer of arms, the countries involved must first evaluate whether the associated benefits outweigh the risks and costs attached to the transfer. Whereas the gains for the exporting country include revenues for the domestic industry in related sectors and in turn the protection of jobs in these industries, the costs are mainly related to political, economic and strategic factors (Brauer 2000 and 2007). Furthermore, exporting should also generate increasing economies of scale, resulting in lower costs and enhanced international competitiveness of involved firms. These gains, however, can be offset by potential negative effects, which are linked to the fact that the exporting country loses control over the arms once they are exported ${ }^{39}$. Thus, these arms could eventually be used against the exporter or his allies and the transfer of tools of destruction can as problematic from a strategic standpoint. In addition, potential copyright infringements or negative reactions and pressure from third countries can emerge as a response to weapon exports. Democratic countries, in particular, may have a strong and negative reaction in the public opinion.

On the other hand, for the trade partners, the transfer can establish or strengthen their relationship. It can also lead to a transfer of knowledge ${ }^{40}$, possible attempts to influence the importers' policy ${ }^{41}$ and may start or fuel an arms race in the region of the importer. All effects have different implications for the potential trading partners depending on the conditions of the contract. In addition to the mostly self-serving reasons described above, arms transfers can also be the result of an altruistic behaviour with the aim to help the receiving country maintain or reestablish safety and security (Akerman \& Seim 2012).

The described potential positive and negative effects create uncertainty about the real outcomes in different aspects related to the transfer. The political environment in the recipient country can be an indicator of the level of uncertainty as well as the political differences between the supplier and

39 Contracts over the export of arms often contain clauses that forbid their use in certain regions of the importing country with ongoing conflicts (e.g. exports of arms from Germany to Turkey and Mexico), but usually do not lead to any consequences when broken.

40 According to Brauer \& Dunne (2009), the knowledge transfer of offset agreements is, if existing at all, relatively small.

41 Investigating arms exports of the US, Sislin (1994) finds successful attempts to influence the partner countries under certain conditions, especially in the first decades of the Cold War. 
the recipient. Indeed, some authors find that countries may discriminate against certain political regimes. In particular, Blanton (2000) finds that the United States largely exports arms to democratic countries. This can either be due to support of the United States for countries that are politically close or be du to the fact that the United Sates expect negative effects to be in general lower when exporting to democratic countries than when sending arms to autocratic regimes.

The political determinants of arms transfers have been investigated, to the best of our knowledge, by only two studies. Both studies use the same dataset on transfers in arms and put the main emphasis on changes after the end of the Cold War. However, the studies differ in the political aspects and time periods covered, the econometric approach implemented and the main results.

The first study, by Akerman \& Seim (2012), investigates the impact of the level of democracy on the probability to trade arms for 34 countries for the years 1950-2007, using a linear probability model with fixed effects. They find that the squared difference in polity between trading partners has a large and significant negative impact on the target variable, but that the effect turns out to be positive and insignificant after the end of the Cold War. The main shortcoming of this study is the use of a linear probability model, since the residuals violate assumptions about homoskedasticity and normality of errors and this results in invalid standard errors and hypothesis tests. A second limitation is that they only focus on the decision to transfer arms, thus disregarding the effect on the quantity transferred.

The second study, by Comola (2012), extends the analysis by using the political orientation of the trading countries as a second political dimension. She investigates the effect of both political dimensions, namely democracy and political orientation, on the volume of arms exported from the 20 major exporters to all independent countries recognized by the United Nations in the period 1975-2004. The estimation method is a gravity-type Tobit model with exporter, importer and time fixed-effects. The main findings are that democracies tend to export and import more arms than autocracies and that while democracies export them mostly to rich countries, autocracies have the tendency to export to poor countries. Furthermore, sharing a political orientation has a positive impact on trade that sharply decreases after the end of the Cold War, especially for democracies. It is worth noting that the measure of political orientation used by Comola, which is constructed using the World Bank Development Research Group's Database of Political Institutions, has several shortcomings. First, it only covers the time period after 1974 and in many cases has no information on the political orientation of the ruling party. Thus, the dataset contains many missing values. 
Second, the variable is a subjective measure, which is not strictly comparable between countries ${ }^{42}$ and distinguishes only three categories ${ }^{43}$ that can not capture smaller changes in the political orientation. Third, it focuses on economic policy rather than on foreign policy and has no variation over time for communist countries, while capitalist or market liberal countries have governments from all three categories. Finally, methodologically, it fails to acknowledge the recent advances in gravity-modelling concerning panel data since it does not include dyadic fixed effects, but only exporter and importer fixed effects, which do not control for all the unobserved heterogeneity that is time-invariant and country-pair specific.

Both studies find that political determinants are important in terms of explaining international flows of major conventional weapons $(\mathrm{MCW})$. Both studies also describe a decrease in the importance of political differences between supplier and recipient after the end of the Cold War. We will extend these studies by using a more comprehensive dataset that includes all exporters and importers trading arms, an extended set of policy variables and controls as well as a more suitable estimation technique that allows us to distinguish between the effect on the extensive and intensive margins of arms trade.

\section{V.II - Data}

In our analysis we combine information from different fields of research and various sources in order to control for different aspects of the transfer of arms. This section describes the data and the construction of our variables. The study covers the period from 1950 to 2007 and uses data for 104 suppliers of arms and 154 recipients listed in Tables E.1 and E.2 in the Appendix.

\section{V.II.I - Data on Arms Transfers}

The identification of the trade in arms and ammunition in the available trade classifications is not straightforward. Although recent revisions of the categories listed in the Harmonized Commodity Description and Coding Systems (HS) allow us to isolate exports and imports of arms and ammunition $^{44}$, the data is mostly based on reports of the importing and exporting countries ${ }^{45}$ and

42 For example, the Clinton and Carter governments in the USA are defined as left-wing. Thus, are labeled with the identical political orientation as communist countries like the Democratic People's Republic of Korea.

43 The dataset distinguishes between regimes that are either left, right, centrist or cannot be assigned to any of the three.

44 For example, the HS12 goods categories has an entry for "arms and ammunition and parts and accessories thereof" (HS12-93).

45 Due to confidentiality reasons, countries may not report all of its detailed trade. In data sources like UN Comtrade these trade flows will usually be included in a category called "others" or in the total trade value only. This makes it impossible to identify the sum of trade for some commodities. 
covered trade in arms is described as being "spotty" (Brauer 2007). Therefore, we use data on arms transfers from the SIPRI Arms Transfers Database. It covers MCWs including air defence systems, aircrafts, anti-submarine warfare weapons, armoured vehicles, artillery, engines (for ships, armoured vehicles and aircrafts), missiles, satellites, sensors, ships and components such as guns and turrets for the years from 1950 to 2012. Information comes from various sources including the media, governments, non-governmental organizations (NGO) and international institutions. The transfers can be of official and unofficial nature and not necessarily involves a direct payment. Transfers to rebel groups or NOGs within the recipient countries are excluded from our sample.

In addition to agreements of transfers, SIPRI also provides information on the volume transferred between the two parties for the year of the delivery in a separate dataset. This dataset is based on the known unit production costs of a core set of weapons and is intended to represent the transfer of military resources rather than the financial value or sales price of the transfer. For used arms the volume is discounted by 33 or 60 percent depending on whether or not it has been significantly refurbished. The volume is denoted as trend-indicator value (TIV) in million US\$ at constant (1990) prices. Deliveries with a value of less than US\$500,000 are denoted as a zero. When the transfer is carried out over several years, the value is split according to the deliveries for each single year.

\section{V.II.II - Political Dimensions}

In order to derive a simplified picture of the global political landscape, we distinguish between two different political dimensions: the level of democracy and political orientation. This results in four main groups of governments: left-wing democracies, right-wing democracies, left-wing autocracies and right-wing autocracies (Figure V.II.1). 
Figure V.II.1: Political Dimensions

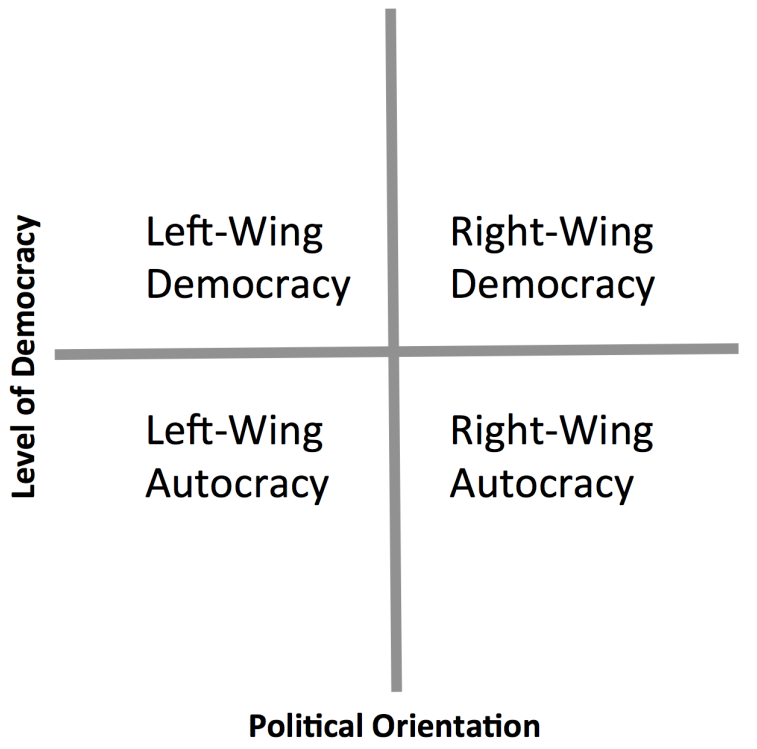

For the level of democracy, data comes from the polity2 variable in the POLITY IV database hosted by the Center for Systemic Peace and George Mason University. It ranges from -10 (strongly autocratic) to +10 (strongly democratic).

As described in section V.I, the most common measure for political orientation has several flaws. We therefore measure political orientation using a new approach, which clearly differs from Comola (2012). In the last sixty years, the world may have shifted from a bipolar system to a unipolar or multipolar system, but the USA remains a (sole) superpower. Therefore, we assume that the political orientation of the USA is constant throughout our sample period. We use the USA as a point of reference in political orientation and measure the distance to the political orientation of the USA by using differences in the voting behaviour in the UN General Assembly (UNGA). We take UNGA Voting Data by Voeten and Strezhnev, where the authors constructed a voting similarity index ranking from 0 to 1 , which is computed based on three categories (approval, abstain and disapproval for an issue) and where abstention is counted as half-agreement with a yes or no vote. The data is described by the authors as measuring common "interests" or "preferences" and we attribute differences in the UNGA voting behaviour to differences in the political alignment of the foreign policy. We believe that our method captures political orientation in a more accurate way than the measure used by Comola (2012). To illustrate our argument, we give an example: The labour government of Tony Blair in United Kingdom (1998-2010) and the republican government of George W. Bush in the USA (2001-2008) have usually been perceived as being very similar with regard to foreign policy. Nevertheless, according to the dataset of the World Bank they are on 
opposite ends with regard to political orientation, while their voting concordance in the UN General Assembly is one of the highest for all countries during that period. Furthermore, the two governments cooperated heavily in the exchange of arms. According to the SIPRI dataset, there are 44 agreements to transfer arms between both countries between 2001-2008, which is a very high number.

We look at the two above-mentioned dimensions for supplier and recipient separately, while also considering bilateral and regional differences. In this way, we are able to account for the spatial dimension of political and international security aspects that could also affect arms transfers. Hence, we first use the level of both dimensions for supplier and recipient to control for its level of democracy and its political orientation. Second, we use the absolute difference of each dimension between supplier and recipient to control for differences between both countries in both dimensions. Third, we also include as regressors the average value of the political dimensions for all countries in the region, separately and in absolute differences. The latter is supposed to control for the political environment in the region of supplier and recipient to ensure that the effect of the political country variables are not just capturing the fact that countries with a certain political angle are often located geographically close together. For example, countries surrounded by autocracies may in general have a different supply or demand for arms than those surrounded by democracies.

In what follows, we examine the degree of correlation between both political dimensions. Figure V.II.2 shows that democratic countries in general do not have higher voting concordance with the US, although in the past two decades there has been a stronger relationship. Voting concordance with USA is on average declining over time, and the level of democracy is rising after a downturn around the 1970s. The only persistent pattern we find is a group of highly democratic countries with relatively similar voting behaviour to the USA that mostly consists of northern democracies. 
Figure V.II.2: Political Orientation and Level of Democracy in Single Years

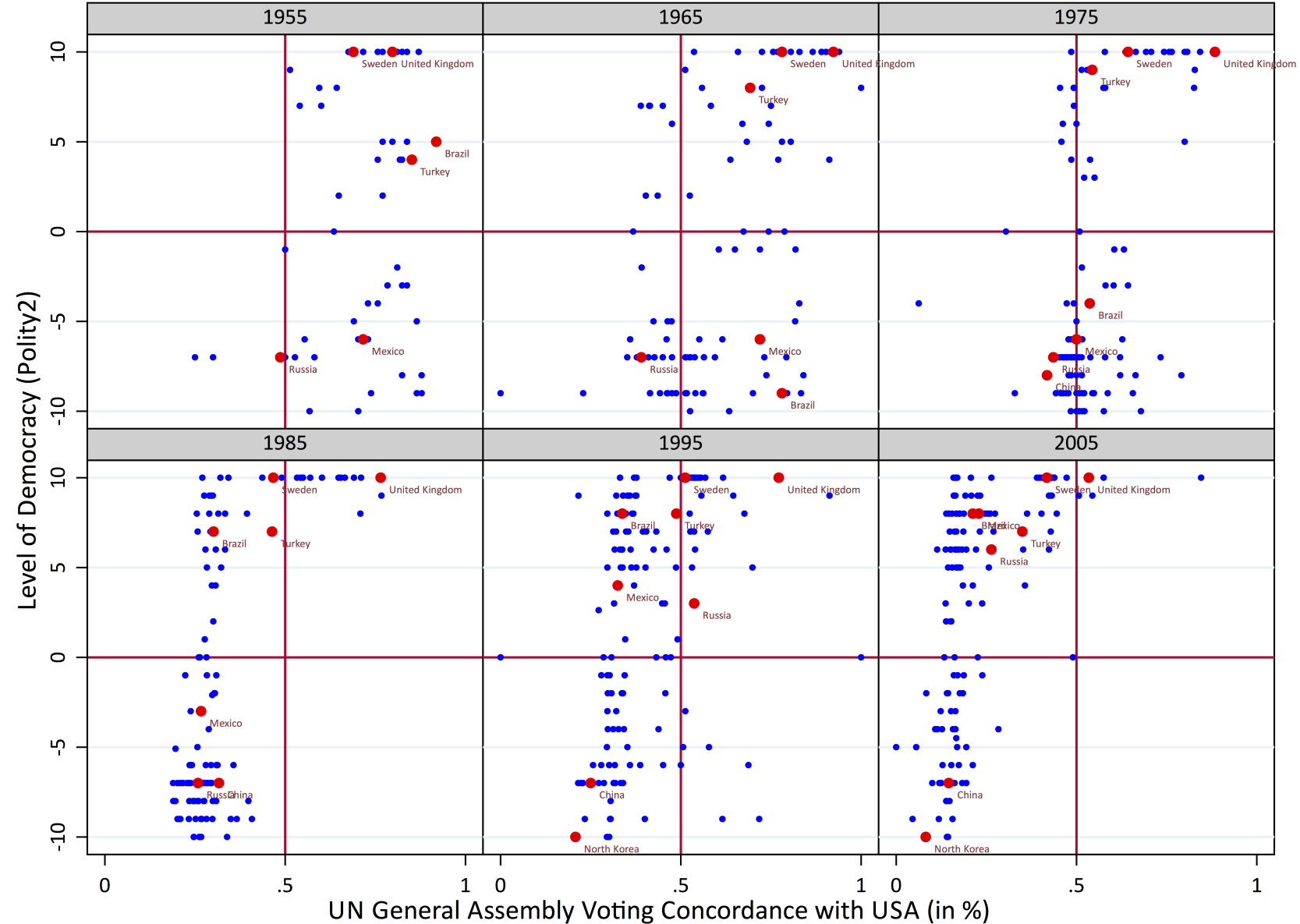

Notes: Markers indicate countries. The red markers shows a few countries as examples tracked over time; The figure only shows countries that were members of the UN and participated in the voting of the UN General Assembly.

\section{V.II.III - Control Variables}

Other variables included in the analysis come from a number of different sources. Information on gross domestic product (GDP) was extracted from the Maddison Project, that, to our knowledge, is the only source of GDP data that also covers socialist or communist countries. Cultural and geographical characteristics are measured with several variables taken from the Centre d'Etudes Prospectives et d'Informations Internationales (CEPII). We use data on conflicts provided by the dataset of armed conflicts from the Centre for the Study of Civil War (CSCW) and the Uppsala Conflict Data Program (UCDP) at the Department of Peace and Conflict Research at Uppsala University and information on mandatory UN embargoes from the SIPRI Arms Embargoes Database. Data on the share of military personnel comes from the National Material Capabilities (v4.0) dataset and information on military and strategic pacts comes from the Formal Alliances (v4.0) dataset of the Correlates of War Project (COW). 


\section{V.III - Analysis}

In this section, we first conduct a simple descriptive analysis that looks at differences between country-pairs that trade and those that do not trade arms and at the political similarity between the trading countries. Second, we conduct an empirical analysis to investigate the determinants of the probability to trade arms and the volume of the transactions.

\section{V.III.I - Descriptive Analysis}

The evolution of the political similarity of countries trading arms for each decade is shown in Figure V.III.1. The figure shows that in the 1950s, transfers of arms mostly occurred between members of a defence agreement, and the largest amount of transfers were between countries with very similar levels of democracy and political orientation. In the following decades, transfers were increasingly conducted between countries more unequal in both political dimensions. Since the end of the Cold War, transfers have again mostly been taking place between countries that are politically close in both dimensions. The share of transfers within defence agreements is declining over time. Interestingly, in the last three decades, transfers within defence agreements have often been between countries that were very different in terms of political orientation, but did not differ in the level of democracy. 
Figure V.III.1: Similarity in Level of Democracy and Political Orientation Between Trading Partners

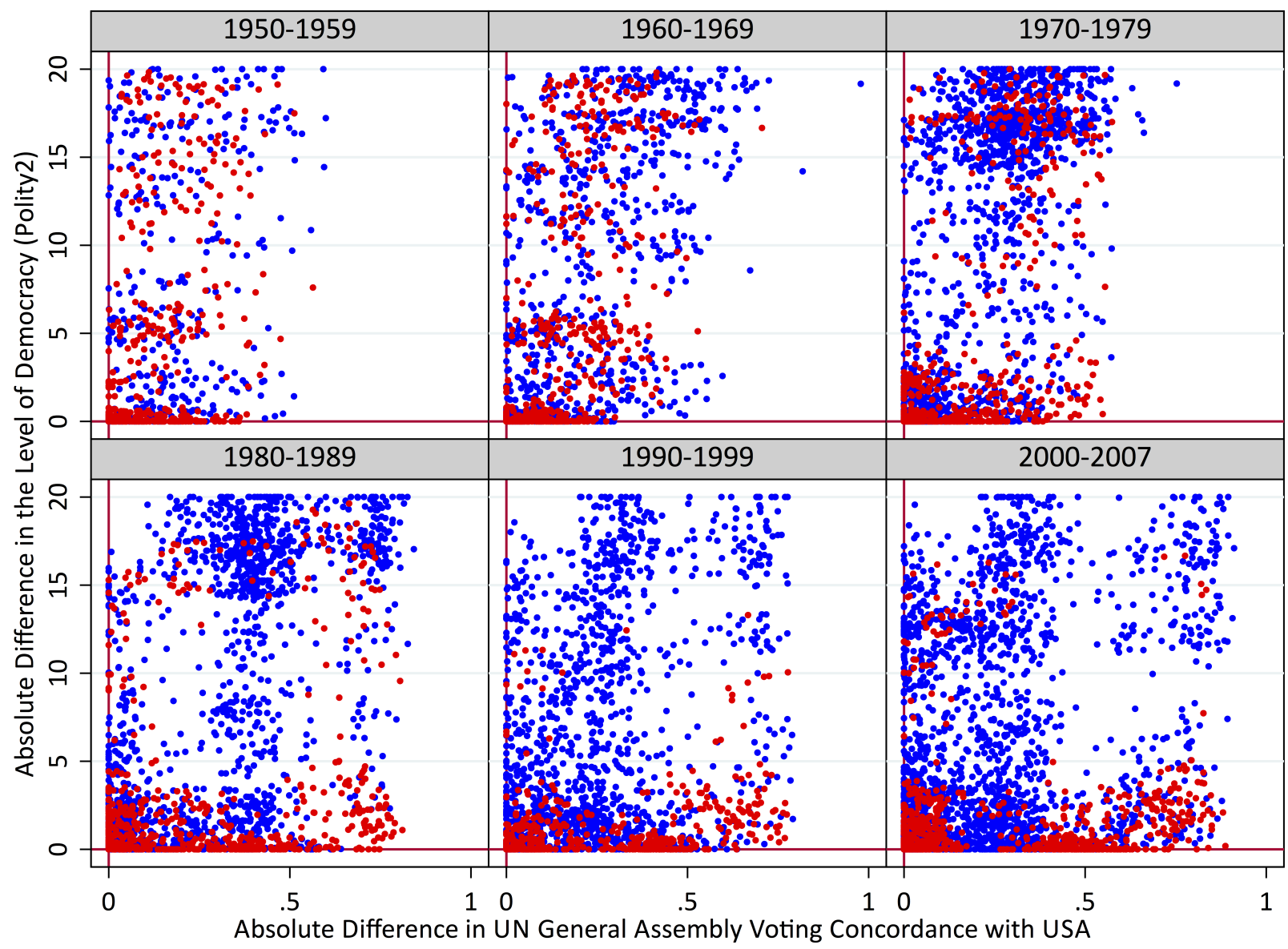

Notes: Blue and red markers indicate agreement on a transfer of arms in the given decade; Red markers indicate that a defence agreement between trading partners is in place; Location of Markers are slightly perturbed to avoid overprinting of markers.

When comparing the average level of democracy over time of countries that are involved in the transfer of arms with those not involved, it is striking that for the exporting country, the average polity2 is much higher (Figure V.III.2). The difference varies over time between four and nine points on the polity2 scale and is decreasing over time. For the importing country, polity tends to be slightly higher than for non-importers except for the period from the mid 1960s until the early 1980 s when the difference is close to zero. For the same time period, absolute difference in polity2 between countries that trade arms is higher than for others. Apparently, in the "hottest phase" of the Cold War, countries trading arms had more pronounced differences in the level of democracy than countries not involved in the transfer of arms. Before and after this period, differences in the level of democracy are smaller for country-pairs that trade arms. 
Figure V.III.2: Difference in Polity of Countries Transferring Arms

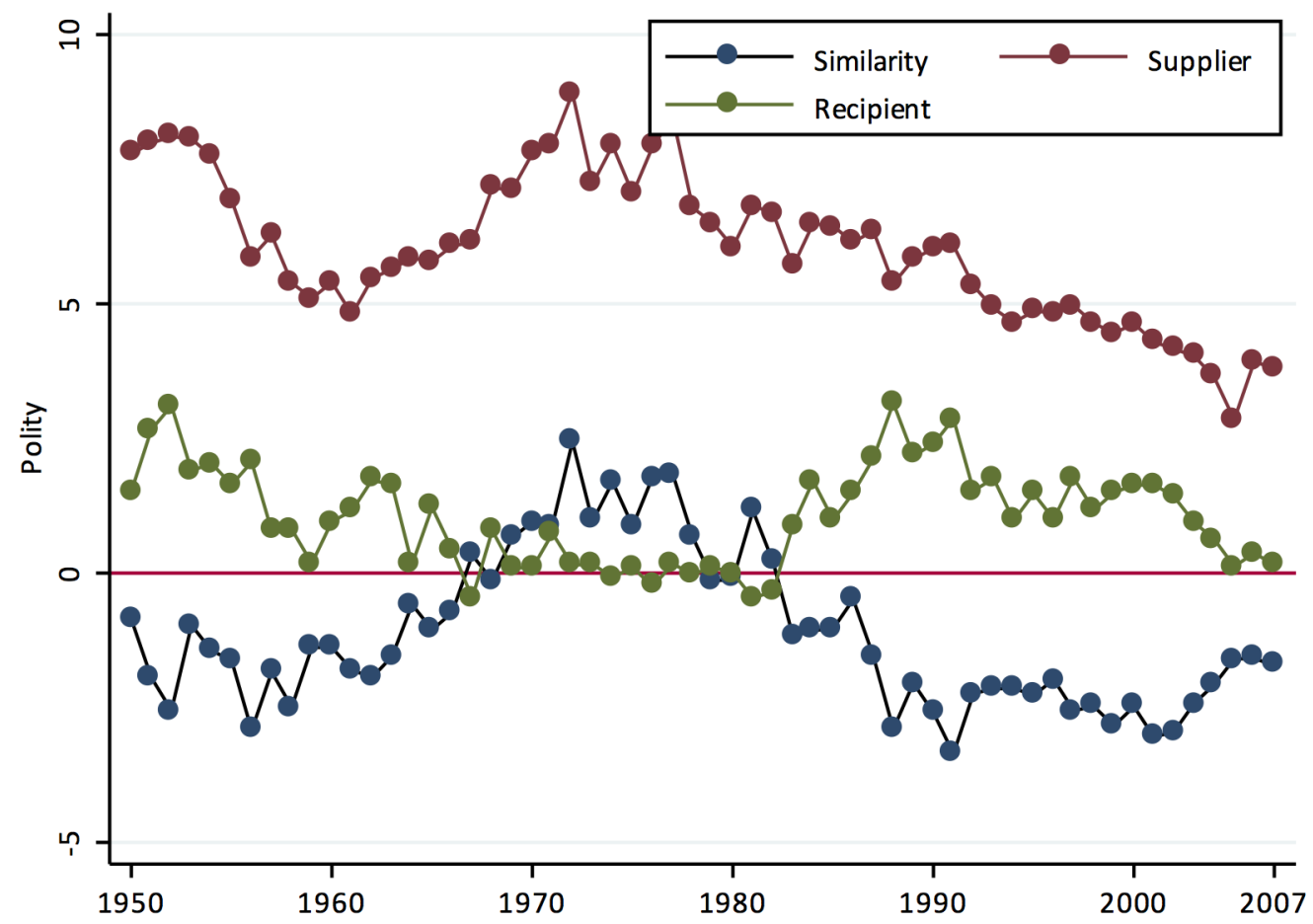

Notes: Graph shows the difference in the mean polity2 of countries transferring arms from the total sample. Negative values indicate lower polity for countries that transfer arms.

Figure V.III.3 analyses differences in political orientation over time. On the one hand, we find that countries exporting arms tend to have on average, a voting behaviour more similar to the USA than countries that do not export arms. Whereas importer of arms tend to show slightly higher orientation towards the USA than non-importers, but less pronounced than exporters and only for some years. On the other hand, similarity in political orientation tends to be lower between countries trading arms than between those not trading arms from the mid 1960s onwards. Political differences between trading countries and political orientation towards the USA of the suppliers of arms is increasing strongly over time.

In short, countries exporting arms appear to be more democratic and oriented towards the US, while recipient countries are close to non-trading countries with regard to both dimensions. While countries trading arms appear to be closer in terms of democracy level, they tend to be more different with regard to their political orientation than countries that do not trade arms. 
Figure V.III.3: Difference in Voting Concordance with USA of Countries Transferring Arms

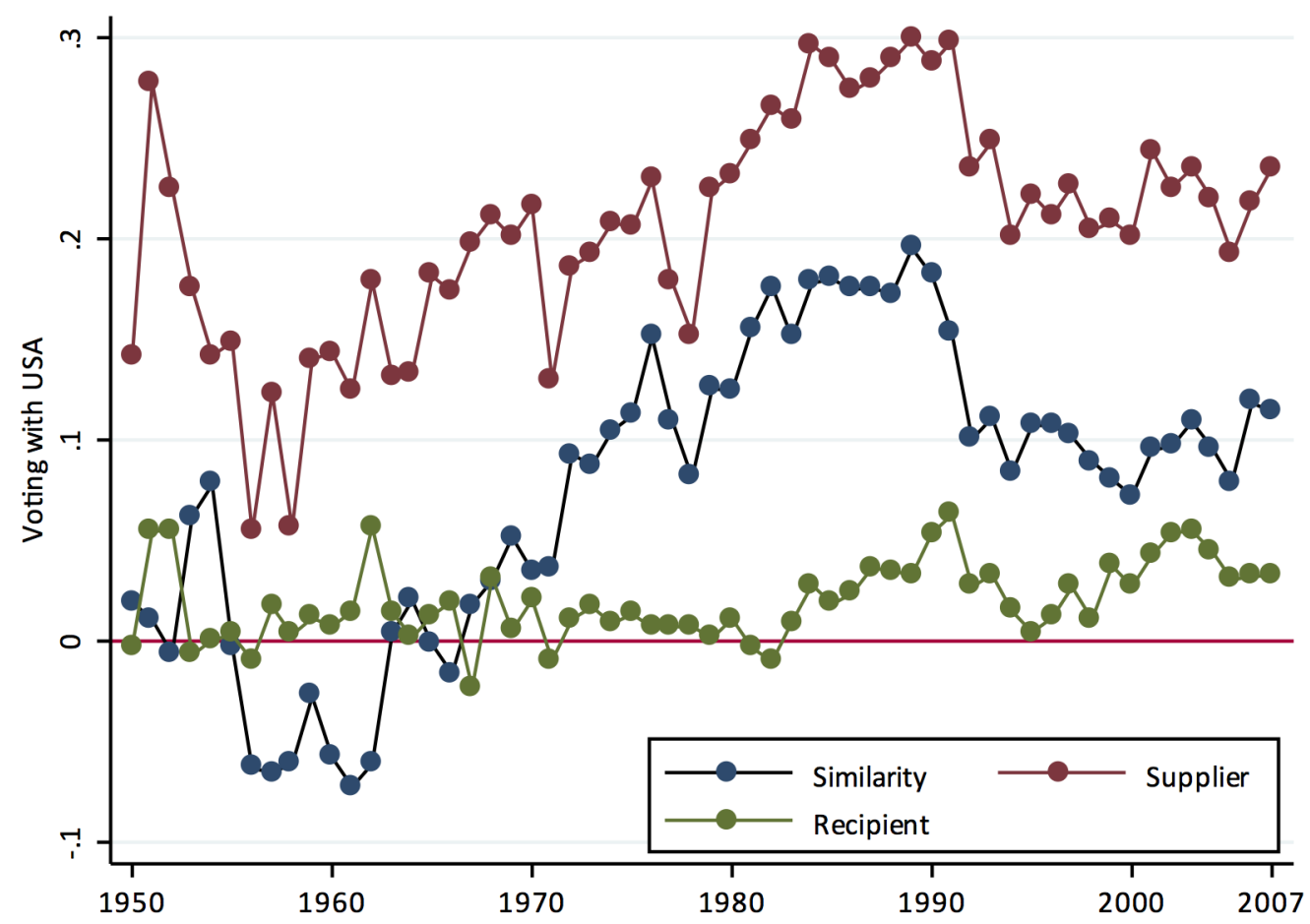

Notes: Graph shows the difference in the mean voting concordance with the USA of countries transferring arms with the total sample. Negative values indicate lower voting concordance with the USA.

\section{V.III.II - Econometric Approach}

Our econometric analysis is based on the gravity model of trade augmented with a number of variables that capture the political situation of supplier and recipient and others that are expected to influence trade in arms for the reasons explained below. The gravity model has been widely used to model bilateral trade flows and is suitable to estimate the effect of specific economic and political factors on trade. It was first used to estimate trade flows by Tinbergen (1962), extended with theoretical foundations by Anderson (1979) and later by Anderson \& van Wincoop (2003) taking into account relative trade costs in the form of multilateral resistance to trade ${ }^{46}$.

We use standard gravity variables, namely GDP and GDP per capita, distance between the countrypair and categorical variables that control for geographical and cultural closeness. In addition, we control for the demand and supply of arms due to conflicts in the recipient country, arms embargoes against the recipient country and military pacts and strategical agreements between supplier and recipient. 
In order to estimate determinants of arms transfer correctly, we also need information on the industrial capacity of the domestic arms industry and domestic demand for arms. As information on both for the time period of this study is difficult to find, we add to the model the share of military personnel divided by the total population as a measure of the degree of militarization in a society and demand for equipment. Militarization can affect supply and demand for arms through various channels. A ceteris paribus higher degree of militarization and therefore higher domestic demand for arms, is expected to strengthen the domestic arms industry. This is because the domestic production of arms and equipment is usually preferred over foreign production for political and strategic reasons. This is especially the case if domestic production can satisfy the needs of the military. Increased demand for domestic production then makes exports of arms more likely due to the existence of economies of scale. Concerning the probability to import, a higher degree of militarization has an ambiguous effect: if higher domestic demand for arms contributes to the formation of a competitive arms industry that can satisfy domestic demand, it should lead to a decrease in the imports of arms. Otherwise, demand for foreign arms should be positively related to the size of the military industry.

Political factors, the main focus of this investigation, are modelled using several variables: first, we include the level of democracy and our measure of political orientation for supplier and recipient. Second, we introduce the absolute difference in both dimensions between supplier and recipient. And third, in order to capture the political environment in the region of the exporter and the region of the importer, we include the average value for both variables of all countries that are geographically close. The empirical model is specified as a probit model to estimate the determinants of the probability that countries $i$ and $j$ agree on a transfer of MCWs:

$$
\operatorname{Pr}\left(\text { transfer }_{i j t}=1 \mid X\right)=\varphi\left(\alpha+X^{\prime} \beta+\kappa_{i}+\lambda_{j}+\alpha_{t}+\varepsilon_{i j t}\right),
$$

where the dependent variable, transfer ${ }_{i j t}$, takes the value one if $\mathrm{j}$ placed an order of major conventional arms in $\mathrm{i}$, or in the case of licensed production, a licence was issued in year $\mathrm{t}$ and zero otherwise. The vector of regressors $X$ is assumed to influence the outcome and consists of the following variables ${ }^{47}$ : In $\mathrm{GDP}_{\mathrm{it}}$ and $\ln \mathrm{GDP}_{\mathrm{jt}}$ denote the natural logarithm of the gross domestic product for the supplier and the recipient in year $t$ and $I n G D P p c_{i t}$ and $\ln \mathrm{GDPpc}_{\mathrm{jt}}$, the natural logarithm of gross domestic product per capita for both countries. Trade costs proxied by geographical and cultural distance are measured by the natural logarithm of distance between

47 See Table III.III.1 for an extensive description of all variables in the model. 
capitals of $\mathrm{i}$ and $\mathrm{j}$ (InDistance $\left.\mathrm{ij}_{\mathrm{ij}}\right)$; a dummy variable that takes the value one if $\mathrm{i}$ and $\mathrm{j}$ share a border (Contiguity $\mathrm{y}_{\mathrm{ij}}$ ); a common language (Language $\left.\mathrm{i}_{\mathrm{ij}}\right)$; or common colonial past $\left(\right.$ Colony $_{\mathrm{ij}}$ ) and a variable that takes the value one if $\mathrm{i}$ or $\mathrm{j}$, and two if both are landlocked (Landlocked $\mathrm{L}_{\mathrm{ij}}$ ).

The first political dimension in the model is the level of democracy. We account for the level of democracy for the supplier (Polity ${ }_{i t}$ ) and the recipient (Polity $y_{\mathrm{jt}}$ ), the absolute difference in the level of democracy between both (Polity_diff $\mathrm{ijt}_{\mathrm{it}}$ ) and the average level of democracy of the surrounding countries for the supplier (Polity_region ${ }_{i t}$ ) and the recipient (Polity_region ${ }_{j t}$ ). Our measure for the second dimension political orientation is covered in a similar fashion for the supplier (votewithUSA ${ }_{i t}$ ), the recipient (votewithUSA ${ }_{j t}$ ), the absolute difference between both variables (votewithUSA_diff $\mathrm{ijt}_{\mathrm{jt}}$ ) and the average value of surrounding countries of the supplier $\left(\right.$ votewithUSA_region $_{i t}$ ) and the recipient (votewithUSA_region ${ }_{j t}$ ).

The degree of militarization is included for the supplier (Militarization ${ }_{\text {it }}$ ) and the recipient (Militarization $_{\mathrm{jt}}$ ). The dummy variable Conflict $\mathrm{j}_{\mathrm{jt}}$ indicates involvement of the government of the recipient in a military conflict with another party and at least 25 battle-related deaths. Pact ${ }_{\mathrm{ijt}}$ is a variable that takes the value one if countries $\mathrm{i}$ and $\mathrm{j}$ have any kind of military or strategic agreement in place in year $t$. This can either be to remain neutral, a promise not to attack each other, to consult each other if a crisis occurs, or to defend each other. Embargo ${ }_{j t}$ takes the value one if a mandatory UN embargo is in place against country $\mathrm{j}$ in year $\mathrm{t}$. Besides the nonlinear probit model, we estimate a linear probability model (LMP) that has the advantage of giving a rough but easily interpretable impression of the size of the effect for each variable in the model without calculating marginal effects.

The main concern regarding the estimation of equation (V.1) is that estimates are rendered biased by unobservable heterogeneity that is time invariant and country specific or time varying and common to all countries and correlated with the error term. Given the large number of observations of over 500,000 in our sample, we have chosen to include fixed-effects by "bruteforce" which has the disadvantage of having high demands in terms of computational power. According to Baltagi (2013), the bias is then considerably reduced when having a high number of observations. In order to control for the bilateral time-invariant heterogeneity, we employ a separate regression based on the approach by Mundlak (1978) and include in equation (V.1) the time averages of the time variant covariates as additional explanatory variables. 


\section{V.III.III - Volume of Transferred Arms}

Estimates on the probability to transfer arms do not account for the size of the transfer, only whether or not a transfer was agreed upon. Thus, the transfer of a single armoured vehicle is given the same importance as the transfer of 200 fighter aircrafts. In order to account for the size of the transfer, we estimate a model with the same explanatory variables as in model (V.1) on a measure of the volume of transferred arms:

$$
\ln \text { Volume }_{i j t}=\beta_{0}+\beta_{1} X+\kappa_{i}+\lambda_{j}+\alpha_{t}+\varepsilon_{i j t}
$$

The dependent variable is the natural logarithm of the value of transferred major conventional arms from country $i$ to country $j$ in year $t$ measured with the TIV of the SIPRI Dataset on Transferred Arms. Different from model (V.1), where t specifies the year of the agreement about the transfer, the transferred value $t$ denotes the time of the delivery. Thus, a transfer that was agreed on in one year and appears in model (V.1) only one time can be conducted over several years and appear in model (V.2) several times, always with the transferred value of that year. As described in section V.II.I, transfers with a TIV of below 500,000 in constant (1990) US\$ are denoted as zero and are therefore not included the regression.

\section{V.III.IV - Two-Stage Approach}

The latter model has the disadvantage that because the dependent variable is transformed by taking the natural logarithm, all trade flows with a TIV of zero are not included in the model. This may cause a sample selection bias associated with unobserved barriers to transfers of arms that are correlated with observed ones and are important in explaining the volume of transfers between country $\mathrm{i}$ and $\mathrm{j}$. The bias could be particularly large due to the very high fraction of zeros in the dependent variable of almost 98 percent. Furthermore, due to the wide range of industries involved in the military industrial complex and the importance of cooperations of firms and consortia we expect the firms in this sector to be very heterogeneous. When leaving this heterogeneity uncontrolled, estimates of the intensive margin will be biased.

Following Helpman et al. (2008), we estimate a two-stage model that allows us to control for unobserved firm heterogeneity and for sample selection bias. The estimation of the model consists of an extension of the Heckman two-stage approach commonly used to correct for selection bias. In this approach, elements of the first stage estimation (a probit model on the probability to export 
arms) are used in a second stage as proxies for firm productivity and as correction for sample selection bias. In the first stage, we estimate the probit model on the probability to transfer MCWs from country $\mathrm{i}$ to $\mathrm{j}$ in year $\mathrm{t}$ :

$$
\operatorname{Pr}\left(\text { Transfer }_{i j t}=1 \mid X\right)=\varphi\left(\alpha+X^{\prime} \beta+\kappa_{i}+\lambda_{j}+\alpha_{t}+\varepsilon_{i j t}\right),
$$

The model differs from the model in equation (V.1) as the dependent variable in equation (V.3) is the probability of a physical transfer of arms from country $i$ to country $j$ in year $t\left(\right.$ Transfer $\left._{i j t}\right)$ and not the probability of placing an order or the agreement on a to transfer $\operatorname{arms}^{48}$. In the second stage, we estimate the volume of transferred MCWs from country $i$ to $j$ in year $t$. The model can be written as:

$$
\ln _{\text {Volume }_{i j t}}=\beta_{0}+\beta_{1} X+\beta_{2} \hat{Z}+\beta_{3} I M R+\kappa_{i}+\lambda_{j}+\alpha_{t}+\varepsilon_{i j t}
$$

Following Helpman et al. (2008), we include two additional terms as regressors in the second stage: the linear prediction of the export down-weighted by its standard error $(\hat{Z})$ and the inverse Mill's ratio (IMR), both calculated using elements obtained from the estimation of equation (V.3). The former term corrects the bias generated by the underlying unobserved firm-level heterogeneity, whereas the latter is a correction for sample selection which addresses the biases generated by unobserved shocks.

In order to fulfil the exclusion restriction of the Heckman approach, we use an exclusion variable, which should only affects the probability to export, but not the volume, and hence must not enter the second step model. The variable measuring mandatory UN embargoes is the best candidate for this purpose. In fact, the assumption that mandatory embargoes, which have the purpose to eliminate trade of arms to a certain destination, only affect probability and not the volume seems intuitive and reasonable and indeed this variable yields no significant estimates when included in model (V.2). The intuition behind this is that once a supplier of arms is willing to violate the embargo, he will do so regardless of the size of the deal.

\section{V.III.V - Trade in Arms versus Trade of Goods}

In previous sections we have emphasized the importance of political factors in explaining transfers of arms. However, we have not yet answered the question of whether the impact of these factors is specific to the nature of transfers in arms or whether it applies for trade flows in general. A

48 The SIPRI Arms Transfers Database provides information on the order of a transfer and the value of the transfer in separate datasets with different timings, which prevented us from matching both datasets. 
direct comparison of estimates for all goods provides evidence of how political orientation and the level of democracy differs in the direction, extent and significance of the impact on trade in goods and transfers of $\mathrm{arms}^{49}$.

In order to make a direct comparison, we construct a dataset that covers the same set of countries over the same years for trade in goods and transfers of arms. Unfortunately, this reduces the number of observations significantly, especially for communist countries and in the early years. Therefore, results are not directly comparable with the results of the previous sections. Information on trade flows of goods comes from the United Nations Comtrade Database for the years $1962-2007$.

\section{V.IV - Findings}

Panel estimates of equation (V.1), obtained for the variables measuring the different aspects of the two political dimensions are reported in Table V.IV.1 and estimates for all variables in Table E.6 in the Appendix. The complete Tables can be found in the Appendix. Column (1) shows the results obtained from a linear probability model, columns (2) and (3) show estimates from a probit model with country and time fixed effects and with country-decade and year fixed effects. Finally, columns (4) and (5) are panel estimates with dyadic random-effects and year and country fixed effects in (4) and using the Mundlak approach in columns (5) to (7).

The variables that serve as a proxy for the country-specific political dimensions have in general, a statistically significant impact on the probability of ordering a transfer of arms in most specifications. An increase in the polity index of the supplier increases the probability to transfer arms significantly, whereas for the recipient, the effect is always significant and negative. Concerning the differences in political factors between trading countries, both an increase in the absolute difference between the polity index and an increase in the discrepancy in voting behaviour, have a significant negative impact on the probability of a transfer. In terms of regional political aspects, only voting with USA in the region of the supplier has a positive and significant effect on the probability of ordering a transfer of arms. When relaxing the assumption of no correlation between unobserved heterogeneity and covariates by using the Mundlak approach in column (5), we find that estimates for all variables have the same sign and remain statistically significant. The only exception is similarity in the level of democracy, which turns insignificant.

49 A comparison between trade in arms and other goods besides arms is not possible. As described in section V.II.I, arms or components of arms (e.g. engines of ships) are often labeled as non-military goods or not reported due to confidentiality reasons. 
Other explanatory variables are also relevant. While military pacts and conflicts in the recipient countries always significantly increase the probability of a transfer, embargoes against the recipient have a negative impact. Militarization of the society in the recipient country has a negative and significant effect on the probability to import arms. A higher domestic demand for arms from the military industry, ceteris paribus, could strengthen the domestic arms industry. If the domestic arms industry is meeting domestic needs, it could lower the probability of order transfers of arms from abroad. This effect appears to overcompensate the demand effect. Estimates for standard gravity variables mostly have the expected signs. GDP has a significant and positive impact on the probability of a transfer in arms and GDP per capita has a significant and negative impact for the exporter and positive impact for the importer. Geographical variables also show expected results, with negative and significant coefficients for distance and positive and significant coefficients for contiguity. Cultural similarities, measured by colonial past and common official language, always have a positive and significant impact.

When estimating the Mundlak approach for the time before and after the end of the Cold War, we find that the direction and significance of some variables change as shown in columns (6) and (7). For instance, less democratic countries are more likely to export arms after 1989. Also regional factors now have a significant impact on the likelihood to transfer arms. In the time before 1990, exporters and importers tend to be surrounded by more democratic countries. After that, exporters tend to be surrounded by less democratic countries and estimates for the importers' region turn insignificant. Also insignificant now are estimates for political orientation of the exporter in both periods and for the importer after 1989. Interestingly, we find that the degree of militarization shows a strong variation over time. For the exporter, a more militarized society has a positive impact on the probability to export before and a negative impact after then end of the Cold War. For the importer, the negative impact found for the full sample is only significant in the later period. Pacts between countries and conflicts in the recipient country both have a significant and positive impact on the probability of a transfer in both time periods. Contrary to the results by Comola (2012), we do not find that differences in the political orientation have no significant impact on the probability of two countries to trade arms after 1989. 
Table V.IV.1: Probability to Agree on a Transfer of Arms

\begin{tabular}{|c|c|c|c|c|c|c|c|}
\hline & (1) & $(2)$ & (3) & (4) & (5) & (6) & (7) \\
\hline & LPM & Probit & $\begin{array}{c}\text { Probit } \\
1950-2007 \\
\end{array}$ & RE Probit & Mundlak & \begin{tabular}{|c|} 
Mundlak \\
$1950-1989$ \\
\end{tabular} & $\begin{array}{c}\text { Mundlak } \\
1990-2007 \\
\end{array}$ \\
\hline Polity $_{\text {it }}$ & $0.00037 * * *$ & $0.0183 * * *$ & -0.00805 & $0.0213^{* * *}$ & $0.0193 * * *$ & 0.00598 & $-0.0191^{* *}$ \\
\hline Polity $_{j \mathrm{t}}$ & $-0.00010 * *$ & $-0.0159 * * *$ & $*-0.0179 * * *$ & $-0.0123 * * *$ & $-0.00753 * * *$ & $-0.00698 * *$ & 0.00519 \\
\hline Polity_diff & $-0.00038 * * *$ & $-0.0152 * * *$ & ${ }^{*}-0.0135^{* * *}$ & $-0.0102 * * *$ & -0.00264 & -0.000231 & 0.00359 \\
\hline Polity_region $_{\text {it }}$ & 0.000010 & 0.00643 & $0.0136^{*}$ & 0.00820 & 0.00687 & $0.0302 * * *$ & $-0.0383 * *$ \\
\hline Polity_region $_{\mathrm{jt}}$ & 0.000021 & -0.00220 & 0.0124 & -0.00364 & -0.00314 & $0.0168^{* *}$ & -0.000119 \\
\hline votewithUSA $_{i t}$ & $-0.0090 * * *$ & $0.641 * * *$ & $0.691 * * *$ & $0.579 * * *$ & $0.436 * * *$ & -0.163 & 0.289 \\
\hline votewithUSA $_{j t}$ & $-0.00623 * * *$ & $-0.855^{* * *}$ & $-0.966 * * *$ & $-0.759 * * *$ & $-0.689 * * *$ & $-0.930 * * *$ & -0.214 \\
\hline votewithUSA_diff $_{\mathrm{ijt}}$ & $-0.0457^{* * *}$ & $-1.392 * * *$ & $-1.928 * * *$ & $-1.196 * * *$ & $-0.941 * * *$ & $-0.911 * * *$ & $-0.528 * *$ \\
\hline votewithUSA_region $_{i t}$ & $0.0299 * * *$ & $0.516^{* * *}$ & 0.210 & $0.530 * * *$ & $0.559 * * *$ & $0.593 * * *$ & 0.0924 \\
\hline votewithUSA_region $_{\mathrm{jt}}$ & 0.00393 & -0.0141 & 0.443 & 0.0517 & 0.109 & 0.0357 & 0.508 \\
\hline Militarization $_{\mathrm{t}}$ & -0.0140 & -1.572 & 1.155 & -1.226 & -0.724 & $9.344 * * *$ & $-36.67 * * *$ \\
\hline Militarization $_{\mathrm{jt}}$ & -0.0441 & $-2.971 *$ & -1.157 & $-4.497 * *$ & $-4.401 * *$ & -3.139 & $-8.332 * *$ \\
\hline Pact $_{i j t}$ & $0.0397 * * *$ & $0.497 * * *$ & $0.544 * * *$ & $0.412^{* * *}$ & $0.355^{* * *}$ & $0.433^{* * *}$ & $0.202 * * *$ \\
\hline Conflict $_{j \mathrm{t}}$ & $0.00496 * * *$ & $0.182 * * *$ & $0.131^{* * *}$ & $0.190 * * *$ & $0.189 * * *$ & $0.166^{* * *}$ & $0.203^{* * *}$ \\
\hline $\begin{array}{l}\text { Embargo }_{j t} \\
\text { Year Dummies }\end{array}$ & $\begin{array}{c}-0.00925 * * * \\
\text { Yes } * * *\end{array}$ & $\begin{array}{c}-0.541 * * * \\
\text { Yes } * * *\end{array}$ & $\begin{array}{l}-0.147 \\
\text { Yes*** }\end{array}$ & $\begin{array}{c}-0.628 * * * \\
\text { Yes } * * *\end{array}$ & $\begin{array}{c}-0.644 * * * \\
\text { Yes } * * *\end{array}$ & Yes*** & $\begin{array}{c}-0.545^{* * *} \\
\text { Yes*** }\end{array}$ \\
\hline Country Dum. & Yes*** & Yes*** & No & Yes*** & Yes*** & Yes*** & Yes*** \\
\hline Country-Decade & No & No & Yes*** & No & No & No & No \\
\hline Observations & 530,205 & 530,205 & 333,932 & 530,205 & 530,205 & 273,521 & 186,549 \\
\hline$R^{\wedge} 2$ (Pseudo $R^{\wedge} 2$ ) & 0.165 & $(0.440)$ & $(0.421)$ & - & - & - & - \\
\hline
\end{tabular}

Notes: *** $p<0.01, * * p<0.05, * p<0.1$;

Regression results for models (V.2) and (V.4) on the transferred volume of arms are shown in Table V.IV.3 for the political variables and for all variables in Table E.7 in the Appendix. The dependent variable is the average value of the arms transferred. In order to control for various biases described in section V.III.IV, we include results for a Helpman et al. (2008) approach in columns (5) to (7).

The political variable estimates are slightly different from the ones shown for the probability to order a transfer, as described above. While polity of the supplier now yields non-significant estimates, the polity index of the recipient is negative and statistically significant, indicating that a one point increase in the level of democracy decreases the transferred volume for the recipient by around 1.2 percent (column (7)). Absolute differences in polity have a significant and negative impact on the volume of transferred arms of 1.7 percent (column (4)) but turns insignificant when controlling for sample selection bias in columns (6) and (7). Voting concordance with the USA in 
the UN General Assembly yields mixed results for the supplier and the recipient, which turns out to be non-significant when using the Helpman et al. (2008) approach. Interestingly, regional political factors present different results. Indeed, when the surrounding countries of the exporter have a more similar voting pattern to the USA, they tend to transfer less arms. When the opposite is true for the importer region, imports of arms increases. These results are in sharp contrast to those obtained from estimating model (V.1). In this case, the probability of agreeing to a transfer increases when the exporters' voting pattern is more in concordance with the US, although the amounts transferred tend to be lower.

The variables military pact and conflict are only affecting arms transfers in the panel estimates when we do not apply the two-stage approach. In this case, a military or strategic pact signed between supplier and recipient increases the volume of arms transferred by about 47 percentage points (column 5). When an armed conflict is taking place in the recipient country, the volume of arms transfers received by the country increases by around 10 percentage points (column 5). Estimates are smaller and even lose statistical significance when using the Heckman two-stage approach with fixed- or random-effects. A mandatory embargo by the UN on the recipient has a non-significant effect on the volume of arms exported. This variable is therefore excluded from the second stage in columns (5) to (7) in order to fulfil the exclusion restriction of the model. The degree of militarization of the society yields mixed estimates for supplier and recipient. While the effect is negative but insignificant for the supplier, it is positive and significant as long as the country-fixed effects are not varying by decade. The effect lies between 14 and 41 percent given an increase of one percentage point in the share of military personnel of the total population.

The volume of arms transfers tends to be higher for suppliers and recipients with higher GDP and lower GDP per capita. Geographical characteristics such as landlockedness and contiguity in most regressions yield positive and significant estimates. At first, it may seem surprising that distance between supplier and recipient also has a significant and positive impact on the volume of arms exported when assuming that larger distance reflects higher transport costs. The positive effect of distance can be explained by the fact that suppliers prefer selling arms to destinations further away to lower the probability of facing these arms in battle. While common colonial past of supplier and recipient has a positive impact on trade volume, the common language effect is negative. 
We also find a lower impact of political variables on the volume for estimations that include controls for sample selection bias and firm heterogeneity and variables measuring political differences between supplier and recipient to turn out insignificant. The same happens with variables controlling for conflicts as well as pacts between supplier and recipient in fixed- and random-effects regressions. The fact that the inverse Mill's ratio is insignificant in the second stage for the random-effects estimation indicates that there is no evidence that selection bias is quantitatively important in this model. The impact of political variables on the volume of trade changes with the end of the Cold War. Estimates for separate fixed-effects regressions for the time during and after the Cold War in columns (8) and (9) show that the effects of political orientation in the region measured for the full sample are driven by the time until 1989. The same applies for the impact of the degree of militarization in the recipient country, pacts and conflicts. This is in sharp contrast to estimation results on the probability of a transfer. In the period after 1989, less democratic countries tend to export more arms.

Table V.IV.2: Volume of Transferred Arms $2^{\text {nd }}$ Stage $2^{\text {nd }}$ Stage $2^{\text {nd }}$ Stage

\begin{tabular}{|c|c|c|c|c|c|c|c|c|c|}
\hline & (1) & (2) & (3) & (4) & (5) & (6) & (7) & (8) & (9) \\
\hline & \multirow[t]{2}{*}{ OLS } & \multirow[t]{2}{*}{ OLS } & \multirow[t]{2}{*}{$\mathrm{FE}$} & RE & \multirow[t]{2}{*}{ OLS } & \multirow[t]{2}{*}{$\mathrm{FE}$} & \multirow[t]{2}{*}{ RE } & \multirow{2}{*}{$\begin{array}{c}\text { FE } \\
1950-1985\end{array}$} & $\mathrm{FE}$ \\
\hline & & & & 1950-2007 & & & & & 1990-2007 \\
\hline Polity $_{\text {it }}$ & 0.0119 & -0.00006 & 0.00130 & 0.00538 & $0.0143^{*}$ & -0.0140 & -0.00930 & 0.0284 & $-0.0836 * *$ \\
\hline Polity $_{j \mathrm{jt}}$ & $-0.0242 * * *$ & $-0.0122^{*}$ & $-0.0238 * * *$ & $-0.0233 * * *$ & k-0.0262*** & * $-0.0119 *$ & $-0.0121 * *$ & -0.00786 & -0.00112 \\
\hline Polity_diff & $-0.0204 * * *$ & $-0.0138 * * *$ & k-0.0156*** & $-0.0173 * * *$ & k-0.0226*** & $*-0.00537$ & -0.00728 & 0.00397 & -0.0163 \\
\hline Polity_region $_{\text {it }}$ & $0.0235^{* *}$ & -0.0163 & $0.0205^{*}$ & $0.0255^{* *}$ & $0.0231 * *$ & 0.0134 & 0.00814 & 0.0125 & -0.00351 \\
\hline Polity_region $_{\mathrm{jt}}$ & 0.00603 & 0.0213 & -0.0110 & -0.00735 & 0.00527 & 0.00222 & 0.0104 & -0.00213 & 0.0570 \\
\hline votewithUSA $_{i t}$ & $0.450 *$ & $1.076^{* *}$ & -0.0569 & -0.00343 & $0.518^{* *}$ & -0.422 & $-0.494 *$ & 0.196 & -0.550 \\
\hline votewithUSA $_{j \mathrm{jt}}$ & $-0.598 * * *$ & $-0.992 * * *$ & -0.212 & -0.268 & $-0.681 * * *$ & 0.257 & 0.297 & 0.0668 & 0.433 \\
\hline votewithUSA_diff ${ }_{\mathrm{ijt}}$ & $-1.614^{* * *}$ & $-1.928 * * *$ & $-0.848^{* * *}$ & $-1.038 * * *$ & $-1.778 * * *$ & -0.0464 & -0.0576 & -0.414 & -1.298 \\
\hline votewithUSA_region $_{\text {it }}$ & $-1.042 * * *$ & 0.443 & $-0.683 * *$ & $-0.868 * * *$ & $-0.911 * * *$ & $-1.118 * * *$ & $*-1.222 * * *$ & $-1.026^{*}$ & 1.153 \\
\hline votewithUSA_region $_{\mathrm{jt}}$ & -0.250 & 0.400 & $0.544 * *$ & 0.338 & -0.266 & $0.747 * * *$ & $0.539 * *$ & $1.304^{* * *}$ & -1.120 \\
\hline Militarization $_{\text {it }}$ & -3.511 & -14.19 & -3.293 & -1.688 & -4.286 & 1.149 & 4.512 & -12.62 & -24.92 \\
\hline Militarization $_{\mathrm{jt}}$ & $14.86 * * *$ & 1.721 & $15.09 * * *$ & $13.69 * * *$ & $15.05^{* * *}$ & $14.37^{* * *}$ & $12.56^{* * *}$ & $13.88^{* *}$ & 1.477 \\
\hline Pact $_{\mathrm{ijt}}$ & $0.246 * * *$ & $0.355^{* * *}$ & $0.368 * * *$ & $0.319 * * *$ & $0.382 * * *$ & -0.0302 & -0.177 & $0.526 * * *$ & 0.0665 \\
\hline Conflict $_{j \mathrm{t}}$ & $0.0730 *$ & 0.0169 & $0.138^{* * *}$ & $0.114^{* * *}$ & $0.0924^{* *}$ & -0.0216 & -0.0781 & $0.179 * *$ & 0.00911 \\
\hline Embargo $_{j t}$ & -0.129 & -0.0540 & -0.165 & -0.183 & - & - & - & - & -0.358 \\
\hline$\hat{z}$ & - & - & - & - & -0.124 & 0.0668 & $0.190 * * *$ & - & - \\
\hline Inverse Mills Ratio & - & - & - & - & $53.41 * *$ & $-0.123 * * *$ & ${ }^{*}-0.00157$ & - & - \\
\hline Year Dummies & Yes*** & Yes $* * *$ & Yes $* * *$ & Yes $* * *$ & Yes $* * *$ & Yes $* * *$ & Yes*** & Yes*** & Yes** \\
\hline Country Dummies & Yes*** & No & - & Yes*** & Yes*** & - & Yes*** & - & - \\
\hline Country-Decade Dum & No & Yes $* * *$ & No & No & No & No & No & No & No \\
\hline Observations & 12,700 & 12,700 & 12,700 & 12,700 & 12,699 & 12,699 & 12,699 & 7,639 & 5,061 \\
\hline $\mathrm{R}^{\wedge} 2$ & 0.400 & 0.470 & 0.169 & 0.382 & 0.400 & 0.171 & 0.386 & 0.068 & 0.021 \\
\hline
\end{tabular}

Notes: ${ }^{* * *} p<0.01,{ }^{* *} p<0.05, * p<0.1$; 
We identify differences between the political determinants of trade in arms and trade in goods by estimating in identical models the probability to export arms and goods. The sample is reduced to ensure that the estimations are comparable as described in section V.III.V. When comparing the results for the probability to transfer arms with those for trade in goods in Table V.IV.3, we find both political dimensions to affect both types of trade, but to differ in the extent and sometimes in the direction of the effect. For the trade volume of arms (Table V.IV.4), exporting countries tend to export more arms when they are more oriented towards the USA, but less so for the volume of other goods. Political differences between exporter and importer appear to affect the volume in the same direction, but much stronger for arms.

Table V.IV.3: Probability to Trade - Arms vs. Goods (1962-2007)

\begin{tabular}{|c|c|c|c|c|c|c|c|c|}
\hline & $\begin{array}{c}(1) \\
\text { Probit }\end{array}$ & $\begin{array}{c}(2) \\
\text { Probit }\end{array}$ & $\begin{array}{c}(3) \\
\text { Probit }\end{array}$ & $\begin{array}{c}(4) \\
\text { Probit }\end{array}$ & $\begin{array}{c}(5) \\
\text { Probit RE }\end{array}$ & $\begin{array}{c}\text { (6) } \\
\text { Probit RE }\end{array}$ & $\begin{array}{c}\qquad(7) \\
\text { Probit RE }\end{array}$ & $\begin{array}{c}\text { (8) } \\
\text { Probit RE }\end{array}$ \\
\hline & Arms & Goods & Arms & Goods & Arms & Goods & Arms & Goods \\
\hline & $0.0135^{* * *}$ & $0.0074 * * *$ & -0.00690 & $0.00740 * * *$ & * 0.0227 & $0.0203 * * *$ & $0.0149 * * *$ & $0.0075^{* * *}$ \\
\hline Polity $_{j \mathrm{j}}$ & $-0.0159 * * *$ & $0.0042 * * *$ & $-0.0184 * * *$ & * -0.00185 & $-0.0112 * * *$ & ${ }^{k} 0.0092 * * *$ & $-0.0131 * * *$ & $0.0044 * * *$ \\
\hline Polity_diff & $-0.0140 * * *$ & $-0.0106 * * *$ & $-0.0131 * * *$ & * $-0.0129 * * *$ & $*-0.0065 * * *$ & ${ }^{k}-0.0027$ & $-0.0099 * * *$ & $-0.0050 * * *$ \\
\hline Polity_region $_{\text {it }}$ & 0.00456 & 0.000709 & 0.00943 & -0.00518 & $0.0178 * * *$ & $0.0148 * * *$ & 0.00606 & $-0.00658 * *$ \\
\hline Polity_region $_{\mathrm{jt}}$ & $-0.0126 * *$ & $-0.00523^{* *}$ & 0788 & $-0.0108 * *$ & $-0.0173 * * *$ & $7 * * *$ & $-0.0129 * *$ & -0.00365 \\
\hline votewithUSA $_{\text {it }}$ & $0.602 * * *$ & $-0.186 * * *$ & $0.526 * *$ & $0.380 * * *$ & $1.969 * * *$ & $0.224^{* * *}$ & $0.546 * * *$ & $-0.550 * * *$ \\
\hline $\operatorname{thUSA}_{\mathrm{jt}}$ & -0.109 & $0.303^{* * *}$ & $-0.630 * * *$ & -0.00535 & $-0.215^{*}$ & $0.302 * * *$ & -0.0748 & $0.270 * * *$ \\
\hline votewithUSA_diff ${ }_{\mathrm{ijt}}$ & $-0.969 * * *$ & $-1.126 * * *$ & $-1.205^{* * *}$ & $-1.522 * * *$ & $-0.941 * * *$ & $-0.154 * * *$ & $-0.899 * * *$ & $-0.390 * * *$ \\
\hline A_region $_{\text {it }}$ & $0.653 * * *$ & -0.0189 & 0.467 & $-0.516 * * *$ & $1.245^{* * *}$ & $-0.645 * * *$ & $0.703 * * *$ & $-0.530 * * *$ \\
\hline votewithUSA_region $_{\mathrm{jt}}$ & $0.348 * *$ & 0.0342 & $0.551^{*}$ & 0.199 & -0.106 & $-0.316 * * *$ & $0.467 * *$ & $-0.370 * * *$ \\
\hline Year & & & Yes*** & Yes*** & Yes*** & Yes*** & & \\
\hline Count & Yes $* * *$ & Yes $* * *$ & & & No & No & Yes*** & Yes*** \\
\hline Country-Decade Dum. & No & No & Yes*** & Yes*** & No & No & No & No \\
\hline & 340,39 & 370,43 & & 347,400 & 373,290 & 373,290 & 373,290 & 373,290 \\
\hline Pseudo $R^{\wedge} 2$ & 0.415 & 0.512 & 0.398 & 0.529 & - & - & - & - \\
\hline
\end{tabular}

Notes: ${ }^{* *} p<0.01, * * p<0.05, * p<0.1$; 
Table V.IV.4: Trade Volume - Arms vs. Goods (1962-2007)

\begin{tabular}{|c|c|c|c|c|c|c|c|c|}
\hline & (1) & $(2)$ & (3) & (4) & (5) & (6) & (7) & (8) \\
\hline & OLS & OLS & OLS & OLS & $\mathrm{FE}$ & $\mathrm{FE}$ & RE & RE \\
\hline & Arms & Goods & Arms & Goods & Arms & Goods & Arms & Goods \\
\hline Polity $_{i t}$ & 0.00972 & $0.0122 * * *$ & 0.000451 & 0.00209 & 0.0301 & $0.00301 * *$ & 0.0122 & $0.00288 * *$ \\
\hline Polity $_{j \mathrm{t}}$ & $-0.0202 * * *$ & $0.00189 *$ & -0.0122 & $-0.0054 * * *$ & 0.00154 & $-0.0049 * * *$ & -0.00601 & $-0.0048 * * *$ \\
\hline Polity_diff ${ }_{i j t}$ & $-0.0145^{* * *}$ & $-0.0071 * * *$ & $-0.0139 * *$ & $-0.0059 * * *$ & 0.00236 & $-0.0029 * * *$ & -0.00655 & $-0.0025 * * *$ \\
\hline Polity_region $_{i t}$ & 0.00441 & $0.0124^{* * *}$ & -0.0134 & -0.00125 & -0.0237 & 0.00512 & -0.0146 & 0.00451 \\
\hline Polity_region $_{\mathrm{jt}}$ & -0.00661 & -0.00407 & 0.0208 & $-0.0101 * *$ & 0.0163 & $-0.00625^{*}$ & 0.0164 & $-0.00667^{*}$ \\
\hline votewithUSA $_{i t}$ & $0.927^{* * *}$ & $-0.564 * * *$ & $1.817^{* * *}$ & -0.0604 & 0.754 & $0.274 * * *$ & $1.127^{* *}$ & $0.249 * * *$ \\
\hline votewithUSA $_{j t}$ & -0.181 & 0.0418 & $-1.008^{* *}$ & 0.0607 & -0.103 & $-0.170 * * *$ & -0.519 & $-0.147^{* *}$ \\
\hline votewithUSA_diff $_{\mathrm{ijt}}$ & $-1.323 * * *$ & $0.0976^{* * *}$ & $-1.761 * * *$ & 0.0394 & -0.325 & $-1.218^{* * *}$ & $-0.941 * * *$ & $-1.120 * * *$ \\
\hline votewithUSA_region $_{\text {it }}$ & $-0.853 * *$ & $-0.432 * * *$ & -0.0115 & $-0.433^{* *}$ & 0.551 & $-0.517^{* * *}$ & 0.255 & $-0.514 * * *$ \\
\hline votewithUSA_region $_{\mathrm{jt}}$ & $-0.741 * *$ & $0.692 * * *$ & -0.0213 & $0.329 * *$ & 0.271 & $0.287^{* *}$ & 0.136 & $0.292 * *$ \\
\hline Year Dummies & Yes*** & Yes*** & Yes*** & Yes*** & Yes*** & Yes*** & Yes*** & Yes $* * *$ \\
\hline Country Dummies & Yes*** & Yes*** & No & No & - & - & No & No \\
\hline Country-Decade Dum. & No & No & Yes*** & Yes*** & Yes*** & Yes*** & Yes*** & Yes*** \\
\hline Observations & 10,282 & 285,374 & 10,282 & 285,374 & 10,282 & 285,374 & 10,282 & 285,374 \\
\hline $\mathrm{R}^{\wedge} 2$ & 0.343 & 0.728 & 0.407 & 0.748 & 0.001 & 0.400 & 0.381 & 0.742 \\
\hline
\end{tabular}

Notes: ${ }^{* * *} p<0.01,{ }^{* *} p<0.05, * p<0.1$;

In order to validate the results obtained by estimating models (V.1) to (V.4), we carry out two robustness checks. The first check evaluates the possible endogeneity of the political factors. The second analyses whether the variation in the sample of countries affects the results.

In the previous regressions, it could be claimed that the measure for the second political dimension could yield an endogeneity bias. Indeed, voting behaviour could be altered by a potential recipient of arms in order to please or appease a potential supplier and make the deal more likely to happen. We investigate the existence of an endogeneity bias by using a three year lag of all variables measuring political orientation. The results are shown in Table E.10 in the Appendix. According to our estimates, the bias, if existing at all, is quantitatively very small and does not affect the main results. The second robustness check consists of excluding the USA from the sample. We do so, because the second political dimension, which is voting concordance with the USA in the UN General Assembly, is using the USA as a reference point. Hence, the value for the country-specific measure always takes the value of one for the USA and the bilateral measure always takes the value of the country specific measure for the partner country. The obtained 
estimation results (Table E.11 and Table E.12) are very similar to the results shown above, indicating that the findings are neither dominated by largest supplier of arms, nor by the lack of variation in political orientation of the largest exporter.

\section{V.V - Conclusion}

The results presented in this paper show the impact of a number of political factors on the probability and volume of arms transfers. We find that the level of democracy and the political orientation of the supplier and recipient countries as well as the differences between them, are important determinants of the probability to trade arms. While suppliers with higher levels of democracy have a higher probability to transfer arms, we find the opposite result for the recipient countries. In addition, when a country is more oriented towards the USA or when both countries tend to be close in both political dimensions, it is more likely that they agree to trade arms While similar political orientation maintains to have a positive effect on the likelihood of transfer after the end of the Cold War, the impact of the political environment in the region of the supplier and the recipient on both margins of trade is affected.

Countries that are involved in conflicts are more likely to import arms and countries with a UN embargo imposed against them are less likely to import arms. Our results are all robust to a number of sensitivity tests, including sample selection bias, the large amount of zero trade flows and reverse causality between UNGA voting behaviour and agreements to transfer arms. Moreover, the effects are not dominated by a single country in the sample. We find that political determinants also play an important role in explaining flows of goods between countries, but that the size of the impact is larger for transfers of arms.

Our results suggest that political closeness between a pair of countries is an important determinant of transfers in arms and that economic and strategic interests are not the only drivers of the transfers. Any attempt to regulate trade in major conventional weapons should therefore reflect the political interests involved. Mandatory UN embargoes appear to be successful in decreasing the probability of arms transfers but have no significant impact on the volume. 


\section{Bibliography}

Abel-Koch, J., 2013. Who uses intermediaries in international trade? Evidence from firm-level survey data. The World Economy, 36(8), pp.1041-1064.

Ahn, J., Khandelwal, A.K. \& Wei, S.-J., 2011. The role of intermediaries in facilitating trade. Journal of International Economics, 84(1), pp.73-85.

Akerman, A., 2014. A Theory on the Role of Wholesalers in International Trade based on Economies of Scope. Research Papers in Economics, 1.

Akerman, A. \& Seim, A.L., 2012. The Global Arms Trade Network 1950-2007. DEGIT Conference Papers, c017_055.

Anderson, J.E., 1979. A Theoretical Foundation for the Gravity Equation. American Economic Review, 69(1), pp.106-16.

Anderson, J.E. \& van Wincoop, E., 2003. Gravity with Gravitas: A Solution to the Border Puzzle. American Economic Review, 93(1), pp.170 - 192.

Auboin, M. \& Ruta, M., 2013. The Relationship Between Exchange Rates and International Trade: A Review of Economic Literature. World Trade Review, 12(3 (July)), pp.577-605.

Bahmani-Oskooee, M. \& Hegerty, S.W., 2007. Exchange rate volatility and trade flows: a review article. Journal of Economic Studies, 34(3), pp.211 - 255.

Baldwin, R., 2006. The Euro's Trade Effect. ECB Working Paper Series, 594.

Baldwin, R. \& Di Nino, V., 2006. Euros and Zeros: The Common Currency Effect on Trade in New Goods. NBER Working Paper Series, 12673.

Baltagi, B., 2008. Econometric Analysis of Panel Data 4th ed., John Wiley \& Sons, 2008.

Barkoulas, J.T., Baum, C.F. \& Caglayan, M., 2002. Exchange rate effects on the volume and variability of trade flows. Journal of International Money and Finance, 21(4), pp.481 - 496.

Bartram, S.M. \& Karolyi, G.A., 2006. The impact of the introduction of the Euro on foreign exchange rate risk exposures. Journal of Empirical Finance, 13(4-5), pp.519-549. 
Baum, C.F., Caglayan, M. \& Ozkan, N., 2004. Nonlinear effects of exchange rate volatility on the volume of bilateral exports. Journal of Applied Econometrics, 19(1), pp.1 - 23.

Berger, H. \& Nitsch, V., 2008. Zooming out: The trade effect of the euro in historical perspective. Journal of International Money and Finance, 27(8), pp.1244- 1260.

Bergin, P.R. \& Lin, C.-Y., 2012. The Dynamic Effects of Currency Union on Trade. Journal of International Economics, 87(2), pp.191-204.

Berman, N. \& Berthou, A., 2009. Financial Market Imperfections and the Impact of Exchange Rate Movements on Exports. Review of International Economics, 17(1), pp.103 - 120.

Berman, N., Martin, P. \& Mayer, T., 2012. How do Different Exporters React to Exchange Rate Changes? The Quarterly Journal of Economics, 127(1), pp.437 - 492.

Bernard, A.B. et al., 2003. Plants and Productivity in International Trade. American Economic Review, 93(4), pp.1268-1290.

Bernard, A.B., Grazzi, M. \& Tomasi, C., 2011. Intermediaries in International Trade: Direct versus indirect modes of export. NBER Working Paper Series, 17711.

Bernard, A.B. \& Jensen, J.B., 2004. Why Some Firms Export. The Review of Economics and Statistics, 86(2), pp.561-569.

Berthou, A. \& Fontagne, L., 2008. The Euro and the Intensive and Extensive Margins of Trade: Evidence from French Firm Level Data. CEPII Working Papers, 6.

Biglaiser, G., 1993. Middlemen as Experts. RAND Journal of Economics, 24(2), pp.212-223.

Blanton, S.L., 2000. Promoting Human Rights and Democracy in the Developing World: U.S. Rhetoric versus U.S. Arms Exports. American Journal of Political Science, 44(1).

Bodnár, K., 2009. Exchange rate exposure of Hungarian enterprises - results of a survey. MNB Occasional Papers, 80.

Boug, P. \& Fagereng, A., 2010. Exchange rate volatility and export performance: a cointegrated VAR approach. Applied Economics, 42(7), pp.851-864.

Brauer, J., 2007. Arms Industries, Arms Trade, and Developing Countries. In Handbook of Defense Economics. Elsevier, pp. 973-1015. 
Brauer, J., 2000. Potential and Actual Arms Production: Implications for the Arms Trade Debate. Defence and Peace Economics, 11(3), pp.461-480.

Brauer, J. \& Dunne, J.P., 2011. Arms Trade Offsets: What Do We Know? In Handbook on the Political Economy of War. University of the West of England, Department of Economics, pp. 243-265.

Broll, U. \& Eckwert, B., 1999. Exchange Rate Volatility and International Trade. Southern Economic Journal, 66(1), pp.178- 185.

Cadek, V., Rottova, H. \& Saxa, B., 2011. Hedging Behaviour of Czech Exporting Firms. Czech National Bank Working Paper Series, 14.

Campa, J.M., 2004. Exchange rates and trade: How important is hysteresis in trade? European Economic Review, 48(3), pp.527 - 548.

Canzoneri, M.B. \& Clark, P.B., 1984. The effects of exchange rate variability on output and employment. International Finance Discussion Papers, 240.

Carranza, L.J., Cayo, J.M. \& Galdon-Sanchez, J.E., 2003. Exchange rate volatility and economic performance in Peru: a firm level analysis. Emerging Markets Review, 4(4), pp.472-496.

Chit, M.M., Rizov, M. \& Willenbockel, D., 2010. Exchange Rate Volatility and Exports: New Empirical Evidence from the Emerging East Asian Economies. The World Economy, 33(2), pp.239 - 263.

Clark, P.B. et al., 2004. Exchange Rate Volatility and Trade Flows - Some New Evidence. International Monetary Fund Occasional Paper, No. 235.

Clark, P.B., 1973. Uncertainty, exchange risk, and the level of international trade. Economic Inquiry, 11(3), pp.302-313.

Comola, M., 2012. Democracies, Politics and Arms Supply: A Bilateral Trade Equation. Review of International Economics, 20(1), pp.150-163.

Ćorić, B. \& Pugh, G., 2010. The effects of exchange rate variability on international trade: a metaregression analysis. Applied Economics, 42(20), pp.2631 - 2644.

Côté, A., 1994. Exchange Rate Volatility and Trade: A Survey. EconWPA, 9406001.

Cotter, J. \& Bredin, D., 2011. Real and Nominal Foreign Exchange Volatility Effects on Exports - The Importance of Timing. Geary Institute (University College Dublin) Working Papers, 200619. 
Crozet, M., Koenig, P. \& Rebeyrol, V., 2009. Exporting to Insecure Markets: a Firm-Level Analysis. CEPR Discussion Papers, 2402.

Crozet, M., Lalanne, G. \& Poncet, S., 2013. Wholesalers in international trade. European Economic Review, 58, pp.1-17.

Cushman, D.O., 1986. Has exchange risk depressed international trade? The impact of thirdcountry exchange risk. Journal of International Money and Finance, 5(3), pp.361 - 379.

Cushman, D.O., 1983. The effects of real exchange rate risk on international trade. Journal of International Economics, 15(August), pp.45-63.

Dixit, A.K., 1989. Entry and Exit Decisions under Uncertainty. Journal of Political Economy, 97(3), pp. $620-38$.

Döhring, B., 2008. Hedging and invoicing strategies to reduce exchange rate exposure - a euro-area perspective. European Economy - Economic Papers, 299.

Eichengreen, B., 2007. The Real Exchange Rate and Economic Growth. Commission on Growth and Development Working Paper, 4(World Bank.).

Eicher, T.S. \& Henn, C., 2011. One Money, One Market: A Revised Benchmark. Review of International Economics, 19(3), pp.419- 435.

Etzel, D., Hauptmann, A. \& Schmerer, H.-J., 2013. Dissecting the German export miracle: Plant-level evidence. Economic Systems, 37(3), pp.387-403.

Fauceglia, D., Shingal, A. \& Wermelinger, M., 2012. "Natural hedging" of exchange rate risk: The role of imported input prices. MPRA Paper, 39438.

Feenstra, R.C., 2004. Advanced International Trade: Theory and Evidence., Princeton, New Jersey: Princeton University Press.

Felbermayr, G. \& Jung, B., 2011. Trade Intermediation and the Organization of Exporters. Review of International Economics, 19(4), pp.634-648.

Fielding, D. \& Shields, K., 2005. The Impact of Monetary Union on Macroeconomic Integration: Evidence from West Africa. Economica, 72(288), pp.683 - 704. 
Flam, H. \& Nordström, H., 2007. Explaining large euro effects on trade: the extensive margin and vertical specialization. Manuscript, Institute for International Economic Studies, Stockholm University.

Franke, G., 1991. Exchange rate volatility and international trading strategy. Journal of International Money and Finance, 10(2), pp.292 - 307.

Frankel, J., 2008. The Estimated Effects of the Euro on Trade: Why Are They Below Historical Effects of Monetary Unions Among Smaller Countries? NBER Working Papers, 14542.

Frankel, J. \& Rose, A.K., 2002. An Estimate Of The Effect Of Common Currencies On Trade And Income. The Quarterly Journal of Economics, 117(2), pp.437-466.

De Grauwe, P., 1988. Exchange Rate Variability and the Slowdown in Growth of International Trade. IMF Staff Papers, 35(1), pp.63 - 84.

Guillou, S., 2008. Exports and exchange rate : a firm-level investigation. Documents de travail de I'OFCE: 2008-02.

Hallet, M., 2008. The role of the euro in Sub-Saharan Africa and in the CFA franc zone. European Economy - Economic Papers, 347.

Helpman, E., Melitz, M. \& Rubinstein, Y., 2008. Estimating Trade Flows: Trading Partners and Trading Volumes. The Quarterly Journal of Economics, 123(2), pp.441-487.

Héricourt, J. \& Poncet, S., 2012. Exchange Rate Volatility, Financial Constraints and Trade: Empirical Evidence from Chinese Firms. CEPII Working Papers, 35.

Hondroyiannis, G. et al., 2008. Some Further Evidence on Exchange-Rate Volatility and Exports. Review of World Economics, 144(1), pp.151 - 180.

Hooper, P. \& Kohlhagen, S.W., 1978. The effect of exchange rate uncertainty on the prices and volume of international trade. Journal of International Economics, 8(4), pp.483 - 511.

Hutson, E. \& O'Driscoll, A., 2010. Firm-Level Exchange Rate Exposure in the Eurozone. International Business Review, 19(5).

Kamps, A., 2006. The euro as invoicing currency in international trade. Working Paper Series, 665.

Kandilov, I.T. \& Leblebicioglu, A., 2011. The impact of exchange rate volatility on plant-level investment: Evidence from Colombia. Journal of Development Economics, 94(2), pp.220 - 230. 
Kaufmann, D., Kraay, A. \& Mastruzzi, M., 2010. The Worldwide Governance Indicators: Methodology and Analytical Issues. World Bank Policy Research Working Paper, 5430.

Klein, M.W. \& Shambaugh, J.C., 2006. Fixed exchange rates and trade. Journal of International Economics, 70(2), pp.359-383.

Kurihara, Y., 2011. Introducing a Common Currency in Central Franc Zone: Is it Appropriate? Journal of Knowledge Management, Economics and Information Technology, 1(6).

Makin, J.H., 1978. Portfolio Theory and the Problem of Foreign Exchange Risk. Journal of Finance, $33(2)$, pp. $517-34$.

Masson, P.R., 2008. Currency Unions in Africa: Is the Trade Effect Substantial Enough to Justify their Formation? The World Economy, 31(4), pp.533 - 547.

Mayer, T. \& Zignago, S., 2011. Notes on CEPII's distances measures: The GeoDist database.

McCann, F., 2013. Indirect Exporters. Journal of Industry, Competition and Trade, 13(4), pp.519535.

McKenzie, M.D., 1999. The Impact of Exchange Rate Volatility on International Trade Flows. Journal of Economic Surveys, 13(1), pp.71- 106.

Melitz, M.J., 2003. The Impact of Trade on Intra-Industry Reallocations and Aggregate Industry Productivity. Econometrica, 71(6), pp.1695- 1725.

Mundlak, Y., 1978. On the Pooling of Time Series and Cross Section Data. Econometrica, 46(1), pp.69-85.

Ozturk, I., 2006. Exchange Rate Volatility and Trade: A Literature Survey. International Journal of Applied Econometrics and Quantitative Studies, 3(1).

Raddatz, C., 2011. Over the hedge : exchange rate volatility, commodity price correlations, and the structure of trade. World Bank Policy Research Working Paper Series, 5590.

Rauch, J.E., 1999. Networks versus markets in international trade. Journal of International Economics, 48(1), pp.7-35.

Rodrik, D., 2008. The Real Exchange Rate and Economic Growth. Brookings Papers on Economic Activity, Fall 2008, pp.365-439. 
Rose, A.K., 2000. One Money, One Market: Estimating the Effect of Common Currencies on Trade. Economic Policy, 15(30), pp.7-46.

Rose-Ackerman, S., 1999. Corruption and Government: Causes, Consequences, and Reform, Cambridge University Press.

Rubinstein, A. \& Wolinsky, A., 1987. Middlemen. The Quarterly Journal of Economics, 102(3), pp.581-93.

Sanderson, L., 2009. Exchange rates and export performance: evidence from micro-data. Reserve Bank of New Zealand Bulletin, pp.43- 52.

Santos Silva, J.M.C. \& Tenreyro, S., 2010. Currency Unions in Prospect and Retrospect. Annual Review of Economics, 2(1), pp.51- 74.

Sislin, J., 1994. Arms as Influence: The Determinants of Successful Influence. The Journal of Conflict Resolution, 38(4), pp.665-689.

Solakoglu, M.N., Solakoglu, E.G. \& Demirağ, T., 2008. Exchange rate volatility and exports: a firmlevel analysis. Applied Economics, 40(7), pp.921-929.

De Sousa, J., 2012. The currency union effect on trade is decreasing over time. Economics Letters, 117(3), pp.917-920.

De Sousa, J. \& Lochard, J., 2005. Do Currency Barriers Solve the Border Effect Puzzle? Evidence from the CFA Franc Zone. Review of World Economics, 141(3), pp.422 - 441.

De Sousa, J., Mayer, T. \& Zignago, S., 2012. Market access in global and regional trade. Regional Science and Urban Economics, 42(6), pp.1037 - 1052.

Spulber, D.F., 1999. Market Microstructure, Cambridge University Press.

Tinbergen, J., 1962a. Shaping the World Economy; Suggestions for an International Economic Policy, New York: Twentieth Century Fund.

Tinbergen, J., 1962b. Shaping the World Economy; Suggestions for an International Economic Policy, New York: Twentieth Century Fund.

Tsangarides, C.G., Ewenczyk, P. \& Hulej, M., 2006. Stylized Facts on Bilateral Trade and Currency Unions : Implications for Africa. IMF Working Paper, (WP/06/31). 
United Nations Department of Economic and Social Affairs, 2007. Future revision of the Classification by Broad Economic Categories (BEC),

Viaene, J.-M. \& de Vries, C.G., 1992. International trade and exchange rate volatility. European Economic Review, 36(6), pp.1311 - 1321.

Vicarelli, C. \& Pappalardo, C., 2012. Euro introduction and export behaviour of Italian firms. MPRA Paper, 43386.

Zerihun, S., 2012. A Firm's Choice Between Direct and Indirect Export Channel of Exports by: A Study of Manufacturing Firms in Sub Saharan African Economies. Available at SSRN 2167982.

Zhao, X. \& Kim, Y., 2009. Is the CFA Franc Zone an Optimum Currency Area? World Development, 37(12), pp.1877- 1886. 


\section{Appendix}

A - Exchange Rate Volatility and the Euro Effect 108

B - The CFA Franc Zone and the Euro 116

C - Exchange Rate Policy and Exports of Firms 118

D - Direct and Indirect Exports and the Role of Uncertainty 128

E - Political Determinants of International Arms Transfers $\quad 130$ 


\section{A Exchange Rate Volatility and the Euro Effect}

Figure A.1: Share of Total Exports by BEC Category, 1996-2010

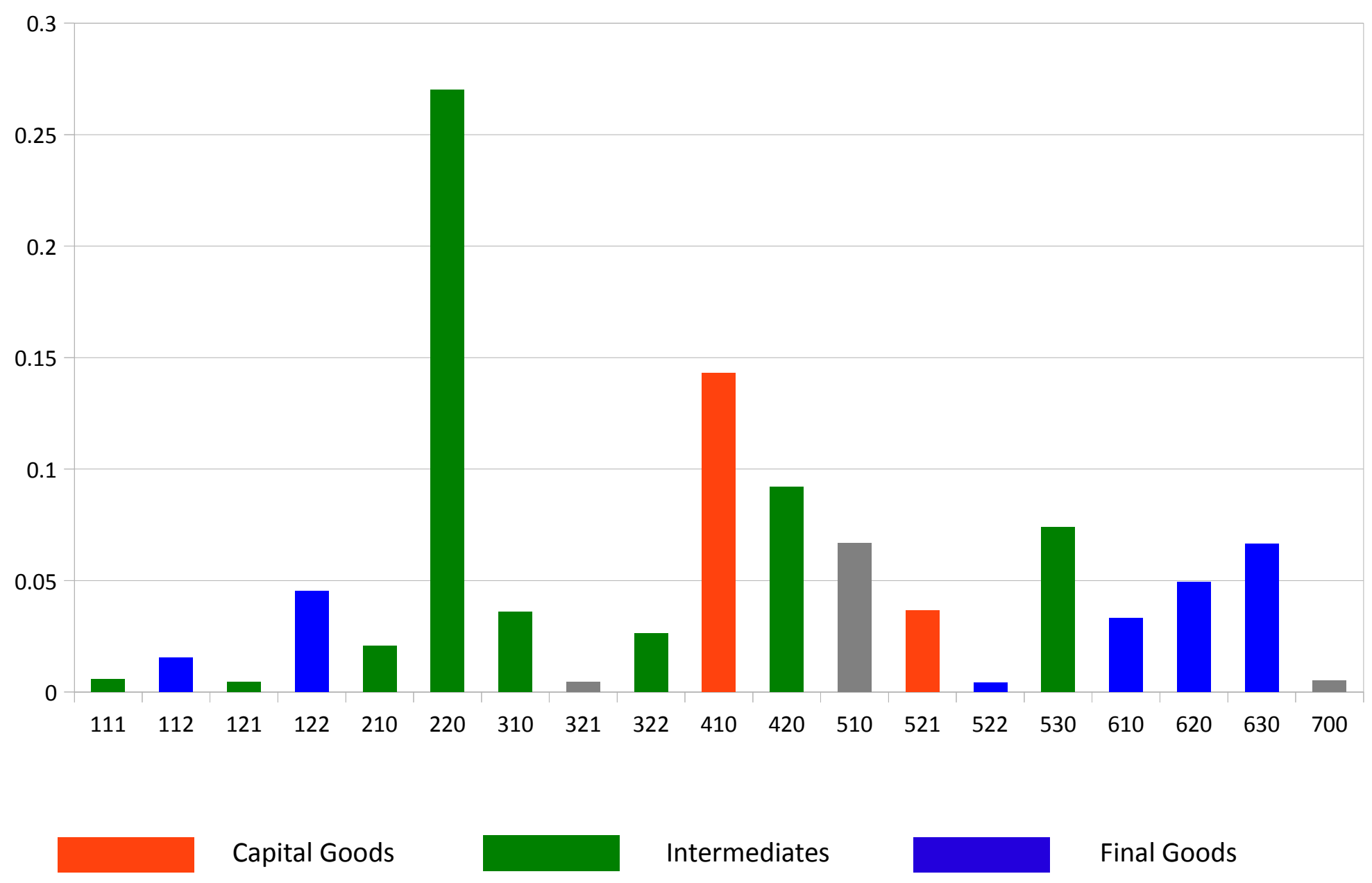


Figure A.2: Log of Total Trade Value

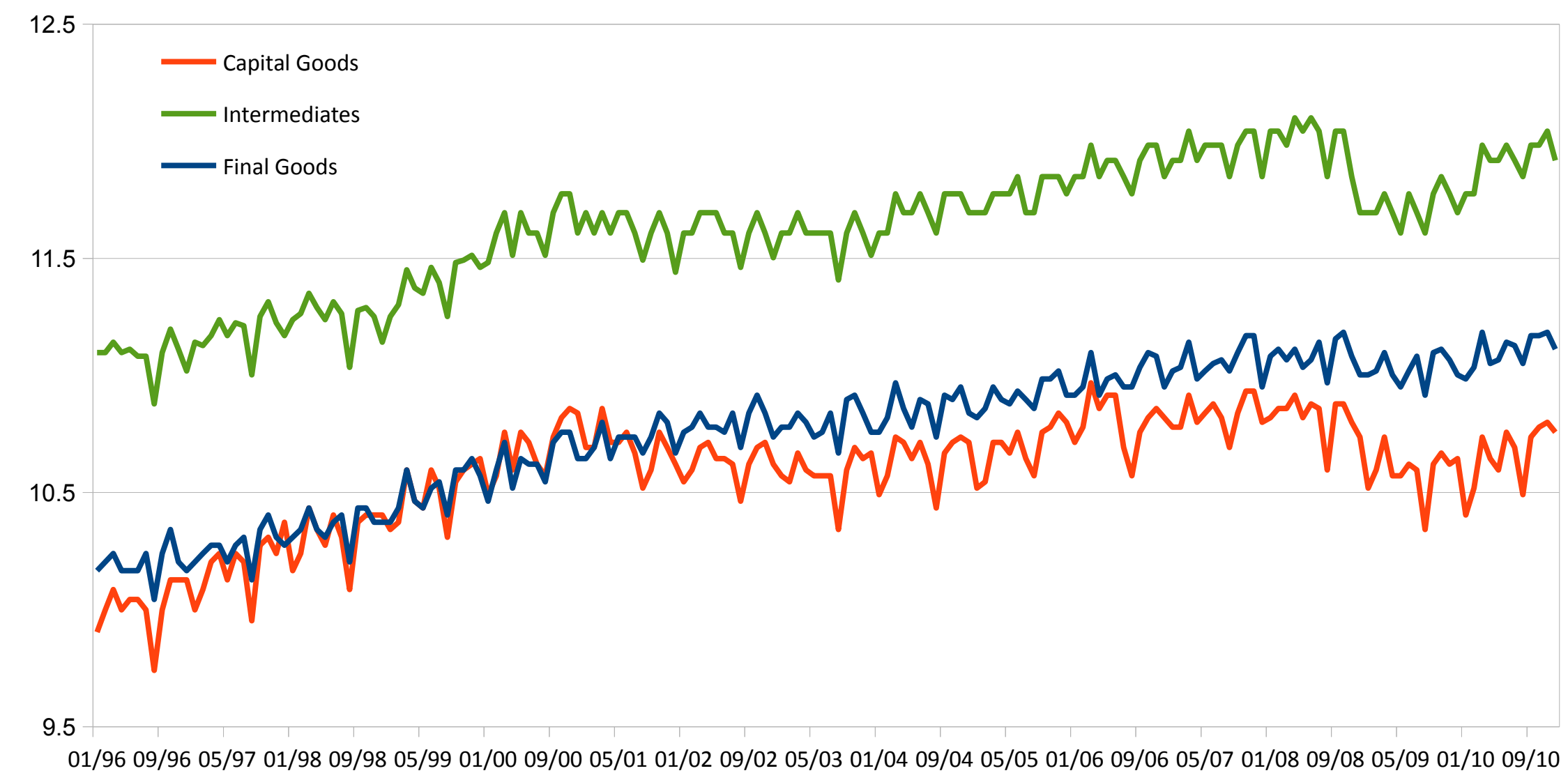


Table A.1: Coverage

\begin{tabular}{lllll}
\hline \multicolumn{5}{c}{ Countries } \\
\hline Austria & Estonia & Ireland & Netherlands & Slovenia \\
Belgium & Finland & Italy & Norway & Spain \\
Bulgaria & France & Japan & Poland & Sweden \\
Cyprus & Germany & Latvia & Portugal & Switzerland \\
China & Greece & Lithuania & Romania & Turkey \\
Czech Republic & Hungary & Luxembourg & Russia & United Kingdom \\
Denmark & India & Malta & Slovakia & USA \\
\hline
\end{tabular}

Non-EU members in italic letters.

Table A.2: BEC Categories

\begin{tabular}{cl}
\hline BEC Code & \\
\hline $111^{2}$ & Food and beverages / primary / mainly for industry \\
$112^{3}$ & Food and beverages / primary / mainly for household consumption \\
$121^{2}$ & Food and beverages / processed / mainly for industry \\
$122^{3}$ & Food and beverages / processed / mainly for household consumption \\
$210^{2}$ & Industrial supplies n.e.s. / primary \\
$220^{2}$ & Industrial supplies n.e.s. / processed \\
$310^{2}$ & Fuels and lubricants / primary \\
321 & Fuels and lubricants / processed / motor spirit \\
$322^{2}$ & Fuels and lubricants / processed / other \\
$410^{1}$ & Capital goods (except transport equipment) \\
$420^{2}$ & Capital goods / parts and accessories \\
510 & Transport equipment and parts and accessories thereof / passenger motor cars \\
$521^{1}$ & Transport equipment and parts and accessories thereof / other / industrial \\
$522^{3}$ & Transport equipment and parts and accessories thereof / other / non-industrial \\
$530^{2}$ & Transport equipment and parts and accessories thereof / parts and accessor. \\
$610^{3}$ & Consumer goods n.e.s. / durable \\
$620^{3}$ & Consumer goods n.e.s. / semi-durable \\
$630^{3}$ & Consumer goods n.e.s. / non-durable \\
700 & Goods not elsewhere specified
\end{tabular}

Superscript denotes whether the category is ${ }^{1}$ capital, ${ }^{2}$ intermediate or $^{3}$ consumption good. 
Table A.3: Variables

\begin{tabular}{|c|c|c|}
\hline Variable & Description & Source \\
\hline $\ln X_{\mathrm{ijkt}}$ & Log of exports of good $k$ from country $i$ to $j$ at time $t$ in US\$ & Eurostat \\
\hline $\ln Y_{i j t}$ & Log of the cross-product of nominal GDP of the countries $i$ and $j$ at time $t$ in US\$ & CEPII \\
\hline In Dist ${ }_{i j}$ & Log of distance between capitals of country $i$ and $\mathrm{j}$ in $\mathrm{km}$ & CEPII \\
\hline $\mathrm{EU}_{\mathrm{ijt}}$ & Dummy whether (1) or not $(0)$ the countries $i$ and $j$ are both members of the EU at time $t$ & CIA World Factbook 2011 \\
\hline Euro $_{\mathrm{ijt}}$ & Dummy whether ( 1 ) or not $(0)$ the countries $\mathrm{i}$ and $\mathrm{j}$ have the Euro as a common currency and time $\mathrm{t}$ & CIA World Factbook 2011 \\
\hline Border $_{i j}$ & Dummy whether ( 1 ) or not $(0)$ the countries $i$ and $j$ share a common border & CEPII \\
\hline Language $_{\mathrm{ij}}$ & Dummy whether (1) or not (0) the countries $i$ and $j$ share a common official language & CEPII \\
\hline Landlocked $_{\mathrm{ij}}$ & Dummy whether none (0), one of the countries $i$ and $j(1)$, or both (2) are landlocked & CIA World Factbook 2011 \\
\hline Island $_{\mathrm{ij}}$ & Dummy whether none (0), one of the countries $i$ and $j(1)$, or both (2) are on an island & CIA World Factbook 2011 \\
\hline Colony $_{\text {ij }}$ & Dummy whether $(1)$ or not $(0)$ the the countries $i$ and $j$ ever had a colonial link & CEPII \\
\hline Volatility $_{\mathrm{ijt}}$ & Bilateral volatility measure of the nominal exchange rate of the countries $i$ and $j$ at time $t$ & WM Company/Reuters \\
\hline In Exch. Rate ${ }_{i j t}$ & Log of the bilateral nominal exchange rate of the countries $i$ and $j$ at time $t$ & WM Company/Reuters \\
\hline Corruption $_{\mathrm{ijt}}$ & Cross-product of the corruption measure of countries $i$ and $j$ at time $t$ & International Country Risk Guide (ICRG) \\
\hline
\end{tabular}


Table A.4: Fixed Effects Regressions - Capital Goods

\begin{tabular}{|c|c|c|c|c|c|c|}
\hline & (1) & (2) & (3) & (4) & (5) & (6) \\
\hline \multirow{2}{*}{ In GDP } & $0.426 * * *$ & $0.504^{* * *}$ & $0.632 * * *$ & $0.575^{* * *}$ & $0.446 * * *$ & $0.457^{* * *}$ \\
\hline & $(0.0300)$ & (0.0313) & (0.0291) & (0.0207) & $(0.0382)$ & $(0.0272)$ \\
\hline \multirow{2}{*}{$\mathrm{EU}_{\mathrm{ijt}}$} & $0.119 * * *$ & $0.119 * * *$ & $0.138 * * *$ & $0.143 * * *$ & $0.113 * * *$ & \\
\hline & $(0.0160)$ & $(0.0160)$ & (0.0159) & $(0.0159)$ & $(0.0160)$ & \\
\hline \multirow{2}{*}{ Euro $_{i \mathrm{ijt}}$} & $-0.112 * * *$ & $-0.112 * * *$ & $-0.100 * * *$ & $-0.0923 * * *$ & & $-0.101 * * *$ \\
\hline & (0.0207) & $(0.0207)$ & $(0.0206)$ & $(0.0204)$ & & $(0.0207)$ \\
\hline \multirow{2}{*}{ Volatility $_{\mathrm{ijt}}$} & $-2.805^{* * *}$ & $-2.923 * * *$ & & & $-2.656 * * *$ & $-3.091 * * *$ \\
\hline & $(0.514)$ & $(0.513)$ & & & $(0.513)$ & $(0.512)$ \\
\hline \multirow{2}{*}{ L1.Volatility $_{\mathrm{ijt}}$} & $-3.485 * * *$ & $-3.520 * * *$ & & & $-3.286 * * *$ & $-3.879 * * *$ \\
\hline & $(0.612)$ & $(0.612)$ & & & (0.611) & $(0.610)$ \\
\hline \multirow{2}{*}{ L2.Volatility $_{\mathrm{ijt}}$} & $-3.528 * * *$ & $-3.459 * * *$ & & & $-3.370 * * *$ & $-3.965 * * *$ \\
\hline & (0.509) & $(0.508)$ & & & $(0.508)$ & $(0.505)$ \\
\hline \multirow{2}{*}{ L3.Volatility $_{\mathrm{ijt}}$} & $-1.468 * * *$ & $-1.455 * * *$ & & & $-1.323^{* *}$ & $-1.505 * * *$ \\
\hline & $(0.531)$ & $(0.531)$ & & & $(0.530)$ & $(0.531)$ \\
\hline \multirow{2}{*}{ In ExRate $_{\mathrm{ijt}}$} & $-0.301 * * *$ & & $-0.332 * * *$ & & $-0.302 * * *$ & $-0.300 * * *$ \\
\hline & $(0.0710)$ & & (0.0689) & & $(0.0710)$ & $(0.0710)$ \\
\hline \multirow{2}{*}{ In L1.ExRate ${ }_{\mathrm{ijt}}$} & 0.0499 & & 0.0849 & & 0.0499 & 0.0486 \\
\hline & $(0.0634)$ & & $(0.0612)$ & & $(0.0634)$ & $(0.0634)$ \\
\hline \multirow{2}{*}{ In L2. ExRate ${ }_{\mathrm{ijt}}$} & $0.271 * * *$ & & $0.241 * * *$ & & $0.272 * * *$ & $0.274 * * *$ \\
\hline & $(0.0734)$ & & $(0.0730)$ & & $(0.0734)$ & $(0.0734)$ \\
\hline \multirow{2}{*}{ In L3. ExRate ${ }_{\mathrm{ijt}}$} & 0.0825 & & $0.0933^{*}$ & & 0.0823 & 0.0809 \\
\hline & (0.0547) & & $(0.0544)$ & & $(0.0547)$ & (0.0547) \\
\hline Obs. & 283,895 & 283,895 & 287,010 & 291,256 & 283,895 & 283,895 \\
\hline $\mathbf{R}^{2}$ & 0.194 & 0.194 & 0.198 & 0.200 & 0.194 & 0.194 \\
\hline
\end{tabular}

\section{Table A.5: Fixed Effects Regressions - Intermediates}

\begin{tabular}{|c|c|c|c|c|c|c|}
\hline & (1) & (2) & (3) & (4) & (5) & (6) \\
\hline \multirow{2}{*}{ In GDP ${ }_{\mathrm{ijt}}$} & $0.506^{* * *}$ & $0.560 * * *$ & $0.473 * * *$ & $0.606 * * *$ & $0.493 * * *$ & $0.631 * * *$ \\
\hline & $(0.0325)$ & (0.0131) & (0.0159) & $(0.0104)$ & (0.0199) & (0.0174) \\
\hline \multirow{2}{*}{$E U_{i j t}$} & $0.0891 * * *$ & $0.0890 * * *$ & $0.101 * * *$ & $0.103 * * *$ & $0.0936 * * *$ & \\
\hline & $(0.00898)$ & $(0.00898)$ & $(0.00888)$ & (0.00887) & $(0.00897)$ & \\
\hline \multirow{2}{*}{ Euro $_{i j t}$} & $0.0939 * * *$ & $0.0939 * * *$ & $0.104 * * *$ & $0.100 * * *$ & & $0.101 * * *$ \\
\hline & $(0.0116)$ & $(0.0116)$ & $(0.0115)$ & $(0.0115)$ & & (0.0116) \\
\hline \multirow{2}{*}{ Volatility $_{\mathrm{ijt}}$} & $-2.435 * * *$ & $-2.450 * * *$ & & & $-2.559 * * *$ & $-2.659 * * *$ \\
\hline & $(0.285)$ & $(0.284)$ & & & $(0.284)$ & $(0.284)$ \\
\hline \multirow{2}{*}{ L1.Volatility $_{\mathrm{ijt}}$} & $-2.560 * * *$ & $-2.534 * * *$ & & & $-2.722 * * *$ & $-2.866 * * *$ \\
\hline & (0.339) & (0.338) & & & $(0.338)$ & $(0.337)$ \\
\hline \multirow{2}{*}{ L2.Volatility $_{\mathrm{ijt}}$} & $-1.865 * * *$ & $-1.875 * * *$ & & & $-1.993 * * *$ & $-2.203 * * *$ \\
\hline & $(0.282)$ & $(0.282)$ & & & $(0.282)$ & $(0.280)$ \\
\hline \multirow{2}{*}{ L3.Volatility $_{\mathrm{ijt}}$} & $-0.615^{* *}$ & $-0.613 * *$ & & & $-0.738^{* *}$ & $-0.648 * *$ \\
\hline & $(0.298)$ & (0.298) & & & (0.297) & $(0.298)$ \\
\hline \multirow{2}{*}{ In ExRate ${ }_{i j t}$} & $-0.0911 * *$ & & $-0.115^{* * *}$ & & $-0.0910 * *$ & $-0.0904^{* *}$ \\
\hline & $(0.0394)$ & & $(0.0383)$ & & $(0.0394)$ & $(0.0394)$ \\
\hline \multirow{2}{*}{ In L1.ExRate ${ }_{\mathrm{ijt}}$} & $0.0820 * *$ & & $0.0892 * * *$ & & $0.0820 * *$ & $0.0809 * *$ \\
\hline & $(0.0349)$ & & $(0.0337)$ & & (0.0349) & (0.0349) \\
\hline \multirow{2}{*}{ In L2.ExRate ${ }_{\mathrm{ijt}}$} & -0.0136 & & -0.0217 & & -0.0139 & -0.0122 \\
\hline & (0.0409) & & $(0.0407)$ & & (0.0409) & (0.0409) \\
\hline \multirow{2}{*}{ In L3.ExRate ${ }_{\mathrm{ijt}}$} & 0.0191 & & 0.0192 & & 0.0195 & 0.0185 \\
\hline & $(0.0301)$ & & (0.0299) & & $(0.0301)$ & $(0.0301)$ \\
\hline Obs. & $1,045,992$ & $1,045,992$ & $1,057,399$ & $1,073,052$ & $1,045,992$ & $1,045,992$ \\
\hline $\mathbf{R}^{2}$ & 0.113 & 0.113 & 0.116 & 0.119 & 0.113 & 0.113 \\
\hline
\end{tabular}


Table A.6: Fixed Effects Regressions - Final Goods

\begin{tabular}{|c|c|c|c|c|c|c|}
\hline & (1) & (2) & (3) & (4) & (5) & (6) \\
\hline \multirow{2}{*}{ In GDP $P_{\mathrm{ijt}}$} & $0.417^{* * *}$ & $0.352^{* * *}$ & $0.639 * * *$ & $0.538^{* * *}$ & $0.439 * * *$ & $0.456^{* * *}$ \\
\hline & $(0.0127)$ & $(0.0140)$ & (0.0134) & $(0.0132)$ & (0.0109) & (0.0128) \\
\hline \multirow{2}{*}{$\mathrm{EU}_{\mathrm{ijt}}$} & $0.202 * * *$ & $0.202^{* * *}$ & $0.209 * * *$ & $0.209 * * *$ & $0.205^{* * *}$ & \\
\hline & $(0.00787)$ & (0.00787) & $(0.00778)$ & $(0.00780)$ & $(0.00785)$ & \\
\hline \multirow{2}{*}{ Euro $_{\mathrm{ijt}}$} & $0.0648 * * *$ & $0.0647 * * *$ & $0.0705^{* * *}$ & $0.0722 * * *$ & & $0.0813^{* * *}$ \\
\hline & (0.00999) & (0.00999) & $(0.00996)$ & $(0.00992)$ & & (0.00997) \\
\hline \multirow{2}{*}{ Volatility $_{\mathrm{ijt}}$} & $-2.426 * * *$ & $-2.492 * * *$ & & & $-2.502 * * *$ & $-2.896 * * *$ \\
\hline & $(0.234)$ & $(0.234)$ & & & $(0.234)$ & $(0.233)$ \\
\hline \multirow{2}{*}{ L1.Volatility $_{\mathrm{ijt}}$} & $-2.186 * * *$ & $-2.193 * * *$ & & & $-2.288 * * *$ & $-2.846 * * *$ \\
\hline & $(0.282)$ & $(0.282)$ & & & $(0.282)$ & $(0.281)$ \\
\hline \multirow{2}{*}{ L2.Volatility $_{\mathrm{ijt}}$} & $-1.438 * * *$ & $-1.420 * * *$ & & & $-1.518 * * *$ & $-2.189 * * *$ \\
\hline & $(0.235)$ & $(0.235)$ & & & $(0.235)$ & $(0.233)$ \\
\hline \multirow{2}{*}{ L3.Volatility $_{\mathrm{ijt}}$} & $-0.967 * * *$ & $-0.979 * * *$ & & & $-1.045 * * *$ & $-1.001 * * *$ \\
\hline & $(0.247)$ & $(0.247)$ & & & $(0.247)$ & $(0.247)$ \\
\hline \multirow{2}{*}{ In ExRate ${ }_{\mathrm{ijt}}$} & $-0.276 * * *$ & & $-0.291 * * *$ & & $-0.276 * * *$ & $-0.275 * * *$ \\
\hline & $(0.0347)$ & & $(0.0338)$ & & $(0.0347)$ & $(0.0347)$ \\
\hline \multirow{2}{*}{ In L1.ExRate ${ }_{\mathrm{ijt}}$} & $-0.0592 *$ & & $-0.0582 *$ & & $-0.0591^{*}$ & $-0.0615^{* *}$ \\
\hline & $(0.0311)$ & & $(0.0301)$ & & $(0.0311)$ & $(0.0311)$ \\
\hline \multirow{2}{*}{ In L2.ExRate ${ }_{\mathrm{ijt}}$} & $0.0667^{*}$ & & $0.0654^{*}$ & & $0.0665^{*}$ & $0.0713^{* *}$ \\
\hline & $(0.0360)$ & & (0.0359) & & $(0.0360)$ & $(0.0360)$ \\
\hline \multirow{2}{*}{ In L3.ExRate ${ }_{\mathrm{ijt}}$} & $-0.0589 * *$ & & $-0.0447^{*}$ & & $-0.0587^{* *}$ & $-0.0614^{* *}$ \\
\hline & $(0.0268)$ & & $(0.0267)$ & & $(0.0268)$ & $(0.0268)$ \\
\hline Obs. & 879,509 & 879,509 & 889,410 & 902,978 & 879,509 & 879,509 \\
\hline $\mathbf{R}^{2}$ & 0.167 & 0.166 & 0.170 & 0.171 & 0.167 & 0.166 \\
\hline
\end{tabular}


Table A.7: Beta Coefficients

\begin{tabular}{|c|c|c|c|c|c|c|c|c|c|c|c|c|}
\hline & \multicolumn{4}{|c|}{ Capital Goods } & \multicolumn{4}{|c|}{ Intermediates } & \multicolumn{4}{|c|}{ Final Goods } \\
\hline & $\mathrm{FE}$ & RE & $\mathrm{FE}$ & RE & FE & RE & $\mathrm{FE}$ & RE & $\mathrm{FE}$ & RE & $\mathrm{FE}$ & RE \\
\hline In GDP ${ }_{\mathrm{ijt}}$ & 0.364 & 0.385 & 0.198 & 0.380 & 0.492 & 0.368 & 0.476 & 0.372 & 0.346 & 0.374 & 0.195 & 0.374 \\
\hline In Distance $_{i j}$ & & -0.374 & & -0.374 & & -0.429 & & -0.434 & & -0.401 & & -0.403 \\
\hline $\mathrm{EU}_{\mathrm{ijt}}$ & 0.019 & 0.019 & 0.020 & 0.020 & 0.013 & 0.013 & 0.013 & 0.013 & 0.034 & 0.034 & 0.034 & 0.034 \\
\hline Euro $_{\mathrm{ijt}}$ & -0.013 & -0.012 & -0.008 & -0.009 & 0.010 & 0.009 & 0.008 & 0.007 & 0.008 & 0.008 & 0.009 & 0.008 \\
\hline Border $_{\mathrm{ij}}$ & & 0.062 & & 0.067 & & 0.106 & & 0.103 & & 0.088 & & 0.088 \\
\hline Language $_{\mathrm{ij}}$ & & 0.015 & & 0.016 & & 0.006 & & 0.005 & & 0.011 & & 0.012 \\
\hline Colony $_{\mathrm{ij}}$ & & 0.037 & & 0.040 & & 0.018 & & 0.017 & & 0.024 & & 0.024 \\
\hline Island $_{i}$ & & -0.107 & & -0.111 & & -0.078 & & -0.079 & & -0.039 & & -0.040 \\
\hline Landlocked $_{i}$ & & -0.352 & & -0.355 & & -0.322 & & -0.326 & & -0.119 & & -0.119 \\
\hline Volatility $_{\mathrm{ijt}}$ & -0.007 & -0.006 & -0.004 & -0.005 & -0.005 & -0.005 & -0.006 & -0.006 & -0.006 & -0.006 & -0.006 & -0.006 \\
\hline L1.Volatility $_{\mathrm{ijt}}$ & -0.008 & -0.008 & -0.005 & -0.007 & -0.005 & -0.005 & -0.006 & -0.007 & -0.006 & -0.006 & -0.005 & -0.005 \\
\hline L2.Volatility $_{\mathrm{ijt}}$ & -0.009 & -0.008 & -0.005 & -0.007 & -0.004 & -0.004 & -0.005 & -0.005 & -0.004 & -0.004 & -0.003 & -0.004 \\
\hline L3.Volatility $_{\mathrm{ijt}}$ & -0.004 & -0.003 & 0.000 & -0.002 & -0.001 & -0.001 & -0.002 & -0.003 & -0.003 & -0.003 & -0.002 & -0.002 \\
\hline In ExRate ${ }_{i j t}$ & -0.306 & -0.301 & -0.304 & -0.300 & -0.083 & -0.082 & -0.082 & -0.082 & -0.289 & -0.289 & -0.287 & -0.287 \\
\hline In L1.ExRate ${ }_{\mathrm{ijt}}$ & 0.051 & 0.059 & 0.051 & 0.058 & 0.074 & 0.074 & 0.075 & 0.075 & -0.062 & -0.062 & -0.063 & -0.063 \\
\hline In L2.ExRate ${ }_{\mathrm{ijt}}$ & 0.277 & 0.245 & 0.277 & 0.246 & -0.012 & -0.013 & -0.012 & -0.013 & 0.070 & 0.069 & 0.069 & 0.068 \\
\hline In L3.ExRate ${ }_{\mathrm{ijt}}$ & 0.085 & 0.077 & 0.082 & 0.075 & 0.017 & 0.018 & 0.017 & 0.017 & -0.062 & -0.062 & -0.064 & -0.063 \\
\hline Corruption $_{\mathrm{ijt}}$ & -0.021 & -0.020 & & & & & & & 0.001 & 0.002 & & \\
\hline Zhat & & & 0.028 & 0.015 & & & -0.007 & -0.009 & & & 0.007 & 0.004 \\
\hline IMR & & & 0.005 & 0.014 & & & 0.012 & 0.014 & & & 0.009 & 0.009 \\
\hline Obs. & 283,895 & 283,895 & 283,895 & 283,895 & $1,045,992$ & $1,045,992$ & $1,045,992$ & $1,045,992$ & 879,509 & 879,509 & 879,509 & 879,509 \\
\hline
\end{tabular}


Table A.8: Robustness Checks (RE Regressions as in Column (2) in Tables A.5, A.6 and A.7)

\begin{tabular}{|c|c|c|c|c|c|c|c|c|c|c|}
\hline & (1) & (2) & (3) & (4) & (5) & (6) & (7) & (8) & (9) & (10) \\
\hline & \multicolumn{3}{|c|}{ Sample 1999-2010 } & \multicolumn{3}{|c|}{ Without Big Four } & \multicolumn{4}{|c|}{ Adding Countries to Sample (Capital Goods) } \\
\hline & 1 & 2 & 3 & 1 & 2 & 3 & 1 & 1 & 1 & 1 \\
\hline \multirow{2}{*}{ In GDP } & $0.474^{*}$ & $0.529^{*}$ & $0.477^{*}$ & $0.448^{*}$ & 0.489 & $0.390 * * *$ & $0.477^{*}$ & $0.461^{* * *}$ & $0.460 * * *$ & $0.459^{*}$ \\
\hline & $(0.0134)$ & (0.0109) & $(0.00954)$ & $(0.0112)$ & $(0.00964)$ & $(0.00840)$ & $(0.0121)$ & (0.0119) & (0.0119) & (0.0129) \\
\hline \multirow{2}{*}{ In Distance } & $-1.201 * * *$ & $-1.549 * * *$ & $-1.265^{* * *}$ & $-1.266 * * *$ & $-1.575^{* * *}$ & $-1.315^{* * *}$ & $-1.246 * * *$ & $-1.222^{* * *}$ & $-1.217^{* * *}$ & $-1.297 * * *$ \\
\hline & $(0.0554)$ & (0.0499) & $(0.0437)$ & $(0.0482)$ & $(0.0473)$ & $(0.0415)$ & $(0.0488)$ & (0.0498) & $(0.0502)$ & $(0.0524)$ \\
\hline \multirow{2}{*}{$\mathrm{EU}_{\mathrm{ijt}}$} & $0.130 * * *$ & $0.0958 * * *$ & $0.204 * * *$ & $0.0564 * * *$ & $0.0775^{* * *}$ & $0.136 * * *$ & $0.0893 * * *$ & $0.119 * * *$ & $0.127 * * *$ & $0.129 * * *$ \\
\hline & (0.0162) & $(0.00902)$ & $(0.00797)$ & $(0.0165)$ & $(0.00980)$ & $(0.00846)$ & $(0.0165)$ & $(0.0163)$ & (0.0161) & $(0.0163)$ \\
\hline \multirow{2}{*}{ Euro $_{\text {ijt }}$} & $-0.0761 * * *$ & $0.134^{* * *}$ & $0.107^{* * *}$ & $-0.103 * * *$ & $0.116 * * *$ & $0.0680 * * *$ & $-0.104 * * *$ & $-0.103 * * *$ & $-0.105 * * *$ & $-0.0841 * * *$ \\
\hline & (0.0244) & $(0.0140)$ & $(0.0120)$ & $(0.0211)$ & (0.0127) & (0.0108) & $(0.0211)$ & (0.0209) & $(0.0206)$ & $(0.0208)$ \\
\hline \multirow{2}{*}{ Border } & $0.601^{* * *}$ & $1.153 * * *$ & $0.860 * * *$ & $0.539 * * *$ & $1.255^{* * *}$ & $0.816 * * *$ & $0.501^{* * *}$ & $0.581^{* * *}$ & $0.603 * * *$ & $0.492 * * *$ \\
\hline & (0.0998) & $(0.0897)$ & $(0.0790)$ & $(0.0885)$ & $(0.0869)$ & $(0.0766)$ & $(0.0896)$ & $(0.0888)$ & $(0.0900)$ & $(0.0946)$ \\
\hline \multirow{2}{*}{ Language } & $0.193^{*}$ & 0.103 & $0.152^{*}$ & $0.304^{* * *}$ & 0.00207 & $0.179^{* *}$ & $0.298 * * *$ & $0.249 * *$ & $0.213^{* *}$ & $0.322 * * *$ \\
\hline & (0.115) & (0.104) & $(0.0906)$ & (0.105) & (0.104) & $(0.0908)$ & (0.101) & (0.102) & (0.104) & (0.108) \\
\hline \multirow{2}{*}{ Colony } & $0.548 * * *$ & $0.290 * * *$ & $0.338 * * *$ & 0.1 & $0.247^{* *}$ & 0.1. & $0.363^{* * *}$ & $0.543 * * *$ & $0.533 * * *$ & $0.819 * * *$ \\
\hline & (0.121) & (0.109) & (0.0959) & (0.122) & (0.120) & (0.106) & (0.113) & $(0$. & (0. & (0. \\
\hline \multirow{2}{*}{ Island } & $-0.815^{* * *}$ & $-0.578 * * *$ & -0.156 & 0.1 & 0.104 & $1.210 * * *$ & $-0.912 * * *$ & $-1.034 * * *$ & $-1.027^{* * *}$ & $-1.293^{* * *}$ \\
\hline & (0.199) & (0.172) & (0.152) & $(0.1$ & (0.167) & (0. & (0.184) & $(0.18$ & (0.186) & \\
\hline \multirow{2}{*}{ Landlocked } & $-1.510 * * *$ & $-2.275 * * *$ & $-1.116 * * *$ & $-1.247 * * *$ & $-1.575^{* * *}$ & $0.872 * * *$ & $-2.123 * * *$ & $-1.721 * * *$ & $-1.655^{* * *}$ & $-1.358 * * *$ \\
\hline & $(0.264)$ & (0.193) & (0.169) & (0.247) & (0.191) & $(0.166)$ & $(0.248)$ & (0.237) & (0.235) & \\
\hline \multirow{2}{*}{ Volatility $_{\mathrm{ijt}}$} & -0.0637 & $-1.349 * * *$ & $-1.162 * * *$ & -0.236 & $-1.024^{* *}$ & $-0.968 * * *$ & -0.250 & -0 . & -0.329 & -0.154 \\
\hline & $(0.764)$ & (0.424) & (0.341) & (0.769) & $(0.455)$ & (0.355) & $(0.776)$ & (0. & $(0.731)$ & $(0.748)$ \\
\hline \multirow{2}{*}{ L1.Volatility $\}_{j t}$} & -0.699 & $1.202 * *$ & -0.00509 & -0.5 & $1.176^{* *}$ & -0.277 & -0.561 & -1.5 & $-1.709 *$ & $-1.744 *$ \\
\hline & (0.985) & (0.550) & $(0.4$ & $(0.9$ & (0.596) & $(0.4$ & $(1.0$ & (0. & (0.959) & (0.987) \\
\hline \multirow{2}{*}{ L2.Volatility $\}_{j t}$} & $2.008^{* *}$ & 0.0105 & $1.635^{* * *}$ & 1.62 & -0.682 & $1.761^{* * *}$ & $1.814^{*}$ & 1.4 & 1.373 & 1.5 \\
\hline & (1.007) & $(0.560)$ & (0.454) & (1.040) & $(0.6$ & & (1.049) & $(0.9$ & (0.983) & (1. \\
\hline \multirow{2}{*}{ L3.Volatility $\}_{j \mathrm{t}}$} & -0.547 & 0.153 & -0.225 & -0.480 & $0.970^{* *}$ & 0.436 & -0.518 & -0.8 & -0.550 & -0.555 \\
\hline & $(0.753)$ & $(0.415)$ & (0.339) & $(0.795)$ & (0.4 & & $(0 . \varepsilon$ & (0. & (0. & (0. \\
\hline \multirow{2}{*}{ In ExRate ${ }_{i j t}$} & 0.878 & -0.408 & -0.195 & 0.363 & -0.524 & -0.0683 & 0.930 & 0.2 & 0.155 & -0.0256 \\
\hline & (0.582) & (0.323) & $(0.286)$ & (0.655) & $(0.386)$ & & $(0.6$ & & (0. & (0. \\
\hline \multirow{2}{*}{ In L1.ExRate } & $-3.464 * * *$ & 0.645 & -0.183 & -2.301 & 0.699 & -0.325 & $-2.837^{* *}$ & $-1.863^{*}$ & -1.632 & -1.437 \\
\hline & $(1.2$ & (0.694) & $(0.6$ & $(1.4$ & & & & & & \\
\hline \multirow{2}{*}{ In L2.ExRate } & $3.299 * * *$ & 0.00908 & 0.838 & 1.647 & -0.133 & 0.5 & 1.4 & 1.2 & 1.300 & 1.5 \\
\hline & $(1.17)$ & & & $(1.4$ & & & (1. & & & \\
\hline In L3.ExRa & $-0.831 *$ & -0.256 & $-0.802 * * *$ & 0.37 & 0.0121 & -0.4 & 0.5 & 0.2 & 0.0 & -0 \\
\hline & $(0.4$ & & 10.2 & $(0.640)$ & & & & & & \\
\hline C & $-0.00826^{* *}$ & 0.00143 & 0.00143 & 0.00280 & $0.00737 * * *$ & $0.0115 * * *$ & 0.00230 & -0.00394 & $-0.00577^{*}$ & $-0.0112^{* * *}$ \\
\hline & $(0.00332)$ & $(0.00184)$ & (0.00164 & $(0.00345)$ & $(0.00202)$ & (0.0017 & $(0.00349)$ & $(0.00325)$ & $(0.00316)$ & $(0.00311$ \\
\hline Year > 1998 & yes & yes & yes & - & - & - & - & - & - & - \\
\hline USA & yes & yes & yes & - & - & - & yes & yes & yes & yes \\
\hline Russia & yes & yes & yes & - & 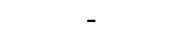 & - & - & yes & yes & yes \\
\hline Japan & yes & yes & yes & - & - & - & - & - & yes & yes \\
\hline China & yes & yes & yes & - & $\begin{array}{l}- \\
-\end{array}$ & - & - & - & - & yes \\
\hline Turkey & yes & yes & yes & yes & $r=0$ & yes & yes & yes & yes & - \\
\hline Obs. & 258,383 & 950,750 & 800,811 & 226,992 & 837,354 & 702,413 & 242,764 & 256,432 & 270,343 & 270,092 \\
\hline$R^{2}$ & 0 . & 0 & 0 & 0.719 & 0 & 0.704 & 0 & 0.709 & 0.705 & 0.708 \\
\hline RMSE & 1.186 & 1.254 & 1.026 & 1.112 & 1.249 & 0.999 & 1.148 & 1.162 & 1.166 & 1.183 \\
\hline
\end{tabular}

Standard errors in parentheses; ignificance levels: * $10 \% * * 5 \% * * * 1 \%$

Sector 1, 2 and 3 denote capital, intermediate and final goods, respectively. 
B The CFA Franc Zone and the Euro

Table B.1: Countries

\begin{tabular}{|c|c|c|c|}
\hline \multicolumn{4}{|c|}{ Countries } \\
\hline Albania & Egypt & Libyan Arab Jamahiriya & Rwanda \\
\hline Algeria & Eritrea & Lithuania & Saudi Arabia \\
\hline Argentina & Estonia & Luxembourg & Senegal \\
\hline Armenia & Ethiopia & Macao & Sierra Leone \\
\hline Australia & Fiji & Macedonia & Singapore \\
\hline Austria & Finland & Madagascar & Slovakia \\
\hline Azerbaijan & France & Malawi & Slovenia \\
\hline Bangladesh & Gabon & Malaysia & South Africa \\
\hline Belarus & Gambia & Mali & Spain \\
\hline Belgium & Georgia & Malta & Sri Lanka \\
\hline Benin & Germany & Mauritania & Sudan \\
\hline Bolivia & Ghana & Mexico & Suriname \\
\hline Botswana & Greece & Morocco & Swaziland \\
\hline Brazil & Guinea & Mozambique & Sweden \\
\hline Bulgaria & Guinea-Bissau & Namibia & Switzerland \\
\hline Burkina Faso & Haiti & Nepal & Syrian Arab Republic \\
\hline Burundi & Hong Kong & Netherlands & Thailand \\
\hline Cambodia & Hungary & New Zealand & Togo \\
\hline Cameroon & Iceland & Niger & Tunisia \\
\hline Canada & India & Nigeria & Turkey \\
\hline Central African Republic & Indonesia & Norway & Uganda \\
\hline Chile & Iran & Pakistan & Ukraine \\
\hline China & Iraq & Papua New Guinea & United Arab Emirates \\
\hline Colombia & Ireland & Paraguay & United Kingdom \\
\hline Congo & Israel & Peru & United Republic of Tanzania \\
\hline Cyprus & Italy & Philippines & United States of America \\
\hline Czech Republic & Jamaica & Poland & Uruguay \\
\hline Côte d'Ivoire & Japan & Portugal & Venezuela \\
\hline Denmark & Jordan & Republic of Korea & Viet Nam \\
\hline Djibouti & Kenya & Republic of Moldova & Yemen \\
\hline Dominican Republic & Latvia & Romania & Zambia \\
\hline Ecuador & Lesotho & Russian Federation & Zimbabwe \\
\hline
\end{tabular}


Table B.2: Variables

\begin{tabular}{|c|c|c|}
\hline Variable & Description & Source \\
\hline In Exports ${ }_{\mathrm{ijkt}}$ & Log of nominal exports of from country $i$ to $j$ in year $t$ & UN Comtrade \\
\hline In GDP ${ }_{\mathrm{ijt}}$ & Log of the crossproduct of average nominal GDP of the countries $i$ and $j$ in year $t$ & Penn World Tables \\
\hline In Distance ${ }_{\mathrm{ij}}$ & Log of distance between capitals of country $i$ and $j$ in $\mathrm{km}$ & CEPII \\
\hline $\mathrm{CFAEZ}_{\mathrm{ijt}}$ & \multicolumn{2}{|c|}{ Dummy whether ( 1 ) or not $(0)$ exporter $\mathrm{i}$ is a CFA member and importer $\mathrm{j}$ is a Eurozone member in year $\mathrm{t}$ BCEAO / BEAC / Eurostat } \\
\hline EZCFA $_{\mathrm{ijt}}$ & \multicolumn{2}{|c|}{ Dummy whether (1) or not $(0)$ exporter $\mathrm{i}$ is a Eurozone member and importer $\mathrm{j}$ is a CFA member in year $\mathrm{t}$ BCEAO / BEAC / Eurostat } \\
\hline IntraCFA $_{\mathrm{ijt}}$ & Dummy whether (1) or not (0) exporter $\mathrm{i}$ and importer $\mathrm{j}$ are both CFA members in year $\mathrm{t}$ & BCEAO / BEAC/ Eurostat \\
\hline Border $_{i j}$ & Dummy whether $(1)$ or not $(0)$ country $i$ and $j$ share a common border & CEPII \\
\hline Language $_{\mathrm{ij}}$ & Dummy whether (1) or not $(0)$ a language is spoken by at least 9 percent of the population in $\mathrm{i}$ and $\mathrm{j}$ & CEPII \\
\hline Landlocked $_{\mathrm{ij}}$ & Dummy whether none (0), one of the countries $i$ and $j(1)$, or both (2) are landlocked & ClA's World Factbook 2011 \\
\hline Colony $_{\mathrm{ij}}$ & Dummy whether ( 1 ) or not ( 0 ) the countries $\mathrm{i}$ and $\mathrm{j}$ ever had a colonial link & CEPII \\
\hline RTA $_{\mathrm{ijt}}$ & Dummy whether ( 1 ) or not $(0)$ the countries $i$ and $j$ have signed a RTA in year $t$ & de Sousa (2012) \\
\hline $\mathrm{Cu}_{\mathrm{ijt}}$ & Dummy whether (1) or not $(0)$ the countries $i$ and $j$ have the same currency in year $t$ & de Sousa (2012) \\
\hline
\end{tabular}




\section{Exchange Rate Policy and Exports of Firms}

Table C.1: BEEPS Surveys

\begin{tabular}{lcc}
\hline & $(1)$ & $(2)$ \\
\hline & Freq. & Percent \\
\hline only in 2009 & 5,967 & 34.38 \\
only in 2007 & 1,789 & 10.31 \\
only in 2005 & 3,387 & 19.52 \\
only in 2002 & 2,232 & 12.86 \\
only in 2002, 05 & 1,334 & 7.69 \\
only in 2005, 09 & 1,917 & 11.05 \\
only in 2007, 09 & 11 & 0.06 \\
only in 2002, 05, 09 & 712 & 4.10 \\
Total & 17,354 & 100 \\
\hline
\end{tabular}

Table C.2: Number of Firms in Every Round of the Survey by Country

\begin{tabular}{|c|c|c|c|c|c|}
\hline & (1) & $(2)$ & (3) & (4) & (5) \\
\hline & 2002 & 2005 & 2007 & 2009 & Total \\
\hline Albania & 110 & 146 & 215 & 32 & 503 \\
\hline Belarus & 0 & 0 & 0 & 226 & 226 \\
\hline Georgia & 0 & 0 & 0 & 258 & 258 \\
\hline Ukraine & 381 & 453 & 0 & 604 & 1438 \\
\hline Uzbekistan & 0 & 0 & 0 & 361 & 361 \\
\hline Russia & 298 & 390 & 0 & 745 & 1433 \\
\hline Poland & 333 & 750 & 0 & 299 & 1382 \\
\hline Romania & 206 & 524 & 0 & 355 & 1085 \\
\hline Serbia & 82 & 165 & 0 & 361 & 608 \\
\hline Kazakhstan & 198 & 424 & 0 & 431 & 1053 \\
\hline Moldova & 0 & 0 & 0 & 350 & 350 \\
\hline Bosnia & 0 & 0 & 0 & 280 & 280 \\
\hline Azerbaijan & 0 & 0 & 0 & 355 & 355 \\
\hline FYROM & 0 & 0 & 0 & 311 & 311 \\
\hline Armenia & 0 & 0 & 0 & 278 & 278 \\
\hline Kyrgyz & 0 & 0 & 0 & 185 & 185 \\
\hline Estonia & 163 & 202 & 0 & 261 & 626 \\
\hline Czech Republic & 142 & 304 & 0 & 192 & 638 \\
\hline Hungary & 194 & 480 & 0 & 281 & 955 \\
\hline Latvia & 160 & 171 & 0 & 248 & 579 \\
\hline Lithuania & 178 & 180 & 0 & 247 & 605 \\
\hline Slovakia & 128 & 151 & 0 & 205 & 484 \\
\hline Slovenia & 182 & 200 & 0 & 270 & 652 \\
\hline Bulgaria & 194 & 214 & 980 & 238 & 1626 \\
\hline Croatia & 115 & 188 & 601 & 97 & 1001 \\
\hline Montenegro & 0 & 2 & 0 & 80 & 82 \\
\hline Total & 3,064 & 4,944 & 1,796 & 7,550 & 17,354 \\
\hline
\end{tabular}


Table C.3: Exporting Firms by Country

\begin{tabular}{lcccc}
\hline & $(1)$ & $(2)$ & $(3)$ & $(4)$ \\
\hline Country & Not Exporting & Exporting & Total & Share \\
\hline Albania & 364 & 139 & 503 & 0.28 \\
Armenia & 241 & 37 & 278 & 0.13 \\
Azerbaijan & 329 & 26 & 355 & 0.07 \\
Belarus & 170 & 56 & 226 & 0.25 \\
Bosnia & 176 & 104 & 280 & 0.37 \\
Bulgaria & 1,083 & 543 & 1,626 & 0.33 \\
Croatia & 570 & 431 & 1,001 & 0.43 \\
Czech Republic & 402 & 236 & 638 & 0.37 \\
Estonia & 399 & 227 & 626 & 0.36 \\
FYROM & 174 & 137 & 311 & 0.44 \\
Georgia & 225 & 33 & 258 & 0.13 \\
Hungary & 600 & 355 & 955 & 0.37 \\
Kazakhstan & 952 & 101 & 1,053 & 0.10 \\
Kyrgyz & 157 & 28 & 185 & 0.15 \\
Latvia & 409 & 170 & 579 & 0.29 \\
Lithuania & 388 & 217 & 605 & 0.36 \\
Moldova & 290 & 60 & 350 & 0.17 \\
Montenegro & 68 & 14 & 82 & 0.17 \\
Poland & 993 & 389 & 1,382 & 0.28 \\
Romania & 853 & 232 & 1,085 & 0.21 \\
Russia & 1,186 & 247 & 1,433 & 0.17 \\
Serbia & 356 & 252 & 608 & 0.41 \\
Slovakia & 289 & 195 & 484 & 0.40 \\
Slovenia & 289 & 363 & 652 & 0.56 \\
Ukraine & 1,118 & 320 & 1,438 & 0.22 \\
Uzbekistan & 320 & 41 & 361 & 0.11 \\
Total & 12,401 & 4,953 & 17,354 & 0.29 \\
\hline & & & & \\
\hline
\end{tabular}


Table C.4: Exporting Firms by Industry

\begin{tabular}{lccccc}
\hline & & $(1)$ & $(2)$ & $(3)$ & $(4)$ \\
\hline Industry & & Not Exporting & Exporting & Total & Share \\
\hline Other manufacturing & 2 & 667 & 496 & 1,163 & 0.43 \\
Food & 15 & 1,376 & 786 & 2,162 & 0.36 \\
Textiles & 17 & 97 & 139 & 236 & 0.59 \\
Garments & 18 & 551 & 391 & 942 & 0.42 \\
Chemicals & 24 & 120 & 131 & 251 & 0.52 \\
Plastics \& rubber & 25 & 83 & 88 & 171 & 0.51 \\
Non metallic mineral & 26 & 153 & 91 & 244 & 0.37 \\
Basic metals & 27 & 38 & 42 & 80 & 0.53 \\
Fabricated metal products & 28 & 508 & 416 & 924 & 0.45 \\
Machinery and equipment & 29 & 316 & 397 & 713 & 0.56 \\
Electronics & 31 & 83 & 93 & 176 & 0.53 \\
Construction & 45 & 1,588 & 181 & 1,769 & 0.10 \\
Other services & 50 & 1,308 & 273 & 1,581 & 0.17 \\
Wholesale & 51 & 1,480 & 507 & 1,987 & 0.26 \\
Retail & 52 & 2,608 & 257 & 2,865 & 0.09 \\
Hotel and restaurants & 55 & 646 & 117 & 763 & 0.15 \\
Transport & 60 & 595 & 432 & 1,027 & 0.42 \\
IT & 72 & 184 & 116 & 300 & 0.39 \\
Total & All & 12,401 & 4,953 & 17,354 & 0.29 \\
\hline
\end{tabular}


Figure C.1: Range of the Share of Exports to EU-27 by Country $(2002,2005$, 2007 and 2009)*

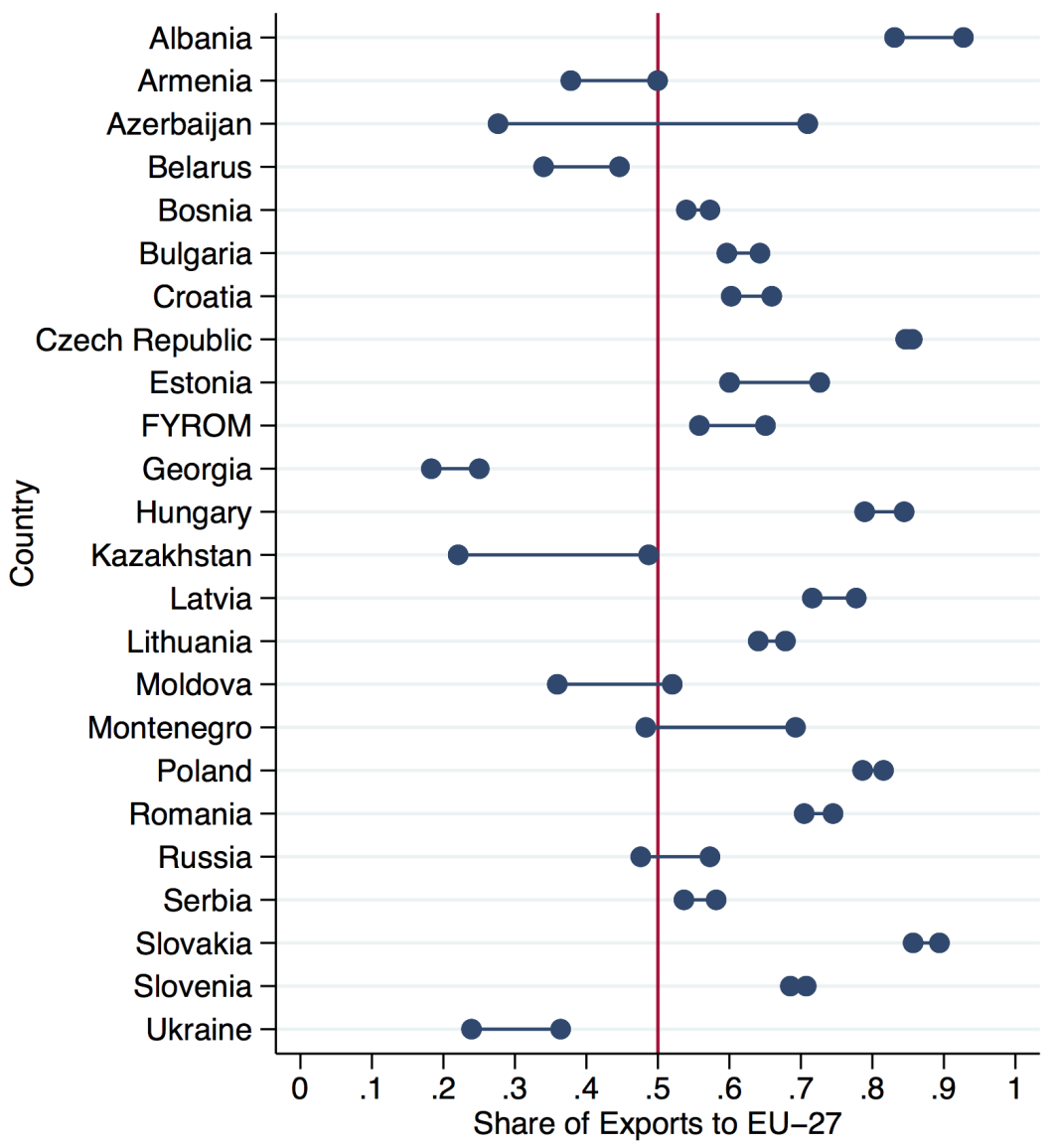

Source: UN Comtrade

*Data for Uzbekistan is unavailable. Data for Montenegro is for the years 2007 and 2009 only. 
Table C.5: Firms per Industry and Country

\begin{tabular}{|c|c|c|c|c|c|c|c|c|c|c|c|c|c|c|c|c|c|c|c|}
\hline & (1) & (2) & (3) & (4) & (5) & (6) & (7) & (8) & (9) & (10) & (11) & (12) & (13) & (14) & (15) & (16) & (17) & (18) & (19) \\
\hline & 2 & 15 & 17 & 18 & $23-24$ & 25 & 26 & 27 & 28 & 29 & $31-32$ & 45 & 50 & 51 & 52 & 55 & $60-64$ & 72 & \\
\hline Industry & $\begin{array}{c}\text { Other } \\
\text { manu- } \\
\text { facturing }\end{array}$ & Food & Textiles & Garments & Chemicals & $\begin{array}{l}\text { Plastics \& } \\
\text { rubber }\end{array}$ & $\begin{array}{l}\text { Non metallic } \\
\text { mineral } \\
\text { products }\end{array}$ & $\begin{array}{l}\text { Basic } \\
\text { metals }\end{array}$ & $\begin{array}{l}\text { Fabric. } \\
\text { metal } \\
\text { products }\end{array}$ & $\begin{array}{l}\text { Machinery } \\
\text { and } \\
\text { equipment }\end{array}$ & Electronics & Construction & $\begin{array}{l}\text { Other } \\
\text { services }\end{array}$ & Wholesale & Retail & $\begin{array}{l}\text { Hotel and } \\
\text { restaurants }\end{array}$ & Transport & IT & All \\
\hline Albania & 21 & 59 & 22 & 7 & 8 & 5 & 10 & 7 & 14 & 1 & 0 & 60 & 41 & 84 & 68 & 51 & 44 & 1 & 503 \\
\hline Belarus & 21 & 13 & 7 & 13 & 6 & 5 & 7 & 1 & 8 & 4 & 0 & 12 & 5 & 25 & 81 & 1 & 11 & 6 & 226 \\
\hline Georgia & 22 & 39 & 1 & 1 & 1 & 1 & 12 & 7 & 4 & 0 & 0 & 45 & 7 & 14 & 70 & 17 & 17 & 0 & 258 \\
\hline Ukraine & 119 & 225 & 11 & 135 & 11 & 2 & 17 & 2 & 38 & 113 & 3 & 123 & 180 & 175 & 144 & 58 & 64 & 18 & 1,438 \\
\hline Uzbekistan & 15 & 28 & 10 & 10 & 9 & 3 & 17 & 3 & 7 & 12 & 6 & 36 & 7 & 28 & 112 & 25 & 31 & 2 & 361 \\
\hline Russia & 106 & 198 & 13 & 102 & 78 & 16 & 16 & 8 & 76 & 82 & 16 & 165 & 160 & 145 & 153 & 34 & 58 & 7 & 1,433 \\
\hline Poland & 48 & 160 & 12 & 131 & 2 & 17 & 16 & 3 & 142 & 66 & 2 & 155 & 131 & 177 & 155 & 35 & 114 & 16 & 1,382 \\
\hline Romania & 53 & 187 & 8 & 104 & 13 & 7 & 9 & 4 & 87 & 55 & 3 & 87 & 97 & 97 & 169 & 40 & 59 & 6 & 1,085 \\
\hline Serbia & 53 & 68 & 14 & 7 & 11 & 9 & 6 & 4 & 29 & 11 & 6 & 64 & 63 & 83 & 103 & 28 & 44 & 5 & 608 \\
\hline Kazakhstan & 64 & 204 & 4 & 65 & 5 & 4 & 16 & 1 & 32 & 54 & 9 & 140 & 87 & 121 & 169 & 28 & 44 & 6 & 1,053 \\
\hline Moldova & 15 & 47 & 2 & 18 & 2 & 2 & 3 & 0 & 14 & 3 & 1 & 41 & 13 & 24 & 128 & 10 & 27 & 0 & 350 \\
\hline Bosnia & 44 & 11 & 3 & 8 & 2 & 5 & 2 & 2 & 18 & 8 & 2 & 34 & 9 & 38 & 75 & 9 & 10 & 0 & 280 \\
\hline Azerbaijan & 22 & 39 & 8 & 3 & 4 & 1 & 13 & 1 & 6 & 10 & 7 & 30 & 21 & 33 & 120 & 15 & 16 & 6 & 355 \\
\hline FYROM & 25 & 25 & 6 & 27 & 2 & 2 & 4 & 3 & 10 & 3 & 2 & 43 & 3 & 38 & 82 & 12 & 23 & 1 & 311 \\
\hline Armenia & 22 & 28 & 4 & 2 & 9 & 1 & 6 & 6 & 7 & 5 & 1 & 24 & 8 & 16 & 83 & 26 & 20 & 10 & 278 \\
\hline Kyrgyz & 20 & 29 & 8 & 3 & 2 & 4 & 5 & 2 & 1 & 3 & 4 & 24 & 6 & 13 & 42 & 5 & 13 & 1 & 185 \\
\hline Estonia & 64 & 46 & 5 & 12 & 2 & 4 & 7 & 1 & 11 & 7 & 3 & 77 & 87 & 69 & 116 & 58 & 50 & 7 & 626 \\
\hline Czech Republic & 47 & 60 & 3 & 4 & 9 & 11 & 9 & 7 & 25 & 25 & 7 & 82 & 87 & 67 & 92 & 45 & 49 & 9 & 638 \\
\hline Hungary & 61 & 108 & 8 & 47 & 5 & 13 & 8 & 6 & 129 & 63 & 5 & 90 & 87 & 121 & 112 & 35 & 45 & 12 & 955 \\
\hline Latvia & 54 & 49 & 4 & 12 & 0 & 1 & 5 & 2 & 7 & 6 & 0 & 51 & 81 & 109 & 124 & 24 & 48 & 2 & 579 \\
\hline Lithuania & 58 & 58 & 14 & 10 & 1 & 4 & 6 & 0 & 6 & 10 & 7 & 84 & 53 & 73 & 101 & 50 & 65 & 5 & 605 \\
\hline Slovakia & 22 & 40 & 3 & 5 & 7 & 3 & 5 & 4 & 18 & 18 & 2 & 58 & 100 & 67 & 73 & 24 & 28 & 7 & 484 \\
\hline Slovenia & 32 & 57 & 10 & 4 & 7 & 12 & 10 & 3 & 33 & 29 & 4 & 90 & 101 & 80 & 85 & 41 & 44 & 10 & 652 \\
\hline Bulgaria & 71 & 215 & 24 & 159 & 47 & 23 & 18 & 1 & 75 & 103 & 73 & 70 & 83 & 155 & 233 & 52 & 70 & 154 & 1,626 \\
\hline Croatia & 76 & 157 & 31 & 53 & 7 & 16 & 16 & 2 & 123 & 22 & 13 & 80 & 64 & 126 & 143 & 35 & 29 & 8 & 1,001 \\
\hline Montenegro & 8 & 12 & 1 & 0 & 1 & 0 & 1 & 0 & 4 & 0 & 0 & 4 & 0 & 9 & 32 & 5 & 4 & 1 & 82 \\
\hline Total & 1,163 & 2,162 & 236 & 942 & 251 & 171 & 244 & 80 & 924 & 713 & 176 & 1,769 & 1,581 & 1,987 & 2,865 & 763 & 1,027 & 300 & 17,354 \\
\hline
\end{tabular}


Figure C.2: Range of Volatility to the Euro (2001, 2004, 2006 and 2008)*

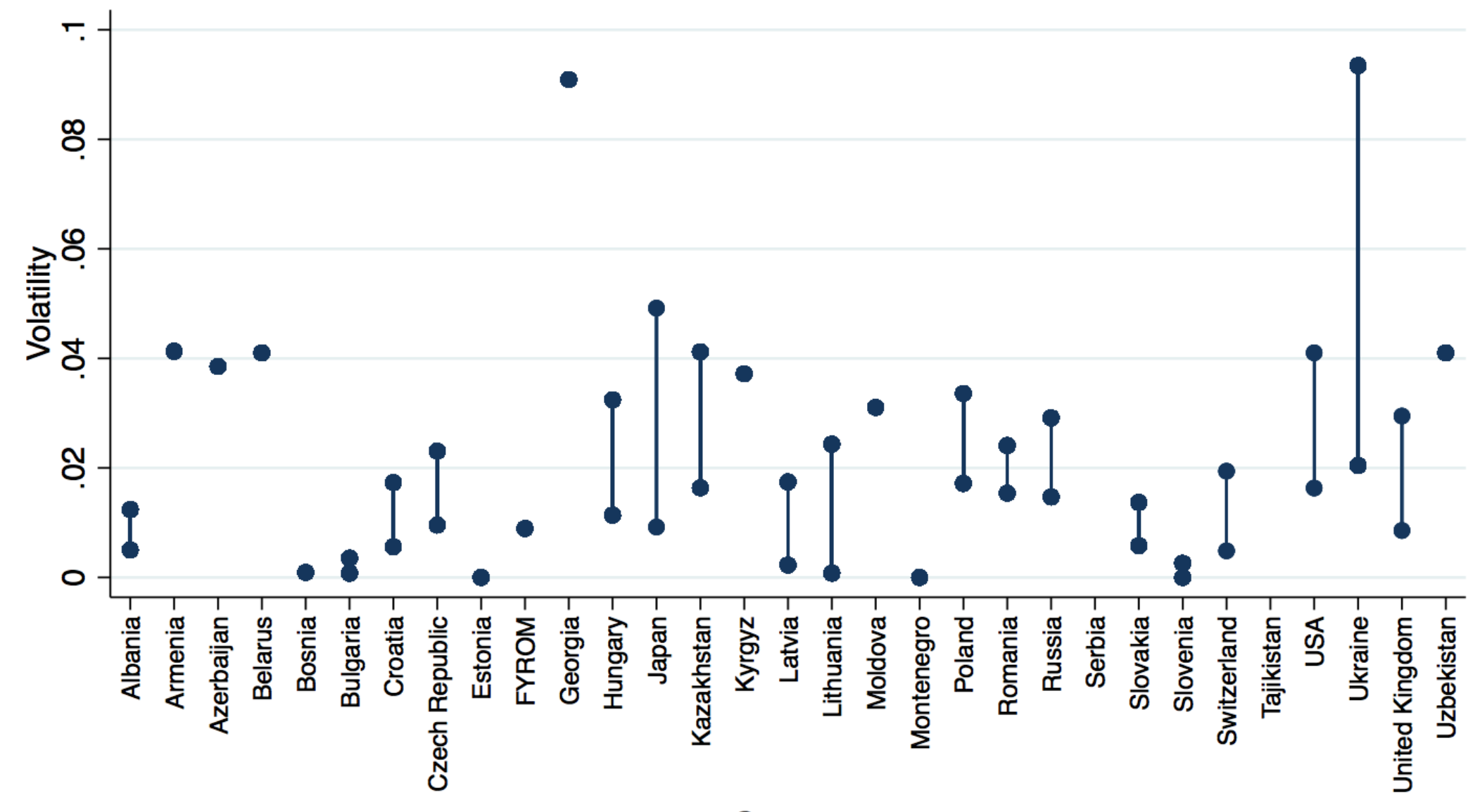

Country

*Coverage for years and countries as in the study sample (see Table C.3) 
Table C.6: Correlation Table

\begin{tabular}{lcccccccccc}
\hline & ExportIntensity & In Sales & Quality & Size & Euro & ERM & Peg & In ExRate & Volatility & RTA \\
\hline ExportIntensity & 1.00 & 0.18 & 0.17 & 0.24 & 0.05 & 0.05 & 0.07 & -0.03 & -0.06 & 0.12 \\
In Sales & 0.18 & 1.00 & 0.28 & 0.61 & 0.17 & 0.02 & 0.07 & 0.15 & -0.01 & 0.12 \\
Quality & 0.17 & 0.28 & 1.00 & 0.31 & 0.08 & 0.00 & 0.05 & 0.03 & -0.04 & 0.12 \\
Size & 0.24 & 0.61 & 0.31 & 1.00 & 0.03 & 0.00 & 0.02 & 0.05 & 0.03 & -0.01 \\
Euro & 0.05 & 0.17 & 0.08 & 0.03 & 1.00 & -0.06 & -0.07 & 0.03 & -0.09 & 0.21 \\
ERM & 0.05 & 0.02 & 0.00 & 0.00 & -0.06 & 1.00 & -0.12 & -0.19 & -0.17 & 0.36 \\
Peg & 0.07 & 0.07 & 0.05 & 0.02 & -0.07 & -0.12 & 1.00 & -0.28 & -0.17 & 0.16 \\
In ExchangeRate & -0.03 & 0.15 & 0.03 & 0.05 & 0.03 & -0.19 & -0.28 & 1.00 & 0.07 & -0.09 \\
Volatility & -0.06 & -0.01 & -0.04 & 0.03 & -0.09 & -0.17 & -0.17 & 0.07 & 1.00 & -0.35 \\
RTA & 0.12 & 0.12 & 0.12 & -0.01 & 0.21 & 0.36 & 0.16 & -0.09 & -0.35 & 1.00 \\
\hline
\end{tabular}




\section{Table C.7: Probability to Export by Industry (Probit)}

\begin{tabular}{|c|c|c|c|c|c|c|c|c|c|c|c|c|c|c|c|c|c|c|}
\hline & (1) & $(2)$ & (3) & (4) & (5) & (6) & (7) & (8) & (9) & (10) & (11) & (12) & (13) & (14) & (15) & (16) & (17) & (18) \\
\hline \multirow[b]{2}{*}{ Industry } & 2 & 15 & 17 & 18 & $23-24$ & 25 & 26 & 27 & 28 & 29 & $31-32$ & 45 & 50 & 51 & 52 & 55 & $60-64$ & 72 \\
\hline & $\begin{array}{c}\text { Other } \\
\text { manu- } \\
\text { facturing }\end{array}$ & Food & Textiles & Garments & Chemicals & $\begin{array}{l}\text { Plastics \& } \\
\text { rubber }\end{array}$ & $\begin{array}{l}\text { Non-met. } \\
\text { mineral } \\
\text { products }\end{array}$ & $\begin{array}{l}\text { Basic } \\
\text { metals }\end{array}$ & $\begin{array}{l}\text { Fabricate } \\
\text { metal } \\
\text { products }\end{array}$ & $\begin{array}{c}\text { Machinery } \\
\& \\
\text { equipment }\end{array}$ & Electronics & $\begin{array}{c}\text { Construc- } \\
\text { tion }\end{array}$ & $\begin{array}{l}\text { Other } \\
\text { services }\end{array}$ & Wholesale & Retail & $\begin{array}{l}\text { Hotels \& } \\
\text { restaurants }\end{array}$ & Transport & IT \\
\hline \multirow[t]{2}{*}{ In Sales } & $0.166 * * *$ & $0.398 * * *$ & 0.301 & $0.171 * * *$ & $0.720 * * *$ & $0.652^{*}$ & -0.00987 & $1.296 * *$ & $0.215^{* * *}$ & $0.944 * * *$ & 0.0916 & $0.254 * * *$ & $0.456 * * *$ & $0.325^{* * *}$ & $0.120 * * *$ & $0.153^{* * *}$ & $0.336 * * *$ & 0.144 \\
\hline & (0.0521) & $(0.100)$ & $(0.184)$ & (0.0319) & $(0.247)$ & $(0.393)$ & $(0.0514)$ & (0.517) & $(0.0648)$ & $(0.205)$ & $(0.0736)$ & $(0.0668)$ & (0.0960) & (0.0719) & (0.0401) & $(0.0402)$ & $(0.0741)$ & $(0.226)$ \\
\hline \multirow[t]{2}{*}{ Quality } & $0.495 * *$ & $1.110 * * *$ & 0.224 & 0.249 & $1.982 *$ & $4.738 * * *$ & $0.518^{*}$ & 2.056 & $0.471 * *$ & 0.0594 & 0.119 & $0.832 * * *$ & $0.993 * * *$ & $1.110 * * *$ & $0.718 * * *$ & $0.401 * *$ & $0.742 * * *$ & -0.0139 \\
\hline & $(0.200)$ & $(0.303)$ & $(0.382)$ & $(0.153)$ & (1.036) & (1.501) & $(0.292)$ & $(1.858)$ & (0.195) & (0.589) & $(0.230)$ & $(0.228)$ & (0.290) & $(0.265)$ & (0.207) & (0.169) & $(0.244)$ & $(0.800)$ \\
\hline \multirow[t]{2}{*}{ Size } & $0.562 * * *$ & $0.544 * * *$ & $0.913^{*}$ & $0.740 * * *$ & $1.485^{*}$ & 0.228 & $0.746^{*}$ & 0.0827 & $0.550 * * *$ & $2.388 * * *$ & $0.355^{* *}$ & -0.163 & $-0.332 * *$ & 0.0237 & $0.176^{*}$ & $0.360 * * *$ & $-0.695 * * *$ & 0.776 \\
\hline & (0.155) & (0.165) & $(0.535)$ & (0.0806) & $(0.774)$ & $(0.803)$ & $(0.401)$ & (1.335) & $(0.171)$ & $(0.471)$ & $(0.172)$ & $(0.142)$ & (0.160) & (0.121) & $(0.100)$ & (0.101) & (0.174) & $(0.683)$ \\
\hline \multirow[t]{2}{*}{ Euro } & 0.496 & 0.896 & -0.907 & -0.0321 & -1.229 & 4.139 & 0.606 & 76.55 & -0.108 & $4.573 * *$ & -0.227 & 0.454 & 0.0709 & 0.163 & $0.737 * * *$ & -0.227 & 0.0972 & 1.465 \\
\hline & $(0.428)$ & $(0.562)$ & (0.938) & $(0.716)$ & (3.397) & (3.573) & (0.664) & (0) & $(0.367)$ & $(1.851)$ & $(0.676)$ & $(0.423)$ & $(0.827)$ & $(0.436)$ & $(0.284)$ & $(0.358)$ & (0.518) & (2.390) \\
\hline \multirow[t]{2}{*}{ ERM } & -0.131 & $1.806^{* * *}$ & 0.669 & 0.491 & -0.307 & 0.151 & -0.172 & $-8.612 * *$ & 0.508 & 1.016 & 0.293 & 0.0347 & $0.604 * *$ & 0.523 & 0.0969 & -0.218 & $0.587^{*}$ & -2.986 \\
\hline & $(0.250)$ & (0.619) & $(0.763)$ & $(0.305)$ & (3.168) & (2.669) & $(0.386)$ & (3.777) & $(0.408)$ & (1.885) & $(0.715)$ & $(0.325)$ & $(0.280)$ & (0.331) & (0.209) & (0.249) & (0.314) & (1.876) \\
\hline \multirow[t]{2}{*}{ Peg } & $-0.571 * *$ & -0.333 & -1.247 & $0.378 * *$ & 0.668 & 1.050 & -0.0136 & -1.882 & $-0.735^{* *}$ & $3.234 * *$ & $-1.351 * *$ & 0.487 & 0.127 & -0.243 & $-0.487^{* *}$ & $-0.544^{*}$ & -0.0467 & -1.663 \\
\hline & $(0.258)$ & $(0.254)$ & $(0.794)$ & (0.179) & (2.075) & $(1.403)$ & $(0.355)$ & (3.993) & $(0.294)$ & $(1.445)$ & $(0.544)$ & $(0.332)$ & $(0.372)$ & $(0.256)$ & $(0.228)$ & (0.305) & $(0.315)$ & (1.721) \\
\hline \multirow[t]{2}{*}{ In ExchangeRate } & $-0.0569 *$ & $-0.134 * * *$ & -0.172 & $-0.0151-$ & $-1.080 * * *$ & -0.447 & 0.00761 & $-0.732 *$ & $-0.0681 * *$ & $-0.323 * * *$ & -0.102 & $-0.0922 * *$ & -0.0564 & $-0.0683 * *$ & * -0.0227 & 0.0326 & $-0.0677^{*}$ & 0.220 \\
\hline & $(0.0318)$ & $(0.0420)$ & $(0.121)$ & (0.0189) & $(0.252)$ & (0.294) & $(0.0451)$ & $(0.380)$ & $(0.0306)$ & (0.117) & $(0.0711)$ & $(0.0422)$ & $(0.0378)$ & $(0.0343)$ & $(0.0241)$ & $(0.0265)$ & $(0.0370)$ & $(0.207)$ \\
\hline \multirow[t]{2}{*}{ Volatility } & $-23.97 * * *$ & 0.770 & -12.61 & -2.398 & 34.90 & -29.94 & -3.954 & $-118.5^{* *}$ & $-17.47^{* *}$ & 2.526 & -6.442 & -2.242 & 0.429 & 2.416 & $-16.26 * * *$ & ${ }^{*}-17.22 * * *$ & -1.786 & $-131.0 *$ \\
\hline & $(6.496)$ & $(1.176)$ & $(12.88)$ & $(2.897)$ & $(32.08)$ & $(55.36)$ & (6.128) & $(46.88)$ & (7.382) & (11.96) & $(10.68)$ & $(2.389)$ & $(1.531)$ & $(1.590)$ & $(6.075)$ & $(6.327)$ & $(1.721)$ & (73.97) \\
\hline \multirow[t]{2}{*}{ RTA } & $0.0117^{* *}$ & $-0.0152 *$ & 0.0118 & $0.0324 * * *$ & $0.109 * *$ & $0.0952 * *$ & $0.0229 *$ & $0.231 * * *$ & $0.0165 * * c$ & $0.0819 * * *$ & $0.0218 * *$ & -0.00410 & 0.00126 & $0.0258 * * *$ & $* 0.0116 * *$ & 0.00209 & 0.00714 & 0.0142 \\
\hline & $(0.00559)$ & $(0.00778)$ & (0.0149) & $(0.00459)$ & $(0.0445)$ & $(0.0411)$ & (0.0129) & $(0.0834)$ & $(0.00653)$ & (0.0229) & $(0.0106)$ & $(0.00680)$ & (0.00735) & ) $(0.00758)$ & ) $(0.00525)$ & $(0.00561)$ & $(0.00664)$ & $(0.0337)$ \\
\hline Year Dummies & Yes & Yes & Yes & Yes & Yes & Yes & Yes & Yes & Yes & Yes & Yes & Yes & Yes & Yes & Yes & Yes & Yes & Yes \\
\hline Country Dum. & No & No & No & No & No & No & No & No & No & No & No & No & No & No & No & No & No & No \\
\hline Observations & 1,163 & 2,162 & 236 & 942 & 251 & 171 & 244 & 80 & 924 & 713 & 176 & 1,769 & 1,581 & 1,987 & 2,865 & 763 & 1,027 & 300 \\
\hline
\end{tabular}

Notes: Reported values are marginal effects at the mean of the independent variables; Robust standard errors in parentheses; ${ }^{* * *} p<0.01,{ }^{* *} p<0.05,{ }^{*} p<0.1$ 
Table C.8: Export Intensity Regression Results by Industry (OLS)

\begin{tabular}{|c|c|c|c|c|c|c|c|c|c|c|c|c|c|c|c|c|c|c|}
\hline & (1) & (2) & (3) & (4) & (5) & (6) & (7) & (8) & (9) & (10) & (11) & $(12)$ & (13) & (14) & (15) & $(16)$ & (17) & (18) \\
\hline & 2 & 15 & 17 & 18 & $3-24$ & 25 & 26 & 27 & 28 & 29 & $31-32$ & 45 & 50 & 51 & 52 & 55 & $60-64$ & 72 \\
\hline Industry & $\begin{array}{c}\text { Other } \\
\text { manu- } \\
\text { facturing }\end{array}$ & Food & Textiles & Garments & Chemicals & $\begin{array}{c}\text { Plastics \& } \\
\text { rubber }\end{array}$ & $\begin{array}{c}\text { Non-met. } \\
\text { mineral } \\
\text { products }\end{array}$ & $\begin{array}{c}\text { Basic } \\
\text { metals }\end{array}$ & $\begin{array}{c}\text { Fabricate } \\
\text { metal } \\
\text { products }\end{array}$ & $\begin{array}{c}\text { Machinery } \\
\& \\
\text { equipment } \\
\end{array}$ & Electronics & $\begin{array}{l}\text { onstruc- } \\
\text { tion }\end{array}$ & $\begin{array}{l}\text { Other } \\
\text { services }\end{array}$ & Vholesale & Retail & $\begin{array}{l}\text { Hotels \& } \\
\text { restaurants }\end{array}$ & Transport & IT \\
\hline In Sales & $\begin{array}{l}0.947^{*} \\
(0.556)\end{array}$ & $\begin{array}{c}1.493^{* * *} \\
(0.294)\end{array}$ & $\begin{array}{l}2.124^{*} \\
(1.278)\end{array}$ & $\begin{array}{c}-0.0244 \\
(0.666)\end{array}$ & $\begin{array}{c}2.003^{* *} \\
(0.831)\end{array}$ & $\begin{array}{l}\text { 1.391* } \\
(0.816)\end{array}$ & $\begin{array}{l}-0.880 \\
(0.747)\end{array}$ & $\begin{array}{c}3.683^{* *} \\
(1.696)\end{array}$ & $\begin{array}{c}2.521^{* * *} \\
(0.630)\end{array}$ & $\begin{array}{c}2.952^{* * *} \\
(0.825)\end{array}$ & $\begin{array}{l}-1.016 \\
(1.578)\end{array}$ & $\begin{array}{c}0.503 * * * \\
(0.129)\end{array}$ & $\begin{array}{c}1.185^{* * *} \\
(0.230)\end{array}$ & $\begin{array}{c}0.581^{* *} \\
(0.230)\end{array}$ & $\begin{array}{c}0.111 \\
(0.0808)\end{array}$ & $\begin{array}{c}1.498 * * * \\
(0.472)\end{array}$ & $\begin{array}{c}3.016^{* * *} \\
(0.541)\end{array}$ & $\begin{array}{c}-0.626 \\
(1.225)\end{array}$ \\
\hline Quality & $\begin{array}{c}1.711 \\
(2.450)\end{array}$ & $\begin{array}{c}6.528^{* * *} \\
(1.427)\end{array}$ & $\begin{array}{c}0.885 \\
(5.556)\end{array}$ & $\begin{array}{l}-2.340 \\
(3.849)\end{array}$ & $\begin{array}{l}-0.422 \\
(3.397)\end{array}$ & $\begin{array}{c}14.55^{* * *} \\
(4.386)\end{array}$ & $\begin{array}{c}1.005 \\
(3.695)\end{array}$ & $\begin{array}{c}1.860 \\
(5.717)\end{array}$ & $\begin{array}{c}3.114 \\
(2.482)\end{array}$ & $\begin{array}{c}1.459 \\
(2.867)\end{array}$ & $\begin{array}{c}5.014 \\
(5.186)\end{array}$ & $\begin{array}{c}1.177^{*} \\
(0.644)\end{array}$ & $\begin{array}{c}4.571^{* * *} \\
(1.682)\end{array}$ & $\begin{array}{c}4.885 * * * \\
(1.373)\end{array}$ & $\begin{array}{c}1.731^{* *} \\
(0.773)\end{array}$ & $\begin{array}{c}8.006 * * \\
(3.817)\end{array}$ & $\begin{array}{c}7.707^{* * *} \\
(2.906)\end{array}$ & $\begin{array}{l}-2.363 \\
(5.522)\end{array}$ \\
\hline Size & $\begin{array}{c}10.65^{* * *} \\
(1.724)\end{array}$ & $\begin{array}{c}5.254 * * * \\
(0.936)\end{array}$ & $\begin{array}{c}17.61^{* * *} \\
(3.583)\end{array}$ & $\begin{array}{c}24.80 * * * \\
(1.865)\end{array}$ & $\begin{array}{c}6.608 * * \\
(2.737)\end{array}$ & $\begin{array}{c}1.459 \\
(2.911)\end{array}$ & $\begin{array}{c}11.31^{* * *} \\
(2.449)\end{array}$ & $\begin{array}{c}2.527 \\
(4.301)\end{array}$ & $\begin{array}{c}10.16^{* * *} \\
(1.739)\end{array}$ & $\begin{array}{c}10.30 * * * \\
(2.040)\end{array}$ & $\begin{array}{c}13.85^{* * *} \\
(3.478)\end{array}$ & $\begin{array}{l}-0.163 \\
(0.412)\end{array}$ & $\begin{array}{c}-0.640 \\
(0.702)\end{array}$ & $\begin{array}{c}0.234 \\
(0.795)\end{array}$ & $\begin{array}{c}0.805^{* *} \\
(0.358)\end{array}$ & $\begin{array}{c}5.658^{* * *} \\
(1.441)\end{array}$ & $\begin{array}{c}-9.704 * * * \\
(1.583)\end{array}$ & $\begin{array}{l}7.659 * \\
(4.150)\end{array}$ \\
\hline Euro & $\begin{array}{l}10.66^{*} \\
(6.069)\end{array}$ & $\begin{array}{c}-5.376^{* *} \\
(2.488)\end{array}$ & $\begin{array}{c}-13.16 \\
(13.10)\end{array}$ & $\begin{array}{c}-7.742 \\
(11.83)\end{array}$ & $\begin{array}{c}21.38 \\
(18.61)\end{array}$ & $\begin{array}{c}9.898 \\
(8.303)\end{array}$ & $\begin{array}{l}22.77^{*} \\
(13.49)\end{array}$ & $\begin{array}{c}38.99 * * * \\
(9.294)\end{array}$ & $\begin{array}{c}7.129 \\
(6.297)\end{array}$ & $\begin{array}{c}25.40 * * * \\
(6.920)\end{array}$ & $\begin{array}{c}17.04 \\
(15.10)\end{array}$ & $\begin{array}{c}1.163 \\
(1.686)\end{array}$ & $\begin{array}{c}1.871 \\
(5.794)\end{array}$ & $\begin{array}{c}0.187 \\
(2.945)\end{array}$ & $\begin{array}{c}3.335^{* *} \\
(1.576)\end{array}$ & $\begin{array}{c}0.588 \\
(6.277)\end{array}$ & $\begin{array}{c}0.782 \\
(7.221)\end{array}$ & $\begin{array}{c}-8.247 \\
(7.105)\end{array}$ \\
\hline ERM & $\begin{array}{c}10.22 * * * \\
(3.734)\end{array}$ & $\begin{array}{c}9.731^{* *} \\
(4.043)\end{array}$ & $\begin{array}{c}19.97^{* *} \\
(9.253)\end{array}$ & $\begin{array}{c}20.73 * * * \\
(6.795)\end{array}$ & $\begin{array}{c}7.387 \\
(11.62)\end{array}$ & $\begin{array}{c}13.05 \\
(10.84)\end{array}$ & $\begin{array}{c}3.142 \\
(8.555)\end{array}$ & $\begin{array}{c}-9.883 \\
(11.91)\end{array}$ & $\begin{array}{c}7.037 \\
(6.640)\end{array}$ & $\begin{array}{c}16.14 * * * \\
(5.865)\end{array}$ & $\begin{array}{c}18.76 \\
(14.63)\end{array}$ & $\begin{array}{c}1.210 \\
(0.944)\end{array}$ & $\begin{array}{c}0.683 \\
(1.351)\end{array}$ & $\begin{array}{c}3.563 \\
(2.706)\end{array}$ & $\begin{array}{c}-0.568 \\
(0.841)\end{array}$ & $\begin{array}{l}-4.611 \\
(2.826)\end{array}$ & $\begin{array}{c}7.978 * * \\
(3.914)\end{array}$ & $\begin{array}{l}-6.314 \\
(4.619)\end{array}$ \\
\hline Peg & $\begin{array}{l}-1.397 \\
(3.718)\end{array}$ & $\begin{array}{l}-1.046 \\
(2.095)\end{array}$ & $\begin{array}{l}-10.90 \\
(7.548)\end{array}$ & $\begin{array}{c}17.52^{* * *} \\
(4.164)\end{array}$ & $\begin{array}{c}5.837 \\
(5.381)\end{array}$ & $\begin{array}{l}10.09 * \\
(5.183)\end{array}$ & $\begin{array}{c}2.624 \\
(6.430)\end{array}$ & $\begin{array}{l}-1.563 \\
(13.04)\end{array}$ & $\begin{array}{l}-5.015 \\
(4.097)\end{array}$ & $\begin{array}{c}3.854 \\
(6.619)\end{array}$ & $\begin{array}{c}-18.10 * * \\
(8.564)\end{array}$ & $\begin{array}{c}1.976 \\
(1.458)\end{array}$ & $\begin{array}{c}1.818 \\
(1.948)\end{array}$ & $\begin{array}{r}4.384^{* *} \\
(1.857)\end{array}$ & $\begin{array}{c}-1.323^{* * *} \\
(0.495)\end{array}$ & $\begin{array}{c}-5.846 * * \\
(2.287)\end{array}$ & $\begin{array}{c}2.810 \\
(4.028)\end{array}$ & $\begin{array}{c}6.645 \\
(9.377)\end{array}$ \\
\hline In Exch & $\begin{array}{l}0.0351 \\
(0.424)\end{array}$ & $\begin{array}{c}-0.512 * * \\
(0.223)\end{array}$ & $\begin{array}{c}-0.901 \\
(1.202)\end{array}$ & $\begin{array}{c}1.389 * * * \\
(0.477)\end{array}$ & $\begin{array}{c}-4.342^{* * * *} \\
(0.742)\end{array}$ & $\begin{array}{c}-0.469 \\
(0.710)\end{array}$ & $\begin{array}{c}0.149 \\
(0.689)\end{array}$ & $\begin{array}{l}-1.818^{*} \\
(1.074)\end{array}$ & $\begin{array}{c}-0.179 \\
(0.352)\end{array}$ & $\begin{array}{l}-0.243 \\
(0.481)\end{array}$ & $\begin{array}{c}-0.180 \\
(1.241)\end{array}$ & $\begin{array}{c}-0.0803 \\
(0.0685)\end{array}$ & $\begin{array}{r}-0.0610 \\
(0.149)\end{array}$ & $\begin{array}{l}-0.0457 \\
(0.178)\end{array}$ & $\begin{array}{l}-0.0858 \\
(0.0643)\end{array}$ & $\begin{array}{r}-0.0604 \\
(0.346)\end{array}$ & $\begin{array}{l}-0.583 \\
(0.389)\end{array}$ & $\begin{array}{l}2.082^{*} \\
(1.234)\end{array}$ \\
\hline Volatility & $\begin{array}{c}-149.3^{* *}- \\
(61.80)\end{array}$ & $\begin{array}{c}-29.66 * * * \\
(7.819)\end{array}$ & $\begin{array}{l}-67.60 \\
(172.6)\end{array}$ & $\begin{array}{l}-31.87 \\
(56.35)\end{array}$ & $\begin{array}{c}179.0 \\
(173.2)\end{array}$ & $\begin{array}{c}93.39 \\
(99.28)\end{array}$ & $\begin{array}{c}32.39 \\
(83.46)\end{array}$ & $\begin{array}{l}-121.5 \\
(164.1)\end{array}$ & $\begin{array}{c}-263.0 * * * \\
(82.99)\end{array}$ & $\begin{array}{l}{ }^{*} 132.2^{* *} \\
(60.69)\end{array}$ & $\begin{array}{l}-51.52 \\
(201.2)\end{array}$ & $\begin{array}{c}-11.39 * * \\
(5.763)\end{array}$ & $\begin{array}{c}0.130 \\
(5.759)\end{array}$ & $\begin{array}{c}7.206 \\
(9.137)\end{array}$ & $\begin{array}{c}-25.82 * * * \\
(9.726)\end{array}$ & $\begin{array}{c}* 56.96 * * * \\
(21.63)\end{array}$ & $\begin{array}{l}-20.31 \\
(24.65)\end{array}$ & $\begin{array}{l}-34.78 \\
(59.75)\end{array}$ \\
\hline RTA & $\begin{array}{l}0.167^{* *} \\
(0.0688)\end{array}$ & $\begin{array}{c}-0.0867 * \\
(0.0457)\end{array}$ & $\begin{array}{l}0.348 * \\
(0.178)\end{array}$ & $\begin{array}{c}0.678 * * * \\
(0.0960)\end{array}$ & $\begin{array}{c}0.733^{* * *} \\
(0.167)\end{array}$ & $\begin{array}{c}0.389 * * * \\
(0.109)\end{array}$ & $\begin{array}{c}0.470 * * * \\
(0.133)\end{array}$ & $\begin{array}{c}0.508 * * \\
(0.192)\end{array}$ & $\begin{array}{c}0.229 * * * \\
(0.0771)\end{array}$ & $\begin{array}{c}0.418^{* * *} \\
(0.0909)\end{array}$ & $\begin{array}{c}0.482 * * \\
(0.191)\end{array}$ & $\begin{array}{c}-0.0306 \\
(0.0187)\end{array}$ & $\begin{array}{l}0.00286 \\
(0.0259)\end{array}$ & $\begin{array}{c}0.108 * * * \\
(0.0379)\end{array}$ & $\begin{array}{c}0.0152 \\
(0.0148)\end{array}$ & $\begin{array}{c}0.109 * \\
(0.0634)\end{array}$ & $\begin{array}{l}0.00691 \\
(0.0787)\end{array}$ & $\begin{array}{l}0.314^{*} \\
(0.168)\end{array}$ \\
\hline Constant & $\begin{array}{c}-23.39 * * * \\
(7.901)\end{array}$ & $\begin{array}{l}-4.194 \\
(3.010)\end{array}$ & $\begin{array}{c}-39.93 * * * \\
(15.30)\end{array}$ & $\begin{array}{c}*-45.47^{* * *} \\
(6.727)\end{array}$ & $\begin{array}{l}-15.22 \\
(9.873)\end{array}$ & $\begin{array}{c}-21.68 * * \\
(10.48)\end{array}$ & $\begin{array}{l}-11.66 \\
(9.086)\end{array}$ & $\begin{array}{c}-47.25^{* *} \\
(21.04)\end{array}$ & $\begin{array}{c}-38.24 * * * \\
(7.200)\end{array}$ & $\begin{array}{c}-53.80 * * * \\
(9.061)\end{array}$ & $\begin{array}{c}2.498 \\
(21.31)\end{array}$ & $\begin{array}{c}-2.571^{* *} \\
(1.225)\end{array}$ & $\begin{array}{c}-7.541^{* * *} \\
(2.245)\end{array}$ & $\begin{array}{l}-3.860^{*} \\
(2.139)\end{array}$ & $\begin{array}{l}-0.390 \\
(0.908)\end{array}$ & $\begin{array}{c}-15.68 * * * \\
(4.616)\end{array}$ & $\begin{array}{c}2.521 \\
(5.949)\end{array}$ & $\begin{array}{l}-11.90 \\
(11.86)\end{array}$ \\
\hline Year Dummies & Yes & Yes & Yes & Yes & Yes & Yes & Yes & Yes & Yes & Yes & Yes & Yes & Yes & Yes & Yes & Yes & Yes & Yes \\
\hline $\begin{array}{l}\text { Country Dum. } \\
\text { Observations }\end{array}$ & $\begin{array}{c}\text { No } \\
1,163\end{array}$ & $\begin{array}{c}\text { No } \\
2,162\end{array}$ & $\begin{array}{l}\text { No } \\
236\end{array}$ & $\begin{array}{l}\text { No } \\
942\end{array}$ & $\begin{array}{l}\text { No } \\
251\end{array}$ & $\begin{array}{l}\text { No } \\
171\end{array}$ & $\begin{array}{l}\text { No } \\
244\end{array}$ & $\begin{array}{l}\text { No } \\
80\end{array}$ & $\begin{array}{l}\text { No } \\
924\end{array}$ & $\begin{array}{l}\text { No } \\
713\end{array}$ & $\begin{array}{l}\text { No } \\
176\end{array}$ & $\begin{array}{c}\text { No } \\
1,769\end{array}$ & $\begin{array}{c}\text { No } \\
1,581\end{array}$ & $\begin{array}{c}\text { No } \\
1,987\end{array}$ & $\begin{array}{c}\text { No } \\
2,865\end{array}$ & $\begin{array}{l}\text { No } \\
763\end{array}$ & $\begin{array}{c}\text { No } \\
1,027\end{array}$ & $\begin{array}{l}\text { No } \\
300\end{array}$ \\
\hline $\mathrm{R}^{\wedge} 2$ & 0.182 & 0.190 & 0.260 & 0.359 & 0.362 & 0.304 & 0.233 & 0.521 & 0.207 & 0.243 & 0.234 & 0.024 & 0.049 & 0.038 & 0.029 & 0.141 & 0.071 & 0.121 \\
\hline
\end{tabular}


Table C.9: Robustness Check - Regional Differences

\begin{tabular}{|c|c|c|c|c|c|c|}
\hline & \multicolumn{3}{|c|}{ Asia } & \multicolumn{3}{|c|}{ Europe } \\
\hline & $(1)$ & (2) & (3) & $(4)$ & $(5)$ & (6) \\
\hline & OLS & OLS & OLS & OLS & OLS & OLS \\
\hline In Sales & $\begin{array}{c}0.279 * * \\
(0.138)\end{array}$ & $\begin{array}{c}0.327^{* *} \\
(0.139)\end{array}$ & $\begin{array}{c}1.048^{* * *} \\
(0.198)\end{array}$ & $\begin{array}{c}-0.0311 \\
(0.129)\end{array}$ & $\begin{array}{c}0.691 * * * \\
(0.132)\end{array}$ & $\begin{array}{c}1.117^{* * *} \\
(0.175)\end{array}$ \\
\hline Quality & $\begin{array}{c}5.752 * * * \\
(0.934)\end{array}$ & $\begin{array}{c}4.715^{* * *} \\
(0.915)\end{array}$ & $\begin{array}{c}3.912 * * * \\
(0.914)\end{array}$ & $\begin{array}{c}5.557 * * * \\
(0.695)\end{array}$ & $\begin{array}{c}4.292^{* * *} \\
(0.650)\end{array}$ & $\begin{array}{c}3.566 * * * \\
(0.651)\end{array}$ \\
\hline Size & $\begin{array}{c}2.148^{* * *} \\
(0.417)\end{array}$ & $\begin{array}{c}1.547^{* * *} \\
(0.426)\end{array}$ & $\begin{array}{c}0.676 \\
(0.487)\end{array}$ & $\begin{array}{c}8.885^{* * *} \\
(0.441)\end{array}$ & $\begin{array}{c}6.358^{* * *} \\
(0.404)\end{array}$ & $\begin{array}{c}5.769 * * * \\
(0.461)\end{array}$ \\
\hline Euro & - & - & - & $\begin{array}{c}2.164 \\
(1.338)\end{array}$ & $\begin{array}{c}4.500 * * * \\
(1.245)\end{array}$ & - \\
\hline ERM & - & - & - & $\begin{array}{c}1.281 \\
(0.883)\end{array}$ & $\begin{array}{c}5.115^{* * *} \\
(0.816)\end{array}$ & - \\
\hline Peg & - & - & - & $\begin{array}{c}2.391 * * * \\
(0.770)\end{array}$ & $\begin{array}{c}0.466 \\
(0.735)\end{array}$ & - \\
\hline In ExchangeRate & $\begin{array}{l}0.0561 \\
(0.146)\end{array}$ & $\begin{array}{l}0.0577 \\
(0.142)\end{array}$ & $\begin{array}{c}85.54 \\
(96.50)\end{array}$ & $\begin{array}{l}-0.0737 \\
(0.0903)\end{array}$ & $\begin{array}{l}-0.0272 \\
(0.0850)\end{array}$ & $\begin{array}{c}-9.118^{* * *} \\
(2.344)\end{array}$ \\
\hline Volatility & $\begin{array}{c}58.91^{* *} \\
(23.14)\end{array}$ & $\begin{array}{c}84.38 * * * \\
(24.48)\end{array}$ & $\begin{array}{c}90.55 \\
(181.4)\end{array}$ & $\begin{array}{c}-23.35 * * * \\
(5.212)\end{array}$ & $\begin{array}{c}-37.65 * * * \\
(5.503)\end{array}$ & $\begin{array}{c}-14.93 * * * \\
(5.365)\end{array}$ \\
\hline RTA & $\begin{array}{c}2.197^{* * *} \\
(0.739)\end{array}$ & $\begin{array}{c}2.219 * * \\
(0.867)\end{array}$ & $\begin{array}{c}38.03 \\
(38.50)\end{array}$ & $\begin{array}{c}0.0474 * * * \\
(0.0153)\end{array}$ & $\begin{array}{l}0.0297^{*} \\
(0.0172)\end{array}$ & $\begin{array}{c}0.0151 \\
(0.0406)\end{array}$ \\
\hline Constant & $\begin{array}{c}-29.27^{* * *} \\
(8.775)\end{array}$ & $\begin{array}{c}-27.43 * * * \\
(9.698)\end{array}$ & $\begin{array}{c}-466.1 \\
(480.3)\end{array}$ & $\begin{array}{c}-3.622 * * * \\
(1.362)\end{array}$ & $\begin{array}{c}7.576^{* * *} \\
(1.742)\end{array}$ & $\begin{array}{c}50.23 * * * \\
(11.23)\end{array}$ \\
\hline Year Dummies & No & Yes & Yes & No & Yes & Yes \\
\hline Industry Dummies & No & Yes & Yes & No & Yes & Yes \\
\hline Country Dummies & No & No & Yes & No & No & Yes \\
\hline Observations & 3,923 & 3,923 & 3,923 & 13,431 & 13,431 & 13,431 \\
\hline $\mathrm{R}^{\wedge} 2$ & 0.046 & 0.089 & 0.105 & 0.086 & 0.216 & 0.232 \\
\hline
\end{tabular}




\section{Direct and Indirect Exports and the Role of Uncertainty}

Table D.1: Covered Countries and Sectors

\begin{tabular}{|c|c|c|c|c|c|c|c|c|c|c|c|c|c|c|c|c|c|c|c|c|}
\hline \multirow[t]{2}{*}{ Country } & \multicolumn{20}{|c|}{ Sector } \\
\hline & 2 & 15 & 17 & 18 & 24 & 25 & 26 & 27 & 28 & 29 & 31 & 45 & 50 & 51 & 52 & 55 & 60 & 72 & All & $\%$ \\
\hline Ibania & 10 & 25 & 9 & 5 & 3 & 0 & 1 & 3 & 3 & 0 & 0 & 2 & 6 & 12 & 3 & 16 & 27 & 0 & 125 & 2.54 \\
\hline Belarus & 15 & 29 & 4 & 4 & 3 & 2 & 3 & 0 & 3 & 4 & 0 & 18 & 2 & 24 & 3 & 2 & 29 & 1 & 146 & 2.97 \\
\hline Georgia & 4 & 29 & 2 & 1 & 1 & 0 & 3 & 1 & 0 & 1 & 0 & 3 & 9 & 6 & 5 & 0 & 10 & 0 & 75 & 1.53 \\
\hline Tajikistan & 6 & 18 & 9 & 4 & 3 & 2 & 2 & 1 & 0 & 1 & 1 & 2 & 2 & 13 & 1 & 0 & 1 & 0 & 66 & 1.34 \\
\hline Ukraine & 26 & 61 & 5 & 26 & 6 & 0 & 2 & 0 & 10 & 50 & 1 & 4 & 23 & 22 & 4 & 6 & 24 & 1 & 271 & 5.51 \\
\hline Uzbekistan & 6 & 36 & 6 & 3 & 6 & 2 & 3 & 0 & 0 & 7 & 1 & 0 & 7 & 7 & 0 & 0 & 8 & 1 & 93 & 1.89 \\
\hline Russia & 24 & 46 & 3 & 4 & 31 & 3 & 1 & 4 & 11 & 38 & 8 & 10 & 8 & 13 & 2 & 2 & 12 & 0 & 219 & 4.45 \\
\hline Poland & 19 & 49 & 6 & 39 & 2 & 11 & 6 & 3 & 43 & 34 & 1 & 14 & 12 & 37 & 7 & 1 & 40 & 5 & 329 & 6.69 \\
\hline Romania & 16 & 24 & 3 & 45 & 3 & 2 & 5 & 3 & 17 & 20 & 0 & 2 & 7 & 9 & 6 & 9 & 16 & 3 & 190 & 3.86 \\
\hline erbia & 29 & 36 & 12 & 5 & 8 & 5 & 3 & 2 & 17 & 7 & 2 & 12 & 13 & 28 & 18 & 5 & 21 & 2 & 225 & 4.58 \\
\hline Kazakhstan & 7 & 42 & 0 & 2 & 2 & 0 & 1 & 0 & 4 & 9 & 2 & 5 & 4 & 15 & 0 & 0 & 2 & 0 & 95 & 1.93 \\
\hline Moldova & 9 & 47 & 2 & 15 & 0 & 0 & 2 & 0 & 15 & 2 & 1 & 0 & 7 & 12 & 13 & 1 & 15 & 0 & 141 & 2.87 \\
\hline Bosnia & 35 & 17 & 1 & 6 & 2 & 4 & 2 & 2 & 13 & 9 & 0 & 19 & 4 & 18 & 6 & 4 & 15 & 0 & 157 & 3.19 \\
\hline zerbaijan & 2 & 12 & 2 & 1 & 1 & 0 & 0 & 0 & 0 & 2 & 0 & 3 & 0 & 2 & 1 & 1 & 1 & 0 & 28 & 0.57 \\
\hline YROM & 26 & 16 & 6 & 24 & 4 & 0 & 5 & 2 & 6 & 3 & 2 & 13 & 2 & 20 & 11 & 2 & 21 & 2 & 165 & 3.36 \\
\hline ia & 8 & 56 & 3 & 8 & 5 & 5 & 3 & 1 & 3 & 6 & 1 & 0 & 5 & 5 & 0 & 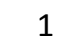 & 7 & 3 & 120 & 2.44 \\
\hline Kyrgyz & 8 & 23 & 9 & 1 & 1 & 1 & 3 & 0 & 2 & 2 & 1 & 2 & 4 & 10 & 1 & 0 & 6 & 0 & 74 & 1.50 \\
\hline Estonia & 33 & 22 & 3 & 6 & 1 & 3 & 3 & 0 & 7 & 3 & 3 & 11 & 16 & 17 & 13 & 9 & 18 & 2 & 170 & 3.46 \\
\hline Czech Rep & 28 & 37 & 2 & 1 & 4 & 7 & 4 & 6 & 16 & 15 & 5 & 7 & 22 & 24 & 14 & 2 & 20 & 5 & 219 & 4.45 \\
\hline Hungary & 16 & 43 & 7 & 20 & 4 & 10 & 5 & 5 & 69 & 33 & 3 & 14 & 12 & 31 & 17 & 8 & 16 & 0 & 313 & 6.36 \\
\hline Latvia & 25 & 35 & 0 & 7 & 0 & 0 & 1 & 0 & 3 & 1 & 0 & 7 & 13 & 17 & 11 & 2 & 20 & 0 & 142 & 2.89 \\
\hline Lithuania & 28 & 34 & 11 & 5 & 1 & 3 & 4 & 0 & 3 & 7 & 4 & 7 & 11 & 27 & 18 & 2 & 31 & 0 & 196 & 3.99 \\
\hline Slovakia & 12 & 25 & 1 & 4 & 5 & 2 & 1 & 4 & 7 & 14 & 1 & 11 & 26 & 24 & 12 & 2 & 15 & 2 & 168 & 3.42 \\
\hline Slovenia & 23 & 44 & 8 & 3 & 6 & 10 & 6 & 2 & 28 & 28 & 3 & 16 & 28 & 42 & 38 & 11 & 32 & 7 & 335 & 6.81 \\
\hline Bulgaria & 22 & 63 & 12 & 83 & 25 & 15 & 7 & 1 & 23 & 40 & 36 & 3 & 13 & 40 & 10 & 3 & 18 & 49 & 463 & 9.41 \\
\hline Croatia & 37 & 62 & 21 & 25 & 6 & 7 & 11 & 1 & 73 & 14 & 9 & 8 & 13 & 44 & 19 & 16 & 14 & 1 & 381 & 7.75 \\
\hline Montenegro & 3 & 0 & 0 & 0 & 0 & 0 & 1 & 0 & 2 & 0 & 0 & 0 & 0 & 2 & 3 & 0 & 0 & 1 & 12 & 0.24 \\
\hline Total & 477 & 931 & 147 & 347 & 133 & 94 & 88 & 41 & 378 & 350 & 85 & 193 & 269 & 521 & 236 & 104 & 439 & 85 & 4918 & 100 \\
\hline$\%$ & 9.7 & 18.9 & 2.99 & 7.06 & 2.7 & 1.9 & 1.789 & 0.8 & 7.69 & 7.12 & 1.7 & 3.92 & 5.47 & 10.6 & 4.8 & 2.11 & 8.93 & 1.7 & 100 & \\
\hline
\end{tabular}

Notes: Sectors 45-72 are considered as service sectors. 
Table D.2: Correlation

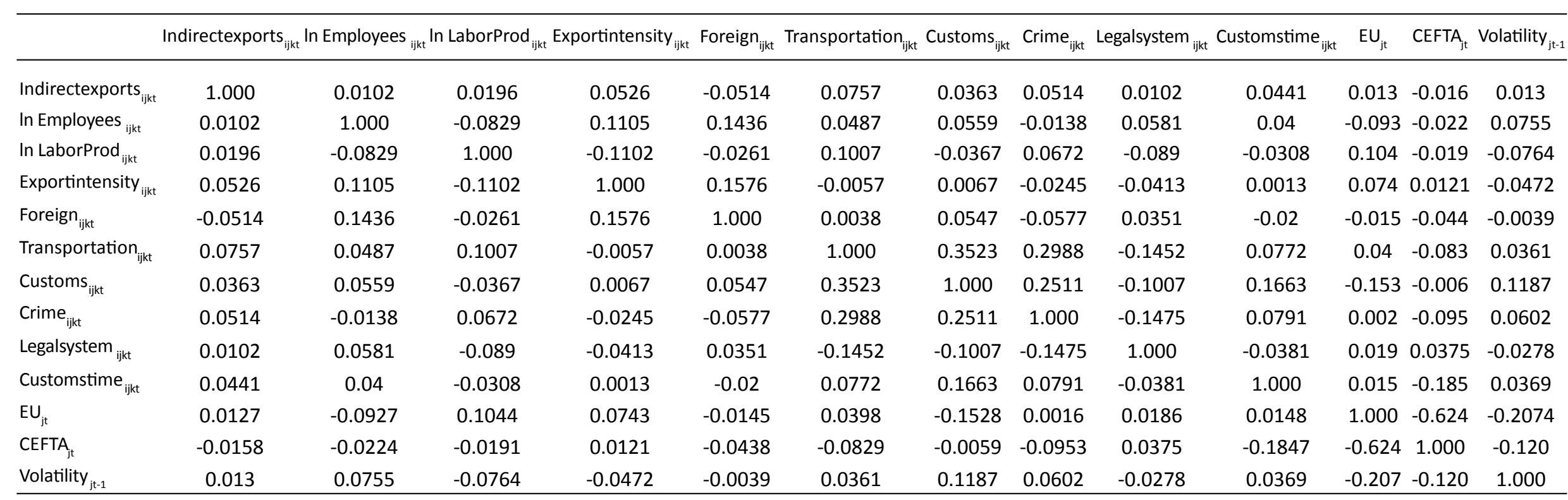




\section{E Political Determinants of International Arms Transfers}

Table E.1: List of Suppliers

\begin{tabular}{|c|c|c|c|c|}
\hline \multicolumn{5}{|c|}{ Country Name } \\
\hline Algeria & Czechoslovakia & Japan & Norway & Sweden \\
\hline Angola & DR Congo & Jordan & Oman & Switzerland \\
\hline Argentina & Denmark & Kazakhstan & Pakistan & Syria \\
\hline Australia & Egypt & Kenya & Panama & Taiwan \\
\hline Austria & Estonia & Kuwait & Peru & Thailand \\
\hline Bahrain & Finland & Kyrgyzstan & Philippines & Turkey \\
\hline Bangladesh & France & Latvia & Poland & Uganda \\
\hline Belarus & Gabon & Lebanon & Portugal & Ukraine \\
\hline Belgium & Georgia & Libya & Qatar & United Arab Emirates \\
\hline Bosnia and Herzegovina & Germany & Lithuania & Romania & United Kingdom \\
\hline Brazil & Ghana & Malawi & Russia & United States of America \\
\hline Bulgaria & Greece & Malaysia & Saudi Arabia & Uruguay \\
\hline Cambodia & Guatemala & Mexico & Senegal & Uzbekistan \\
\hline Canada & Hungary & Moldova & Serbia & Venezuela \\
\hline Chad & India & Morocco & Singapore & Vietnam \\
\hline Chile & Indonesia & Netherlands & Slovakia & Yemen Arab Republic \\
\hline China & Iran & New Zealand & South Africa & Yemen People's Republic \\
\hline Colombia & Iraq & Nicaragua & South Korea & Yugoslavia \\
\hline Croatia & Ireland & Niger & Soviet Union & Zambia \\
\hline Cuba & Israel & Nigeria & Spain & Zimbabwe \\
\hline Czech Republic & Italy & North Korea & Sudan & \\
\hline
\end{tabular}


Table E.2: List of Recipients

\begin{tabular}{|c|c|c|c|c|}
\hline \multicolumn{5}{|c|}{ Country Name } \\
\hline Afghanistan & Congo & India & Mozambique & South Korea \\
\hline Albania & Costa Rica & Indonesia & Myanmar & Spain \\
\hline Algeria & Croatia & Iran & Namibia & Sri Lanka \\
\hline Angola & Cuba & Iraq & Nepal & Sudan \\
\hline Argentina & Czech Republic & Ireland & Netherlands & Swaziland \\
\hline Armenia & Czechoslovakia & Israel & New Zealand & Sweden \\
\hline Australia & DR Congo & Italy & Nicaragua & Switzerland \\
\hline Austria & Denmark & Jamaica & Niger & Syria \\
\hline Azerbaijan & Djibouti & Japan & Nigeria & Taiwan \\
\hline Bahrain & Dominican Republic & Jordan & North Korea & Tajikistan \\
\hline Bangladesh & East Timor & Kazakhstan & Norway & Tanzania \\
\hline Belarus & Ecuador & Kenya & Oman & Thailand \\
\hline Belgium & Egypt & Kuwait & Pakistan & Togo \\
\hline Benin & El Salvador & Kyrgyzstan & Panama & Trinidad and Tobago \\
\hline Bolivia & Equatorial Guinea & Laos & Paraguay & Tunisia \\
\hline Bosnia and Herzegovina & Eritrea & Latvia & Peru & Turkey \\
\hline Botswana & Estonia & Lebanon & Philippines & Turkmenistan \\
\hline Brazil & Ethiopia & Lesotho & Poland & Uganda \\
\hline Bulgaria & Finland & Liberia & Portugal & United Arab Emirates \\
\hline Burkina Faso & France & Libya & Qatar & United Kingdom \\
\hline Burundi & Gabon & Lithuania & Romania & United States of America \\
\hline Cambodia & Gambia & Madagascar & Russia & Uruguay \\
\hline Cameroon & Georgia & Malawi & Rwanda & Venezuela \\
\hline Canada & Germany & Malaysia & Saudi Arabia & Vietnam \\
\hline Cape Verde & Ghana & Mali & Senegal & Yemen \\
\hline Central African Republic & Greece & Mauritania & Sierra Leone & Yemen Arab Republic \\
\hline Chad & Guatemala & Mauritius & Singapore & Yemen People's Republic \\
\hline Chile & Guinea & Mexico & Slovakia & Yugoslavia \\
\hline China & Guinea-Bissau & Moldova & Slovenia & Zambia \\
\hline Colombia & Honduras & Mongolia & Somalia & Zimbabwe \\
\hline Comoros & Hungary & Morocco & South Africa & \\
\hline
\end{tabular}


Table E.3: Transfers of Arms by Supplier

\begin{tabular}{|c|c|c|c|c|c|c|c|c|c|c|c|c|c|c|c|}
\hline \multirow{2}{*}{ Country } & \multicolumn{7}{|c|}{ Decade } & \multirow{2}{*}{ Country } & \multicolumn{7}{|c|}{ Decade } \\
\hline & 1 & 2 & 3 & 4 & 5 & 6 & All & & 1 & 2 & 3 & 4 & 5 & 6 & All \\
\hline Algeria & - & 1 & 0 & 1 & 0 & 0 & 2 & Lithuania & - & - & - & - & 0 & 1 & 1 \\
\hline Angola & - & - & 1 & 1 & 1 & 0 & 3 & Malawi & - & 0 & 0 & 0 & 1 & 0 & 1 \\
\hline Argentina & 0 & 4 & 6 & 7 & 4 & 4 & 25 & Malaysia & 0 & 0 & 1 & 1 & 1 & 0 & 3 \\
\hline Australia & 2 & 6 & 15 & 11 & 8 & 16 & 58 & Mexico & 1 & 0 & 0 & 0 & 0 & 0 & 1 \\
\hline Austria & 0 & 2 & 8 & 14 & 9 & 21 & 54 & Moldova & - & - & - & - & 6 & 6 & 12 \\
\hline Bahrain & - & - & 0 & 0 & 0 & 1 & 1 & Morocco & 0 & 1 & 1 & 0 & 0 & 0 & 2 \\
\hline Bangladesh & - & - & 0 & 1 & 0 & 0 & 1 & Netherlands & 22 & 43 & 74 & 70 & 77 & 91 & 377 \\
\hline Belarus & - & - & - & - & 25 & 19 & 44 & New Zealand & 0 & 3 & 4 & 2 & 3 & 2 & 14 \\
\hline Belgium & 2 & 14 & 1 & 10 & 13 & 24 & 64 & Nicaragua & 2 & 0 & 0 & 3 & 11 & 0 & 16 \\
\hline $\mathrm{BIH}$ & - & - & - & - & 0 & 1 & 1 & Niger & - & 0 & 1 & 0 & 0 & 0 & 1 \\
\hline Brazil & 0 & 4 & 22 & 53 & 12 & 18 & 109 & Nigeria & - & 0 & 0 & 1 & 0 & 0 & 1 \\
\hline Bulgaria & 0 & 0 & 0 & 5 & 25 & 17 & 47 & North Korea & - & - & - & - & 8 & 3 & 11 \\
\hline Cambodia & 0 & 0 & 0 & 0 & 3 & 0 & 3 & Norway & 2 & 8 & 7 & 12 & 17 & 22 & 68 \\
\hline Canada & 46 & 51 & 59 & 71 & 52 & 44 & 323 & Oman & - & - & 1 & 1 & 1 & 1 & 4 \\
\hline Chad & - & 0 & 0 & 2 & 0 & 0 & 2 & Pakistan & 0 & 1 & 1 & 1 & 1 & 6 & 10 \\
\hline Chile & 0 & 0 & 2 & 7 & 5 & 2 & 16 & Panama & 0 & 0 & 1 & 0 & 0 & 0 & 1 \\
\hline China & - & - & 53 & 144 & 127 & 108 & 432 & Peru & 0 & 0 & 0 & 2 & 0 & 3 & 5 \\
\hline Colombia & 0 & 0 & 0 & 0 & 0 & 1 & 1 & Poland & 2 & 9 & 15 & 8 & 29 & 21 & 84 \\
\hline Croatia & - & - & - & - & 0 & 1 & 1 & Portugal & 0 & 0 & 17 & 3 & 1 & 2 & 23 \\
\hline Cuba & 0 & 0 & 2 & 0 & 0 & 0 & 2 & Qatar & - & - & 0 & 0 & 4 & 1 & 5 \\
\hline Czech Republic & - & - & - & - & 33 & 30 & 63 & Romania & 0 & 0 & 7 & 11 & 11 & 4 & 33 \\
\hline Czechoslovakia & 4 & 19 & 15 & 7 & 4 & - & 49 & Russia & 215 & 628 & 905 & 828 & 303 & 300 & 3,179 \\
\hline DR Congo & - & 0 & 1 & 0 & 0 & 0 & 1 & Saudi Arabia & 1 & 1 & 3 & 5 & 1 & 1 & 12 \\
\hline Denmark & 0 & 6 & 1 & 9 & 15 & 12 & 43 & Senegal & - & 0 & 1 & 0 & 0 & 0 & 1 \\
\hline Egypt & 7 & 9 & 11 & 34 & 5 & 0 & 66 & Singapore & - & 1 & 4 & 13 & 4 & 7 & 29 \\
\hline Estonia & - & - & - & - & 1 & 0 & 1 & Slovakia & - & - & - & - & 17 & 9 & 26 \\
\hline Finland & 1 & 4 & 2 & 4 & 18 & 19 & 48 & South Africa & - & 2 & 2 & - & 25 & 45 & 74 \\
\hline France & 92 & 328 & 542 & 449 & 230 & 165 & 1,806 & South Korea & - & - & - & - & 12 & 13 & 25 \\
\hline Gabon & - & 0 & 1 & 0 & 0 & 0 & 1 & Spain & 1 & 2 & 15 & 49 & 36 & 41 & 144 \\
\hline Georgia & - & - & - & - & 2 & 2 & 4 & Sudan & 0 & 1 & 0 & 1 & 0 & 0 & 2 \\
\hline Germany & - & - & 137 & 155 & 235 & 180 & 707 & Sweden & 5 & 14 & 48 & 67 & 53 & 73 & 260 \\
\hline Ghana & - & 0 & 1 & 0 & 0 & 1 & 2 & Switzerland & - & - & - & - & - & 29 & 29 \\
\hline Greece & 0 & 0 & 0 & 0 & 2 & 3 & 5 & Syria & 0 & 1 & 2 & 10 & 2 & 1 & 16 \\
\hline Guatemala & 1 & 0 & 0 & 0 & 0 & 0 & 1 & Taiwan & 0 & 1 & 0 & - & - & - & 1 \\
\hline Hungary & 1 & 1 & 1 & 2 & 3 & 4 & 12 & Thailand & 0 & 0 & 0 & 0 & 0 & 1 & 1 \\
\hline India & 0 & 0 & 4 & 2 & 5 & 14 & 25 & Turkey & 0 & 0 & 1 & 0 & 5 & 20 & 26 \\
\hline Indonesia & 0 & 1 & 2 & 1 & 3 & 1 & 8 & Uganda & - & 1 & 0 & 0 & 0 & 0 & 1 \\
\hline Iran & 0 & 3 & 3 & 3 & 4 & 13 & 26 & Ukraine & - & - & - & - & 88 & 139 & 227 \\
\hline Iraq & 2 & 0 & 2 & 11 & 0 & 0 & 15 & UAE & - & - & 1 & 3 & 5 & 7 & 16 \\
\hline Ireland & 0 & 0 & 1 & 0 & 1 & 2 & 4 & United Kingdom & 311 & 280 & 310 & 307 & 183 & 83 & 1,474 \\
\hline Israel & 3 & 10 & 45 & 59 & 81 & 156 & 354 & USA & 849 & 1,042 & 1,225 & 1,127 & 980 & 718 & 5,941 \\
\hline Italy & 6 & 65 & 181 & 151 & 108 & 118 & 629 & Uruguay & 0 & 1 & 0 & 0 & 0 & 1 & 2 \\
\hline Japan & 5 & 12 & 6 & 4 & 2 & 1 & 30 & Uzbekistan & - & - & - & - & 0 & 2 & 2 \\
\hline Jordan & 1 & 0 & 4 & 8 & 3 & 5 & 21 & Venezuela & 0 & 1 & 1 & 0 & 0 & 3 & 5 \\
\hline Kazakhstan & - & - & - & - & 12 & 2 & 14 & Vietnam & - & - & 0 & 0 & 0 & 1 & 1 \\
\hline Kenya & - & 0 & 0 & 1 & 1 & 0 & 2 & Yemen AR & 0 & 0 & 0 & 1 & - & - & 1 \\
\hline Kuwait & - & 1 & 1 & 2 & 2 & 0 & 6 & Yemen PR & - & 0 & 2 & 1 & - & - & 3 \\
\hline Kyrgyzstan & - & - & - & - & 2 & 3 & 5 & Yugoslavia & 3 & 8 & 13 & 12 & 3 & 1 & 40 \\
\hline Latvia & - & - & - & - & 1 & 0 & 1 & Zambia & - & 0 & 0 & 1 & 0 & 0 & 1 \\
\hline Lebanon & 0 & 1 & 0 & 0 & 1 & 0 & 2 & Zimbabwe & - & - & - & 0 & 0 & 1 & 1 \\
\hline Libya & 0 & 0 & 6 & 32 & 3 & 7 & 48 & Total & 1,587 & 2,590 & 3,798 & 3,799 & 2,947 & 2,673 & 17,394 \\
\hline
\end{tabular}




\section{Table E.4: Variables}

\begin{tabular}{|c|c|}
\hline Variable & Description \\
\hline & Dependent Variables \\
\hline Trade $_{\mathrm{ijt}}$ & $=1$ if arms were exported from $i$ to $j$ in year $t$ \\
\hline \multirow[t]{2}{*}{ Volume $_{\mathrm{ijt}}$} & value of arms exported from $i$ to $j$ in year $t$ \\
\hline & Gravity Variables \\
\hline In GDP & natural logarithm of GDP in 1990 US\$ for i \\
\hline In $\mathrm{GDP}_{\mathrm{jt}}$ & natural logarithm of GDP in 1990 US\$ for $\mathrm{j}$ \\
\hline In GDPpc $c_{\text {it }}$ & natural logarithm of GDP per capita in 1990 US\$ for i \\
\hline In $G D P p c_{j t}$ & natural logarithm of GDP per capita in 1990 US\$ for $\mathrm{j}$ \\
\hline In Distance ${ }_{\mathrm{ij}}$ & natural logarithm of Distance between capitals of $i$ and $j$ in $\mathrm{km}$ \\
\hline Contiguity $_{\mathrm{ij}}$ & $=1$ if $\mathrm{i}$ and $\mathrm{j}$ share a common border \\
\hline Language $_{\mathrm{ij}}$ & $=1$ if a language is spoken by at least $9 \%$ of the population in $\mathrm{i}$ and $\mathrm{j}$ \\
\hline Colony $_{\mathrm{ij}}$ & $=1$ if $\mathrm{i}$ and $\mathrm{j}$ share a common colonial history \\
\hline \multirow[t]{2}{*}{ Landlocked $_{i j}$} & $=1$ if $\mathrm{i}$ or $\mathrm{j}$ are landlocked and 2 if both \\
\hline & Political Variables \\
\hline Polity $_{\text {it }}$ & interpolated and prolonged polity 2 of $\mathrm{i}$ in year $\mathrm{t}^{*}$ \\
\hline Polity $_{j \mathrm{t}}$ & interpolated and prolonged polity 2 of $j$ in year $t^{*}$ \\
\hline Polity_similarity ${ }_{\mathrm{ijt}}$ & absolute difference of Polity ${ }_{i t}$ and Polity ${ }_{j t}$ in year $t$ \\
\hline Polity_neigbours ${ }_{\text {it }}$ & mean of polity 2 index for contigous countries and within $3000 \mathrm{~km}$ of $\mathrm{i}$ in year $\mathrm{t}^{*}$ \\
\hline Polity_neigbours ${ }_{j t}$ & mean of polity 2 index for contigous countries and within $3000 \mathrm{~km}$ of $\mathrm{j}$ in year $\mathrm{t}^{*}$ \\
\hline USA $_{\text {it }}$ & UN General Assembly Voting similarity index (agree3un) for $\mathrm{i}$ with the USA in year $\mathrm{t}$ \\
\hline USA $_{\mathrm{jt}}$ & UN General Assembly Voting similarity index (agree3un) for i with the USA in year $t$ \\
\hline USA_similarity ${ }_{i j t}$ & absolute difference of USA ${ }_{i t}$ and USA ${ }_{j t}$ in year $t$ \\
\hline USA_neighbours $_{\text {it }}$ & mean of agree3un index for contigous countries and within $3000 \mathrm{~km}$ of $\mathrm{i}$ in year $\mathrm{t}$ \\
\hline \multirow[t]{2}{*}{ USA_neighbours $_{j \mathrm{t}}$} & mean of agree 3 un index for contigous countries and within $3000 \mathrm{~km}$ of $\mathrm{j}$ in year $\mathrm{t}$ \\
\hline & Military, Alliances and Conflicts \\
\hline Militarization $_{\text {it }}$ & share of military personnel of total population for $i$ in year $t$ \\
\hline Militarization $_{\mathrm{jt}}$ & share of military personnel of total population for $\mathrm{j}$ in year $\mathrm{t}$ \\
\hline Pact $_{\mathrm{ijt}}$ & $=1$ if any kind of military pact is in place between $i$ and $j$ in year $t$ \\
\hline Conflict $_{\mathrm{jt}}$ & $=1$ if an armed conflict is ongoing in $\mathrm{j}$ in year $\mathrm{t}$ \\
\hline Embargo $_{j \mathrm{t}}$ & $=1$ if a mandatory embargo was imposed by the UN against $\mathrm{c}$ in year $\mathrm{t}$ \\
\hline
\end{tabular}

* the polity2 variable was interpolated and prolonged over interruption and transition periods. 
Table E.5: Summary Statistics

\begin{tabular}{|c|c|c|c|c|c|}
\hline & Obs. & Mean & Std. Dev. & Min & Max \\
\hline Transfer $_{\mathrm{ijt}}$ & 530,205 & 0.0172 & 0.1302 & 0 & 1 \\
\hline In Value $_{\mathrm{ijt}}$ & 12,700 & 3.0766 & 1.7752 & 0 & 8.43 \\
\hline In $\mathrm{GDP}_{i \mathrm{t}}$ & 530,205 & 10.9758 & 1.7168 & 6.80 & 16.06 \\
\hline In $\mathrm{GDP}_{\mathrm{jt}}$ & 530,205 & 10.2121 & 1.9067 & 4.99 & 16.06 \\
\hline In GDPpc & 530,205 & 1.4370 & 1.1026 & -2.88 & 3.75 \\
\hline In $\mathrm{GDPpc}_{\mathrm{jt}}$ & 530,205 & 1.1143 & 1.1399 & -2.88 & 3.92 \\
\hline In Distance & 530,205 & 8.6510 & 0.7974 & 2.35 & 9.90 \\
\hline Contiguity $_{\mathrm{ij}}$ & 530,205 & 0.2968 & 0.4995 & 0 & 2 \\
\hline Language $_{\mathrm{ij}}$ & 530,205 & 0.0185 & 0.1347 & 0 & 1 \\
\hline Colony $_{\mathrm{ij}}$ & 530,205 & 0.1415 & 0.3485 & 0 & 1 \\
\hline Landlocked $_{i j}$ & 530,205 & 0.0268 & 0.1615 & 0 & 1 \\
\hline Polity $_{i t}$ & 530,205 & 1.0452 & 7.7146 & -10 & 10 \\
\hline Polity $_{j \mathrm{t}}$ & 530,205 & 0.3727 & 7.4651 & -10 & 10 \\
\hline Polity_similarity ${ }_{i j t}$ & 530,205 & 8.0176 & 6.5430 & 0 & 20 \\
\hline Polity_neigbours $_{\text {it }}$ & 530,205 & 0.3585 & 4.0740 & -8.6 & 10 \\
\hline Polity_neigbours ${ }_{j t}$ & 530,205 & -0.1974 & 4.0644 & -9 & 10 \\
\hline USA $_{\text {it }}$ & 530,205 & 0.4681 & 0.2107 & 0 & 1 \\
\hline USA $_{j \mathrm{t}}$ & 530,205 & 0.4434 & 0.2054 & 0 & 1 \\
\hline USA_similarity ${ }_{\mathrm{ijt}}$ & 530,205 & 0.1616 & 0.1493 & 0 & 1 \\
\hline USA_neighbours $_{\text {it }}$ & 530,205 & 0.4532 & 0.1577 & 0.14 & 0.98 \\
\hline USA_neighbours $_{\mathrm{jt}}$ & 530,205 & 0.4392 & 0.1646 & 0.14 & 0.98 \\
\hline Militarization $_{\mathrm{it}}$ & 530,205 & 0.0082 & 0.0084 & 0 & 0.08 \\
\hline Militarization $_{\mathrm{jt}}$ & 530,205 & 0.0069 & 0.0078 & 0 & 0.08 \\
\hline Conflict $_{j \mathrm{t}}$ & 530,205 & 0.1720 & 0.3774 & 0 & 1 \\
\hline Pact $_{i \mathrm{it}}$ & 530,205 & 0.0855 & 0.2797 & 0 & 1 \\
\hline Embargo $_{j \mathrm{t}}$ & 530,205 & 0.0054 & 0.0732 & 0 & 1 \\
\hline
\end{tabular}


Table E.6: Probability to Agree on a Transfer of Arms

\begin{tabular}{|c|c|c|c|c|c|c|c|}
\hline & $(1)$ & $(2)$ & (3) & (4) & (5) & (6) & (7) \\
\hline & LPM & Probit & $\begin{array}{c}\text { Probit } \\
1950-2007\end{array}$ & RE Probit & Mundlak & \begin{tabular}{|c|} 
Mundlak \\
$1950-1989$ \\
\end{tabular} & $\begin{array}{c}\text { Mundlak } \\
1990-2007 \\
\end{array}$ \\
\hline In $\mathrm{GDP}_{\mathrm{it}}$ & $\begin{array}{c}0.0180 * * * \\
(0.00122)\end{array}$ & $\begin{array}{c}0.713 * * * \\
(0.0455)\end{array}$ & $\begin{array}{c}0.355^{* *} \\
(0.165)\end{array}$ & $\begin{array}{c}0.729 * * * \\
(0.0507)\end{array}$ & $\begin{array}{c}0.722 * * * \\
(0.0516)\end{array}$ & $\begin{array}{c}0.755^{* * *} \\
(0.137)\end{array}$ & $\begin{array}{l}0.307^{*} \\
(0.161)\end{array}$ \\
\hline In $\mathrm{GDP}_{\mathrm{jt}}$ & $\begin{array}{c}0.00404 * * * \\
(0.00114)\end{array}$ & $\begin{array}{c}0.0574 \\
(0.0385)\end{array}$ & $\begin{array}{c}0.213 \\
(0.147)\end{array}$ & $\begin{array}{c}0.0571 \\
(0.0468)\end{array}$ & $\begin{array}{c}0.0218 \\
(0.0477)\end{array}$ & $\begin{array}{c}0.409 * * * \\
(0.0873)\end{array}$ & $\begin{array}{c}0.225 \\
(0.154)\end{array}$ \\
\hline In GDPpc ${ }_{i t}$ & $\begin{array}{c}-0.0133^{* * *} \\
(0.000951)\end{array}$ & $\begin{array}{c}-0.526 * * * \\
(0.0541)\end{array}$ & $\begin{array}{c}-0.538^{* * *} \\
(0.184)\end{array}$ & $\begin{array}{c}-0.550 * * * \\
(0.0606)\end{array}$ & $\begin{array}{c}-0.542^{* * *} \\
(0.0614)\end{array}$ & $\begin{array}{l}-0.286^{*} \\
(0.147)\end{array}$ & $\begin{array}{c}-0.451 * * \\
(0.192)\end{array}$ \\
\hline In GDPpc ${ }_{j t}$ & $\begin{array}{c}0.00377^{* * *} \\
(0.00114)\end{array}$ & $\begin{array}{c}0.185^{* * *} \\
(0.0370)\end{array}$ & $\begin{array}{c}0.212 \\
(0.137)\end{array}$ & $\begin{array}{c}0.244 * * * \\
(0.0442)\end{array}$ & $\begin{array}{c}0.287 * * * \\
(0.0451)\end{array}$ & $\begin{array}{c}-0.126 \\
(0.0835)\end{array}$ & $\begin{array}{l}-0.0364 \\
(0.152)\end{array}$ \\
\hline In Distance ${ }_{i j}$ & $\begin{array}{c}0.00175^{* * *} \\
(0.000369)\end{array}$ & $\begin{array}{c}-0.162 * * * \\
(0.0130)\end{array}$ & $\begin{array}{c}-0.169 * * * \\
(0.0135)\end{array}$ & $\begin{array}{c}-0.282^{* * * *} \\
(0.0250)\end{array}$ & $\begin{array}{c}-0.255^{* * *} \\
(0.0253)\end{array}$ & $\begin{array}{c}-0.321 * * * \\
(0.0347)\end{array}$ & $\begin{array}{c}-0.193 * * * \\
(0.0338)\end{array}$ \\
\hline Contiguity $_{\mathrm{ij}}$ & $\begin{array}{c}0.00848 * * * \\
(0.00183)\end{array}$ & $\begin{array}{c}0.0784^{* *} \\
(0.0322)\end{array}$ & $\begin{array}{c}0.0970 * * * \\
(0.0331)\end{array}$ & $\begin{array}{l}0.00317 \\
(0.0679)\end{array}$ & $\begin{array}{l}-0.0119 \\
(0.0677)\end{array}$ & $\begin{array}{l}0.00565 \\
(0.0931)\end{array}$ & $\begin{array}{c}0.105 \\
(0.0867)\end{array}$ \\
\hline Language $_{\mathrm{ij}}$ & $\begin{array}{c}-0.0086 * * * \\
(0.000730)\end{array}$ & $\begin{array}{c}0.0744 * * * \\
(0.0230)\end{array}$ & $\begin{array}{c}0.0689 * * * \\
(0.0239)\end{array}$ & $\begin{array}{c}0.122^{* * *} \\
(0.0469)\end{array}$ & $\begin{array}{l}0.114^{* *} \\
(0.0469)\end{array}$ & $\begin{array}{l}0.00317 \\
(0.0628)\end{array}$ & $\begin{array}{c}0.198 * * * \\
(0.0623)\end{array}$ \\
\hline Colony $_{\mathrm{ij}}$ & $\begin{array}{c}0.0580 * * * \\
(0.00309)\end{array}$ & $\begin{array}{c}0.518 * * * \\
(0.0264)\end{array}$ & $\begin{array}{c}0.552 * * * \\
(0.0276)\end{array}$ & $\begin{array}{c}0.588 * * * \\
(0.0667)\end{array}$ & $\begin{array}{c}0.599 * * * \\
(0.0671)\end{array}$ & $\begin{array}{c}0.901 * * * \\
(0.0856)\end{array}$ & $\begin{array}{c}0.269 * * * \\
(0.0884)\end{array}$ \\
\hline Landlocked $_{\mathrm{ij}}$ & $\begin{array}{c}0.0592 * * * \\
(0.00877)\end{array}$ & $\begin{array}{c}-0.229 \\
(0.247)\end{array}$ & $\begin{array}{c}0.508 \\
(0.329)\end{array}$ & $\begin{array}{l}-0.635^{*} \\
(0.342)\end{array}$ & $\begin{array}{c}-0.311 \\
(0.565)\end{array}$ & $\begin{array}{c}1.649 \\
(1.464)\end{array}$ & $\begin{array}{l}-0.672 \\
(0.741)\end{array}$ \\
\hline Polity $_{\text {it }}$ & $\begin{array}{c}0.00037 * * * \\
(3.54 \mathrm{e}-05)\end{array}$ & $\begin{array}{r}0.0183 * * * \\
(0.00264)\end{array}$ & $\begin{array}{l}-0.00 \\
(0.006\end{array}$ & $\begin{array}{c}0.0213 * * * \\
(0.00301)\end{array}$ & $\begin{array}{c}0.0193 * * * \\
(0.00305)\end{array}$ & $\begin{array}{c}0.00598 \\
(0.00515)\end{array}$ & $\begin{array}{l}-0.0191 * * \\
(0.00953)\end{array}$ \\
\hline Polity $_{\mathrm{jt}}$ & $\begin{array}{c}-0.00010 * * \\
(4.65 e-05)\end{array}$ & $\begin{array}{c}-0.0159 * * * \\
(0.00195)\end{array}$ & $\begin{array}{c}* 0.0179 * * * \\
(0.00307)\end{array}$ & $\begin{array}{c}-0.0123 * * * \\
(0.00219)\end{array}$ & $\begin{array}{c}-0.00753^{* * *} \\
(0.00230)\end{array}$ & $\begin{array}{c}-0.00698 * * \\
(0.00332)\end{array}$ & $\begin{array}{c}0.00519 \\
(0.00575)\end{array}$ \\
\hline Polity_diff ${ }_{i j t}$ & $\begin{array}{c}-0.00038 * * * \\
(2.85 e-05)\end{array}$ & $\begin{array}{c}-0.0152^{* * *} \\
(0.00139)\end{array}$ & $\begin{array}{c}*-0.0135 * * * \\
(0.00149)\end{array}$ & $\begin{array}{c}-0.0102 * * * \\
(0.00183)\end{array}$ & $\begin{array}{c}-0.00264 \\
(0.00213)\end{array}$ & $\begin{array}{l}-0.000231 \\
(0.00307)\end{array}$ & $\begin{array}{c}0.00359 \\
(0.00466)\end{array}$ \\
\hline Polity_region $_{\text {it }}$ & $\begin{array}{l}0.0000103 \\
(0.000118)\end{array}$ & $\begin{array}{c}0.00643 \\
(0.00490)\end{array}$ & $\begin{array}{r}0.0136^{*} \\
(0.00819)\end{array}$ & $\begin{array}{c}0.00820 \\
(0.00549)\end{array}$ & $\begin{array}{c}0.00687 \\
(0.00552)\end{array}$ & $\begin{array}{l}0.0302 * * * \\
(0.00846)\end{array}$ & $\begin{array}{c}-0.0383^{* *} \\
(0.0170)\end{array}$ \\
\hline Polity_region $_{\mathrm{jt}}$ & $\begin{array}{l}0.0000205 \\
(0.000132)\end{array}$ & $\begin{array}{l}-0.00220 \\
(0.00427)\end{array}$ & $\begin{array}{c}0.0124 \\
(0.00866)\end{array}$ & $\begin{array}{c}-0.00364 \\
(0.00477)\end{array}$ & $\begin{array}{l}-0.00 \\
(0.00\end{array}$ & $\begin{array}{l}0.0168 * * \\
(0.00759)\end{array}$ & $\begin{array}{c}-0.000119 \\
(0.0146)\end{array}$ \\
\hline votewithUSA $_{\text {it }}$ & $\begin{array}{c}-0.0090 * * * \\
(0.00280)\end{array}$ & $\begin{array}{c}0.641 * * * \\
(0.0932)\end{array}$ & $\begin{array}{c}0.691 * * * \\
(0.173)\end{array}$ & $\begin{array}{c}0.579 * * * \\
(0.105)\end{array}$ & $\begin{array}{c}0.436 * * * \\
(0.107)\end{array}$ & $\begin{array}{l}-0.163 \\
(0.162)\end{array}$ & $\begin{array}{c}0.289 \\
(0.267)\end{array}$ \\
\hline votewithUSA $_{\mathrm{jt}}$ & $\begin{array}{c}-0.00623^{* * *} \\
(0.00224)\end{array}$ & $\begin{array}{c}-0.855 * * * \\
(0.104)\end{array}$ & $\begin{array}{c}-0.966 * * * \\
(0.179)\end{array}$ & $\begin{array}{c}-0.759 * * * \\
(0.108)\end{array}$ & $\begin{array}{c}-0.689 * * * \\
(0.110)\end{array}$ & $\begin{array}{c}-0.930^{* * *} \\
(0.157)\end{array}$ & $\begin{array}{c}-0.214 \\
(0.289)\end{array}$ \\
\hline votewithUSA_diff ${ }_{\mathrm{ijt}}$ & $\begin{array}{r}-0.045 \\
(0.00\end{array}$ & $\begin{array}{c}-1.392 * * * \\
(0.0762)\end{array}$ & $\begin{array}{c}-1.928^{* * *} \\
(0.102)\end{array}$ & $\begin{array}{c}-1.196^{* * * *} \\
(0.0856)\end{array}$ & $\begin{array}{c}-0.941^{* * *} \\
(0.0919)\end{array}$ & *** & $\begin{array}{c}-0.528 * * \\
(0.211)\end{array}$ \\
\hline votewithUSA_region $_{i t}$ & $\begin{array}{c}0.0299 * * * \\
(0.00429)\end{array}$ & $\begin{array}{c}0.516 * * * \\
(0.123)\end{array}$ & $\begin{array}{c}0.210 \\
(0.283)\end{array}$ & $\begin{array}{c}0.530 * * * \\
(0.144)\end{array}$ & $\begin{array}{c}0.559 * * * \\
(0.145)\end{array}$ & $\begin{array}{c}0.593 * * * \\
(0.204)\end{array}$ & $\begin{array}{l}0.0924 \\
(0.662)\end{array}$ \\
\hline votewithUSA_region $_{\mathrm{jt}}$ & $\begin{array}{c}0.00393 \\
(0.00391)\end{array}$ & $\begin{array}{l}-0.0141 \\
(0.131)\end{array}$ & $\begin{array}{c}0.443 \\
(0.274)\end{array}$ & $\begin{array}{l}0.0517 \\
(0.149)\end{array}$ & $\begin{array}{c}0.109 \\
(0.150)\end{array}$ & $\begin{array}{l}0.0357 \\
(0.224)\end{array}$ & $\begin{array}{c}0.508 \\
(0.515)\end{array}$ \\
\hline Militarization $_{\mathrm{it}}$ & $\begin{array}{l}-0.0140 \\
(0.0364)\end{array}$ & $\begin{array}{c}-1.572 \\
(2.290)\end{array}$ & $\begin{array}{c}1.155 \\
(4.239)\end{array}$ & $\begin{array}{l}-1.226 \\
(2.465)\end{array}$ & $\begin{array}{c}-0.724 \\
(2.477)\end{array}$ & $\begin{array}{c}9.344 * * * \\
(3.350)\end{array}$ & $\begin{array}{c}-36.67 * * * \\
(8.026)\end{array}$ \\
\hline Militarization $_{\mathrm{jt}}$ & $\begin{array}{l}-0.0441 \\
(0.0504)\end{array}$ & $\begin{array}{l}-2.971^{*} \\
(1.523)\end{array}$ & $\begin{array}{l}-1.157 \\
(2.728)\end{array}$ & $\begin{array}{c}-4.497 * * \\
(1.795)\end{array}$ & $\begin{array}{c}-4.401 * * \\
(1.810)\end{array}$ & $\begin{array}{l}-3.139 \\
(2.383)\end{array}$ & $\begin{array}{c}-8.332 * * \\
(3.992)\end{array}$ \\
\hline Pact $_{i \mathrm{it}}$ & $\begin{array}{c}0.0397 * * * \\
(0.00129)\end{array}$ & $\begin{array}{c}0.497 * * * \\
(0.0229)\end{array}$ & $\begin{array}{c}0.544 * * * \\
(0.0250)\end{array}$ & $\begin{array}{c}0.412 * * * \\
(0.0352)\end{array}$ & $\begin{array}{c}0.355^{* * * *} \\
(0.0356)\end{array}$ & $\begin{array}{c}0.433 * * * \\
(0.0505)\end{array}$ & $\begin{array}{c}0.202 * * * \\
(0.0616)\end{array}$ \\
\hline Conflict $_{j t}$ & $\begin{array}{c}0.00496 * * * \\
(0.000648)\end{array}$ & $\begin{array}{c}0.182 * * * \\
(0.0205)\end{array}$ & $\begin{array}{c}0.131 * * * \\
(0.0285)\end{array}$ & $\begin{array}{c}0.190 * * * \\
(0.0225)\end{array}$ & $\begin{array}{c}0.189 * * * \\
(0.0225)\end{array}$ & $\begin{array}{c}0.166 * * * \\
(0.0317)\end{array}$ & $\begin{array}{c}0.203 * * * \\
(0.0443)\end{array}$ \\
\hline Embargo $_{j t}$ & $\begin{array}{c}-0.00925 * * * \\
(0.00196)\end{array}$ & $\begin{array}{c}-0.541 * * * \\
(0.135)\end{array}$ & $\begin{array}{l}-0.147 \\
(0.169)\end{array}$ & $\begin{array}{c}-0.628^{* * *} \\
(0.139)\end{array}$ & $\begin{array}{c}-0.644 * * * \\
(0.140)\end{array}$ & - & $\begin{array}{c}-0.545 * * * \\
(0.161)\end{array}$ \\
\hline $\begin{array}{l}\text { Constant } \\
\text { Year Dummies }\end{array}$ & $\begin{array}{c}-0.304 * * * \\
(0.0261) \\
\text { Yes*** }\end{array}$ & $\begin{array}{c}-8.242 * * * \\
(0.780) \\
\text { Yes*** }\end{array}$ & $\begin{array}{c}-5.527^{* *} \\
(2.630) \\
\text { Yes*** }\end{array}$ & $\begin{array}{c}-7.468^{* * *} \\
(0.942) \\
\text { Yes*** }\end{array}$ & $\begin{array}{c}-15.16 * * * \\
(3.125) \\
\text { Yes*** }\end{array}$ & $\begin{array}{c}-16.88^{* *} \\
(7.313) \\
\text { Yes*** }\end{array}$ & $\begin{array}{c}-12.20 * * * \\
(4.300) \\
\text { Yes*** }\end{array}$ \\
\hline $\begin{array}{l}\text { Country Dum. } \\
\text { Country-Decade }\end{array}$ & $\begin{array}{l}\text { Yes*** } \\
\text { No }\end{array}$ & $\begin{array}{c}\text { Yes*** } \\
\text { No }\end{array}$ & $\begin{array}{c}\text { No } \\
\text { Yes*** }\end{array}$ & $\begin{array}{c}\text { Yes*** } \\
\text { No }\end{array}$ & $\begin{array}{l}\text { Yes*** } \\
\text { No }\end{array}$ & $\begin{array}{l}\text { Yes*** } \\
\text { No }\end{array}$ & $\begin{array}{l}\text { Yes*** } \\
\text { No }\end{array}$ \\
\hline Observations & 530,205 & 530,205 & 333,932 & 530,205 & 530,205 & 273,521 & 186,549 \\
\hline$R^{\wedge} 2$ (pseudo $\left.R^{\wedge} 2\right)$ & 0.165 & $(0.440)$ & $(0.421)$ & - & - & - & - \\
\hline
\end{tabular}

Notes: Robust standard errors in parentheses; ${ }^{* *} p<0.01,{ }^{* *} p<0.05,{ }^{*} p<0.1$; 
Table E.7: Volume of Transferred Arms

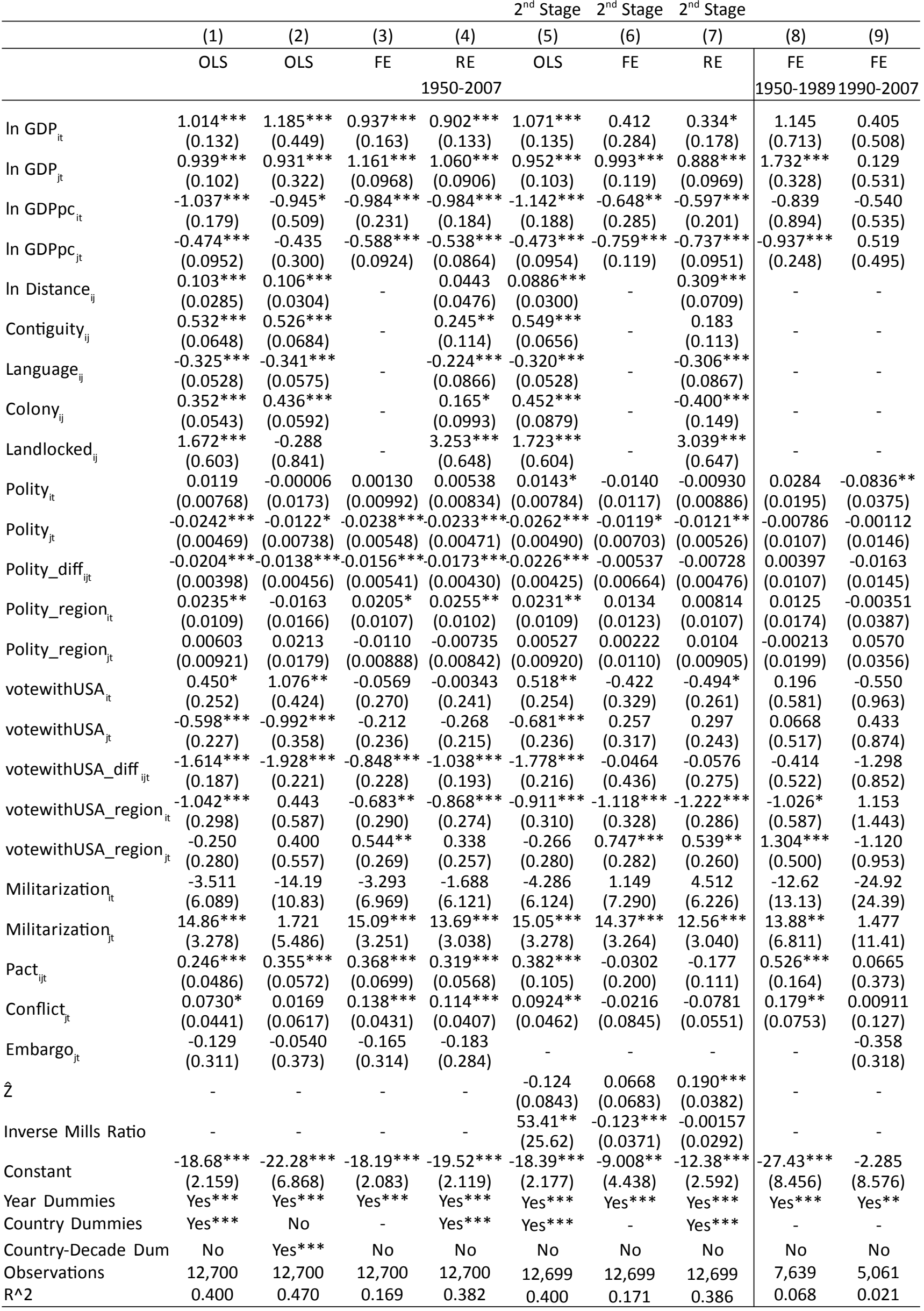

Notes: Robust standard errors in parentheses; ${ }^{* * *} p<0.01,{ }^{* *} p<0.05,{ }^{*} p<0.1$; 
Table E.8: Probability to Trade - Arms vs. Goods (1962-2007)

\begin{tabular}{|c|c|c|c|c|c|c|c|c|}
\hline & $\begin{array}{c}\text { (1) } \\
\text { Probit }\end{array}$ & $\begin{array}{c}(2) \\
\text { Probit }\end{array}$ & $\begin{array}{c}\text { (3) } \\
\text { Probit }\end{array}$ & $\begin{array}{c}\text { (4) } \\
\text { Probit }\end{array}$ & $\begin{array}{c}\text { (5) } \\
\text { Probit RE }\end{array}$ & $\begin{array}{c}\text { (6) } \\
\text { Probit RE }\end{array}$ & $\begin{array}{c}\text { (7) } \\
\text { Probit RE }\end{array}$ & $\begin{array}{c}\text { (8) } \\
\text { Probit RE }\end{array}$ \\
\hline & $s$ & Is & & $s$ & $s$ & Is & $s$ & Is \\
\hline In $\mathrm{GDP}_{\text {it }}$ & $*$ & ** & $\begin{array}{r}1.52 \\
(0.2\end{array}$ & & & $*$ & $\begin{array}{c}1.092 * * * \\
(0.0891)\end{array}$ & 10. \\
\hline In $\mathrm{GDP}_{\mathrm{jt}}$ & $\begin{array}{c}-0.132 * * * \\
(0.0484)\end{array}$ & $\begin{array}{c}0.536^{* * *} \\
(0.0292)\end{array}$ & $\begin{array}{l}-0.0486 \\
(0.163)\end{array}$ & $\begin{array}{c}0.131 \\
(0.0831)\end{array}$ & $\begin{array}{c}0.130 * * * \\
(0.0112)\end{array}$ & $\begin{array}{l}0.626 * * * \\
(0.0115)\end{array}$ & $\begin{array}{c}-0.161^{* * *} \\
(0.0598)\end{array}$ & $\begin{array}{c}0.799 * * * \\
(0.0350)\end{array}$ \\
\hline$P p c_{i t}$ & $\begin{array}{r}-0.7 \\
10.0\end{array}$ & $\begin{array}{c}0.242 * * * \\
(0.0283)\end{array}$ & $\begin{array}{r}-1.30 \\
(0.2\end{array}$ & $\begin{array}{r}0 . \\
(0.0\end{array}$ & $\begin{array}{r}-0.25 \\
(0.0\end{array}$ & $\begin{array}{l}0.252 \\
(0.01\end{array}$ & $\begin{array}{c}-0.874 * * * \\
(0.0909)\end{array}$ & $\begin{array}{c}0.407 * * * \\
(0.0318)\end{array}$ \\
\hline In $\mathrm{GDPp}_{\mathrm{jt}}$ & $\begin{array}{l}0.33 \\
(0.0\end{array}$ & $\begin{array}{r}-0.17 \\
(0.02\end{array}$ & $\begin{array}{c}0.44 \\
10 .\end{array}$ & & $\begin{array}{l}0.04 \\
10.0\end{array}$ & $\begin{array}{r}-0.113 \\
(0.01\end{array}$ & $\begin{array}{l}0.412 \\
(0.05\end{array}$ & $\begin{array}{r}-0 . \\
10\end{array}$ \\
\hline In Distance $_{i j}$ & $\begin{array}{r}-0.1 \\
(0.0\end{array}$ & $\begin{array}{l}-0.65 \\
10.00\end{array}$ & $\begin{array}{c}-0.2 \\
10.0\end{array}$ & & $\begin{array}{r}-0.23 \\
10.0\end{array}$ & $\begin{array}{r}-0.92 \\
(0.02\end{array}$ & $\begin{array}{r}-0.29 \epsilon \\
(0.02\end{array}$ & $\begin{array}{r}-1 . \\
1.0\end{array}$ \\
\hline ity $_{i j}$ & & & & & & $\begin{array}{l}-0.1 \\
(0.1\end{array}$ & $\begin{array}{c}0.0150 \\
(0.0721)\end{array}$ & \\
\hline$g_{i j}$ & $\begin{array}{l}0.1 \\
(0 .\end{array}$ & $\begin{array}{l}0.3 \\
10\end{array}$ & $\begin{array}{l}0.1 \\
10\end{array}$ & & & $\begin{array}{l}0.87 \\
(0.0\end{array}$ & $\begin{array}{l}0.15 \\
(0.0\end{array}$ & $\begin{array}{l}0.5 \\
10\end{array}$ \\
\hline Colony & & & & & & $\begin{array}{r}1.38 \\
(0.2\end{array}$ & $\begin{array}{l}0.48 \\
0.0\end{array}$ & 7) \\
\hline ndlocked $_{i j}$ & -1. & $\begin{array}{r}-1.0 \\
10\end{array}$ & & $\begin{array}{r}-2.4 \\
10 .\end{array}$ & & $\begin{array}{r}-0.25 \\
(0.0\end{array}$ & $\begin{array}{r}-1.21 \\
(0.4\end{array}$ & \\
\hline ity $_{\text {it }}$ & & $\begin{array}{l}0.0 \\
(0.0\end{array}$ & $\begin{array}{l}-0.0 \\
(0.0\end{array}$ & $\begin{array}{r}0.00 \\
(0.0\end{array}$ & $\begin{array}{l}{ }^{k} 0.02 \\
(0.01\end{array}$ & $\begin{array}{l}0.020 \\
10.00\end{array}$ & $\begin{array}{r}0.014 \\
(0.00\end{array}$ & \\
\hline Polity & & & & & & & & \\
\hline lity_diff & & & & & & & & \\
\hline region $_{\text {it }}$ & & & & & & $\begin{array}{l}0.01 \\
10.0\end{array}$ & $\begin{array}{r}0.0 \\
10.0\end{array}$ & \\
\hline jt & & & & & & & & \\
\hline rith 11 & 0.6 & & & & & $\begin{array}{l}0.22 \\
(0.0\end{array}$ & $\begin{array}{r}0.5 \\
10\end{array}$ & \\
\hline jt & & $\begin{array}{l}0.3 \\
10\end{array}$ & $\begin{array}{r}-0.6 \\
10\end{array}$ & & & $\begin{array}{r}0.30 \\
(0.0\end{array}$ & $\begin{array}{l}-0.0 \\
(0.1\end{array}$ & 0. \\
\hline thUSA_diff $_{\mathrm{ijt}}$ & $\begin{array}{r}1 \\
-0 . \\
10\end{array}$ & $\begin{array}{r}-1 . \\
10\end{array}$ & $\begin{array}{r}-1.2 \\
10\end{array}$ & -1 & -0.5 & $\begin{array}{r}-0.1 \\
(0.0\end{array}$ & $\begin{array}{r}-0.89 \\
(0.1\end{array}$ & $\begin{array}{l}-0 \\
(C\end{array}$ \\
\hline votewithUSA_region $_{\text {it }}$ & 0. & & & $\begin{array}{r}-0 . \\
1 C\end{array}$ & ** & $\begin{array}{r}-0.6 \\
10\end{array}$ & $\begin{array}{r}0.7 \\
10\end{array}$ & *** \\
\hline$S A \_r$ & $\begin{array}{l}0.3 \\
10\end{array}$ & $\begin{array}{l}0 . \\
0 .\end{array}$ & & & & $\begin{array}{r}-0.31 \\
10.1\end{array}$ & $\begin{array}{l}0.46 \\
(0.1\end{array}$ & $\begin{array}{l}\text { *** } \\
19)\end{array}$ \\
\hline tion $_{\text {it }}$ & $\begin{array}{l}-2 . \\
(3.1\end{array}$ & $\begin{array}{r}-27 \\
(1\end{array}$ & 0 & $\begin{array}{r}-6.5 \\
12\end{array}$ & 25 & $\begin{array}{r}-26.8 \\
(1 .\end{array}$ & $\begin{array}{l}-3 . \\
13.3\end{array}$ & -29 \\
\hline Militariz & $\begin{array}{r}-6 . \\
(1\end{array}$ & $\begin{array}{r}-2.5 \\
10\end{array}$ & & & & & $\begin{array}{r}-7.79 \\
(2.1\end{array}$ & 2. \\
\hline & *** & $\begin{array}{c}0.728 * * * \\
(0.0215)\end{array}$ & $\begin{array}{l}L^{* * *} \\
285)\end{array}$ & $\begin{array}{l}* * * \\
25)\end{array}$ & $\begin{array}{l}* * * \\
06)\end{array}$ & $\begin{array}{c}0.0432 \\
(0.0492)\end{array}$ & $\begin{array}{c}0.312^{* * *} \\
(0.0409)\end{array}$ & *** \\
\hline Conf & $\begin{array}{c}0.1 \\
10 .\end{array}$ & $\begin{array}{c}-0.0374 * * * \\
(0.0114)\end{array}$ & $\begin{array}{c}0.1 \\
(0 .\end{array}$ & $78^{*}$ & $\begin{array}{l}0.2 \\
10\end{array}$ & $\begin{array}{c}-0.0925^{* * *} \\
(0.0134)\end{array}$ & $\begin{array}{c}0.166 * * * \\
(0.0258)\end{array}$ & $\begin{array}{c}-0.0706 * * * \\
(0.0137)\end{array}$ \\
\hline Emb & $\begin{array}{r}-0.5 € \\
10 .\end{array}$ & $\begin{array}{r}-0.5 \\
(0 . C\end{array}$ & 4 & $\begin{array}{r}-0 . \\
10\end{array}$ & $\begin{array}{c}-0.722 * * * \\
(0.159)\end{array}$ & $\begin{array}{c}-0.554^{* * *} \\
(0.0511)\end{array}$ & $\begin{array}{c}-0.692 * * * \\
(0.160)\end{array}$ & $\begin{array}{r}-0.6 \\
10 .\end{array}$ \\
\hline ant & $\begin{array}{c}-10.03 * * * \\
(1.215)\end{array}$ & $\begin{array}{l}-0.573 \\
(0.607)\end{array}$ & $\begin{array}{c}-18.31 * * * \\
(3.939)\end{array}$ & $\begin{array}{c}7.992 * * * \\
(1.571)\end{array}$ & $\begin{array}{l}-0.722 * * * \\
-9.128 * * *\end{array}$ & $\begin{array}{l}-0.554 * * * \\
-4.247^{* * *}\end{array}$ & $\begin{array}{c}(1.399) \\
-10.35^{* * *}\end{array}$ & $\begin{array}{l}(0.792) \\
-0.181\end{array}$ \\
\hline & & Yes*** & Yes*** & Yes*** & Yes*** & Yes*** & Yes*** & Yes*** \\
\hline Coun & Yes $* * *$ & Yes*** & No & No & No & No & Yes*** & Yes*** \\
\hline Country-Decade Dum. & No & No & Yes*** & Yes*** & No & No & No & No \\
\hline Observations & 340,391 & 370,438 & 232,005 & 347,400 & 373,290 & 373,290 & 373,290 & 373,290 \\
\hline Pseudo $\mathrm{R}^{\wedge} 2$ & 0.415 & 0.512 & 0.398 & 0.529 & - & - & - & - \\
\hline
\end{tabular}

Notes: (robust) standard errors in parentheses; *** $p<0.01, * * p<0.05, * p<0.1$; 
Table E.9: Volume of Trade - Arms vs. Goods (1962-2007)

\begin{tabular}{|c|c|c|c|c|c|c|c|c|}
\hline & (1) & $(2)$ & (3) & (4) & (5) & (6) & (7) & (8) \\
\hline & OLS & OLS & OLS & OLS & $\mathrm{FE}$ & FE & RE & RE \\
\hline & Arms & Goods & Arms & Goods & Arms & Joods & Arms & Goods \\
\hline In $G D P_{i t}$ & $\begin{array}{l}-0 \\
0 .\end{array}$ & & $\begin{array}{l}2 \\
9)\end{array}$ & $* *$ & $\begin{array}{l}* * \\
4)\end{array}$ & ** & $\begin{array}{l}-1.242 \\
(0.761)\end{array}$ & $* *$ \\
\hline In GDP ${ }_{j t}$ & $\begin{array}{c}0.645^{* * *} \\
(0.126)\end{array}$ & $\begin{array}{c}1.390 * * * \\
(0.0273)\end{array}$ & $\begin{array}{c}0.965 * * \\
(0.384)\end{array}$ & $\begin{array}{l}0.752 \\
(0.08\end{array}$ & $\begin{array}{c}0.915^{* * *} \\
(0.326)\end{array}$ & $\begin{array}{c}1.020 * * * \\
(0.0606)\end{array}$ & $\begin{array}{c}0.910 * * * \\
(0.320)\end{array}$ & $\begin{array}{l}0.99 \\
10.0\end{array}$ \\
\hline In $\mathrm{GDPpc}_{\text {it }}$ & $\begin{array}{c}0.138 \\
(0.286)\end{array}$ & $\begin{array}{l}0.656^{\prime} \\
(0.035\end{array}$ & $\begin{array}{c}0.544 \\
(0.737)\end{array}$ & $\begin{array}{l}0.0583 \\
(0.104)\end{array}$ & $\begin{array}{l}1.551^{*} \\
(0.847)\end{array}$ & $\begin{array}{l}-0.125^{* *} \\
(0.0636)\end{array}$ & $\begin{array}{c}0.969 \\
(0.763)\end{array}$ & $\begin{array}{l}-0.107^{*} \\
(0.0636)\end{array}$ \\
\hline In $\mathrm{GDPpc}_{\mathrm{jt}}$ & $\begin{array}{l}-0.206^{*} \\
(0.113)\end{array}$ & $\begin{array}{c}-0.308 \\
(0.02\end{array}$ & $\begin{array}{c}-0.420 \\
(0.348)\end{array}$ & $\begin{array}{c}0.141^{*} \\
(0.0764)\end{array}$ & $\begin{array}{l}-0.247 \\
(0.295)\end{array}$ & $\begin{array}{c}0.0156 \\
(0.0558)\end{array}$ & $\begin{array}{c}-0.338 \\
(0.289)\end{array}$ & $\begin{array}{c}0.0273 \\
(0.0558)\end{array}$ \\
\hline In Distance ${ }_{\mathrm{ij}}$ & $\begin{array}{r}0.0993 \\
(0.03\end{array}$ & $\begin{array}{r}-1.357 \\
(0.006\end{array}$ & $\begin{array}{l}0.083 \\
(0.03\end{array}$ & $\begin{array}{l}-1.372 \\
(0.006\end{array}$ & $1.0-$ & 10. & $\begin{array}{l}-0.00474 \\
(0.0543)\end{array}$ & $\begin{array}{r}-1.43 \\
10.0\end{array}$ \\
\hline Con & ) & $\begin{array}{l}0.48 \\
(0.0\end{array}$ & $\begin{array}{l}0.617 \\
(0.07\end{array}$ & $\begin{array}{r}0.47 \\
(0.0\end{array}$ & - & - & $\begin{array}{c}0.338 * * * \\
(0.130)\end{array}$ & $* *$ \\
\hline Lang & $\begin{array}{r}-0.3 \\
(0.0\end{array}$ & $\begin{array}{l}0.63 \\
(0.0\end{array}$ & $\begin{array}{r}-0.325 \\
(0.06\end{array}$ & $\begin{array}{l}0.63 \\
(0.0\end{array}$ & - & - & $\begin{array}{c}-0.253^{* * *} \\
(0.0961)\end{array}$ & $\begin{array}{c}0.672 * * * \\
(0.0452)\end{array}$ \\
\hline Colo & $\begin{array}{l}0.33 \\
(0.0\end{array}$ & $\begin{array}{l}1.12 \\
(0.0\end{array}$ & $\begin{array}{l}0.376 \\
(0.06\end{array}$ & $\begin{array}{l}1.15 \\
(0.0\end{array}$ & - & - & & $\begin{array}{l}1.20 \\
(0.0\end{array}$ \\
\hline ocked $_{i j}$ & & -0. & & $\begin{array}{r}-2.98 \\
(0.1\end{array}$ & - & - & & ** \\
\hline Polit & & $\begin{array}{l}0.0 \\
0.0\end{array}$ & & & & & & \\
\hline Polit & $\begin{array}{r}-0.0202 \\
(0.0055\end{array}$ & $\begin{array}{l}0.001 \\
(0.00\end{array}$ & $\begin{array}{r}-0.0 \\
(0.00\end{array}$ & $\begin{array}{r}-0.005 \\
(0.00\end{array}$ & $\begin{array}{l}0.0 \\
10.0\end{array}$ & $\begin{array}{l}-0.0 \\
10 .\end{array}$ & $\begin{array}{l}-0.00 \\
(0.008\end{array}$ & $\begin{array}{r}-0.00 \\
(0.0\end{array}$ \\
\hline Polity_diff & & $\begin{array}{l}-0.00 \\
(0.0\end{array}$ & & & $\begin{array}{r}0.0 \\
(0.0\end{array}$ & & & \\
\hline gion $_{\text {it }}$ & & $\begin{array}{l}0.01 \\
(0.0\end{array}$ & & & & & & \\
\hline Poli & $\begin{array}{l}-0 \\
(0\end{array}$ & $\begin{array}{l}-0 . \\
0.0\end{array}$ & $\begin{array}{r}0.0 \\
(0.0\end{array}$ & (**) & $\begin{array}{l}0 . \\
(0 .\end{array}$ & $\begin{array}{l}-0 \\
10\end{array}$ & $\begin{array}{r}0.01 \\
(0.01\end{array}$ & 7* \\
\hline votewithUSA $_{\text {it }}$ & 0. & $\begin{array}{r}-0.5 \\
(0.0\end{array}$ & $\begin{array}{r}1.8 \\
10\end{array}$ & & & 0 & ** & L) \\
\hline withUS & -1 & $\begin{array}{r}0 \\
10\end{array}$ & & & & & & \\
\hline ithUSA_di & $\begin{array}{c}-1.323 * * * \\
(0.224)\end{array}$ & $\begin{array}{c}0.0976 * * * \\
(0.0342)\end{array}$ & $\begin{array}{r}-1.76 \\
(0.2\end{array}$ & $\begin{array}{l}0 . \\
10 .\end{array}$ & & $\begin{array}{l}18 * * * \\
387)\end{array}$ & $\begin{array}{c}-0.941 * * * \\
(0.286)\end{array}$ & $\begin{array}{c}-1.120 * * * \\
(0.0376)\end{array}$ \\
\hline vithUSA_region $_{\text {it }}$ & $\begin{array}{c}-0.8 \\
10.3\end{array}$ & $\begin{array}{r}-0.4 \\
10 .\end{array}$ & $\begin{array}{l}-0.0 \\
(0.7\end{array}$ & $\begin{array}{r}-0.4 \\
10\end{array}$ & $\begin{array}{l}0 . \\
0 .\end{array}$ & -0. & $\begin{array}{l}0 . \\
0 .\end{array}$ & $\begin{array}{c}-0.514 * * * \\
(0.127)\end{array}$ \\
\hline votewithUSA_region $_{\mathrm{jt}}$ & $\begin{array}{c}-0.7 \\
10\end{array}$ & & & & & & & \\
\hline Milit & $\begin{array}{l}-10 \\
(7.8\end{array}$ & $\begin{array}{r}-20 . \\
(1 .\end{array}$ & $\begin{array}{l}-5 . \\
(15\end{array}$ & $\begin{array}{r}0 \\
(2\end{array}$ & & & & 2. \\
\hline Milit & $\begin{array}{c}8.293 * * \\
(4.089)\end{array}$ & $\begin{array}{r}-6.30 \\
(1.1\end{array}$ & $\begin{array}{l}-0.0534 \\
(6.847)\end{array}$ & $3.540^{*}$ & 4.053 & $\begin{array}{r}4.0 \\
(1\end{array}$ & $\begin{array}{c}1.788 \\
(6.031)\end{array}$ & $\begin{array}{c}3.959 * * * \\
(1.285)\end{array}$ \\
\hline & $\begin{array}{l}0.24 \\
(0.0\end{array}$ & $\begin{array}{c}0.1 \\
0 .\end{array}$ & $\begin{array}{l}0.2 \\
10 .\end{array}$ & & $\begin{array}{l}0 . \\
10\end{array}$ & $\begin{array}{l}0.3 \\
10\end{array}$ & ** & $\begin{array}{l}0.3 \\
10\end{array}$ \\
\hline Con & $\begin{array}{c}-0.000576 \\
(0.0495)\end{array}$ & $\begin{array}{l}-0.00 \\
(0.01\end{array}$ & $\begin{array}{l}-0.0243 \\
(0.0671)\end{array}$ & $\begin{array}{l}0.00698 \\
(0.0167)\end{array}$ & $\begin{array}{c}0.0106 \\
(0.0608)\end{array}$ & $\begin{array}{r}0.000 \\
(0.01\end{array}$ & $\begin{array}{l}0.00423 \\
(0.0590)\end{array}$ & $\begin{array}{c}0.000913 \\
(0.0119)\end{array}$ \\
\hline & $\begin{array}{c}0.131 \\
(0.340)\end{array}$ & $\begin{array}{c}-0.347^{* * *} \\
(0.0582)\end{array}$ & $\begin{array}{c}-0.00512 \\
(0.410)\end{array}$ & $\begin{array}{c}-0.254 * * * \\
(0.0749)\end{array}$ & $\begin{array}{l}-0.147 \\
(0.366)\end{array}$ & $\begin{array}{c}-0.202^{* * *} \\
(0.0511)\end{array}$ & $\begin{array}{l}-0.106 \\
(0.346)\end{array}$ & $\begin{array}{c}-0.200 * * * \\
(0.0512)\end{array}$ \\
\hline Cons & $\begin{array}{c}0.306 \\
(3.457)\end{array}$ & $\begin{array}{c}-1.931 * * * \\
(0.602)\end{array}$ & $\begin{array}{c}0.149 \\
(10.32)\end{array}$ & $\begin{array}{c}10.97^{* * *} \\
(1.758)\end{array}$ & $\begin{array}{c}10.38 \\
(9.570)\end{array}$ & $\begin{array}{l}-7.083 \\
(1,711)\end{array}$ & $\begin{array}{c}8.222 \\
(10.24)\end{array}$ & $\begin{array}{c}6.402 * * * \\
(1.211)\end{array}$ \\
\hline 10 & Yes*** & Yes*** & Yes*** & Yes*** & Yes*** & Yes*** & Yes*** & Yes*** \\
\hline Country Dummies & Yes*** & Yes*** & No & No & - & - & No & No \\
\hline Country-Decade Dum. & No & No & Yes*** & Yes*** & Yes*** & Yes*** & Yes*** & Yes*** \\
\hline Observations & 10,282 & 253 & 10,282 & 285,374 & 10,282 & 285,374 & 10,282 & 285,374 \\
\hline $\mathrm{R}^{\wedge} 2$ & 0.343 & 0.728 & 0.407 & 0.748 & 0.001 & 0.400 & 0.381 & 0.742 \\
\hline
\end{tabular}

Notes: Robust standard errors in parentheses; ${ }^{* *} p<0.01,{ }^{* *} p<0.05,{ }^{*} p<0.1$; 
Table E.10: Probability to Agree on a Transfer of Arms with Lagged Measures of Political Orientation (1953-2007)

\begin{tabular}{|c|c|c|c|c|c|c|}
\hline & $\begin{array}{c}\text { (1) } \\
\text { Probit }\end{array}$ & $\begin{array}{c}(2) \\
\text { Probit }\end{array}$ & $\begin{array}{c}\text { (3) } \\
\text { Probit }\end{array}$ & $\begin{array}{c}(4) \\
\text { Probit }\end{array}$ & $\begin{array}{c}\text { (5) } \\
\text { RE Probit }\end{array}$ & $\begin{array}{c}\text { (6) } \\
\text { RE Probit }\end{array}$ \\
\hline In $\mathrm{GDP}_{\text {it }}$ & $\begin{array}{l}0.456 * * * \\
(0.00670)\end{array}$ & $\begin{array}{c}0.761^{* * *} \\
(0.0499)\end{array}$ & $\begin{array}{c}0.545^{* * *} \\
(0.0447)\end{array}$ & $\begin{array}{c}0.641 * * * \\
(0.167)\end{array}$ & $\begin{array}{c}0.475 * * * \\
(0.0128)\end{array}$ & $\begin{array}{c}0.786^{* * *} \\
(0.0557)\end{array}$ \\
\hline In $\mathrm{GDP}_{\mathrm{jt}}$ & $\begin{array}{l}0.111^{* * *} \\
(0.00398)\end{array}$ & $\begin{array}{r}-0.00329 \\
(0.0442)\end{array}$ & $\begin{array}{l}-0.0200 \\
(0.0426)\end{array}$ & $\begin{array}{c}0.183 \\
(0.173)\end{array}$ & $\begin{array}{c}0.124 * * * \\
(0.0108)\end{array}$ & $\begin{array}{l}-0.0345 \\
(0.0528)\end{array}$ \\
\hline In $\mathrm{GDPpc}_{\mathrm{it}}$ & $\begin{array}{c}-0.0976 * * * \\
(0.0185)\end{array}$ & $\begin{array}{c}-0.557 * * * \\
(0.0580)\end{array}$ & $\begin{array}{c}-0.393 * * * \\
(0.0538)\end{array}$ & $\begin{array}{c}-0.719 * * * \\
(0.188)\end{array}$ & $\begin{array}{c}-0.150 * * * \\
(0.0209)\end{array}$ & $\begin{array}{c}-0.600 * * * \\
(0.0658)\end{array}$ \\
\hline In $\mathrm{GDPpc}_{\mathrm{jt}}$ & $\begin{array}{c}0.0304 * * * \\
(0.00817)\end{array}$ & $\begin{array}{c}0.281 * * * \\
(0.0418)\end{array}$ & $\begin{array}{c}0.301 * * * \\
(0.0403)\end{array}$ & $\begin{array}{c}0.226 \\
(0.158)\end{array}$ & $\begin{array}{c}0.0697 * * * \\
(0.0183)\end{array}$ & $\begin{array}{c}0.379 * * * \\
(0.0502)\end{array}$ \\
\hline In Distance $_{\mathrm{ij}}$ & $\begin{array}{l}-0.131 * * * \\
(0.00794)\end{array}$ & $\begin{array}{c}-0.155^{* * *} \\
(0.0136)\end{array}$ & $\begin{array}{c}-0.151 * * * \\
(0.0132)\end{array}$ & $\begin{array}{c}-0.160 * * * \\
(0.0141)\end{array}$ & $\begin{array}{c}-0.265 * * * \\
(0.0217)\end{array}$ & $\begin{array}{c}-0.274 * * * \\
(0.0261)\end{array}$ \\
\hline Contiguity $_{\mathrm{ij}}$ & $\begin{array}{c}0.0183 \\
(0.0288)\end{array}$ & $\begin{array}{c}0.0967 * * * \\
(0.0337)\end{array}$ & $\begin{array}{c}0.0974 * * * \\
(0.0338)\end{array}$ & $\begin{array}{c}0.117 * * * \\
(0.0348)\end{array}$ & $\begin{array}{c}-0.102 \\
(0.0851)\end{array}$ & $\begin{array}{c}-0.000692 \\
(0.0714)\end{array}$ \\
\hline Language $_{\mathrm{ij}}$ & $\begin{array}{c}0.0872 * * * \\
(0.0164)\end{array}$ & $\begin{array}{c}0.0729 * * * \\
(0.0240)\end{array}$ & $\begin{array}{c}0.0715^{* * *} \\
(0.0237)\end{array}$ & $\begin{array}{c}0.0699 * * * \\
(0.0248)\end{array}$ & $\begin{array}{c}0.202 * * * \\
(0.0473)\end{array}$ & $\begin{array}{l}0.114 * * \\
(0.0489)\end{array}$ \\
\hline Colony $_{\mathrm{ij}}$ & $\begin{array}{c}0.479 * * * \\
(0.0222)\end{array}$ & $\begin{array}{c}0.469 * * * \\
(0.0277)\end{array}$ & $\begin{array}{l}0.446 * * * \\
(0.0270)\end{array}$ & $\begin{array}{c}0.498 * * * \\
(0.0290)\end{array}$ & $\begin{array}{c}0.675 * * * \\
(0.0822)\end{array}$ & $\begin{array}{c}0.521^{* * *} \\
(0.0696)\end{array}$ \\
\hline Landlocked $_{\mathrm{ij}}$ & $\begin{array}{c}-0.0819 * * * \\
(0.0183)\end{array}$ & $\begin{array}{l}-0.284 \\
(0.276)\end{array}$ & & $\begin{array}{c}0.375 \\
(0.330)\end{array}$ & $\begin{array}{l}-0.0457 \\
(0.0382)\end{array}$ & $\begin{array}{c}-0.761^{* *} \\
(0.368)\end{array}$ \\
\hline Polity $_{\text {it }}$ & $\begin{array}{c}0.0090 * * * \\
(0.00141)\end{array}$ & $\begin{array}{c}0.0164 * * * \\
(0.00280)\end{array}$ & $\begin{array}{c}0.0156 * * * \\
(0.00266)\end{array}$ & $\begin{array}{l}-0.00572 \\
(0.00633)\end{array}$ & $\begin{array}{c}0.0213 * * * \\
(0.00230)\end{array}$ & $\begin{array}{c}0.0194 * * * \\
(0.00321)\end{array}$ \\
\hline Polity $_{j \mathrm{t}}$ & $\begin{array}{c}-0.0129 * * * \\
(0.00132)\end{array}$ & $\begin{array}{c}-0.0156^{* * *} \\
(0.00206)\end{array}$ & $\begin{array}{c}-0.00689 * * * \\
(0.00176)\end{array}$ & $\begin{array}{c}-0.0177^{* * *} \\
(0.00329)\end{array}$ & $\begin{array}{c}-0.0123 * * * \\
(0.00208)\end{array}$ & $\begin{array}{c}-0.0127 * * * \\
(0.00233)\end{array}$ \\
\hline Polity_diff & $\begin{array}{c}-0.0180 * * * \\
(0.00122)\end{array}$ & $\begin{array}{c}-0.0157^{* * *} \\
(0.00145)\end{array}$ & 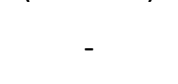 & $\begin{array}{l}-0.0141 * * * \\
(0.00155)\end{array}$ & $\begin{array}{r}-0.011 \\
(0.00\end{array}$ & $\begin{aligned}-0.010 \\
(0.00\end{aligned}$ \\
\hline Polity_region $_{\text {it }}$ & $\begin{array}{c}0.0274 * * * \\
(0.00218)\end{array}$ & $\begin{array}{c}0.00390 \\
(0.00514)\end{array}$ & - & $\begin{array}{r}0.00475 \\
(0.00845)\end{array}$ & $\begin{array}{c}0.0194 * * * \\
(0.00450)\end{array}$ & $\begin{array}{r}0.00 \\
(0.00\end{array}$ \\
\hline Polity_region $_{\mathrm{jt}}$ & $\begin{array}{c}-0.0130 * * * \\
(0.00249)\end{array}$ & $\begin{array}{c}-0.00444 \\
(0.00455)\end{array}$ & - & $\begin{array}{r}0.0129 \\
(0.00884)\end{array}$ & $\begin{array}{c}-0.0162 * * * \\
(0.00413)\end{array}$ & $\begin{array}{c}-0.00578 \\
(0.00506)\end{array}$ \\
\hline votewithUSA $_{i t-3}$ & $\begin{array}{c}1.419 * * * \\
(0.0683)\end{array}$ & $\begin{array}{c}0.698 * * * \\
(0.0974)\end{array}$ & $\begin{array}{r}-0.00542 \\
(0.0790)\end{array}$ & $\begin{array}{c}1.228 * * * \\
(0.159)\end{array}$ & $\begin{array}{c}1.296 * * * \\
(0.0948)\end{array}$ & $\begin{array}{c}0.666^{* * * *} \\
(0.108)\end{array}$ \\
\hline votewithUSA $_{\mathrm{jt-3}}$ & $\begin{array}{c}-0.579 * * * \\
(0.0677)\end{array}$ & $\begin{array}{c}-0.747 * * * \\
(0.108)\end{array}$ & $\begin{array}{l}-0.167 * * \\
(0.0812)\end{array}$ & $\begin{array}{c}-0.809 * * * \\
(0.169)\end{array}$ & $\begin{array}{c}-0.485^{* * *} \\
(0.0953)\end{array}$ & $\begin{array}{c}-0.647 * * * \\
(0.111)\end{array}$ \\
\hline votewithUSA_diff $_{\mathrm{ijt}-3}$ & $\begin{array}{c}-0.844 * * * \\
(0.0634)\end{array}$ & $\begin{array}{c}-1.324 * * * \\
(0.0775)\end{array}$ & 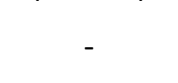 & $\begin{array}{c}-1.828 * * * \\
(0.101)\end{array}$ & $\begin{array}{c}-0.814 * * * \\
(0.0841)\end{array}$ & $\begin{array}{c}-1.117^{* * *} \\
(0.0872)\end{array}$ \\
\hline votewithUSA_region $_{i t-3}$ & $\begin{array}{c}0.880 * * * \\
(0.0792)\end{array}$ & $\begin{array}{c}0.666 * * * \\
(0.126)\end{array}$ & - & $\begin{array}{c}0.543 * * \\
(0.234)\end{array}$ & $\begin{array}{c}0.877^{* * *} \\
(0.126)\end{array}$ & $\begin{array}{c}0.742^{* * *} \\
(0.147)\end{array}$ \\
\hline votewithUSA_region $_{\mathrm{jt}-3}$ & $\begin{array}{c}-0.498 * * * \\
(0.0997)\end{array}$ & $\begin{array}{l}-0.104 \\
(0.135)\end{array}$ & - & $\begin{array}{r}0.00 \\
(0.2\end{array}$ & $\begin{array}{l}-0.3 \\
(0.1\end{array}$ & $\begin{array}{l}-0.107 \\
(0.154)\end{array}$ \\
\hline Militarization $_{\mathrm{it}}$ & $\begin{array}{c}29.92 * * * \\
(0.702)\end{array}$ & $\begin{array}{l}-4.302 * \\
(2.592)\end{array}$ & $\begin{array}{l}-1.901 \\
(2.439)\end{array}$ & $\begin{array}{l}-1.533 \\
(4.853)\end{array}$ & $\begin{array}{c}22.16^{* * *} \\
(1.630)\end{array}$ & $\begin{array}{l}-3.578 \\
(2.740)\end{array}$ \\
\hline Militarization $_{\mathrm{jt}}$ & $\begin{array}{c}2.979 * * * \\
(0.707)\end{array}$ & $\begin{array}{l}-3.235^{*} \\
(1.675)\end{array}$ & $\begin{array}{l}-1.837 \\
(1.646)\end{array}$ & $\begin{array}{l}-4.466 \\
(3.153)\end{array}$ & $\begin{array}{c}-3.454 * * \\
(1.560)\end{array}$ & $\begin{array}{c}-4.625^{* *} \\
(2.002)\end{array}$ \\
\hline Pact $_{i j t}$ & $\begin{array}{c}0.359 * * * \\
(0.0177)\end{array}$ & $\begin{array}{c}0.471 * * * \\
(0.0241)\end{array}$ & $\begin{array}{c}0.659 * * * \\
(0.0223)\end{array}$ & $\begin{array}{c}0.515 * * * \\
(0.0262)\end{array}$ & $\begin{array}{c}0.386 * * * \\
(0.0371)\end{array}$ & $\begin{array}{c}0.408 * * * \\
(0.0373)\end{array}$ \\
\hline Conflict $_{j \mathrm{j}}$ & $\begin{array}{c}0.205^{* * *} \\
(0.0154)\end{array}$ & $\begin{array}{l}0.170 * * * \\
(0.0216)\end{array}$ & $\begin{array}{c}0.165^{* * *} \\
(0.0213)\end{array}$ & $\begin{array}{c}0.121 * * * \\
(0.0298)\end{array}$ & $\begin{array}{c}0.211^{* * *} \\
(0.0226)\end{array}$ & $\begin{array}{c}0.179 * * * \\
(0.0239)\end{array}$ \\
\hline $\mathrm{rgo}_{\mathrm{jt}}$ & $\begin{array}{c}-0.455^{* * *} \\
(0.135)\end{array}$ & $\begin{array}{c}-0.477 * * * \\
(0.142)\end{array}$ & $\begin{array}{c}-0.471 * * * \\
(0.149)\end{array}$ & $\begin{array}{l}-0.199 \\
(0.163)\end{array}$ & $\begin{array}{c}-0.730 * * * \\
(0.158)\end{array}$ & $\begin{array}{c}-0.589 * * * \\
(0.154)\end{array}$ \\
\hline Constant & $\begin{array}{c}-8.390 * * * \\
(0.160)\end{array}$ & $\begin{array}{c}-8.531 * * * \\
(0.867)\end{array}$ & $\begin{array}{c}-6.350 * * * \\
(0.807)\end{array}$ & $\begin{array}{c}-9.602 * * * \\
(2.903)\end{array}$ & $\begin{array}{c}-8.383 * * * \\
(0.292)\end{array}$ & $\begin{array}{c}-7.609 * * * \\
(1.046)\end{array}$ \\
\hline Year Dummies & Yes*** & Yes*** & Yes*** & Yes*** & Yes*** & Yes*** \\
\hline Country Dummies & No & Yes*** & Yes*** & No & No & Yes*** \\
\hline Country-Decade Dum. & No & No & No & Yes*** & No & No \\
\hline Observations & 470,169 & 466,039 & 466,039 & 291,724 & 470,169 & 470,169 \\
\hline $\mathrm{R}^{\wedge} 2$ & 0.347 & 0.439 & 0.429 & 0.417 & - & - \\
\hline
\end{tabular}

Notes: Robust standard errors in parentheses; ${ }^{* * *} p<0.01,{ }^{* *} p<0.05, * p<0.1$; 
Table E.11: Probability to Agree on a Transfer of Arms (without USA)

\begin{tabular}{|c|c|c|c|c|c|c|}
\hline & $\begin{array}{c}\text { (1) } \\
\text { Probit }\end{array}$ & $\begin{array}{c}(2) \\
\text { Probit }\end{array}$ & $\begin{array}{c}\text { (3) } \\
\text { Probit }\end{array}$ & $\begin{array}{c}\text { (4) } \\
\text { Probit }\end{array}$ & $\begin{array}{c}(5) \\
\text { RE Probit }\end{array}$ & $\begin{array}{c}\text { (6) } \\
\text { RE Probit }\end{array}$ \\
\hline In GDP it & (*) & $\begin{array}{c}0.709 * * * \\
(0.0463)\end{array}$ & *** & $\begin{array}{l}* * \\
5)\end{array}$ & $\begin{array}{c}0.437^{* * *} \\
(0.0128)\end{array}$ & $\begin{array}{l}* * * \\
20)\end{array}$ \\
\hline In GDP ${ }_{j t}$ & $\begin{array}{l}0.1 \\
(0.1\end{array}$ & $\begin{array}{r}0.0 \\
(0.0\end{array}$ & $\begin{array}{l}0.00 \\
(0.04\end{array}$ & $\begin{array}{l}0.2 \\
(0.1\end{array}$ & $\begin{array}{l}0.11 \\
(0.0\end{array}$ & $\begin{array}{l}0 . C \\
(0 . C\end{array}$ \\
\hline In GDPpc & $\begin{array}{r}-0.10 \\
(0.0\end{array}$ & $\begin{array}{c}-0.528 \\
(0.05\end{array}$ & $\begin{array}{r}-0.437 \\
10.05\end{array}$ & $\begin{array}{c}-0.570 * * * \\
(0.184)\end{array}$ & $\begin{array}{c}-0.140 * * * \\
(0.0200)\end{array}$ & $\begin{array}{c}-0.542 * * * \\
(0.0615)\end{array}$ \\
\hline In $\mathrm{GDPpc}_{\mathrm{jt}}$ & $\begin{array}{l}0.01 \\
10.00\end{array}$ & $\begin{array}{r}0.18 \\
10.0\end{array}$ & $\begin{array}{l}0.229 \\
(0.03\end{array}$ & $\begin{array}{r}0.1 \\
10.1\end{array}$ & $\begin{array}{c}0.0503^{* * *} \\
(0.0175)\end{array}$ & $\begin{array}{c}0.245^{* * *} \\
(0.0474)\end{array}$ \\
\hline In Distance ${ }_{i j}$ & $\begin{array}{l}-0.17 \\
(0.00\end{array}$ & $\begin{array}{r}-0.2 \\
(0 .\end{array}$ & $\begin{array}{r}-0.21 \\
(0.01\end{array}$ & $\begin{array}{r}-0.21 \\
(0.0\end{array}$ & $\begin{array}{c}-0.306 * * * \\
(0.0209)\end{array}$ & $\begin{array}{c}-0.300 * * * \\
(0.0255)\end{array}$ \\
\hline Contiguity $_{\mathrm{ij}}$ & & & & & & \\
\hline Lang & $\begin{array}{r}0.05 \\
(0.1\end{array}$ & $\begin{array}{r}0.07 \\
10 .\end{array}$ & $\begin{array}{r}0.086 \\
(0.0\end{array}$ & $\begin{array}{r}0.0 \\
10\end{array}$ & $\begin{array}{r}0.14 \\
(0.0\end{array}$ & $* *$ \\
\hline C & $\begin{array}{l}0.5 \\
(0 .\end{array}$ & $\begin{array}{l}0.4 \\
(0\end{array}$ & & & $\begin{array}{l}0.78 \\
(0.08\end{array}$ & $\begin{array}{l}0.57 \\
(0.0\end{array}$ \\
\hline Landlocked $_{\mathrm{ij}}$ & $\begin{array}{r}-0.05 \\
10 .\end{array}$ & $\begin{array}{r}0.6 \\
10\end{array}$ & $\begin{array}{r}0.5 \\
10\end{array}$ & & & \\
\hline & & & & & & \\
\hline Polit & $\begin{array}{r}-0.0 \\
(0 .\end{array}$ & $\begin{array}{l}-0.0 \\
(0 .\end{array}$ & $\begin{array}{l}52 * * * \\
175)\end{array}$ & $\begin{array}{l}-0.0 \\
(0 .\end{array}$ & & \\
\hline Polity_diff ${ }_{\mathrm{ijt}}$ & $\begin{array}{r}-0.017 \\
(0.00\end{array}$ & $\begin{array}{r}-0.0 \\
10.0\end{array}$ & r & & $\begin{array}{r}-0 . \\
10\end{array}$ & $\begin{array}{r}-0.1 \\
10\end{array}$ \\
\hline Polity_region $_{\text {it }}$ & & & - & & & \\
\hline jt & & & - & & & \\
\hline votewithUS & 1 & $\begin{array}{r}0 . \varepsilon \\
10\end{array}$ & $\begin{array}{r}0.15 \\
(0.08\end{array}$ & $\begin{array}{r}0.6 \\
10\end{array}$ & $\begin{array}{r}1.4 \\
10\end{array}$ & $\begin{array}{r}0.8 \\
(0\end{array}$ \\
\hline votewithUSA $_{\mathrm{jt}}$ & & $\begin{array}{r}-1.4 \\
10\end{array}$ & $\begin{array}{c}-0.675^{* * *} \\
(0.0860)\end{array}$ & $\begin{array}{r}-0.9 \\
10\end{array}$ & $\begin{array}{r}-1.2 \\
(0\end{array}$ & $\begin{array}{r}-1.3 \\
10\end{array}$ \\
\hline & $\begin{array}{r}-0.9 \\
10 .\end{array}$ & $\begin{array}{r}-1.4 \\
10 .\end{array}$ & 10.000 & & $\begin{array}{r}-1.0 \\
(0.0\end{array}$ & $\begin{array}{r}-1.32 \\
(0.0\end{array}$ \\
\hline votewithUSA_region $_{\text {it }}$ & $\begin{array}{l}0 . \varepsilon \\
10\end{array}$ & $\begin{array}{r}0 \\
10\end{array}$ & - & & $\begin{array}{r}0.5 \\
10\end{array}$ & $\begin{array}{l}0 . \\
0\end{array}$ \\
\hline votewithUSA_reg & $\begin{array}{r}-0.4 \\
10\end{array}$ & & - & $\begin{array}{r}0 \\
10\end{array}$ & & \\
\hline zation $_{\text {it }}$ & $\begin{array}{r}26 \\
10\end{array}$ & & & & & \\
\hline Militariz & $\begin{array}{r}2.01 \\
10 .\end{array}$ & & & & $\begin{array}{r}-2.9 \\
(1.5\end{array}$ & $\begin{array}{c}-4.429 * * \\
(1.916)\end{array}$ \\
\hline & $\begin{array}{l}0.2 \\
(0.1\end{array}$ & $\begin{array}{l}0.40 \\
(0 . C\end{array}$ & $\begin{array}{l}0.5 \\
10\end{array}$ & ** & $\begin{array}{l}0.32 \\
(0.0\end{array}$ & $\begin{array}{l}* * * \\
75)\end{array}$ \\
\hline Con & 0 & & $\begin{array}{l}* * \\
2)\end{array}$ & & *7) & $* * *$ \\
\hline$F$ & $\begin{array}{c}-0.437 * * * \\
(0.123)\end{array}$ & $\begin{array}{c}-0.504 * * * \\
(0.133)\end{array}$ & $\begin{array}{c}-0.530 * * * \\
(0.135)\end{array}$ & $\begin{array}{l}-0.137 \\
(0.167)\end{array}$ & $\begin{array}{c}-0.675 * * * \\
(0.144)\end{array}$ & $\begin{array}{c}-0.592 * * * \\
(0.141)\end{array}$ \\
\hline Constant & $\begin{array}{c}-7.315^{* * *} \\
(0.176)\end{array}$ & $\begin{array}{c}-8.387^{* * *} \\
(0.711)\end{array}$ & $\begin{array}{c}-6.464 * * * \\
(0.644)\end{array}$ & $\begin{array}{c}-6.202 * * * \\
(2.214)\end{array}$ & $\begin{array}{c}-6.908 * * * \\
(0.303)\end{array}$ & $\begin{array}{c}-7.613^{* * *} \\
(0.865)\end{array}$ \\
\hline Year Dummies & Yes*** & Yes*** & Yes*** & Yes*** & Yes*** & Yes*** \\
\hline Country Dum. & No & Yes*** & Yes*** & No & No & Yes*** \\
\hline Country-Decade Dum. & No & No & No & es $* * *$ & No & No \\
\hline Observations & 519,2 & 511,6 & 511,637 & 310,618 & 519,244 & 519,244 \\
\hline$R^{\wedge} 2$ & 0.276 & 0.379 & 0.368 & 0.357 & - & - \\
\hline
\end{tabular}

Notes: Robust standard errors in parentheses; ${ }^{* *} p<0.01,{ }^{* *} p<0.05,{ }^{*} p<0.1$; 
Table E.12: Volume of Transferred Arms (without USA)

\begin{tabular}{|c|c|c|c|c|c|c|c|c|}
\hline & (1) & (2) & (3) & (4) & (5) & (6) & (7) & (8) \\
\hline & OLS & OLS & OLS & OLS & $\mathrm{FE}$ & RE & $\mathrm{FE}$ & RE \\
\hline In GDP it & $\begin{array}{c}0.363 * * * \\
(0.0161)\end{array}$ & $\begin{array}{c}1.021 * * * \\
(0.136)\end{array}$ & $\begin{array}{c}1.228 * * * \\
(0.439)\end{array}$ & $\begin{array}{c}1.058 * * * \\
(0.129)\end{array}$ & $\begin{array}{c}0.926 * * * \\
(0.171)\end{array}$ & $\begin{array}{c}0.916^{* * * *} \\
(0.138)\end{array}$ & $\begin{array}{c}0.835 * * \\
(0.386)\end{array}$ & 9) \\
\hline In $\mathrm{GDP}_{\mathrm{jt}}$ & $\begin{array}{c}0.277^{* * *} \\
(0.0113)\end{array}$ & $\begin{array}{c}0.470 * * * \\
(0.115)\end{array}$ & $\begin{array}{l}0.559 * \\
(0.337)\end{array}$ & $\begin{array}{c}0.443^{* * *} \\
(0.112)\end{array}$ & $\begin{array}{c}0.666^{* * *} \\
(0.117)\end{array}$ & $\begin{array}{c}0.612^{* * * *} \\
(0.106)\end{array}$ & $\begin{array}{c}0.788^{* *} \\
(0.308)\end{array}$ & $\begin{array}{c}0.692 * * \\
(0.300)\end{array}$ \\
\hline In GDPpc $c_{i t}$ & $\begin{array}{c}-0.112 * * * \\
(0.0320)\end{array}$ & $\begin{array}{c}-1.049 * * * \\
(0.182)\end{array}$ & $\begin{array}{l}-0.952^{*} \\
(0.499)\end{array}$ & $\begin{array}{c}-1.096 * * * \\
(0.180)\end{array}$ & $\begin{array}{c}-0.934^{* * *} \\
(0.240)\end{array}$ & $\begin{array}{c}-0.986^{* * *} \\
(0.189)\end{array}$ & $\begin{array}{l}-0.686 \\
(0.458)\end{array}$ & $\begin{array}{c}-0.854^{* *} \\
(0.434)\end{array}$ \\
\hline In $\mathrm{GDPpc}_{\mathrm{jt}}$ & $\begin{array}{r}-0.075 \\
(0.02\end{array}$ & $\begin{array}{l}-0.0340 \\
(0.104)\end{array}$ & $\begin{array}{l}-0.3 \\
(0.31\end{array}$ & $\begin{array}{c}-0.00556 \\
(0.103)\end{array}$ & $\begin{array}{l}-0.181^{*} \\
(0.109)\end{array}$ & $\begin{array}{r}-0.1 \\
(0.09\end{array}$ & $\begin{array}{l}-0.351 \\
(0.285)\end{array}$ & \\
\hline In Distance $_{\mathrm{ij}}$ & $\begin{array}{r}-0.03 \\
(0.02\end{array}$ & $\begin{array}{c}-0.0716^{* *} \\
(0.0329)\end{array}$ & $\begin{array}{c}-0.0903^{* *} \\
(0.0354)\end{array}$ & $\begin{array}{c}-0.0804^{* *} \\
(0.0324)\end{array}$ & - & $\begin{array}{l}-0.0360 \\
(0.0512)\end{array}$ & $10.0-1$ & $\begin{array}{c}-0.0539 \\
(0.0573)\end{array}$ \\
\hline Contiguity $_{\mathrm{ij}}$ & $\begin{array}{c}0.0654 \\
(0.0617)\end{array}$ & $\begin{array}{c}0.322 * * * \\
(0.0706)\end{array}$ & $\begin{array}{c}0.308 * * * \\
(0.0754)\end{array}$ & $\begin{array}{c}0.288 * * * \\
(0.0704)\end{array}$ & - & $\begin{array}{c}0.147 \\
(0.115)\end{array}$ & - & \\
\hline Language $_{\mathrm{ij}}$ & $\begin{array}{r}-0.142 \\
(0.04\end{array}$ & $\begin{array}{l}0.00 \\
(0.06\end{array}$ & $\begin{array}{l}0.00 \\
(0.0\end{array}$ & $\begin{array}{l}0.05 \\
(0.06\end{array}$ & - & & - & \\
\hline Colony $_{\mathrm{ij}}$ & $\begin{array}{r}0.156 \\
(0.05\end{array}$ & & & $\begin{array}{l}-0.0 \\
(0.0 €\end{array}$ & - & & - & \\
\hline Landlocked $_{\mathrm{ij}}$ & $\begin{array}{r}-0.13 \\
(0.0\end{array}$ & $\begin{array}{l}0.0 \\
(0.4\end{array}$ & $\begin{array}{l}-1 . \\
(0 .\end{array}$ & $\begin{array}{l}-0.0 \\
(0.4\end{array}$ & - & $\begin{array}{l}0.5 \\
(0.5\end{array}$ & - & \\
\hline Polity $_{\text {it }}$ & $\begin{array}{r}-0.018 \\
(0.005\end{array}$ & $\begin{array}{c}0.0110 \\
(0.00820)\end{array}$ & $\begin{array}{l}0.00 \\
(0.01\end{array}$ & $\begin{array}{r}0.00 \\
(0.00\end{array}$ & $\begin{array}{l}-0.004 \\
(0.01 C\end{array}$ & $\begin{array}{r}0.0 \\
0.0\end{array}$ & $\begin{array}{r}0.01 \\
(0.02\end{array}$ & \\
\hline Polity $_{j t}$ & $\begin{array}{r}-0.0 \\
10.0\end{array}$ & $\begin{array}{l}-0.0 \\
10 .\end{array}$ & $\begin{array}{l}-0 \\
0 .\end{array}$ & $\begin{array}{r}-0.0119 * * * \\
(0.00418)\end{array}$ & & & $\begin{array}{l}-0 . \\
10.0\end{array}$ & \\
\hline Polity_diff $_{\mathrm{ijt}}$ & $\begin{array}{r}-0.022 \\
(0.00\end{array}$ & $\begin{array}{l}-0.0 \\
10.0\end{array}$ & $\begin{array}{l}-0.0 \\
(0.1\end{array}$ & - & $\begin{array}{r}-0.0 \\
(0.0\end{array}$ & 8) & $\begin{array}{l}-0.0 \\
(0.00\end{array}$ & 10) \\
\hline Polity_region ${ }_{i t}$ & $\begin{array}{l}0.0357 \\
(0.007\end{array}$ & $\begin{array}{l}0.0279 * \\
(0.0142)\end{array}$ & $\begin{array}{l}0.0 \\
(0 .\end{array}$ & - & $\begin{array}{c}0.0173 \\
(0.0162)\end{array}$ & $\begin{array}{l}0.02 \\
(0.01\end{array}$ & $\begin{array}{l}-0.0148 \\
(0.0233)\end{array}$ & \\
\hline region $_{\mathrm{jt}}$ & $\begin{array}{l}-0.00 \\
(0.00\end{array}$ & $\begin{array}{l}-0.0 \\
(0 . C\end{array}$ & & - & $\begin{array}{r}-0.0 \\
10\end{array}$ & & & \\
\hline votewithUSA $_{i t}$ & $\begin{array}{l}-0.3 \\
(0.2\end{array}$ & $\begin{array}{c}0 . \\
10 .\end{array}$ & & $\begin{array}{l}-0.172 \\
(0.259)\end{array}$ & & & & \\
\hline votewithUSA $_{\mathrm{jt}}$ & $\begin{array}{c}-1.466 * * * \\
(0.233)\end{array}$ & $\begin{array}{l}-0.469^{*} \\
(0.277)\end{array}$ & $\begin{array}{l}-0.3 \\
(0.4\end{array}$ & $\begin{array}{c}-0.260 \\
(0.223)\end{array}$ & $\begin{array}{c}-0.72 \\
(0.2 \varepsilon\end{array}$ & $\begin{array}{r}-0.5 \\
(0.2\end{array}$ & $\begin{array}{l}-0 . \\
10.3\end{array}$ & $\begin{array}{l}-0 . \\
10.3\end{array}$ \\
\hline votewithUSA_diff $_{\mathrm{ijt}}$ & $\begin{array}{l}-0.2 \\
(0.2\end{array}$ & $\begin{array}{r}-0.7 \\
0 .\end{array}$ & $\begin{array}{c}-0.7 \\
10.2\end{array}$ & - & $\begin{array}{r}-0.6 \\
10\end{array}$ & $\begin{array}{r}-0.7 \\
10 .\end{array}$ & $\begin{array}{l}-0 \\
0 .\end{array}$ & $\begin{array}{l}* * * \\
5)\end{array}$ \\
\hline votewithUSA_region $_{i t}$ & $\begin{array}{r}-1.468 \\
(0.2 S\end{array}$ & $\begin{array}{c}-1.279 * * \\
(0.510)\end{array}$ & $\begin{array}{l}0 . \\
10 .\end{array}$ & - & $\begin{array}{l}-0 \\
0 .\end{array}$ & $\begin{array}{l}-1 . \\
(0 .\end{array}$ & 0. & $\begin{array}{c}0.743 \\
(0.871)\end{array}$ \\
\hline votewithUSA_region $_{\mathrm{jt}}$ & $\begin{array}{c}1.090 * * * \\
(0.259)\end{array}$ & $\begin{array}{r}-0.0990 \\
(0.344)\end{array}$ & $\begin{array}{c}0.216 \\
(0.648)\end{array}$ & - & & $\begin{array}{c}0.362 \\
(0.321)\end{array}$ & $\begin{array}{c}0.417 \\
(0.597)\end{array}$ & $\begin{array}{c}0.467 \\
(0.587)\end{array}$ \\
\hline Militarization $_{\text {it }}$ & $\begin{array}{r}29.3 \\
(2.9\end{array}$ & $\begin{array}{r}2 \\
16\end{array}$ & -5. & 1 & 3 & 4.2 & $\begin{array}{l}-1 . \\
(12\end{array}$ & \\
\hline Militarization $_{\mathrm{jt}}$ & $\begin{array}{r}31.9 \\
(2 .\end{array}$ & & ) & $\begin{array}{r}9.4 \\
13\end{array}$ & 3) & $\begin{array}{r}9.6 \\
13\end{array}$ & $\begin{array}{c}5.172 \\
(5.315)\end{array}$ & $\begin{array}{c}2.930 \\
(5.199)\end{array}$ \\
\hline Pact $_{i j t}$ & $\begin{array}{c}0.255^{* * *} \\
(0.0434)\end{array}$ & $\begin{array}{c}0.228 * * * \\
(0.0556)\end{array}$ & $\begin{array}{c}0.317^{* * *} \\
(0.0680)\end{array}$ & $\begin{array}{c}0.262^{* * *} \\
(0.0552)\end{array}$ & $\begin{array}{c}0.374 * * * \\
(0.0778)\end{array}$ & $\begin{array}{c}0.298 * * * \\
(0.0629)\end{array}$ & $\begin{array}{c}0.596 * * * \\
(0.107)\end{array}$ & $\begin{array}{c}0.408 * * * \\
(0.0798)\end{array}$ \\
\hline Conflict $_{\mathrm{jt}}$ & $\begin{array}{c}0.0649 \\
(0.0409)\end{array}$ & $\begin{array}{c}0.0450 \\
(0.0492)\end{array}$ & $\begin{array}{l}0.00191 \\
(0.0686)\end{array}$ & $\begin{array}{c}0.0600 \\
(0.0494)\end{array}$ & $\begin{array}{c}0.130 * * * \\
(0.0499)\end{array}$ & $\begin{array}{r}0.098 \\
(0.04\end{array}$ & $\begin{array}{c}0.0476 \\
(0.0628)\end{array}$ & $\begin{array}{c}0.0307 \\
(0.0605)\end{array}$ \\
\hline bargo $_{\mathrm{jt}}$ & $\begin{array}{c}-0.399 \\
(0.425)\end{array}$ & -0 & $(0.3$ & $\begin{array}{c}-0.241 \\
(0.309)\end{array}$ & $\begin{array}{l}-0 \\
10 .\end{array}$ & $\begin{array}{c}-0.217 \\
(0.278)\end{array}$ & $\begin{array}{c}-0.457 \\
(0.335)\end{array}$ & $\begin{array}{c}-0.221 \\
(0.316)\end{array}$ \\
\hline $\begin{array}{l}\text { Constant } \\
\text { Year Dum }\end{array}$ & $\begin{array}{c}-2.383 * * * \\
(0.521) \\
\text { Yes*** }\end{array}$ & $\begin{array}{c}-11.03 * * * \\
(1.994) \\
\text { Yes*** }\end{array}$ & $\begin{array}{c}-15.74 * * * \\
(5.615) \\
\text { Yes** }\end{array}$ & $\begin{array}{c}-12.08 * * * \\
(1.756) \\
\text { Yes*** }\end{array}$ & $\begin{array}{c}-13.07^{* * *} \\
(2.269) \\
\text { Yes*** }\end{array}$ & $\begin{array}{c}-12.13^{* * *} \\
(2.010) \\
\text { Yes*** }\end{array}$ & $\begin{array}{c}-16.00 * * * \\
(5.502) \\
\text { Yes*** }\end{array}$ & $\begin{array}{c}-15.51 * * * \\
(4.836) \\
\text { Yes*** }\end{array}$ \\
\hline Country Dummies & No & Yes*** & No & Yes*** & - & Yes*** & - & No \\
\hline Country-Decade Dum. & No & No & Yes*** & No & No & No & Yes*** & Yes*** \\
\hline Observations & 9,803 & 9,803 & 9,803 & 9,803 & 9,803 & 9,803 & 9,803 & 9,803 \\
\hline $\mathrm{R}^{\wedge} 2$ & 0.243 & 0.389 & 0.472 & 0.385 & 0.169 & 0.374 & 0.0606 & 0.445 \\
\hline
\end{tabular}

Notes: Robust standard errors in parentheses; ${ }^{* *} p<0.01,{ }^{* *} p<0.05, * p<0.1$; 


\section{Eidesstattliche Erklärung}

"Ich versichere an Eides Statt, dass ich die eingereichte Dissertation "Trade and Uncertainty" selbstständig verfasst habe. Anderer als der von mir angegebenen Hilfsmittel und Schriften habe ich mich nicht bedient. Alle wörtlich oder sinngemäß den Schriften anderer Autorinnen und/oder Autoren entnommenen Stellen habe ich kenntlich gemacht."

Florian Johannsen

Lübeck, den 28. Februar 2014 